\title{
COMPLETE NUMERICAL SIMULATION OF SUBCOOLED FLOW BOILING IN THE PRESENCE OF THERMAL AND CHEMICAL INTERACTIONS
}

\author{
NERI Project No.: 99-0134 \\ DOE Grant No.: DE-FG03-99SF-21930
}

\author{
April 2003 \\ Principle Investigator: V. K. Dhir \\ Collaborators: W. Jia, S. Maity, Q. Bai, N. Basu, D. Li, G. R. Warrier \\ Mechanical and Aerospace Engineering Department \\ University of California, Los Angeles \\ Los Angeles, CA 90095-1597
}

\begin{abstract}
At present, guidelines for fuel cycle designs to prevent axial offset anomalies (AOA) in pressurized water reactor (PWR) cores are based on empirical data from several operating reactors. Although the guidelines provide an ad-hoc solution to the problem, a unified approach based on simultaneous modeling of thermal-hydraulics, chemical, and nuclear interactions with vapor generation at the fuel cladding surface does not exist. As a result, the fuel designs are overly constrained with a resulting economic penalty. The objective of present project is to develop a numerical simulation model supported by laboratory experiments that can be used for fuel cycle design with respect to thermal duty of the fuel to avoid economic penalty, as well as, AOA.

At first, two-dimensional numerical simulation of the growth and departure of a bubble in pool boiling with chemical interaction is considered. A finite difference scheme is used to solve the equations governing conservation of mass, momentum, energy, and species concentration. The Level Set method is used to capture the evolving liquid-vapor interface. A dilute aqueous boron solution is considered in the simulation. From numerical simulations, the dynamic change in concentration distribution of boron during the bubble growth shows that the precipitation of boron can occur near the advancing and receding liquid-vapor interface when the ambient boron concentration level is 3,000 ppm by weight. Secondly, a complete three-dimensional numerical simulation of inception, growth and departure of a single bubble subjected to forced flow parallel to the heater surface was developed.

Experiments on a flat plate heater with water and with boron dissolved in the water were carried out. The heater was made out of well-polished silicon wafer. Numbers of nucleation sites and their locations were well controlled. Bubble dynamics in great details on an isolated
\end{abstract}


nucleation site were obtained while varying the wall superheat, liquid subcooling and flow velocity parametrically. Concentration variation of boron near the liquid-vapor interface was detected successfully with a newly developed miniature concentration sensor. The measured concentration variations at different radial locations from the center of cavity have the same trend as given by the numerical simulations. The deposition of boron was found near the nucleation site on the heater surface, which validates the numerical simulation.

Subcooled flow boiling experiments at three pressures were performed on a nine-rod bundle with water and with boron dissolved in the water. The test runs were conducted with a wide range of mass fluxes (186 to $2800 \mathrm{~kg} / \mathrm{m}^{2} \mathrm{~s}$ ) and heat fluxes (1.0 to $30.0 \mathrm{~W} / \mathrm{cm}^{2}$ ). Not only the variables required to develop mechanistic models for subcooled flow boiling were measured, but also the crud formation during boiling and its effect on the heat transfer process were investigated. 


\section{Table of Contents}

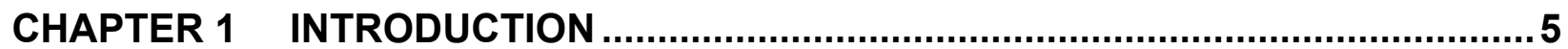

1.1 Subcooled Flow Boiling ................................................................................................................5

1.2 Nucleate Boiling of Binary Mixtures......................................................................................7

1.3 Bubble Dynamics .....................................................................................................................

1.4 Project Objectives .....................................................................................................................8

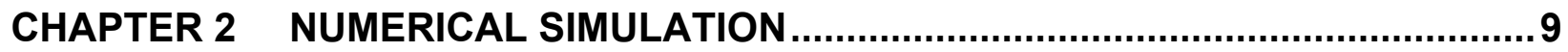

2.1 MODEL DESCRIPTION...........................................................................................9

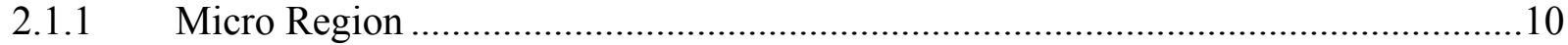

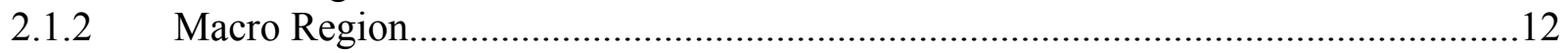

2.2 Results and discussion - Pool Boiling with Chemical Interaction..................................14

$2.3 \quad$ Three Dimensional Flow Boiling …………........................................................................24

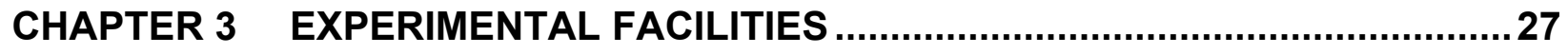

3.1 Flow boiling on a silicon flat plate ..............................................................................27

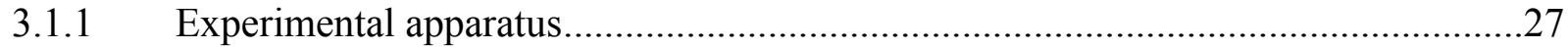

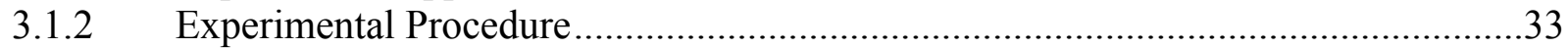

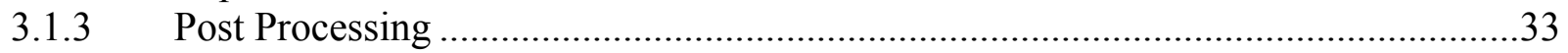

3.2 Pool boiling on a silicon wafer ......................................................................................34

3.2.1 Experimental Apparatus..................................................................................

3.2.2 Experimental Procedure ………………………....................................................

3.3 Flow boiling on a nine-rod bundle...................................................................................36

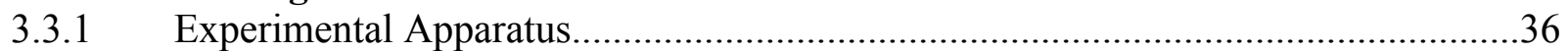

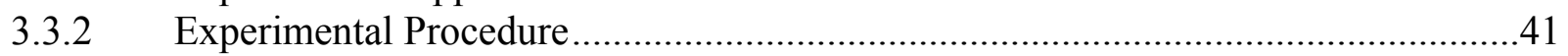

3.4 Uncertainty of Measurements.........................................................................................41

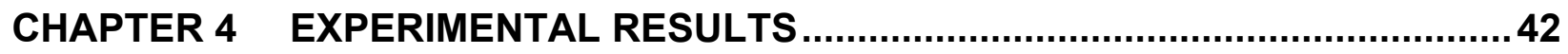

4.1 Silicon Flat Plate ....................................................................................................................42

4.1.1 Bubble Dynamics in Saturated Flow Boiling ......................................................42

4.1.2 Bubble Dynamics in Subcooled Flow Boiling.....................................................72

4.1.3 Bubble Dynamics in Flow Boiling with Aqueous Solution of Boric Acid.................86

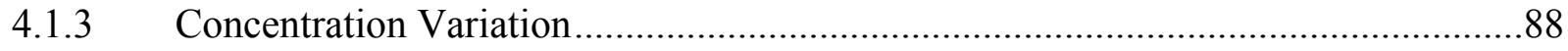


4.1.4 Deposition of Boron near the Cavity ...............................................................97

4.2 Nine Rod Bundle with Zicalloy-4 Cladding................................................................99

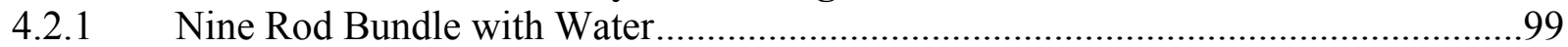

4.2.2 Nine Rod Bundle with Boron ..............................................................................107

CHAPTER 5 CONCLUSIONS ....................................................................... 112

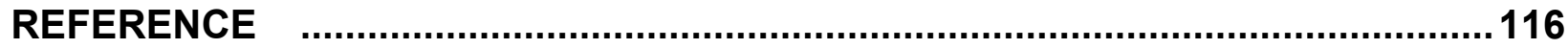

APPENDIX A

APPENDIX B 


\section{Chapter 1 Introduction}

Currently, empirical data from several operating reactors are used to develop guidelines [1] for fuel cycle designs to prevent axial offset anamolies (AOA). Although these guidelines provide a tentative solution to the problem, at present, a unified approach that includes simultaneous modeling of thermal-hydraulics and chemical and nuclear interactions does not exist. As a result, the fuel designs are overly constrained which leads to an economic penalty. The objective of the proposed work is to develop a complete numerical simulation model for thermal-hydraulics and chemical interactions when phase change occurs at the fuel rod surface. The model will be supported by laboratory experiments. Subsequently, the validated model could be coupled with a neutronic package so that it can be used for fuel cycle design and operation without economic penalty as well as without AOA.

The occurrence of AOA is related to the rate of vapor formation and the concentration of boron in the crud on the fuel rod surface. The deposition of boron on the fuel rod cladding contained as an absorber in the primary coolant is strongly dependent on the fluid temperature adjacent to the cladding. The spatial variation of fluid temperature itself depends not only on the imposed heat flux and flow field, but also on the phase change process that occurs as a result of subcooled boiling. For a given $\mathrm{PH}$ value of water and lithium content, the boron concentration affects the neutron flux and, in turn, the wall heat flux. Thus, a strong feedback exists between thermal-hydraulics and chemical concentrations and neutron flux or power. Deposition of boron on the cladding surface can depress the neutron flux and to maintain a fixed power output, the neutron flux must increase elsewhere. If, on the other hand, a local upper limit is imposed on the neutron flux, the power output must decrease.

\subsection{Subcooled Flow Boiling}

Single phase forced convection and subcooled boiling in channels and over rod bundles have been studied extensively in the literature and correlations have been developed for average heat transfer coefficients [e.g. 2 and 3]. The correlations for rod bundles [2] generally give single-phase heat transfer coefficients within $\pm 20 \%$ of data. However, it has been argued by Marek et al. [3] that a fresh look should be taken at these correlations in order to improve their accuracy. For subcooled boiling correlations such as that by Chen [4] are used. Although the information provided by the correlations is adequate for prediction of steady state and transient behavior of the reactor systems, the correlations are of little value in developing a prediction for local deposition of boron with time. The situation becomes even bleaker when subcooled boiling occurs on the fuel rod surface.

During the flow of subcooled liquid on a heated surface, initially the heat is removed by forced convection. At a certain location along the flow directions, bubbles appear on the heater surface. This marks the onset of nucleate boiling. The wall superheat (location) at which nucleation begins depends on several parameters such as a cavity size distribution, surface wettability, and the thickness of the thermal boundary layer. The thickness of the thermal boundary itself depends on the fluid properties as well as the distance from the inlet. Any uncertainty in the local heat transfer coefficient will thus be reflected in the location of boiling inception. Downstream of the point of nucleation, bubbles continue to persist on the heated wall with thickening of the voided region next to the wall, until bubbles start to detach and move away from the heater surface. The location at which bubbles start to detach and move into the 
subcooled bulk liquid is called the location of onset of significant voids (OSV). The photograph in Figure 1-1 shows subcooled boiling on a plane heated surface before OSV, whereas Figure 1-2 provides a visual observation of the process at OSV.

The location at which onset of significant voids occurs again depends on several local flow and thermal parameters as well as on bubble shape, bubble size and packing. In addition to the interfacial mass, momentum and heat transfer, the bubble shape and size at departure are also influenced by the surface wettability. The bubble packing depends on the number density of active nucleation sites on the surface. The active nucleation site density not only depends on the magnitude of heat flux as seen from comparison of Figure 1-1 and Figure 1-2 but also on the surface morphology and wettability. Both of the latter parameters are affected by the presence of crud on the surface.

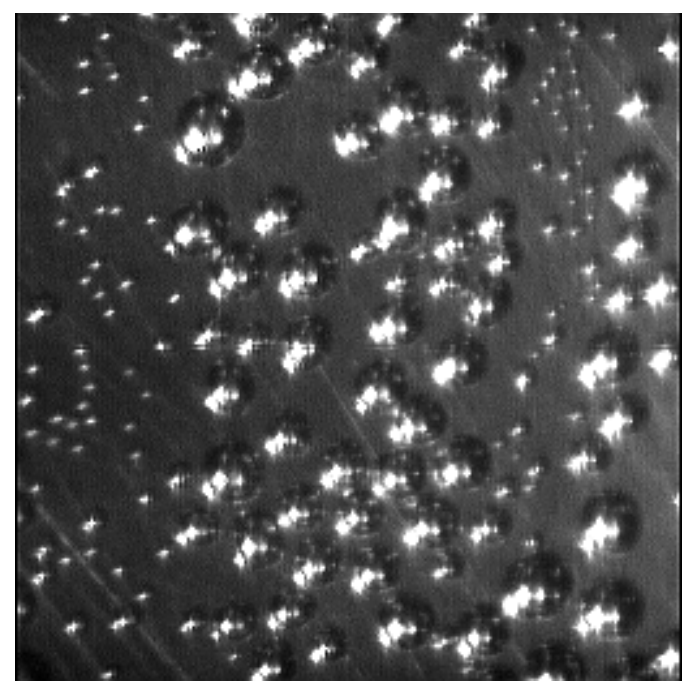

Figure 1-1: Prior to onset of OSV on a flat surface

$$
\left(\mathrm{q}_{\mathrm{w}}=14.2 \mathrm{~W} / \mathrm{cm}^{2}, \Delta \mathrm{T}_{\text {sub }}=31.5^{\circ} \mathrm{C}\right)
$$

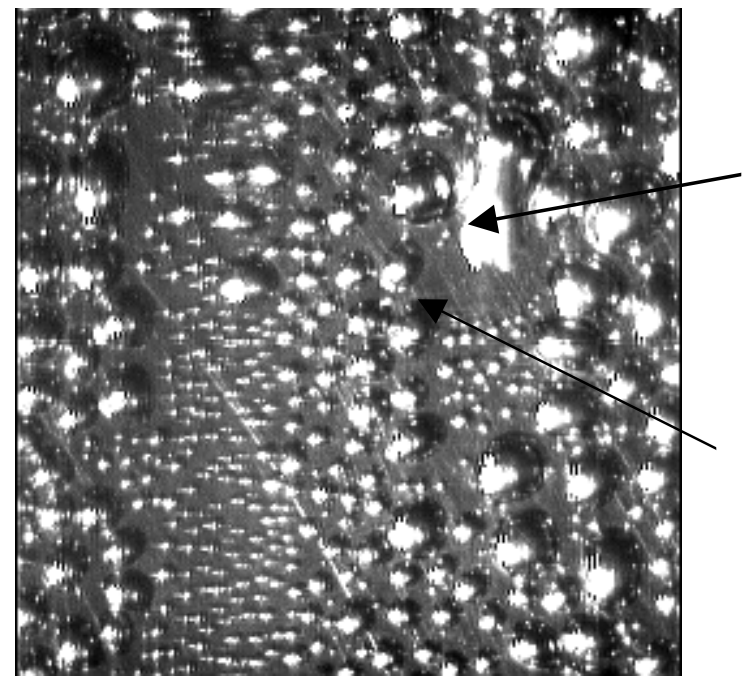

Departing bubble

Surface vacated by bubble

Figure 1-2: At onset of OSV on a flat surface $\left(\mathrm{q}_{\mathrm{w}}=28.2 \mathrm{~W} / \mathrm{cm}^{2}, \Delta \mathrm{T}_{\text {sub }}=31.0^{\circ} \mathrm{C}\right)$ 
In the region between inception of nucleate boiling and the onset of significant voids, bubbles remain attached to the heater wall. Almost all of the energy utilized in evaporation is dumped back into the liquid as a result of condensation at the vapor bubble surface. Although all of the energy from the wall is deposited into the liquid, the evaporation and condensation can significantly alter the temperature profile and, in turn, the chemical concentration near the wall. Vapor bubbles start to detach when the evaporation rate exceeds the condensation at the bubble top and bubbles grow to a size at which buoyancy and drag exceed the surface tension force. During bubble growth and detachment, the heat flux from the wall is generally divided into three parts (Lahey and Moody [5]): heat flux associated with evaporation, forced convection heat transfer to liquid, and heat lost from the wall to the subcooled liquid by pumping action of vapor bubbles. Consequently, the temperature and chemical concentrations are affected by these subprocesses.

After the OSV location, bubbles start to accumulate in the bulk. The variation of void fraction in the axial direction depends on the rate at which vapor is added from the wall, the heat transfer to liquid from the wall, the heat transfer at the vapor liquid interface, and the interfacial drag. In the approach that is currently followed, correlations for various components of the wall heat flux are used and empirical constants in the correlations are adjusted to provide a reasonable agreement of the predictions of void fraction with data [6]. However, recently Kelly [7], has clearly documented the inconsistencies that exist in the currently used models for subcooled boiling. He has shown that bubble size and interfacial areas obtained from heat transfer considerations are inconsistent with interfacial drag. It is also not clear if the liquid pumping model presents the correct physics with respect to the rate at which hotter liquid is pushed away from the wall, and the effect of liquid subcooling on the pumping rate. Rogers et al. [8] have also shown through subcooled boiling experiments at low pressures, that several of the existing correlations do not predict correctly, the effect of flow velocity on the liquid subcooling at OSV and the void fraction at OSV.

At present, little experimental or analytical/numerical information is available in the literature which can be used to obtain, in a satisfactory manner, the partitioning of the heat flux between vapor and liquid and, in turn, the temperature distribution in the liquid. Quantitative studies in which liquid-vapor phase change heat transfer is investigated simultaneously with chemical species concentration in the liquid are practically non-existent. In the absence of precise information on the temperature filed, the chemical concentration gradients, and hence, deposition of boron and the vapor production rate cannot be predicted in a credible manner.

\subsection{Nucleate Boiling of Binary Mixtures}

In the last several decades, nucleate boiling of binary mixtures has been extensively studied by many investigators. For example, Celata et al., [12], and Fujita and Tsutsui [13] have presented a detailed review of experimental and theoretical studies on predicting nucleate boiling heat transfer for mixtures of volatile components. Kern and Stephan [14] have extended their model for micro layer beneath the bubble in nucleate boiling for a pure component to a binary mixture. The bubble shape was assumed to be given and the energy for bubble growth was considered to be supplied only via the heat conduction in micro layer and macro region around the bubble. A strong concentration gradient in the micro region was calculated due to the preferential evaporation of the more volatile component of the mixture.

Very limited information on nucleate boiling heat transfer in boron solution can be found in the literature. Lee et al. [15] and Varma et al. [16] have shown that the heat transfer 
coefficient for lithium bromide solution decreases with the increase in concentration of lithium bromide. In nucleate boiling of a salt solution, only water evaporates into vapor phase and salt is left behind in the liquid phase. As a result a concentration gradient develops in the liquid near the vapor-liquid interface of the bubble. When the concentration of non-volatile species is higher than the solubility limit of the species, it comes out of the solution. The saturation temperature of salt solution increases with concentration. Miyatake et al. [17] developed a model for the growth rate of a spherical bubble in a uniformly superheated binary solution with a non-volatile solute. The predicted growth rates were shown to agree very well with the experimental data for pure water and for aqueous $\mathrm{NaCl}$ solutions. They found that the bubble growth rate in superheated salt solutions is quite insensitive to diffusion, which is completely different from that during bubble growth in binary mixtures of volatile components.

There is practically little information on the temperature field, the gradients of chemical concentration and deposition of boron on the cladding surface during subcooled boiling. As a result, the fuel designs are overly constrained which leads to an economic penalty. It is necessary to simulate the nucleate boiling process along with velocity, temperature and concentration fields of aqueous orthoboric acid in the vicinity of the cladding of a fuel rod.

\subsection{Bubble Dynamics}

The rate of bubble growth and subsequent bubble motion has tremendous influence on heat transfer and the precipitation of non-volatile species. Consequently, these have been the subjects of numerous experimental investigations in the past. As the first step in this study, an extensive survey of the open literature was undertaken. The results of the literature survey by Maity [18] revealed the fact that very limited experimental data is currently available which can be used to validate the numerical simulation for bubble dynamics and heat transfer on an isolated single cavity or multi-cavities with known spacing and size. Most of the data available were obtained from experiments in which the boiling surface had numerous uncontrollable nucleation sites.

\subsection{Project Objectives}

The key objective of the proposed research is to develop a mechanistic basis for the thermal and chemical interactions that occur during subcooled boiling in the rector core. The axial offset anomolies (AOA) are influenced by local heat flux for subcooled nucleate boiling, the nucleation site density on the fuel cladding and the concentration of boron and lithium in the primary coolant. Complete numerical simulations of the boiling process along with thermal, hydraulic and concentration fields in the vicinity of the cladding surface are to be carried out. The model will be validated with data from detailed experiments. A building block type of approach will be used in that starting with a bubble at a single nucleation site, the complexity of the numerical model and experiments will be increased to include merger of bubbles at the wall as well as interaction of the detached bubbles with the bubbles present on the heated surface. The concentrations of boron and lithium in water, $\mathrm{PH}$ value of water, and system pressure will be important variables of the problem. The validated model will be cast in a form that it can be readily combined with a neutronic package to analyze and avoid without economic penalty, conditions leading to AOA. 


\section{Chapter 2 Numerical Simulation}

Son et al. [19] numerically simulated bubble growth during nucleate pool boiling in a pure liquid by using the Level Set method. They divided the domain of calculation into micro and macro-regions. For the macro-region complete conservation equations were solved to obtain the interface shape, and position and associated velocity and temperature fields. For the microregion, lubrication theory was used, which included the disjoining pressure in the thin liquid film. The solutions for micro-region and macro-region were matched at the outer edge of the microlayer. In this work the above-cited numerical method is extended to obtain bubble growth during nucleate pool boiling of water containing orthoboric acid (boron) and flow boiling of pure water. This work represents a first step in analyzing the reactor situation where liquid flow is upward and parallel to the heater surface. When the concentration of boron in aqueous solution of orthoboric acid is higher than the solubility limit, boron is expected to precipitate out from the solution.

\subsection{Model Description}

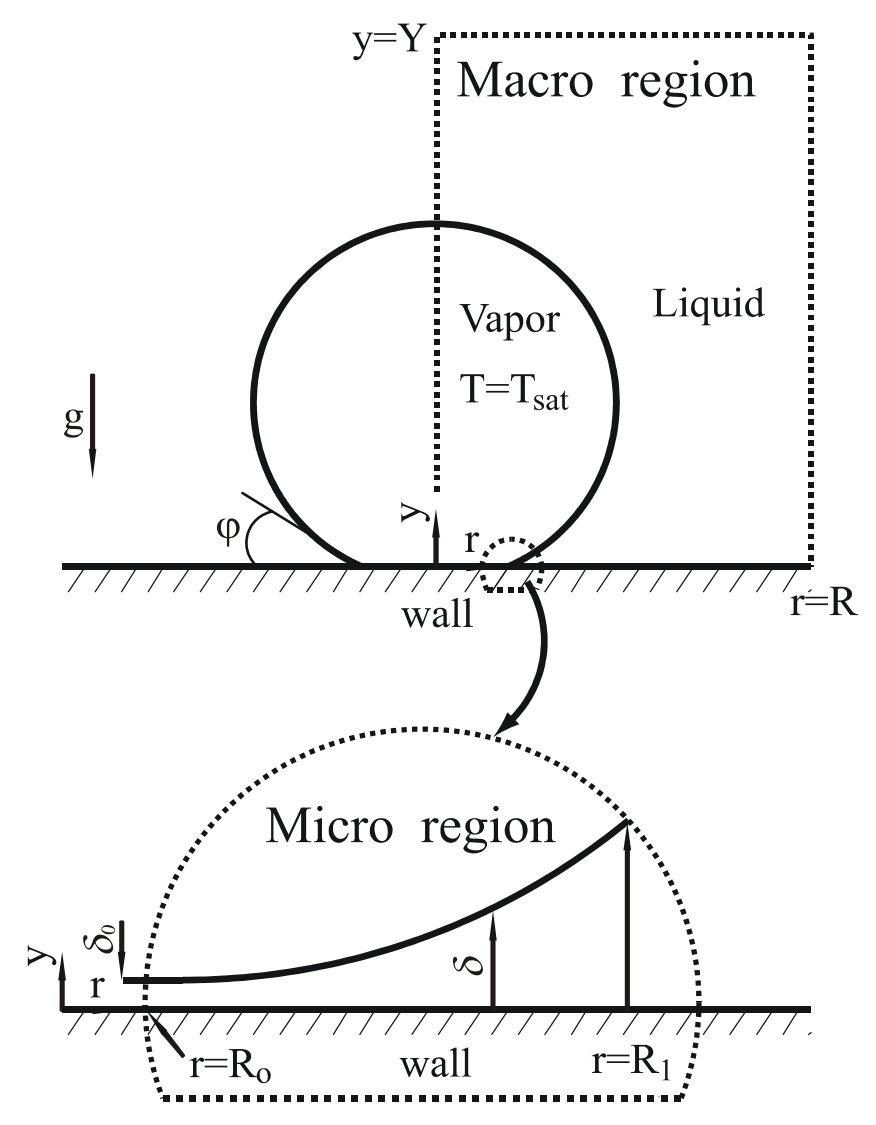

Figure 2-1: Calculation domain (macro and micro regions)

To analyze the growth of a single bubble in nucleate boiling in the aqueous solution of orthoboric acid, the calculation domain is divided into micro-region and macro-region as shown in Figure 2-1. The micro region is a thin film that lies underneath the bubble whereas the macro 
region consists of the bubble and the liquid surrounding the bubble. Numerical calculations of fluid flow, heat transfer and mass transfer are carried out for the aqueous solution of orthoboric acid in both micro and macro regions. The calculated shapes of the interface in the micro region and macro region are matched at the outer edge of the micro-layer for a given contact angle, $\varphi$. In the numerical analysis, the fluid flow is assumed to be axisymmetric and laminar. Neglecting their variation with temperature and concentration, all fluid properties including density, viscosity, thermal conductivity and mass diffusivity are assumed to be constant in each phase. The temperature of vapor inside the bubble is set as the saturation temperature, $T_{s}$ corresponding to the system pressure.

\subsubsection{Micro Region}

In solving the conservation equations for the micro region, lubrication theory and onedimensional heat transfer in the thin film have been assumed in the past by many investigators, as for example, Stephan and Hammer [20], Lay and Dhir [21] and Wayner [22]. The micro region model of Son et al. [19] is extended for a single bubble growth in nucleate boiling of the aqueous solution of orthoboric acid in the present work.

From a quasi-steady-state material balance, the evaporation rate of water in a unit length of interface of the thin film is equal to the change in mass flow rate of water in the same length of the thin film. As such the equation of mass conservation in micro region is written as,

$$
\frac{q}{h_{f g}}=-\frac{1}{r} \frac{\partial}{\partial r} \int_{0}^{\delta} \rho_{l}\left(1-C_{b}\right) r u d y
$$

where $C_{b}$ is the concentration of orthoboric acid in the solution, $q$ is the evaporative heat flux from the interface and $\delta$ is the thickness of the thin film. According to the lubrication theory, the momentum equation in the micro region is written as,

$$
\frac{\partial p_{l}}{\partial r}=\mu \frac{\partial^{2} u}{\partial y^{2}}
$$

where $p_{l}$ is the pressure in the liquid. Since the heat conducted through the thin film must match that due to evaporation from the vapor-liquid interface, by using modified Clausius-Clapeyron equation, the energy conservation equation for the micro region yields,

$$
\frac{k_{l}\left(T_{\text {wall }}-T_{\text {int }}\right)}{\delta}=h_{e v}\left[T_{\text {int }}-T_{v}+\frac{\left(p_{l}-p_{v}\right) T_{v}}{\rho_{l} h_{f g}}\right]
$$

where, $T_{\text {wall }}$ is the wall temperature, $T_{\mathrm{int}}$ is the interface temperature, $T_{v}$ is the vapor temperature, $p_{v}$ is the vapor pressure and $h_{e v}$ is the evaporative heat transfer coefficient. The evaporative heat transfer coefficient is obtained from kinetic theory as,

$$
h_{e v}=2\left[\frac{M}{2 \pi \bar{R} T_{v}}\right]^{1 / 2} \frac{\rho_{v} h_{f g}^{2}}{T_{v}} \text { and } T_{v}=T_{s}(p)
$$

The pressure of the vapor and liquid phases at the interface are related by,

$$
p_{l}=p_{v}-\sigma K-\frac{A_{0}}{\delta^{3}}+\frac{q^{2}}{2 \rho_{v} h_{f g}^{2}}
$$

where $A_{0}$ is the dispersion constant. The second term on the right-hand side of Eq. (4) accounts for the capillary pressure caused by the curvature of the interface, the third term for the disjoining pressure, and the last term originates from the recoil pressure. The curvature of the interface is defined as, 


$$
K=\frac{1}{r} \frac{\partial}{\partial r}\left[r \frac{\partial \delta}{\partial r} / \sqrt{1+\left(\frac{\partial \delta}{\partial r}\right)^{2}}\right]
$$

The combination of the mass conservation, Eq. (1), momentum conservation, Eq. (2), mass balance and energy conservation, Eq. (3), and pressure balance equation, Eq. (4) along with Eq. (5) for the curvature for the micro-region yields a set of three nonlinear first order ordinary differential equations,

$$
\begin{gathered}
\frac{\partial \delta_{r}}{\partial r}=-\frac{\delta_{r}\left(1+\delta_{r}^{2}\right)}{r}+\frac{\left(1+\delta_{r}^{2}\right)^{3 / 2}}{\sigma} \\
\times\left[\frac{\rho_{l} h_{f g}}{T_{v}}\left(T_{\mathrm{int}}-T-\frac{q}{h_{e v}}\right)-\frac{A_{0}}{\delta^{3}}+\frac{q^{2}}{\rho_{v} h_{f g}^{2}}\right] \\
\frac{\partial T_{\text {int }}}{\partial r}=-\frac{q \delta_{r}}{\kappa_{l}+h_{e v} \delta}+\frac{3 T_{v} h_{e v} \mu \Gamma}{\left(\kappa_{l}+h_{e v} \delta\right) \rho_{l}^{2} h_{f g} r \delta^{2}} \\
\frac{\partial\left[\Gamma\left(1-C_{b}\right)\right]}{\partial r}=-\frac{r q}{h_{f g}}
\end{gathered}
$$

where $\Gamma,=-\frac{r \delta^{3} \rho}{3 \mu} \frac{\partial p_{l}}{\partial r}$, is the mass flow rate in the thin film, and $q=\kappa_{l}\left(T_{\text {wall }}-T_{\text {int }}\right) / \delta$, is the heat flux through the thin film.

The mass of boron in solution will not change during the evaporation of water in microlayer if the concentration of boron is below the local solubility limit of boron in the solution. The species conservation equation for boron yields a fourth ordinary differential equation that can be expressed as,

$$
\frac{\partial\left(\Gamma \cdot C_{b}\right)}{\partial r}=0
$$

and if the concentration of boron in orthoboric acid solution is higher than the local solubility limit of boron, boron will precipitate from the solution and the boron concentration will remain constant at the solubility limit.

$$
C_{b}=C_{b, \mathrm{lim}}
$$

Therefore, Eqs. (8) and (9) are rewritten separately in different regions in micro layer as,

$$
\begin{array}{llll}
\frac{\partial \Gamma}{\partial r}=-\frac{r q}{h_{f g}} & \text { for } & C_{b}<C_{b, \mathrm{lim}} \\
\frac{\partial \Gamma}{\partial r}=-\frac{r q}{\left(1-C_{b}\right) h_{f g}} & \text { for } & C_{b}<C_{b, \mathrm{lim}} \\
\Gamma \frac{\partial C_{b}}{\partial r}=-\frac{\partial \Gamma}{\partial r} C_{b} & \text { for } & C_{b}<C_{b, \mathrm{lim}} \\
C_{b}=C_{b, \mathrm{lim}} & \text { for } & C_{b}=C_{b, \mathrm{lim}}
\end{array}
$$

The above four differential equations (6)-(7) and (11)-(12) can be simultaneously integrated by using a Runge-Kutta method, If initial conditions at $r=R_{0}$ are given. In present case, the radial location $R_{1}$ where macro and micro regions meet is the end point for integration of the above set of equations. The radius of dry region beneath a bubble, $R_{0}$, is related to $R_{1}$ from the definition of the apparent contact angle,

$\tan \varphi=0.5 h /\left(R_{1}-R_{0}\right)$

The boundary conditions for film thickness at the end points are: 


$$
\begin{array}{lll}
\delta=\delta_{0}, \delta_{r}=0, \Gamma=0 & \text { at } & r=R_{0} \\
\delta=h / 2, C_{b}=C_{b, i n} & \text { at } & r=R_{1}
\end{array}
$$

where, $\delta_{0}$ is the interline film thickness at the tip of micro-layer, which is calculated by combining Eqs. (3) and (4) and requiring that $T_{\text {int }}=T_{\text {wall }}$ at $r=R_{0}$ and $h$ is the spacing of the two dimensional grid for the macro-region. For a given $T_{\text {int }, 0}$ at $r=R_{0}$, a unique vapor-liquid interface is obtained. For a given $A_{0}, T_{\mathrm{int}, 0}$ is chosen to obtain $\delta=h / 2$ at $r=R_{1}$. Because of possibility of boron precipitation in the microlayer in the region $R_{0} \leq r \leq R_{1}$, the location where precipitation begins needs to be identified. For a given starting position of integration, $r=R^{\prime}, C^{\prime}=C_{b, \lim }$ the species conservation equation, Eq. (12) uniquely gives a $C_{b, i n}$ at $r=R_{1}$. By adjusting starting position of integration, $r=R^{\prime}, C^{\prime}=C_{b, \lim }$ a desired $C_{b, \text { in }}$ is obtained.

\subsubsection{Macro Region}

For numerically analyzing the macro region in an aqueous solution of orthoboric acid, the level set formulation developed by Son et al. [19] for nucleate boiling of pure liquid is used. The interface separating the two phases is captured by $\phi$ which is defined as a signed distance from the interface. The negative sign is chosen for the vapor phase and the positive sign for the liquid phase. The discontinuous pressure across vapor and liquid caused by surface tension force is smoothed into a numerically continuous function with a $\delta$ - function formulation (refer to Sussman et al., [23], for detail). The continuity, momentum, energy, and species conservation equations for the vapor and liquid in the macro region are written as,

$$
\begin{gathered}
\rho_{t}+\nabla \cdot(\rho \vec{u})=0 \\
\rho\left(\vec{u}_{t}+\vec{u} \cdot \nabla \vec{u}\right)=-\nabla p+\nabla \cdot \mu \nabla \vec{u}+\nabla \cdot \mu \nabla \vec{u}^{T} \\
+\rho \vec{g}-\rho \beta_{T}\left(T-T_{s}\right) \vec{g}-\sigma K \nabla H \\
\rho c_{p}\left(T_{t}+\vec{u} \cdot \nabla T\right)=\nabla \cdot \kappa \nabla T \quad \text { for } H>0 \\
T=T_{s}\left(p_{v}\right) \quad \text { for } H=0 \\
\rho\left(C_{b, t}+\vec{u} \cdot \nabla C_{b}\right)=\nabla \cdot \rho D \nabla C_{b} \text { for } H>0 \\
C_{b}=0 \quad \text { for } H=0
\end{gathered}
$$

where $\vec{u}$ is the fluid velocity, $\rho$ is the fluid density, $\mu$ is the fluid shear viscosity, $\vec{g}$ is the gravitational acceleration, $K$ is the local mean curvature of the interface, $p$ is the fluid pressure, $\kappa$ is the thermal conductivity, $T$ is the fluid temperature, $\sigma$ is the surface tension of vapor and liquid interface, and $D$ is the binary diffusivity coefficient of orthoboric acid solution in water. The fluid density, viscosity, thermal conductivity orthoboric acid solution in water are defined in terms of the step function $H$ as,

$$
\begin{aligned}
& \rho=\rho_{v}+\left(\rho_{l}-\rho_{v}\right) H \\
& \mu^{-1}=\mu_{v}^{-1}+\left(\mu_{l}^{-1}-\mu_{v}^{-1}\right) H \\
& \kappa^{-1}=\kappa_{l}^{-1} H \\
& D^{-1}=D_{12}^{-1} H
\end{aligned}
$$

where, $H$ is the Heviside function which is smoothed over three grid spaces as described below,

$$
H= \begin{cases}1 & \text { if } \quad \phi \geq 1.5 h \\ 0 & \text { if } \quad \phi \leq-1.5 h \\ 0.5+\phi / 3 h+\sin (2 \pi \phi / 3 h) /(2 \pi) & \text { if } \quad|\phi| \leq 1.5 h\end{cases}
$$


The mass conservation equation (14) can be rewritten as,

$$
\nabla \cdot \vec{u}=-\left(\rho_{t}+\vec{u} \cdot \nabla \rho\right) / \rho
$$

The term on right hand side of Eq. (25) is the volume expansion due to liquid-vapor phase change. From the conditions of the mass continuity and energy balance at the vapor-liquid interface, the following equations are obtained,

$$
\begin{gathered}
\vec{m}=\rho\left(\vec{u}_{\text {int }}-\vec{u}\right)=\rho_{l}\left(\vec{u}_{\text {int }}-\vec{u}_{l}\right)=\rho_{v}\left(\vec{u}_{\text {int }}-\vec{u}_{v}\right) \\
\vec{m}=\kappa \nabla T / h_{f g}
\end{gathered}
$$

where $\vec{m}$ is the water evaporation rate vector, and $\vec{u}_{\text {int }}$ is interface velocity. If the interface is assumed to advect in the same way as the level set function, the advection equation for density at the interface can be written as,

$$
\rho_{t}+\vec{u}_{\text {int }} \cdot \nabla \rho=0
$$

Combining Eqs. (25), (26) and (28), the continuity equation, Eq. (26) for macro region is rewritten as,

$$
\nabla \cdot \vec{u}=\frac{\vec{m}}{\rho^{2}} \cdot \nabla \rho
$$

The vapor produced as a result of evaporation from the micro region is added to the continuity equation, Eq. (29), through the cells adjacent to the heated wall, and is expressed as,

$$
\left(\frac{1}{V_{c}} \frac{d V}{d t}\right)_{m i c}=\frac{\dot{m}_{m i c}}{V_{c} \rho_{v}} \delta_{\varepsilon}(\phi)
$$

where, $V_{c}$ is the volume of a control volume, $\dot{m}_{\text {mic }}$ is the evaporation rate from the micro-layer and is expressed as,

$$
\dot{m}_{m i c}=\int_{R_{0}}^{R_{1}} \frac{\kappa_{l}\left(T_{w}-T_{\text {int }}\right)}{h_{f g} \delta} r d r
$$

The volume expansion contributed by micro layer is smoothed at the vapor-liquid interface by the smoothed delta function

$$
\delta_{\varepsilon}(\phi)=\partial H / \partial \phi
$$

In level set formulation, the level set function $\phi$ is used to keep track of the vapor-liquid interface location as the set of points where $\phi=0$, and it is advanced by the interfacial velocity while solving the following equation,

$$
\phi_{t}=-\vec{u}_{\text {int }} \cdot \nabla \phi
$$

To keep the values of $\phi$ close to those of a signed distance function, $|\nabla \phi|=1, \phi$ is reinitialized after every time step,

$$
\frac{\partial \phi}{\partial t}=\frac{\phi_{0}}{\sqrt{\phi_{0}^{2}+h^{2}}}(1-|\nabla \phi|)
$$

where, $\phi_{0}$ is a solution of Eq. (33). The mass conservation of boron at the vapor-liquid interface

$$
\vec{m}_{b}=\frac{C_{b} \kappa \nabla T}{\left(1-C_{b}\right) h_{f g}}=-\rho D \nabla C_{b}
$$

is used as a boundary condition at the interface for species conservation equation. The boundary conditions for velocity, temperature, concentration, and level set function for the governing equations, (14)-(19) are: 


$$
\begin{array}{lll}
u=v=0, T=T_{\text {wall }}, C_{b, y}=0, \phi_{y}=-\cos \phi & \text { at } & y=0 \\
u_{y}=v_{y}=0, T=T_{s}, C_{b, y}=0, \phi_{y}=0 & \text { at } & y=Y \\
u=v_{r}=T_{r}=C_{b, r}=\phi_{r}=0 & \text { at } & r=0, R
\end{array}
$$

[24].

For details of solution method for the governing equations one is referred to Son and Dhir

\subsection{Results and discussion - Pool Boiling with Chemical Interaction}

A two-dimensional numerical simulation of bubble growth on a horizontal surface under pool boiling conditions is carried out in order to calculate the distribution of boron concentration in nucleate boiling. In the analysis the change in saturation temperature of the solution caused by variation in boron concentration is neglected. A dilute aqueous solution of orthoboric acid is used in the simulation.

For the numerical calculations, the governing equations for micro and macro regions are non-dimensionalized by defining the characteristic length, $l_{0}$, the characteristic velocity, $u_{0}$, and the characteristic time, $t_{0}$ as,

$$
l_{0}=\sqrt{\sigma /\left[g\left(\rho_{l}-\rho_{v}\right)\right]} ; \quad u_{0}=\sqrt{g l_{0}} ; \quad t_{0}=l_{0} / u_{0}
$$

The governing equations are numerically integrated by following the procedure of Son et al. [19]. The properties of water at 1 atm are used as very weak aqueous solution of orthoboric acid is considered.

The computational domain is chosen to be $\left(R / l_{0}, Y / l_{0}\right)=(1,3)$, so that the bubble growth process is not affected by the boundaries of the computational domain. The initial velocity is assumed to be zero everywhere in the domain. The initial fluid temperature profile is taken to be linear in the natural convection thermal boundary layer and the thermal boundary layer thickness, $\delta_{T}$, is evaluated using the correlation for the turbulent natural convection on a horizontal plate as,

$$
\delta_{T}=7.14\left(v_{l} \alpha_{l} / g \beta_{T} \Delta T\right)^{1 / 3}
$$

The initial concentration of aqueous solution of orthoboric acid, $C_{b, 0}$ is taken to be $0.3 \%$. The mass diffusivity, $D_{12}$, is chosen as $1.0 \times 10^{-8} \mathrm{~m}^{2} / \mathrm{s}$. The calculations are carried out over several cycles of bubble growth and departure until no cycle to cycle change in the bubble growth pattern or in the temperature and concentration profiles is observed. The mesh size for all calculations is chosen as $96 \times 288$. It represents the best trade-off in calculation accuracy and computing time, as has been shown by Son et al. [19]. Due to the explicit treatment of the convection terms and the conditions that the numerical results should not change if the time steps are halved, the dimensionless time step is chosen as $5 \times 10^{-4}$. This satisfies the CFL condition, $\Delta t \leq h /\left(\left|u_{\text {int }}\right|_{\max },\left|v_{\text {int }}\right|_{\max }\right)$.

Figure 2-2 shows the temporal variation of predicted concentration of orthoboric acid at the point $(\mathrm{r}=0.135, \mathrm{y}=0.005)$, and Nusselt number based on the area average heat flux at the wall, $N u_{a v}$ for $\Delta T=6.2 \mathrm{~K}$ and $A_{0}=-8.5 \times 10^{-21} \mathrm{~J}$. After about 14 cycles $t / t_{0}=30.0$ of bubble growth and departure, the quasi steady-state conditions of boron concentration and Nusselt number appear to have been achieved and the effect of ambiguity in specification of initial conditions appears to have died. 


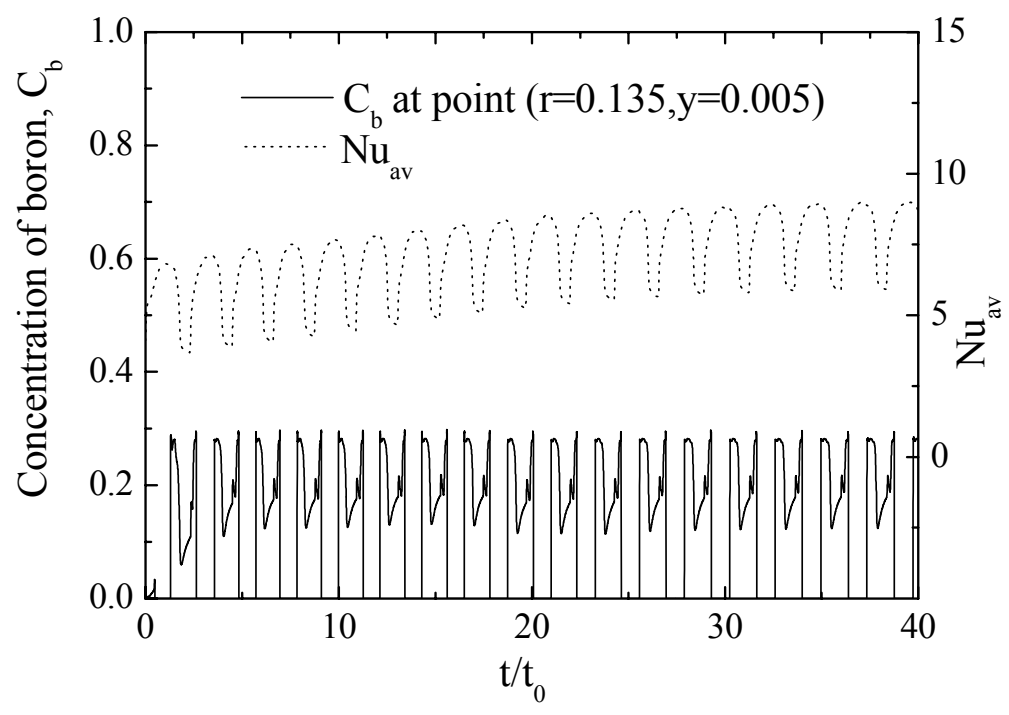

Figure 2-2: Variation of concentration of boron and Nusselt number with time for $\Delta T=6.2$ $\mathrm{K}$ and $A_{0}=-8.5 \times 10^{-21} \mathrm{~J}$

For the flow and heat transfer in micro region beneath the growing bubble in nucleate boiling, there are two typical models which have been developed in the past years (Stephan and Hammer, [20]; Lay and Dhir, [21]). Basically same governing equations and boundary conditions for flow and heat transfer are used by both of them. These equations are rederived as Eq. (6)-(8) and (13) in the present paper. Lay and Dhir [21] iterated on the boundary condition $\partial^{2} \delta / \partial r^{2}$ at $r=R_{0}$ so that the integration of governing equations yielded $\delta=h / 2$ at $r=R_{1}$, whereas Stephan and Hammer [20] set $\partial^{3} \delta / \partial r^{3}$ at $r=R_{0}$ to a small value so that the integration ends at $r=R_{1}$ with a desired curvature. The condition $\partial^{3} \delta / \partial r^{3} \neq 0$ implies $\Gamma \neq 0 \$$ at $r=R_{0}$. This is inconsistent with the condition that no evaporation occurs at the tip of the micro layer. Results for micro layer shape and heat transfer in micro region were obtained by changing the dispersion constant $A_{0}$ in both models. Apparent contact angle $\varphi$ at $r=R_{1}$ and $A_{0}$ are related. If the apparent contact angle $\varphi$ at $r=R_{1}$ is given, the micro layer shape, heat transfer through the micro layer and dispersion constant $A_{0}$ are determined uniquely by using the method of Lay and Dhir [21]. Figure 2-3 shows that the dispersion constant $A_{0}$ and the calculated dimensionless rate of heat transfer, $Q$, from the micro layer decrease with the increase of apparent contact angle, $\varphi$. The non-dimensionalization of the rate of heat transfer from the micro-layer has been carried out by following the approach of Son et al [19]. Here,

$$
Q=\frac{1}{\kappa_{l} l_{0}\left(T_{w}-T_{s}\right)} \int_{R_{0}}^{R_{1}} 2 \pi r q d r
$$




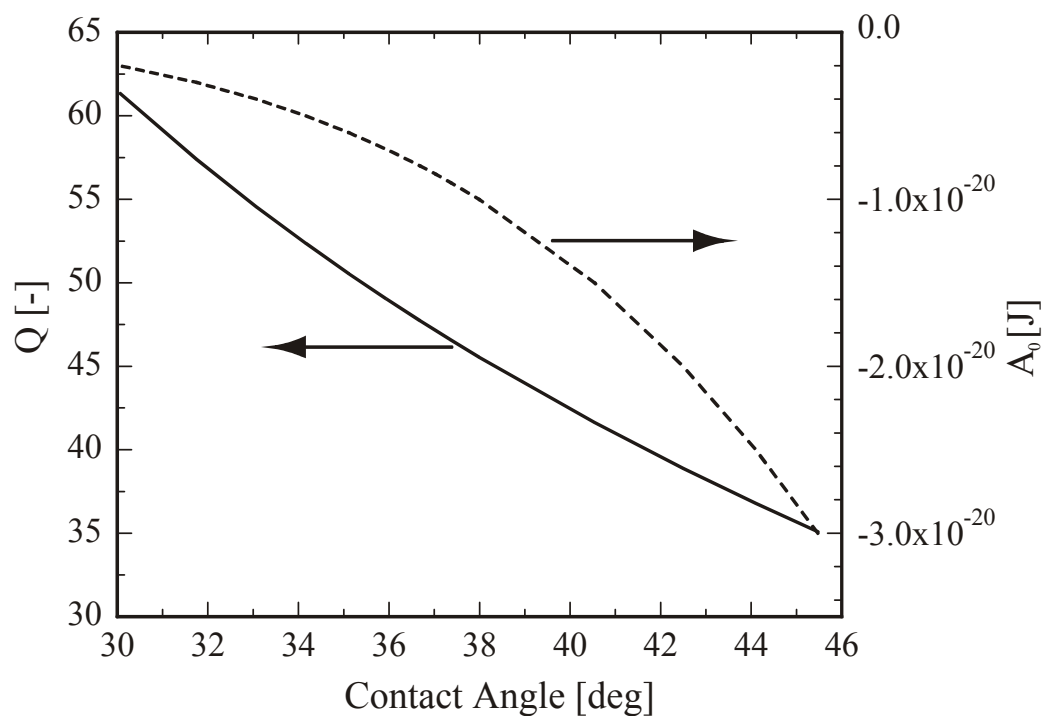

Figure 2-3: Effects of apparent contact angle $\varphi$ on $A_{0}$ and dimensionless heat transfer in micro region $Q$ based on adjustment of $\partial^{2} \delta / \partial r^{2}$ at $r=R_{0}$. (Lay and Dhir's model [21]).

Similar plot corresponding to the approach of Stephan and Hammer [20] is shown in Figure 2-4. Two approaches yield similar results for $Q$ and contact angle $\varphi$, but the dispersion constant $A_{0}$ is very small, and insensitive to the contact angle $\varphi$ from the model of Stephan and Hammer. In the present work, Lay and Dhir's [21] method is modified to the case of the orthoboric acid solution.

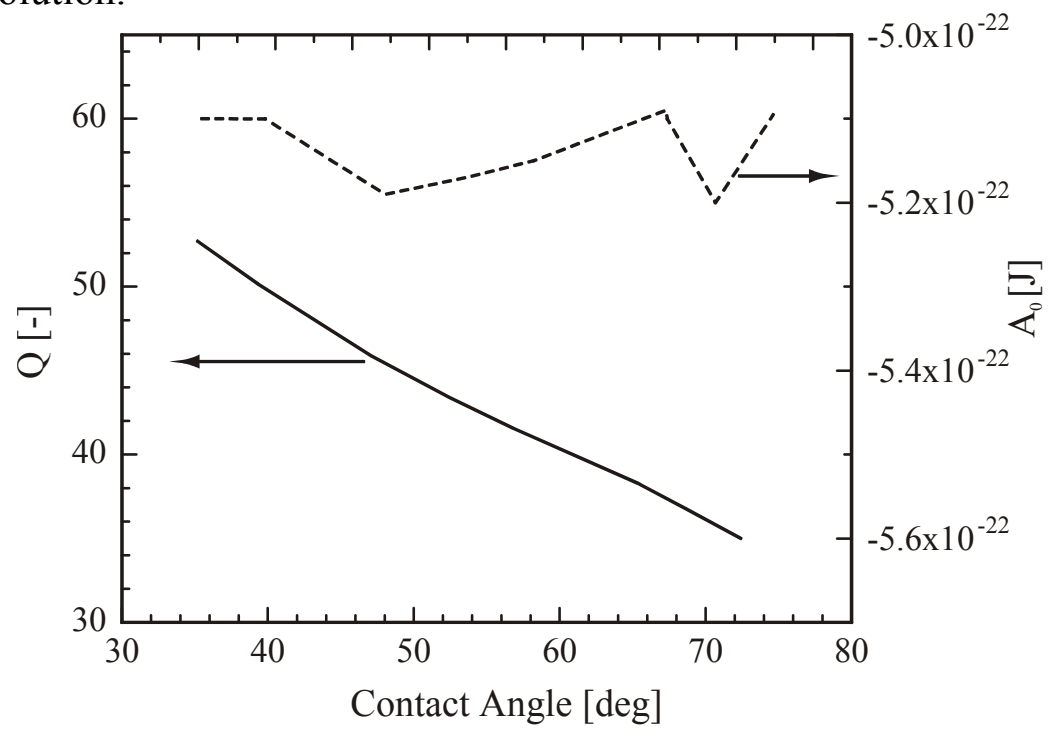

Figure 2-4: Effects of apparent contact angle $\varphi$ on $A_{0}$ and dimensionless heat transfer in micro region $Q$ based on adjustment of $\partial^{3} \delta / \partial r^{3}$ at $r=R_{0}$. (Stephan and Hammer [20]).

Figure 2-5 compares results for flow and heat transfer in the micro region for pure water and orthoboric acid solution at $t / t_{0}=38.38$ for superheat $\Delta T=6.2 \mathrm{~K}$ and $A_{0}=-8.5 \times 10^{-21} \mathrm{~J}$. There is a very small change (below 1\%) in the film thickness $\delta(x)$ and vapor-liquid interface temperature $T_{\text {int }}$ between these two cases. This leads to the heat flux $q$ through the thin film for the orthoboric acid solution approximately to be the same as that for pure water. Because of the 
difficulty in apriori defining the concentrations of orthoboric acid at $R_{1}$ or at the outer edge of the micro layer, two different boundary conditions for concentration of orthoboric acid are used in the calculations. In one case the concentration at the outer edge of the micro layer is taken to be approximately half of the sum of the concentrations at the wall and that corresponding to the solubility limit of orthoboric acid in water at the local temperature, i.e. at $=0.15$. The solubility limit is used because from macro solution it is found that local concentration can exceed the solubility limit when water preferentially evaporates at the interface. The second alternative condition is that $=0.003$. Figure $2-5$ (b) shows the variation of the mass flow rate, $\Gamma(r)$, for the orthoboric acid solution with boundary conditions $C_{b, i n}=0.15,0.003$, and for pure water. Higher is the concentration of boron at the outer edge of the micro layer, larger flow rate of the orthoboric acid solution is calculated. The corresponding changes of boron concentration are shown in Figure 2-5 (c), and the magnified variation in the region near the inner edge is shown in Figure 2-5 (d). For $C_{b, i n}=C_{b, \infty}$, boron precipitates from the liquid just at the inner edge of the micro layer i.e. at $r=R_{0}$. Whereas for $C_{b, i n}=0.5 \times\left(C_{b, l i m}+C_{b, \text { wall }}\right)$, boron precipitates from the orthoboric acid solution in the region from $r=0.18259$ to 0.18261 . The precipitated mass rate of boron in micro layer is $3.18 \times 10^{-10} \mathrm{~kg} / \mathrm{s}$.

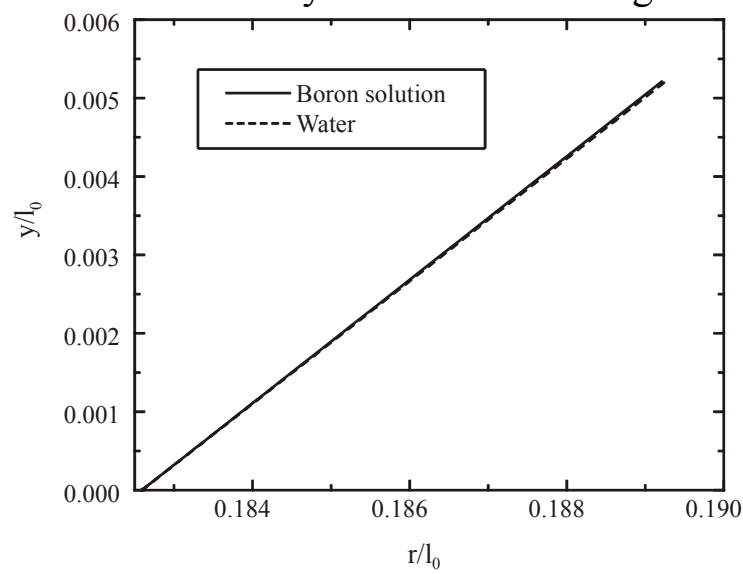

(a)

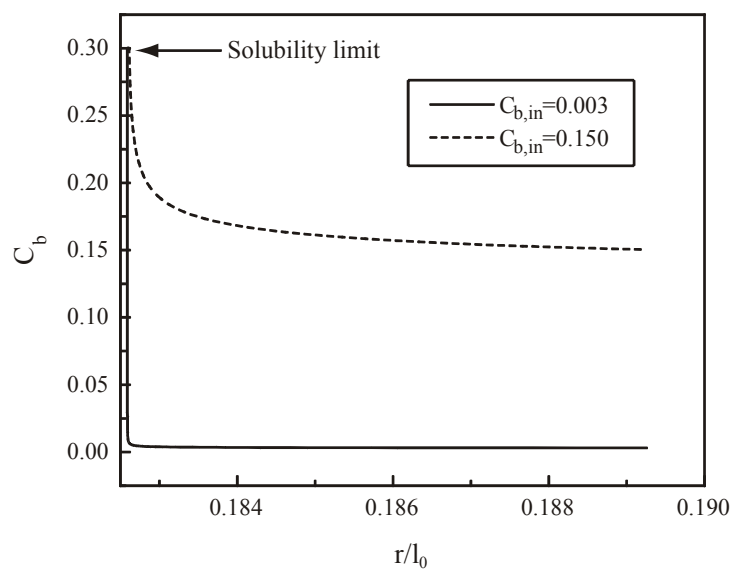

(c)

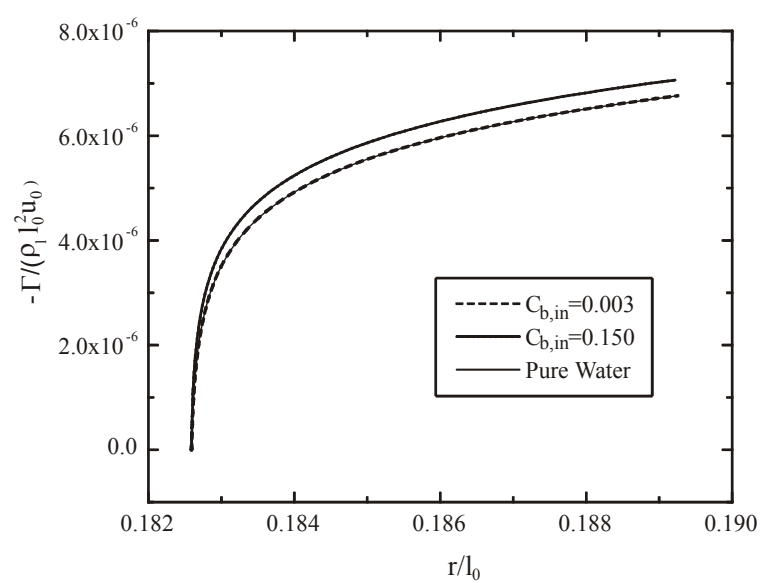

(b)

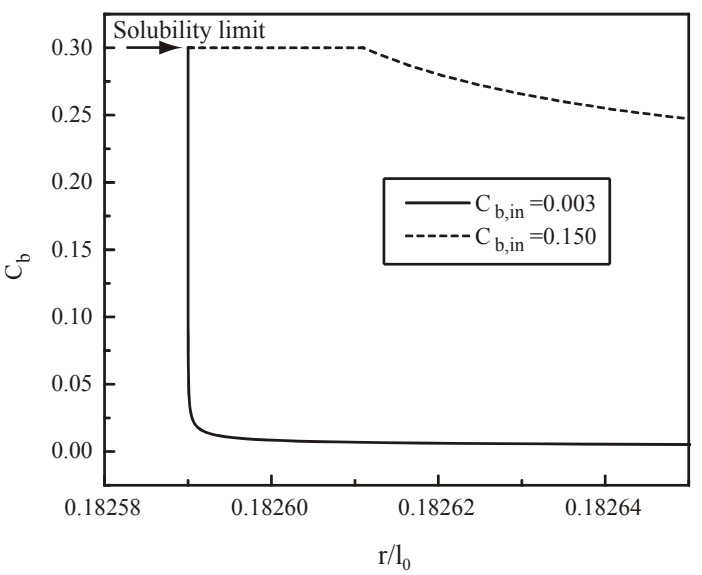

(d)

Figure 2-5: Comparison of calculated results of boron solution and water for the micro region at $\mathrm{t} / \mathrm{t}_{0}=38.38$, (a) interface shape, (b) mass flow rate of liquid, (c) concentration of boron in the micro layer, and (d) concentration near the inner edge of micro layer 
The velocity and temperature fields in and around a bubble growing on the wall in $0.3 \%$ mass concentration orthoboric acid solution at $t / t_{0}=36.79$ are shown in Figure 2-6(a) and (b). Because the calculated heat transfer from the micro region for the orthoboric acid solution is nearly the same as that for pure water, and the thermo-physical properties of pure water are used in the calculations, the velocity and temperature profiles obtained for orthoboric acid solution are very similar to that for pure water. The liquid around the growing bubble is pushed outward during the early growth of the vapor bubble, while a circulatory flow patterns inside the bubble as well as in the liquid outside the bubble are observed for the freely rising detached bubble. Concentration of isotherms in the liquid around the bottom of bubble in Fig. Figure 2-6 (b) reflects a very high heat flux there. Figure 2-7 shows the velocity and temperature distributions associated with a just departed bubble at $t / t_{0}=37.99$, for $\Delta T=6.2 \mathrm{~K}$, and $A_{0}=-8.5 \times 10^{-21} \mathrm{~J}$. A large vortex near the interface results form bulk movement of the bubble in the upward direction and the changes in the bubble interface as the bubble rises in the pool. A thin thermal layer adjacent to the solid surface forms on the area vacated by the departing bubble and the thickness of the thermal layer increases with time due to transient thermal conduction.

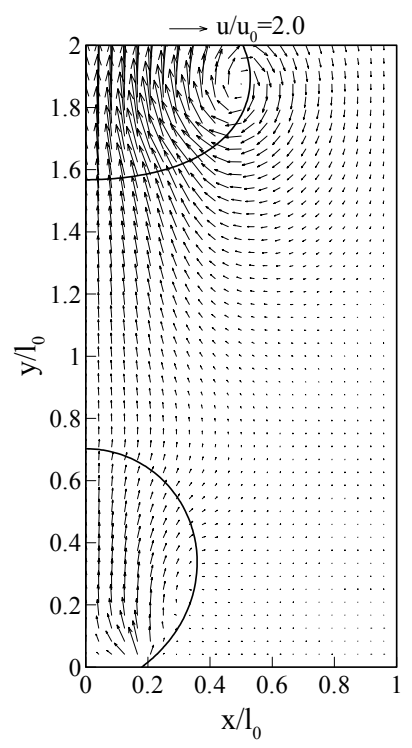

(a)

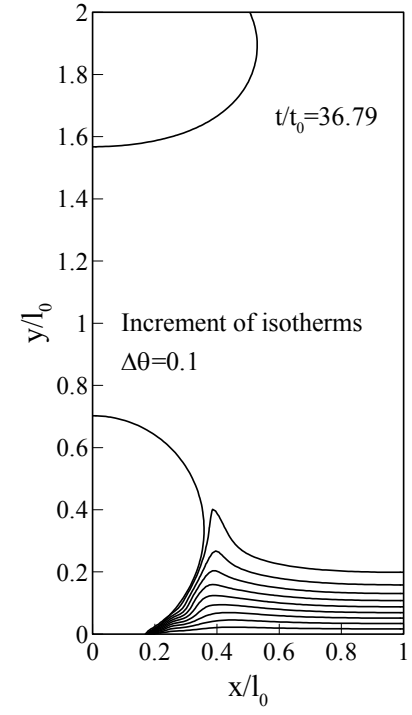

(b)

Figure 2-6: Velocity and temperature distributions for the boron solution at $t / t_{0}=36.79$, and $\Delta \mathrm{T}=6.2 \mathrm{~K}$ 


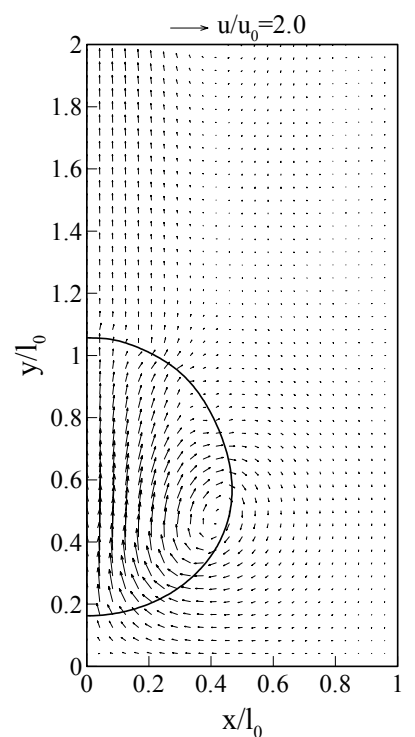

(a)

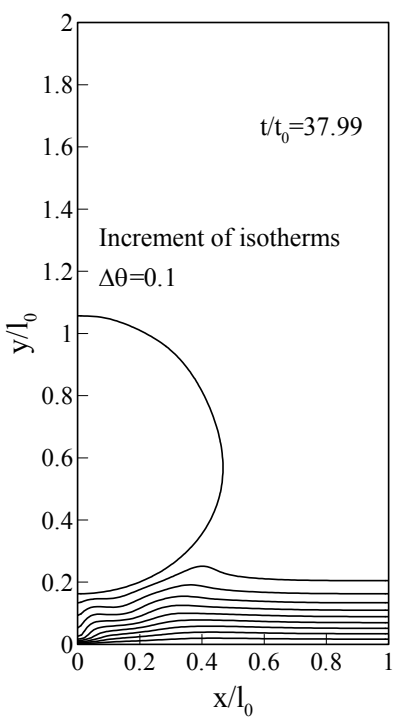

(b)

Figure 2-7: Velocity and temperature distributions for the boron solution at $t / t_{0}=37.99$, and $\Delta \mathrm{T}=6.2 \mathrm{~K}$

Figure 2-8(a) shows the distribution of boron concentration around the growing bubble at $t / t_{0}=36.79$. The concentration of boron is zero in the vapor phase because only water is evaporated from the interface of the bubble. A plume of higher concentration liquid is seen to form on the top of the bubble. This is due to the fact that higher concentration liquid near the interface from the previously departed bubble is pushed upwards as the bubble grows. Figure 2-8(b) shows a magnified distribution near the bubble surface. The higher the evaporative heat transfer at the interface, the larger is the calculated boron concentration. Figure 2-9 shows the orthoboric acid distribution around the bubble just after bubble departure at $t / t_{0}=37.99 \%$. A higher orthoboric acid concentration is found underneath the bubble which is affected by inward flow of liquid after the bubble departure. The liquid with higher concentration of boron is lifted up as the succeeding bubble evolves. The variation of boron concentration is controlled by the evaporative heat transfer at the interface and by the movement of the bulk liquid. 


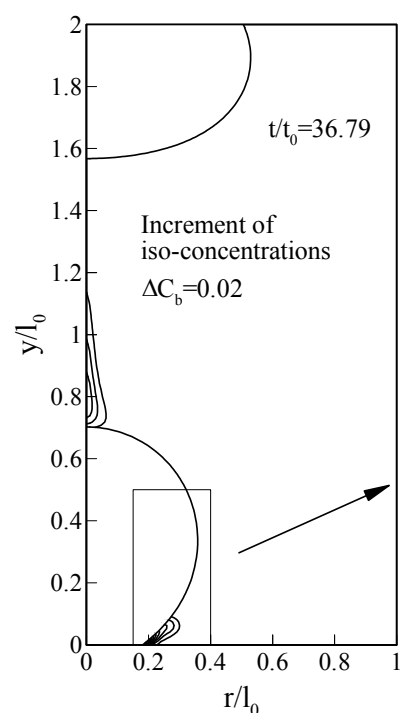

(a)

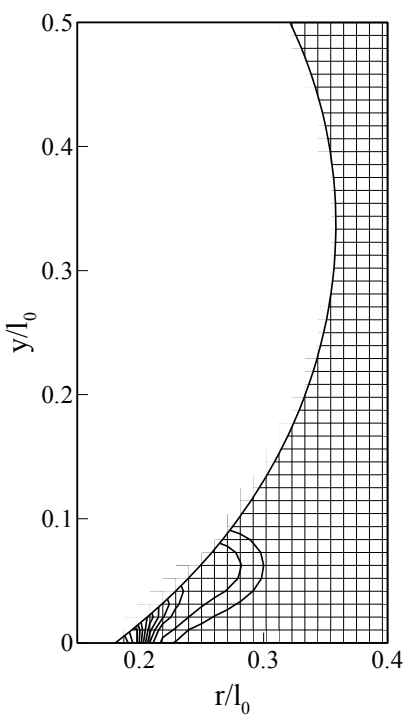

(b)

Figure 2-8: Distribution of boron concentration at $t / t_{0}=36.79$ (14th cycle), $C_{b, 0}=0.003$, and $\Delta \mathrm{T}=6.2 \mathrm{~K}$

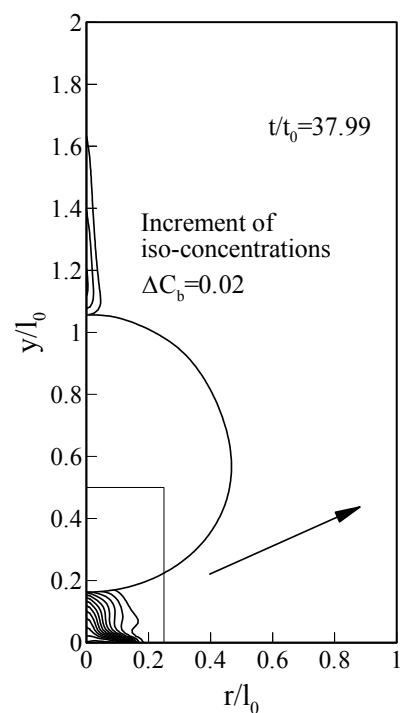

(a)

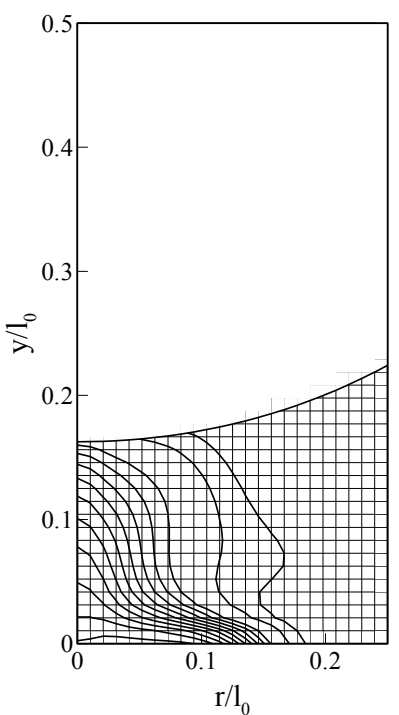

(b)

Figure 2-9: Concentration distribution of Boron at $t / t_{0}=37.99$ (14th cycle), $C_{b, 0}=0.003$, and $\Delta \mathrm{T}=6.2 \mathrm{~K}$

Figure 2-10, 11 and 12 show the variations of boron concentration with time at points $A$ $(r=0.085, y=0.005), B(r=0.135, y=0.005)$ and $C(r=0.105, y=0.055)$ respectively. The solid line represents the variation of boron concentration with time and the dotted line corresponds to the change of solubility limit of boron in aqueous solution of orthoboric acid. The change in solubility limit occurs because of change in local temperature. When the point $A$ is in the liquid near the interface, the temperature is higher than the saturation temperature and as such the 
solubility limit increases. The boron concentration at point $A$ attains a high value in a very short time (which cannot be distinguished from the figure) as the advancing interface moves over point $A$. Thereafter the boron concentration drops to zero as point $A$ lies in the vapor space. The concentration stays at zero until the interface returns back during the departure phase of the bubble. Now once again the concentration rises beyond the solubility limit as the liquid-vapor interface passes over the given location. For point $C$ the highest concentration never exceeds the solubility limit. Since point $C$ is away from the wall, the smaller increase in concentration due to advancement of the interface is a result of the reduced rate of heat transfer. Figure 2-13 shows the temporal variation of precipitation rate in the computational cell at point $A$. It should be noted that the boron is predicted to precipitate out from the liquid only during the moment the vaporliquid interface passes over the point $A$. Figure 2-14 shows the variation of accumulated boron precipitation with time for each bubble cycle. For the first cycle, the initial boron concentration is $0.3 \%$, there is a very little boron precipitated from solution, but after one cycle, the concentration of boron at interface near the wall is near to solubility of solution, after second cycle, the precipitated boron increase to a stable value.

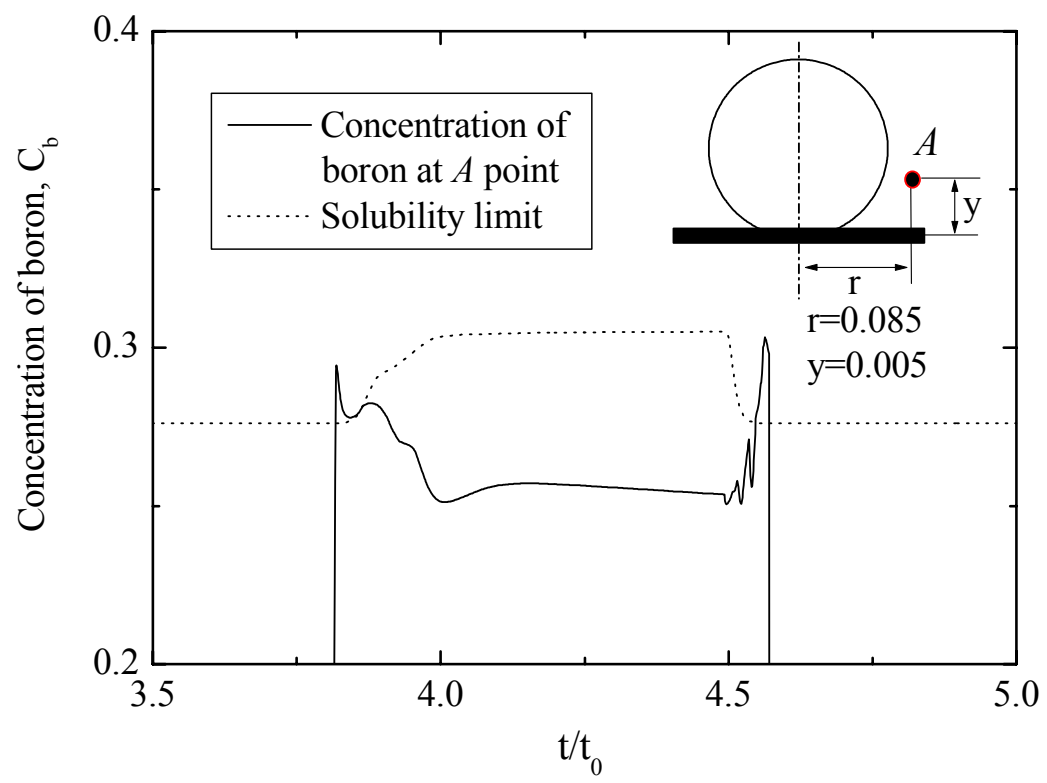

Figure 2-10: Variation of boron concentration and solubility limit of boron in solution with time at point $A$ 


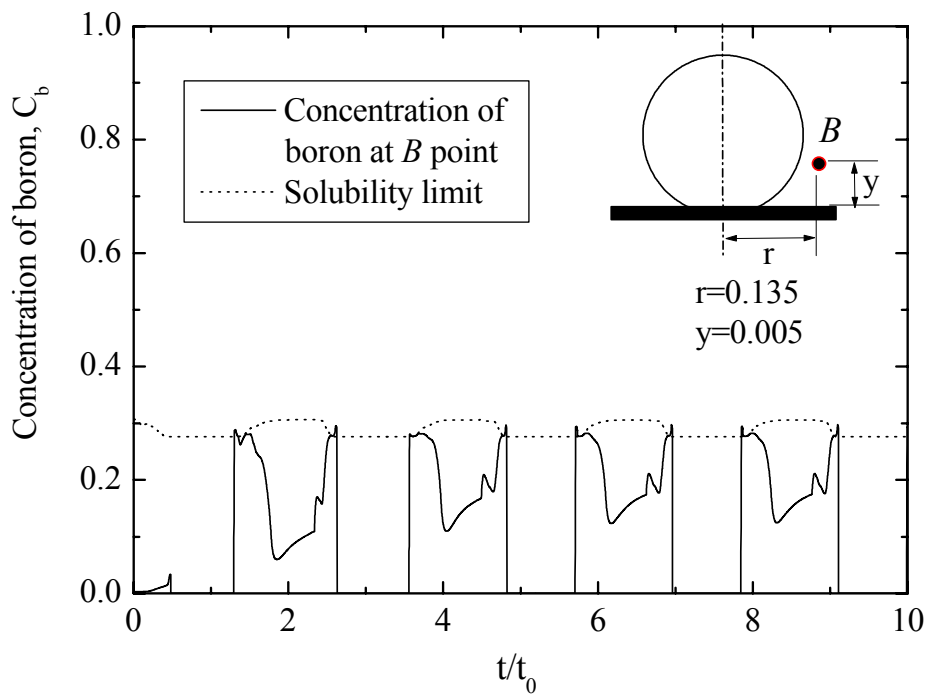

Figure 2-11: Variation of boron concentration and solubility limit of boron in solution with time at point $B$

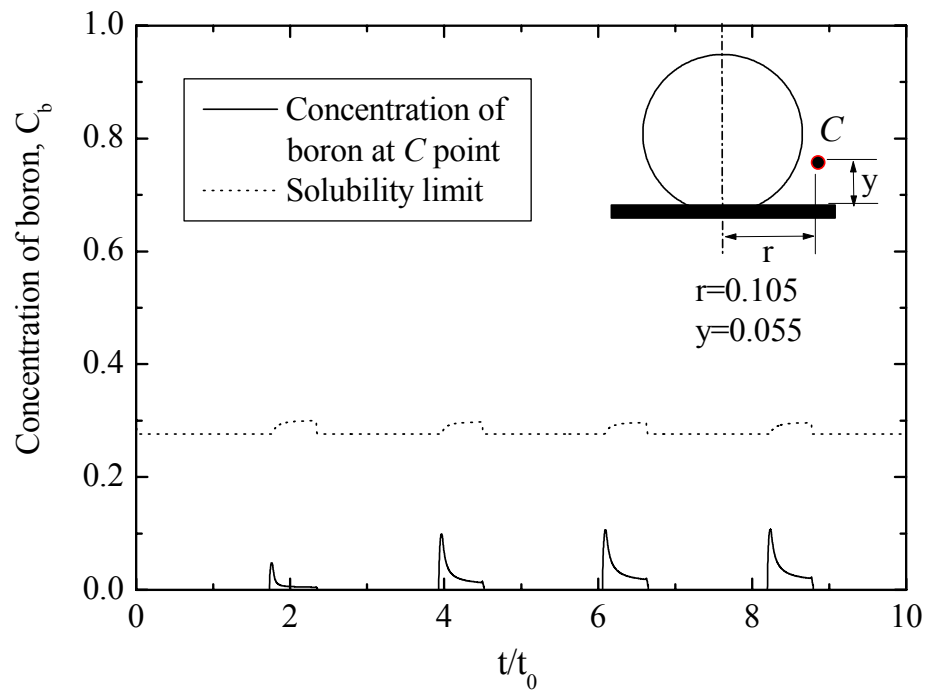

Figure 2-12: Variation of boron concentration and solubility limit of boron in solution with time at point $C$ 


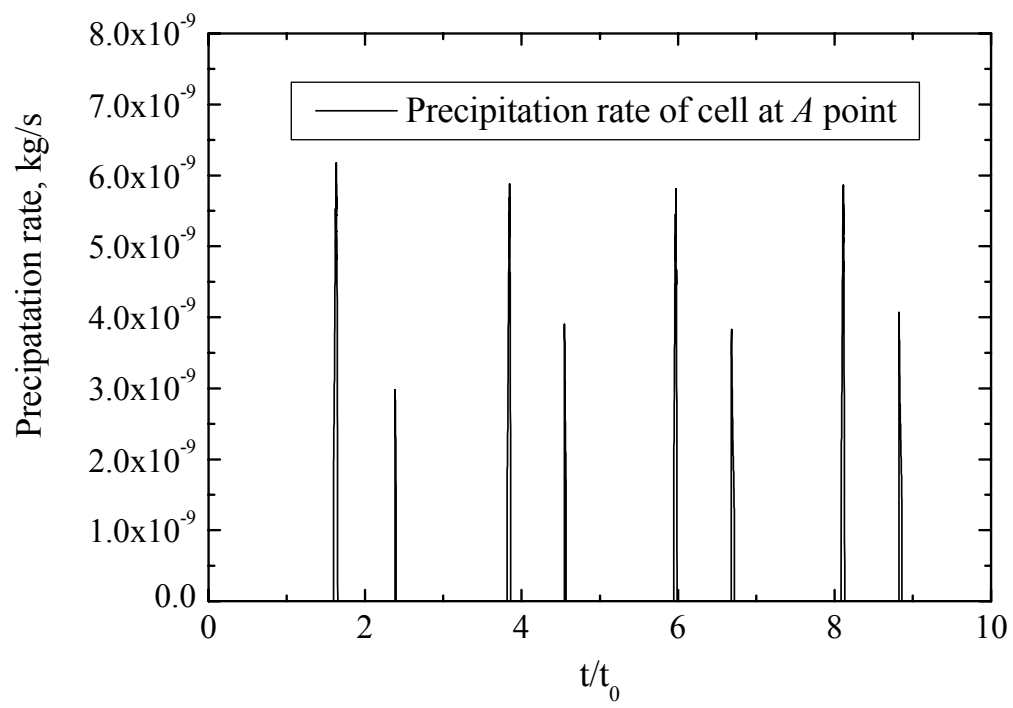

Figure 2-13: Variation of Precipitation rate in computational cell at point $A$ with time

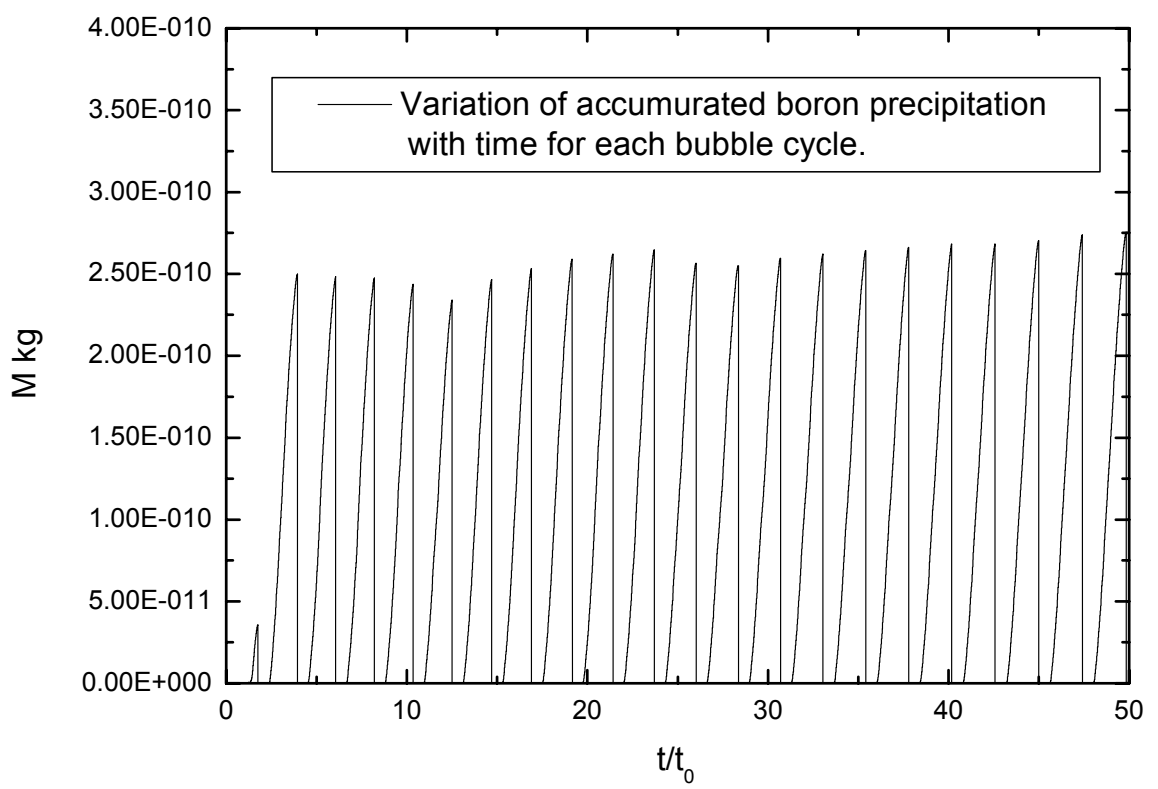

Figure 2-14: Variation of accumulated boron precipitation with time for each bubble cycle 


\subsection{Three Dimensional Flow Boiling}

The computational domain of 3-D flow boiling is shown in Figure 2-15. A nucleation site is located at the center of the bottom plane of a rectangular channel.
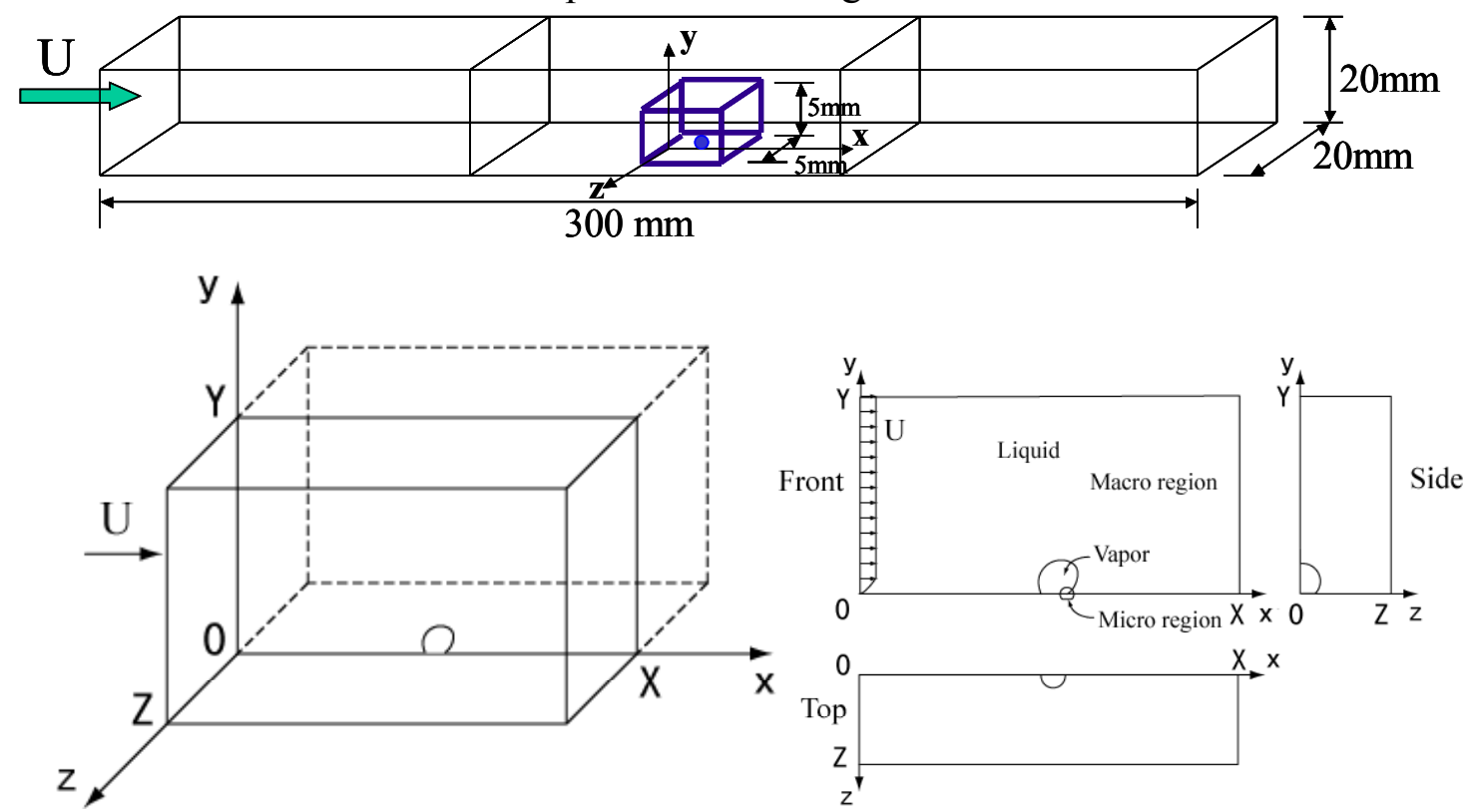

Figure 2-15: Computation Domain for Flow Boiling

The assumptions in this study are:

- The wall temperature remains constant.

- Pure water at $1 \mathrm{~atm}$ is used as the test fluid.

- Fluid is incompressible.

- The thermodynamic properties of the individual phases are assumed to be insensitive to the small changes in the temperature and pressure. So all the properties are constant and are taken at $100^{\circ} \mathrm{C}$.

The boundary conditions for velocity, temperature and level set function are:

$\begin{array}{lll}\mathrm{u}=\mathrm{u}_{\text {in }} ; \mathrm{v}=\mathrm{w}=0 ; \mathrm{T}=\mathrm{T}_{\text {in }} ; \phi_{\mathrm{x}}=0 & \text { at } & \mathrm{x}=0 \\ \mathrm{u}=\mathrm{v}=\mathrm{w}=0 ; \mathrm{T}=\mathrm{T}_{\mathrm{wall}} ; \phi_{\mathrm{y}}=-\cos \varphi & \text { at } & \mathrm{y}=0 \\ \mathrm{u}_{\mathrm{z}}=\mathrm{v}_{\mathrm{z}}=\mathrm{w}_{\mathrm{z}}=0 ; \mathrm{T}_{\mathrm{z}}=0 ; \phi_{\mathrm{z}}=0 & \text { at } & \mathrm{z}=0 \\ \mathrm{u}_{\mathrm{x}}=\mathrm{v}_{\mathrm{x}}=\mathrm{w}_{\mathrm{x}}=0 ; \mathrm{T}_{\mathrm{x}}=0 ; \phi_{\mathrm{x}}=0 & \text { at } & \mathrm{x}=\mathrm{X} \\ \mathrm{u}_{\mathrm{y}}=\mathrm{w}_{\mathrm{y}}=\mathrm{v}=0 ; \mathrm{T}_{\mathrm{y}}=0 ; \phi_{\mathrm{y}}=0 & \text { at } & \mathrm{y}=\mathrm{Y} \\ \mathrm{u}_{\mathrm{z}}=\mathrm{v}_{\mathrm{z}}=\mathrm{w}_{\mathrm{z}}=0 ; \mathrm{T}_{\mathrm{z}}=0 ; \phi_{\mathrm{z}}=0 & \text { at } & \mathrm{z}=\mathrm{Z}\end{array}$

where $\varphi$ is the dynamic contact angle, $\mathrm{u}_{\text {in }}$ is the velocity profile at the inlet and $\mathrm{T}_{\text {in }}$ is the temperature profile at the inlet. The temperature profile $\mathrm{T}_{\text {in }}$ at the inlet was got from experimental data. By using flow over at plate relation, the velocity profile $\mathrm{u}_{\text {in }}$ is known. Fig. 2.4 shows the dynamic contact angle.

For pool boiling case, the dynamic contact angle is larger than static contact angle when the base diameter increases and the dynamic contact angle is smaller than static contact angle when the base diameter decreases. The average contact angle is approximately equal to static contact angle. So it is reasonable to use the average static contact angle instead of dynamic contact angle in pool boiling case. But for flow boiling case, this dynamic contact angle effect 
cannot be ignored. The upstream contact angle increases and downstream contact angle decreases as shown in Figure 2-16. Therefore, it is not reasonable to use the average static contact angle in flow boiling case. The dynamic contact angle has to be considered in flow boiling case. Until now, it is not clear on how the dynamic contact angle changes with flow. So the fitted experimental data are used in calculation as shown in Figure 2-17.

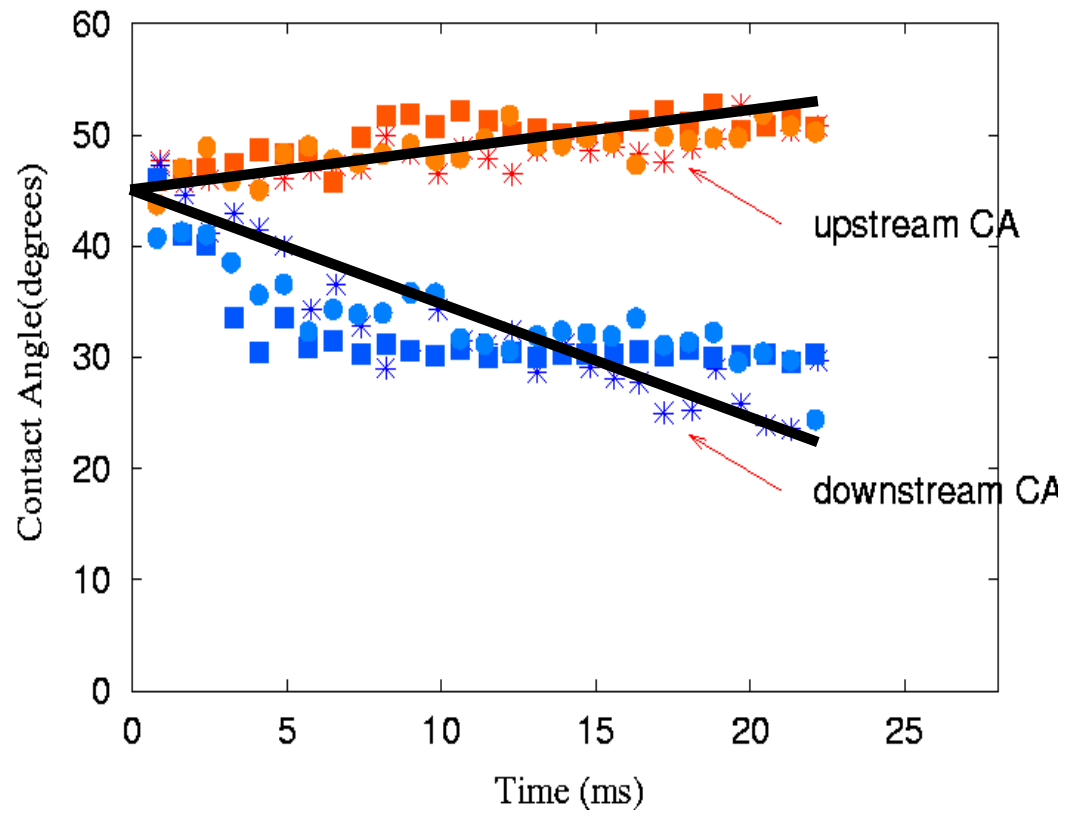

Figure 2-16: The variation of contact angle with time in the growth of a single bubble
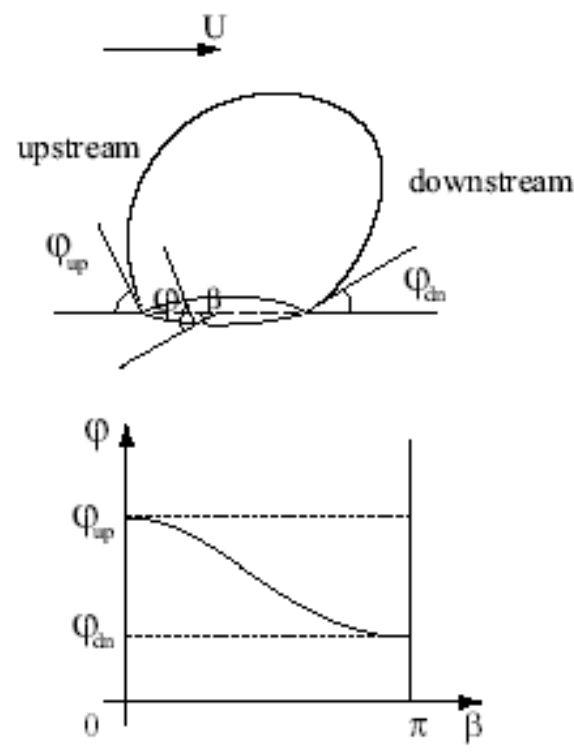

Figure 2-17: Dynamic contact angle

The comparison of bubble growth between numerical results and experimental data is shown in Figure 2-18. In the figure, $\delta_{t}{ }^{*}$ is dimensionless thermal boundary thickness 
$\left(\delta_{t}^{*}=\delta_{t} / \sqrt{\frac{\sigma}{g\left(\rho_{l}-\rho_{v}\right)}}\right)$. Three different thermal boundary layer thickness are shown and $\delta_{\mathrm{t}}{ }^{*}=$ 0.6 is close to the measured thickness of the thermal layer. It can be seen that this model overpredicted the bubble lift-off diameter.

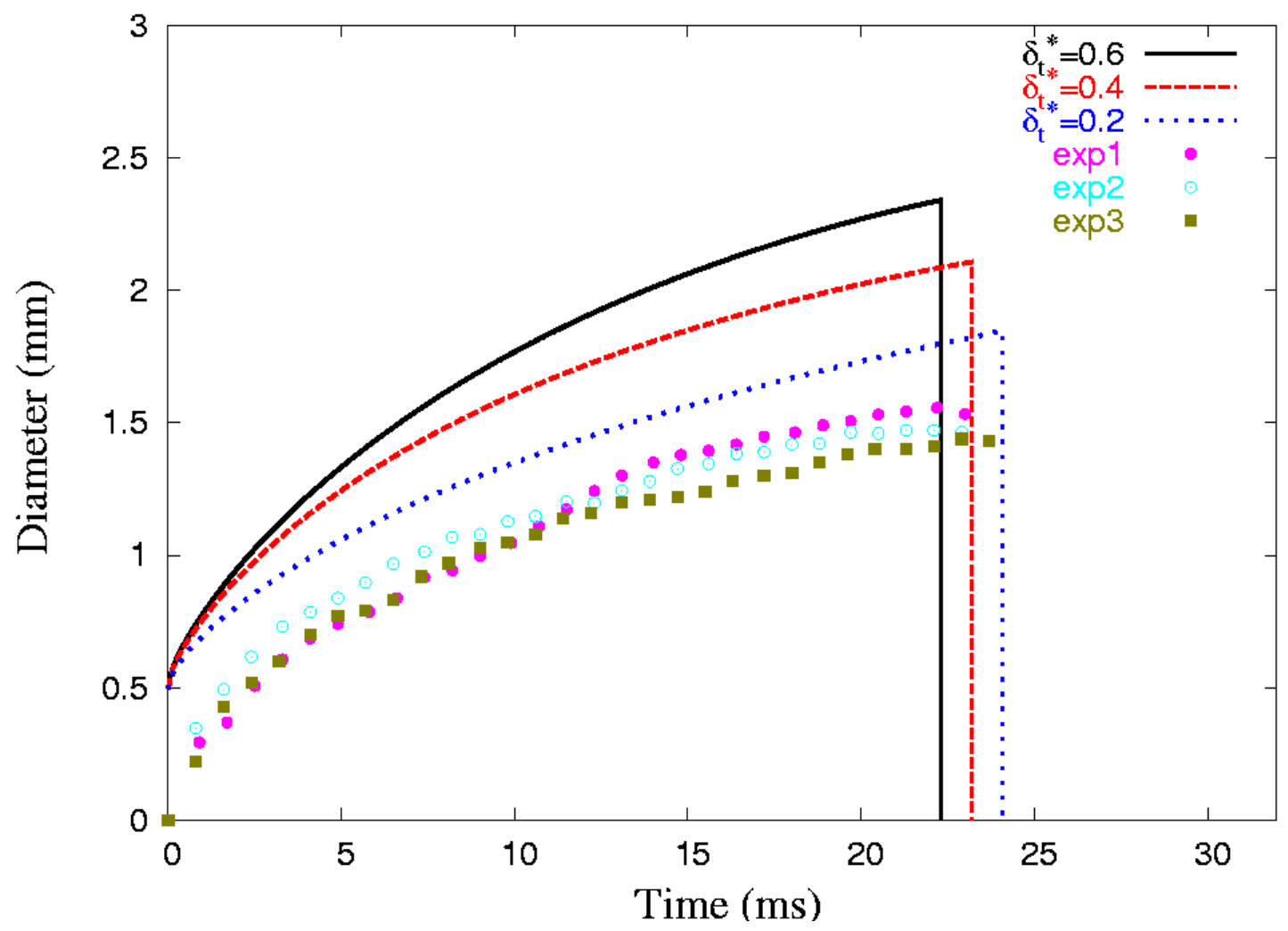

Figure 2-18: The comparison between numerical results and experimental data 


\section{Chapter 3 Experimental Facilities}

Three sets of experiments were conducted. The first one is flow boiling with micromachined single cavity on a silicon flat plate, which investigated the dynamics of isolated single bubbles and boron deposition in subcooled flow boiling. The second one is pool boiling with micro-machined single and multiple cavities on a silicon flat plate, which studied the boron concentration variation near the nucleation site. The last one is subcooled flow boiling on a ninerod bundle enclosed in a square channel to delineate differences between subcooled boiling on a flat surface to that on a simulated fuel rod surface with Zircalloy- 4 cladding. The experimental facilities for these experiments are descried in the following paragraphs.

\subsection{Flow boiling on a silicon flat plate}

An experimental set up was designed to study the nucleation and the behavior of a single bubble in the flow velocity regime of $0.01 \mathrm{~m} / \mathrm{s}$ to $1.00 \mathrm{~m} / \mathrm{s}$ with subcooling ranging from 0 to $10^{\circ} \mathrm{C}$ and wall superheat from $5^{\circ} \mathrm{C}$ to $10^{\circ} \mathrm{C}$. A detailed description of the experimental apparatus and the procedure is presented in this chapter.

\subsubsection{Experimental apparatus}

\section{Flow Loop Design}

The flow loop (Figure 3-1) consists of storage tanks, pump, flowmeter, preheater, test section with developing section for hydrodynamic entry length, and tubing network.

Two Nalgene tanks of $0.3 \mathrm{~m}^{3}$ each are used as storage tanks. One is fitted with two $6 \mathrm{~kW}$, 3- $\phi, 220 \mathrm{VAC}$ Omega heaters for heating purpose. The heaters are used to bring the water to near saturation temperature. The hot water is then pumped with a stainless steel gear pump through the loop. The loop consists of a bypass line for the return of water to the tanks for low velocities. The main line consists of a stainless steel turbine flowmeter (0.08GPM to 8GPM, electronic output $0-10 \mathrm{~V}$ ) for flow measurement purpose. A preheater with $6 \mathrm{~kW}, 3-\phi, 200 \mathrm{VAC}$ Omega heater controlled by a 3- $\phi, 220 \mathrm{VAC}$ variac is used to adjust the subcooling and make up for any heat loss in the loop. A diverging section is used to guide the flow from a $3 / 4$ " circular cross section to a $20 \times 20 \mathrm{~mm}^{2}$ square cross section. The angle of divergence is less than $1^{0}$ to ensure that no flow separation takes place. The test section is mounted on a vertical stand with a horizontal axis to facilitate rotation about that axis. To facilitate rotation, stainless steel hose assemblies are used to connect the test section to the rest of the loop. A developing section of $300 \mathrm{~mm}$ length is used to prevent hydrodynamic entry length problems. Preliminary studies had shown that this length led to a fully developed flow with the geometry and Reynolds number regime under consideration. Identical developing and diverging sections are used at the downstream of the test section to lead the flow back to the storage tanks. Vibration isolators are used under the motor-pump assembly and the test section stand to eliminate the effects of vibrations on the motion and behavior of the bubbles generated. 


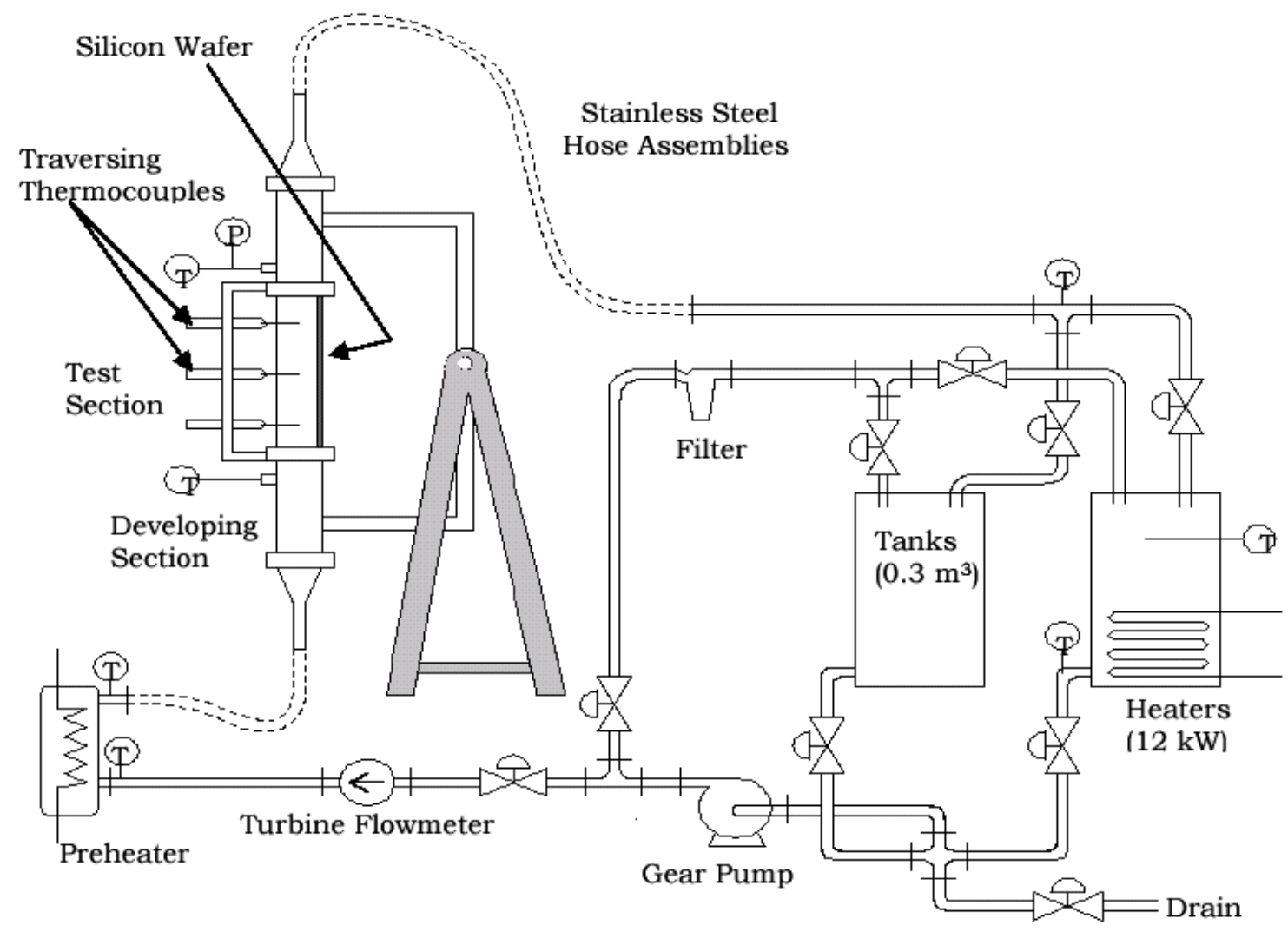

Figure 3-1: Schematic of Flow Boiling Experimental Set Up

\section{Test Section}

The test section is a rectangular flow chamber $\left(20 \times 20 \times 300 \mathrm{~mm}^{3}\right)$ with pyrex glass on three sides mounted on a stainless steel frame to facilitate visual observations and optical measurements (Figure 3-2 \& Figure 3-3). On the fourth side, silicon wafers are mounted on a phenolic G10 base bonded to it by GE two part silicone RTV60. Thermocouples attached to traversing micrometers are mounted from the opposite end to measure the thermal boundary layer in the liquid.

\section{Micro - machined Silicon Wafers and Strain Gage Heaters}

The test surface is made up of three rectangular $(19 \mathrm{mmX}$ X9.9mm) polished $<100>$ silicon wafers. The reasoning behind choosing the silicon wafer as test surface are as follows 1) Silicon wafer can be manufactured using commercial techniques to give an excellent surface finish, which helps in avoiding nucleation of spurious bubbles on the surface and 2) well established MEMS machining techniques can be used to fabricate the desired single cavity needed for the experiments.

Of the three wafers mounted on the G10 base, the middle wafer contains a precisely deep reaction ion etched 10 micron square cavity 50 micron deep at the geometric center (Figure 3-4 \& Figure 3-5). The etched wafers were commercially obtained from MCNC. Originally wafers supplied were circular, but they were diced into required rectangular dimensions at the UCLA Center for High Frequency Laboratory. 
Two rows of precision strain gages, which are used as heating elements (Figure 3-6 \& Figure 3-7), are bonded along the backside of the wafers. These thin film strain gage heaters were obtained from Measurements Group, NJ. Each strain gage heater was $10 \mathrm{~mm}$ x $7.5 \mathrm{~mm}$ with an effective heated portion of $6.5 \mathrm{~mm} \times 6.5 \mathrm{~mm}$. The resistance of each heater element was $120 \Omega$ and could supply approximately $40 \mathrm{~W}$ of power.

\section{Thermocouples}

K-type (Chromel Alumel) thermocouples obtained from Omega were used in the experiment. Grounded sheath thermocouples of outer diameter $1.5 \mathrm{~mm}$ were used to measure the temperature of flowing water at different junctions of the loop, namely the tanks, inlet and outlet of the preheater, inlet and outlet of the test section. Thermal profile in the liquid above the test surface was measured by three sheath thermocouples of diameter $0.25 \mathrm{~mm}$, attached to traversing micrometers. Temperature of the test surface was measured with thermocouples bonded to the back of the wafer surface along the center. Thermocouple leads were fused to form a ball, which was squeezed and then attached to the back of the wafer using Omega bond 200 resin. Three micro-thermocouples of wire diameter $0.125 \mathrm{~mm}$ were installed behind the cavity and the immediate surroundings to measure the wall superheat accurately. Before the thermocouples were attached to the system, a two point calibration was performed at ice point and the boiling point of water and verified by measuring the ambient air temperature with each thermocouple. All subsequent thermocouple readings were adjusted using the results of the calibration.

Lead wires to the strain gage heaters and the thermocouple wires from the wafer back were led through holes in the G10 base to power sources and data acquisition system respectively (Figure 3-2). Thermocouples were placed inside the G10 base along the center to estimate the heat loss at the back.

\section{Support Structure}

The support structure was constructed using G10. The G10 was chosen for its mechanical strength, machinability and its low thermal conductivity. The thermal conductivity of G10 is about $0.16 \mathrm{~W} / \mathrm{mK}$. The silicon wafers with heaters and thermocouples already installed were bonded to the G10 base with GE Silicone two part RTV 60 under evacuated conditions. The thermal conductivity of this RTV60 was earlier determined in a separate study to be in the range of $0.70 \mathrm{~W} / \mathrm{mk}$. Special care was taken to ensure that the three wafers remained aligned with each other during the bonding process. 


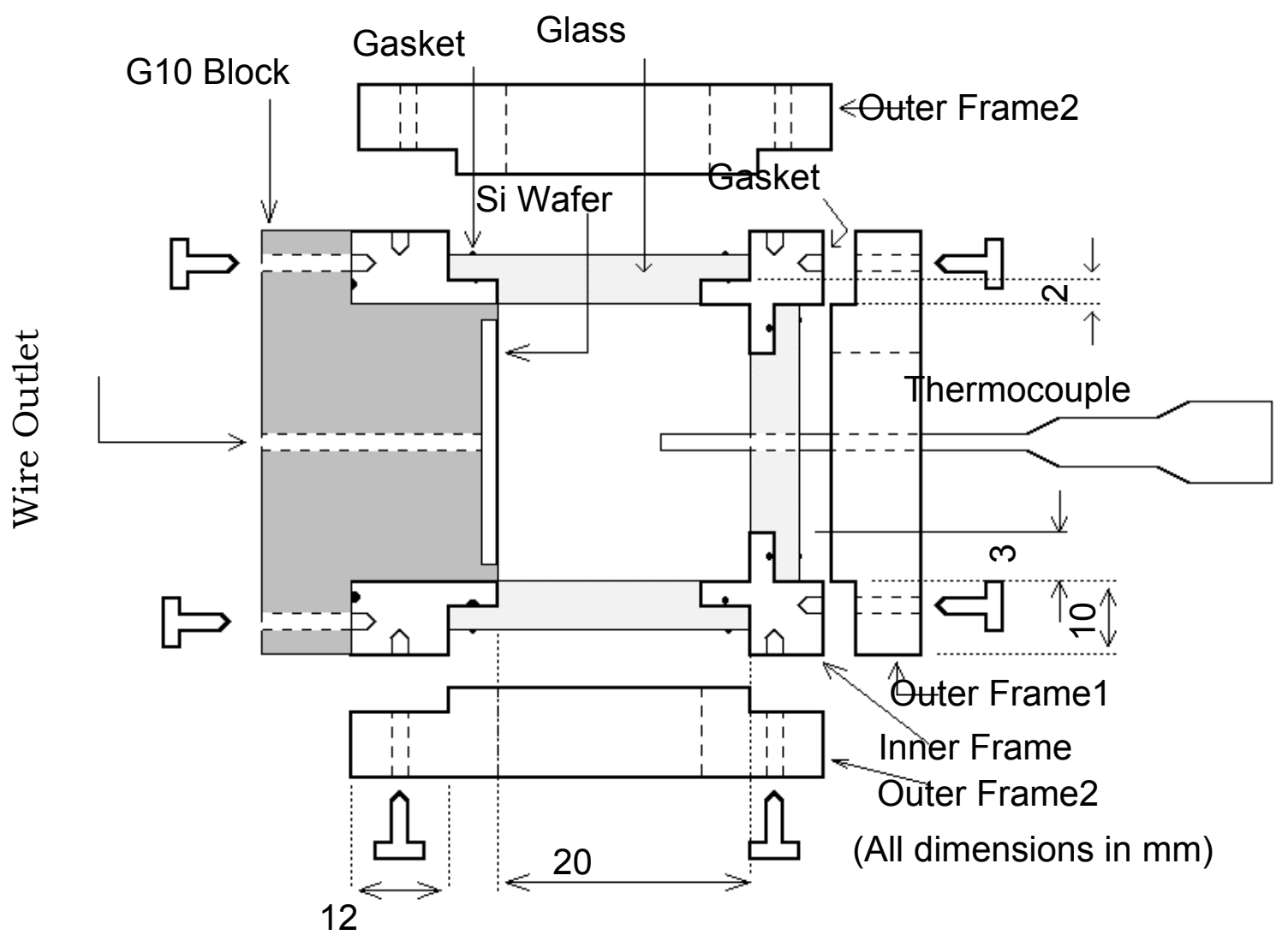

Figure 3-2: Cross View of Test Section

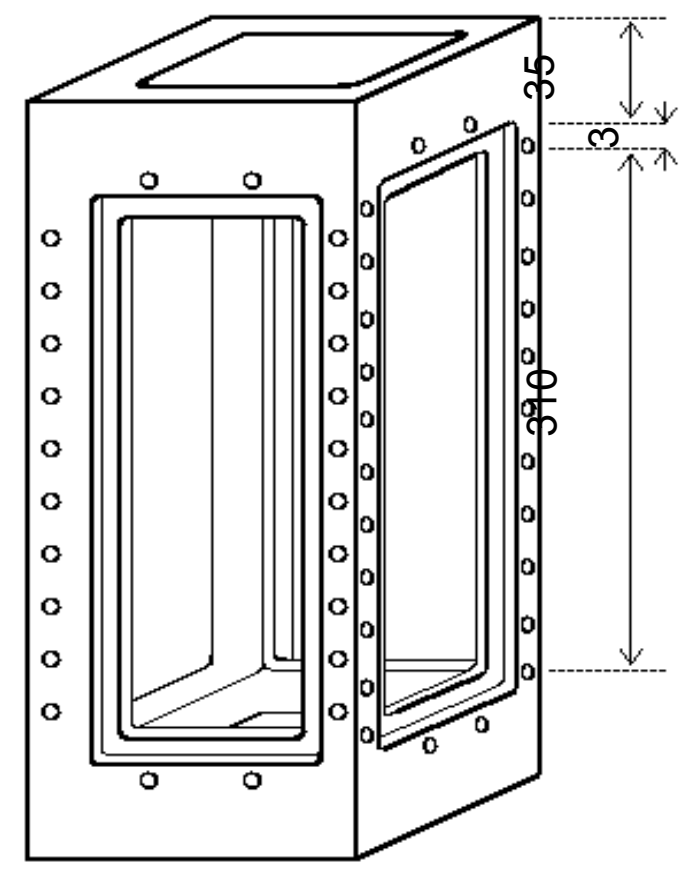

Figure 3-3: Inner Frame 


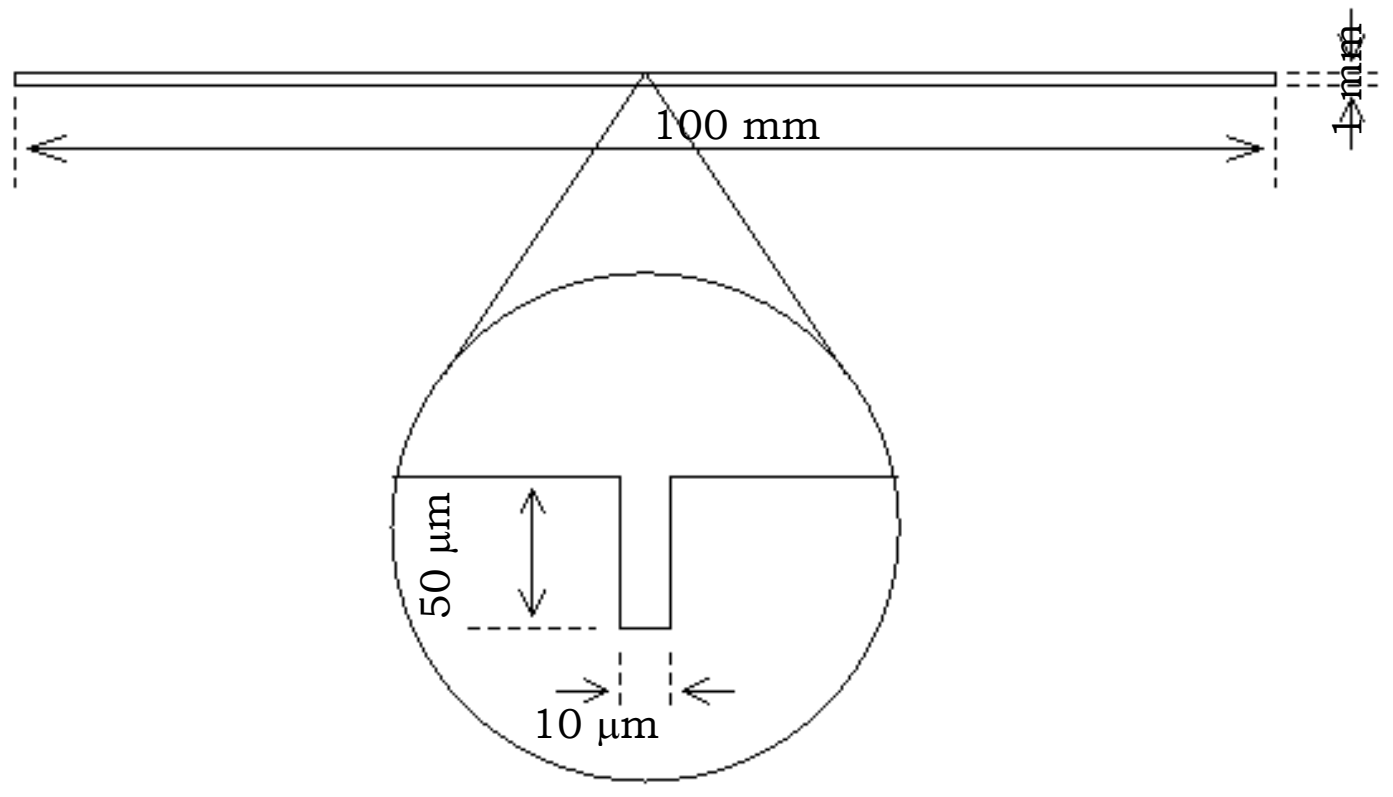

Figure 3-4: Schematic of Silicon Wafer and Cavity

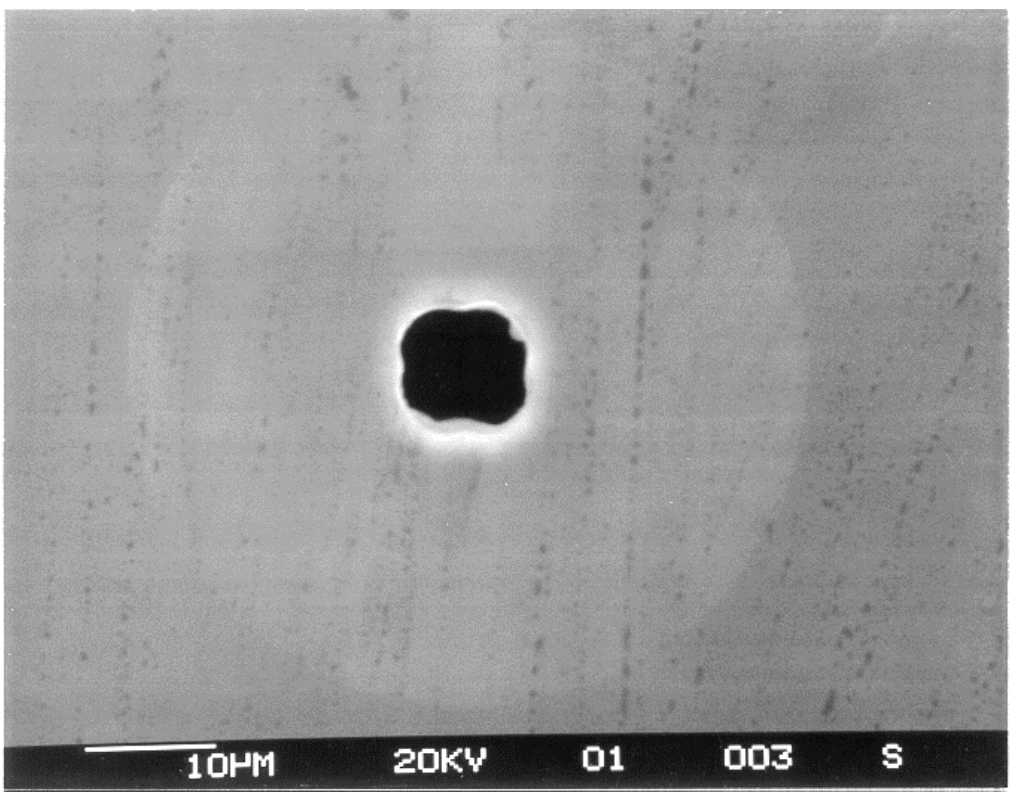

Figure 3-5: SEM Picture of micro-fabricated Cavity on Si Wafer 


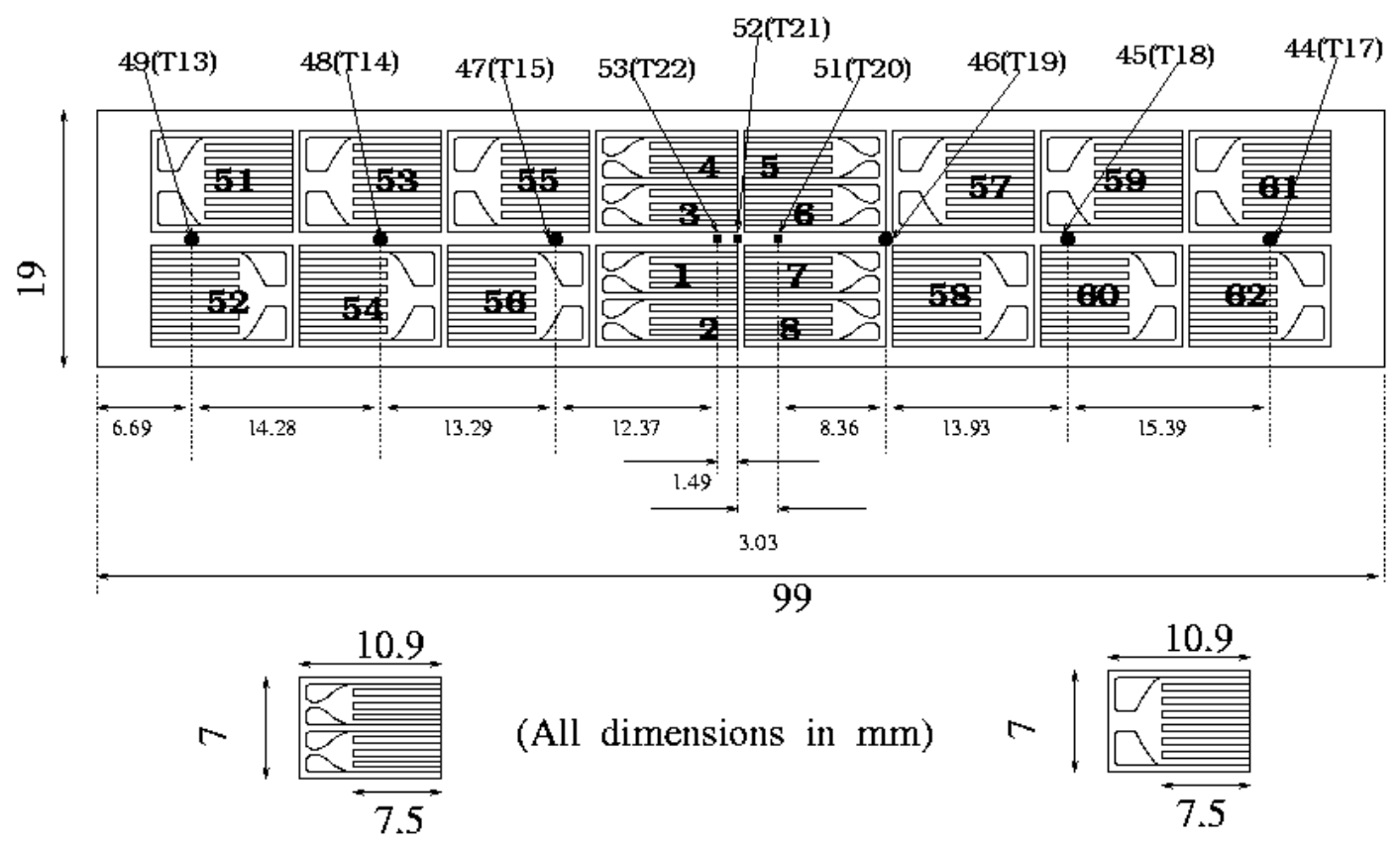

Figure 3-6: Schematic of Positions of Strain Gage Heaters and Thermocouple at Wafer Back

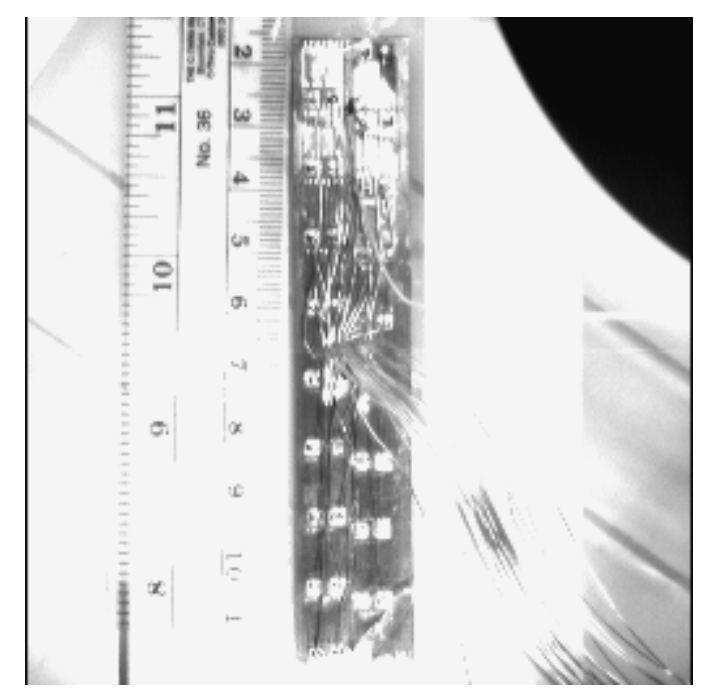

Figure 3-7: Photograph of Heaters and Thermocouples at Wafer Back 


\section{Data Acquisition}

The data generated by the thermocouples and the flowmeter was recorded continuously by a Workbench Data Shuttle PC data acquisition system. Bubble generation, growth and departure was recorded by a High Speed Digital Imaging System (HiSis) linked to a PC. The software was set to the highest speed of 1019 frames in $835.2 \mathrm{~ms}(0.82 \mathrm{~ms} /$ frame) while recording.

\subsubsection{Experimental Procedure}

Before installing the G10 base with the silicon wafers to the test section, The test surface was thoroughly cleaned with deionized (DI) water and spray dried to remove dust particles with compressed clean air. The wafer surface was then wiped clean with soft cotton cloth and sprayed with Acetone. After wiping away the acetone with another soft cotton gage, the wafer was treated with Isopropanol and blow-dried. DI water was then sprayed on the surface to remove any residual layer of chemicals left.

Contact angle of the surface was measured on the surface before each experiment. A single drop of degassed DI water was placed on the surface with the help of a small syringe. A digital image of the droplet profile was analyzed to obtain the static contact angle. The static contact angle measured was about $61^{\circ}$.

The heaters in the tank were first switched on to heat up the DI water to $99^{\circ} \mathrm{C}$. The water was then pumped through the loop at the desired velocity and the temperature was maintained at $99^{\circ} \mathrm{C}$ with the help of the preheater. This was done to remove the non-condensable (dissolved air) from the water. During this time many small air bubble could be seen appearing at the edges of the wafer all along the length of the test section. After about an hour it could be observed that all those bubbles had disappeared, leading to the conclusion that the liquid was sufficiently degassed. The strain gage heaters immediately around the cavity were switched on to activate the cavity. After nucleation had taken place voltage to the rest of the strain gage heaters were switched on. Then the preheater power was adjusted to reach the desired subcooling. After a steady state had been reached, temperature and flowmeter readings were acquired with the data acquisition system while simultaneously high speed movie of the bubbles was obtained and stored. The camera was run at a frame rate of 1019 frames in $835.2 \mathrm{~ms}$ resulting in a frame rate of 0.82 $\mathrm{ms} /$ frame. The traversing micro-thermocouples were then adjusted to measure temperatures at different locations perpendicular to the flow direction to determine the thermal profile in the liquid. The liquid temperature profile was then compared with available single phase forced convection correlations. After a run had been completed, the variac and flow valves were adjusted for different subcoolings and velocity.

\subsubsection{Post Processing}

The surface temperature was estimated using the temperature measured from the back of the wafer.

The photographic images were then analyzed using a custom developed analysis tool. The number of pixels in a physical dimension is determined by taking an image of a scale after every run. The number of pixels between two markings is then measured. It was found that two physically equal dimensions in the horizontal and the vertical dimensions gave equal number of pixels in the $256 \times 256$ aperture of the camera. Thus contact angle could be measured by taking the inverse tan of the ratio of the number of pixels in the vertical and horizontal directions. 
Bubble diameter and height were estimated by measuring the number of pixels and then converting into physical dimensions. The bubble was observed to be approximately ellipsoidal and hence, an equivalent spherical bubble diameter was derived at by equating the volume of the ellipsoid to that of a sphere. However, in flow the bubble was observed to be ellipsoidal but inclined in the direction of the flow. Thus, suitable modifications were made to the analysis procedure to get the correct equivalent diameter. This equivalent diameter was then used to calculate the growth rate. Successive frames were then analyzed to obtain variation of bubble diameter with time, bubble departure diameter and time, variation of bubble sliding distance, sliding velocity, contact angles upstream and downstream with time and finally lift-off diameter and time.

\subsection{Pool boiling on a silicon wafer}

\subsubsection{Experimental Apparatus}

The apparatus for the experiments is schematically shown in Figure 3-8. It consists of a cylindrical Plexiglas test chamber $(\mathrm{D}=150 \mathrm{~mm}, \mathrm{H}=170 \mathrm{~mm})$ with a flat glass window for visual observations. High speed CCD video camera was installed perpendicular to the glass window to record the boiling processes. It was operated at 1200 frames/second. The resolution of the camera is $256 \times 256$ pixels. A circular water heater is located at the bottom of the chamber to control subcooling of the water. A T-type thermocouple probe of a diameter of $0.5 \mathrm{~mm}$ is placed in the upper portion of the chamber to measure the bulk liquid temperature. The concentration sensor is installed onto a precise 3-axis translation stage, which has a resolution of $0.01 \mathrm{~mm}$.

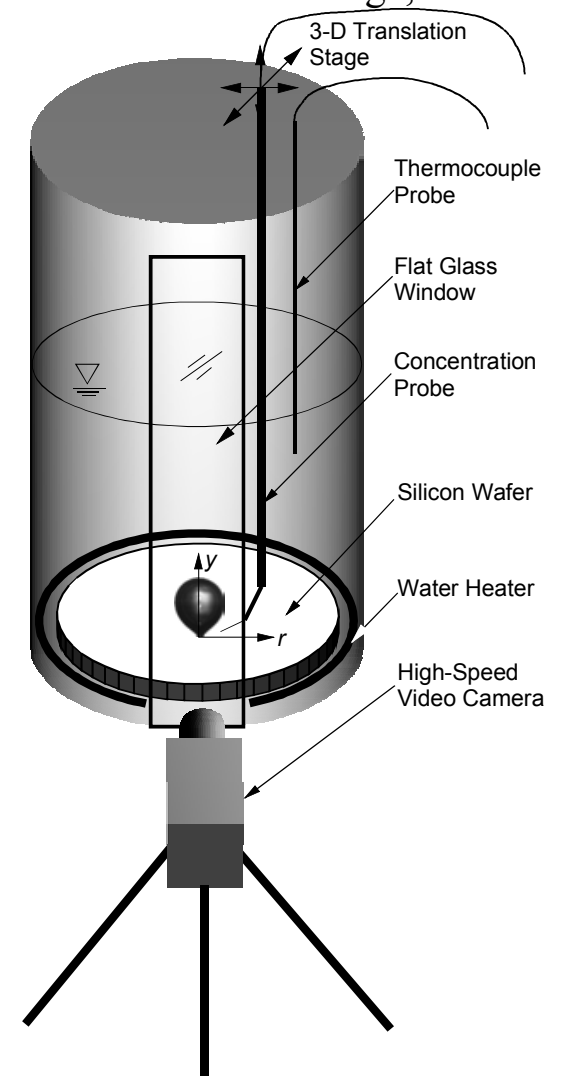

Figure 3-8: Schematic diagram of the experimental set-up 
The specially prepared test surface for generating single bubble is installed at the bottom of the test chamber. The structure is shown in Figure 3-9. It is made of well-polished silicon wafer with $100 \mathrm{~mm}$ in diameter and $1 \mathrm{~mm}$ in thickness. From the manufacturer's specification the surface roughness is less than $5 \AA$. Five cylindrical cavities having diameters of $10 \mu \mathrm{m}$ (no.1), $7 \mu \mathrm{m}$ (no.2 and 4) and $4 \mu \mathrm{m}$ (no.3 and 5) were etched to a depth of about $100 \mu \mathrm{m}$ in the wafer center via the deep reactive ion etching technique (DRIE), see Figure 3-9 (b). By controlling the superheat, any one or a combination of these cavities could be activated.

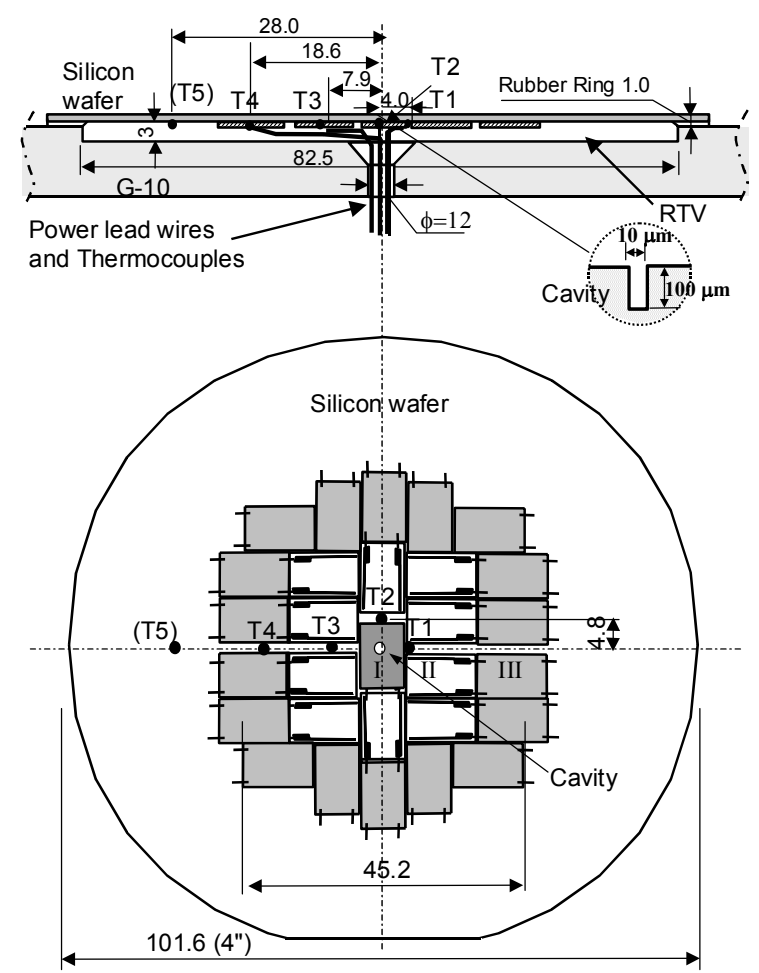

(a) Overview

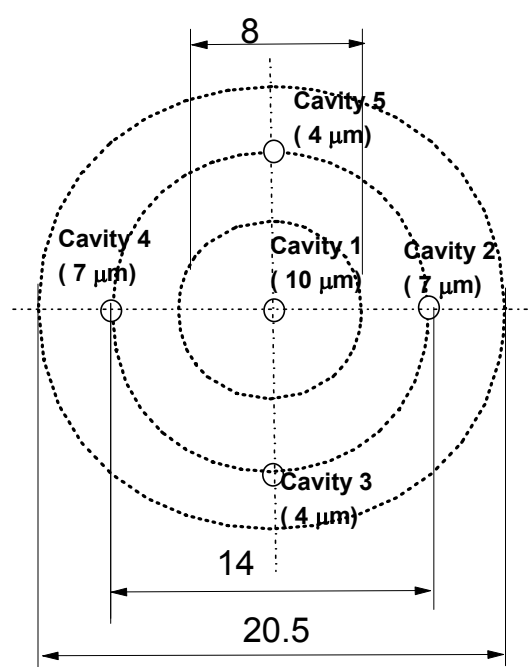

(b) Cavity positions

Figure 3-9: Silicon wafer instrumented with strain gage heaters and thermocouples

At the back of the silicon wafer foil-like strain gage heating elements were bonded. Each of the elements has an effective heating area of $6.5 \times 6.5 \mathrm{~mm}^{2}$ and was separately wired. The heating elements are grouped in different regions. In each group a thermocouple is directly attached to the wafer. The heater surface temperatures in different regions are then separately controlled. Figure 3-9 (a) shows the location of heaters and thermocouples on the silicon wafer. The wafer is cast with RTV, -silicon rubber, on a Phenolic Garolite (G-10) base. The base in turn is mounted in the test chamber.

\subsubsection{Experimental Procedure}

Before the experiment was conducted, the distilled water was degassed thoroughly and the test surface was cleaned. And then, degassed water or solution of desired concentration at room temperature was introduced into the test chamber. The heater in the liquid pool was then switched on to heat the liquid up to saturation temperature. After that, nucleation at the cavity was achieved by energizing the heating elements underneath the cavity. The wall superheat at the cavity area was gradually increased until the inception of nucleation. For saturated water the wall 
superheat at nucleation inception was generally $12-17^{\circ} \mathrm{C}$ and it is $15-21^{\circ} \mathrm{C}$ for aqueous boric acid solution. However, the wall superheat could be reduced to $4-5^{\circ} \mathrm{C}$ to keep the cavity active. While maintaining the wall superheat and liquid subcooling stable, photographic images were acquired with the high-speed video camera at a frame rate of 1200 frame/second.

During the experiments, recording of images of the bubble and output of the concentration sensor must be synchronized. To achieve this, the high-speed video camera was triggered by the rising edge of the rectangular wave applied to the sensor. The oscilloscope that recorded the voltage across the reference resistor was in turn triggered by a synchronizing signal from the camera.

The boiling surface temperature was estimated using the thermocouple data from the back of the wafer. The photographic images obtained were analyzed using a custom developed analysis tool. The number of pixels in a physical dimension is determined by taking an image of an object of known width. Two physically equal dimensions in the horizontal and vertical direction gave equal pixel numbers.

\subsection{Flow boiling on a nine-rod bundle}

\subsubsection{Experimental Apparatus}

\section{Flow loop}

The schematic of the flow loop is shown in Figure 3-10. The flow loop consists of two tanks, a centrifugal pump, flow meter, bypass line, preheater, and test section. Detailed discussions of the various components are given below.

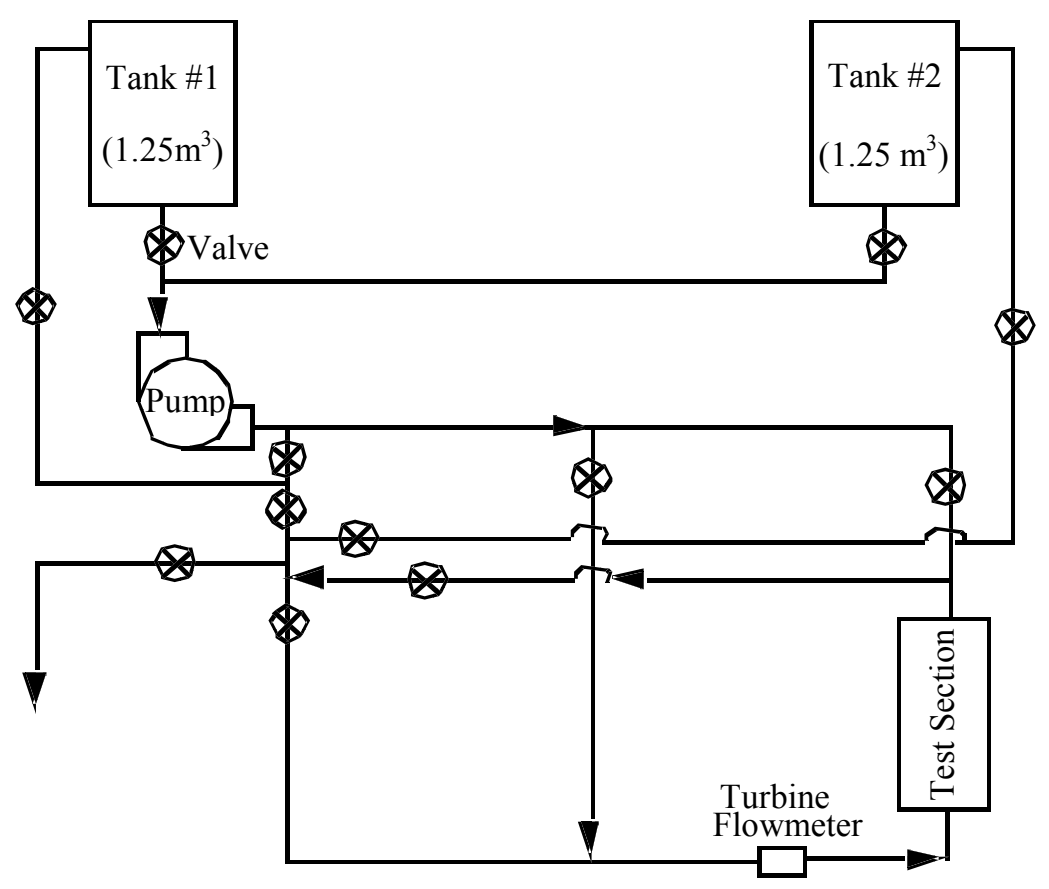

Figure 3-10: Schematic of test loop

Tanks: Each of the tanks has a volume of approximately $1.25 \mathrm{~m}^{3}$. Tank $\# 1$, which was used as the supply tank, is also fitted with immersion heaters (13.5 $\mathrm{kW}$ total power). These 
immersion heaters were used to both degas and preheat the distilled water used in the experiments. A K-type thermocouple mounted on the tank was used to monitor the water temperature.

Pump: The centrifugal pump (Hydrokinetics, maximum flow rate $=400 \mathrm{gpm}$ ) was used to pump the water through the test loop. This pump input line is connected to both tanks, such that water can be drawn from either of the two tanks. Also, using the bypass line provided at the pump discharge, it was possible to pump the water into either of the two tanks.

Turbine Flow Meter: The liquid flow rate was recorded using a $7.62 \mathrm{~cm}$ (3 inch) diameter turbine flow meter (ITT Barton Model \# 7203) fitted with a digital flow totalizer (ITT Barton Model \# BA202). It was installed approximately $0.76 \mathrm{~m}$ (10 pipe diameters) downstream of the pump, so as to minimize measurement errors. The flow meter was calibrated by the manufacturer before it was installed. The flow rate was recorded in gallons per minute $(\mathrm{gpm})$ with an accuracy of $0.01 \mathrm{gpm}$. The maximum capacity of the flowmeter is $700 \mathrm{gpm}$.

Preheater: The preheater consisted of a $210 \mathrm{~kW}$ (480 $\mathrm{V}, 3$ phase) flanged immersion heater fitted vertically onto a stainless steel container vessel. The heater has an immersion length of $1.56 \mathrm{~m}$ with a $0.15 \mathrm{~m}$ cold section. The total bundle diameter of the heater is $0.24 \mathrm{~m}$. The container in which the heater is installed is $1.73 \mathrm{~m}$ long and $0.25 \mathrm{~m}$ in diameter. Water enters the vessel at the bottom through a $7.62 \mathrm{~cm}$ ( 3 inch) inlet pipe, heats up as it flows upwards past the heater coils and exits at the top of the vessel (through a $7.62 \mathrm{~cm}$ ( 3 inch) outlet pipe). K-type thermocouples mounted at the inlet and outlet of the vessel are used to monitor the liquid temperatures. The power to the immersion heater is controlled using a $480 \mathrm{~V}, 350 \mathrm{~A}$ silicon controlled rectifier (SCR) power controller (Phasetronics). Using the power controller and thermocouple outputs, it is possible to control the liquid subcooling accurately.

\section{Nine Rod Bundle Test Section}

The test section used to accommodate the rod bundle is shown in Figure 3-11. The test section consists of three parts: (i) transition section - where the flow cross-section goes from circular to square, (ii) developing section - where the flow is allowed to develop, and (iii) heating section - where the heated rod bundle is mounted and all measurements are made. The heating section is 0.91 meter long and contains a 9-rod bundle, arranged in a $3 \times 3$ matrix. 


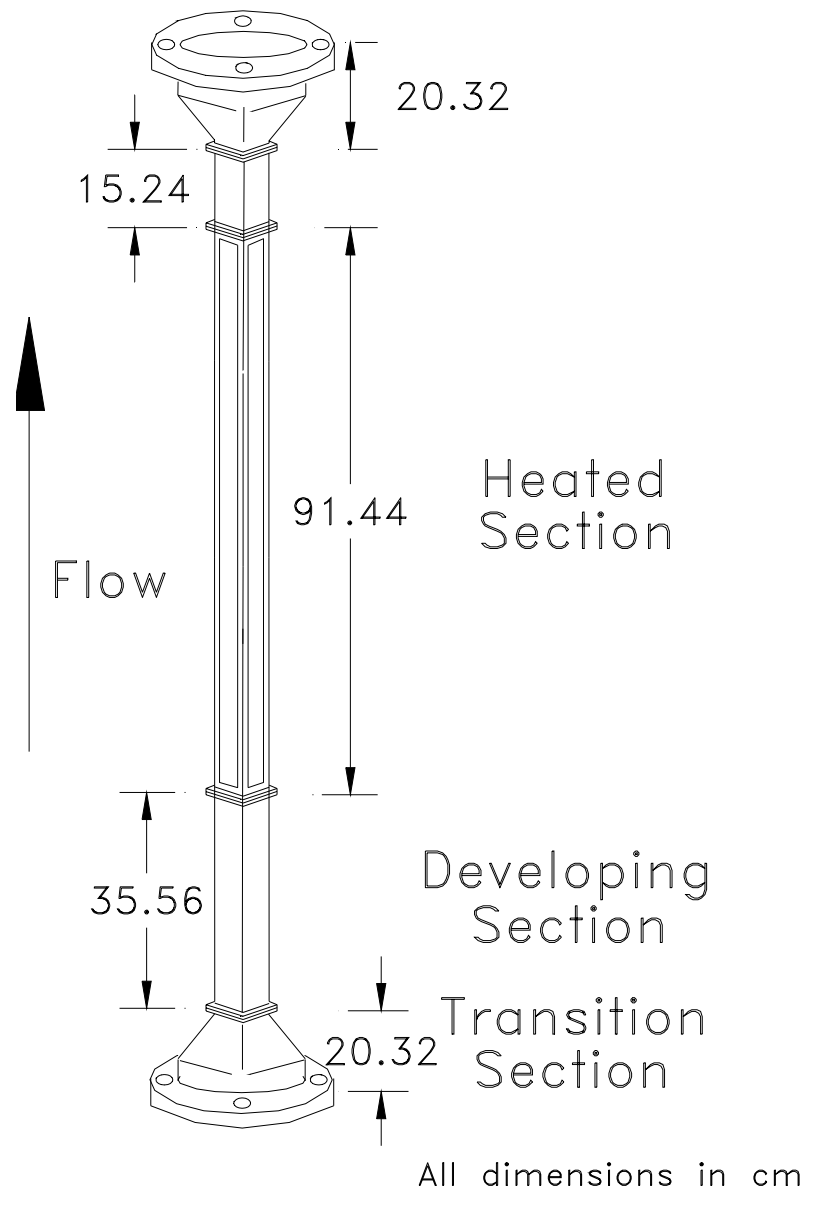

Figure 3-11: Rod bundle test section

Figure 3-12 shows the cross-section of the nine rod bundle heating section. Glass windows are provided on all sides so as to aid visual observation. The diameter of the rods and the pitch of $3 \times 3$ square arrangement are typical of those found in an actual reactor core. The heating rods have an outer diameter of $1.11 \mathrm{~cm}(0.4375 \mathrm{inch})$ and are arranged with a pitch of $1.43 \mathrm{~cm}(0.5625 \mathrm{inch})$. Since the rods are to be Joule heated using a DC power source (100 kW total capacity), care has to be taken in selecting the rod material. The important parameters taken into consideration during material selection included (i) melting point, (ii) resistivity, and (iii) oxidation characteristics, and (iv) prototypicality. After taking all these factors into consideration, Zircalloy- 4 has been chosen as the suitable rod material. The wall thickness of the cladding $(0.015 \mathrm{~cm}, 0.006 \mathrm{inch})$ was determined by the total resistance of the tube (which has to have a value that maximizes the rate of heat generation in the tube). Power to the tubes is provided using copper bus bars mounted at the ends of the test section (at the inlet and exit of the heated section) 


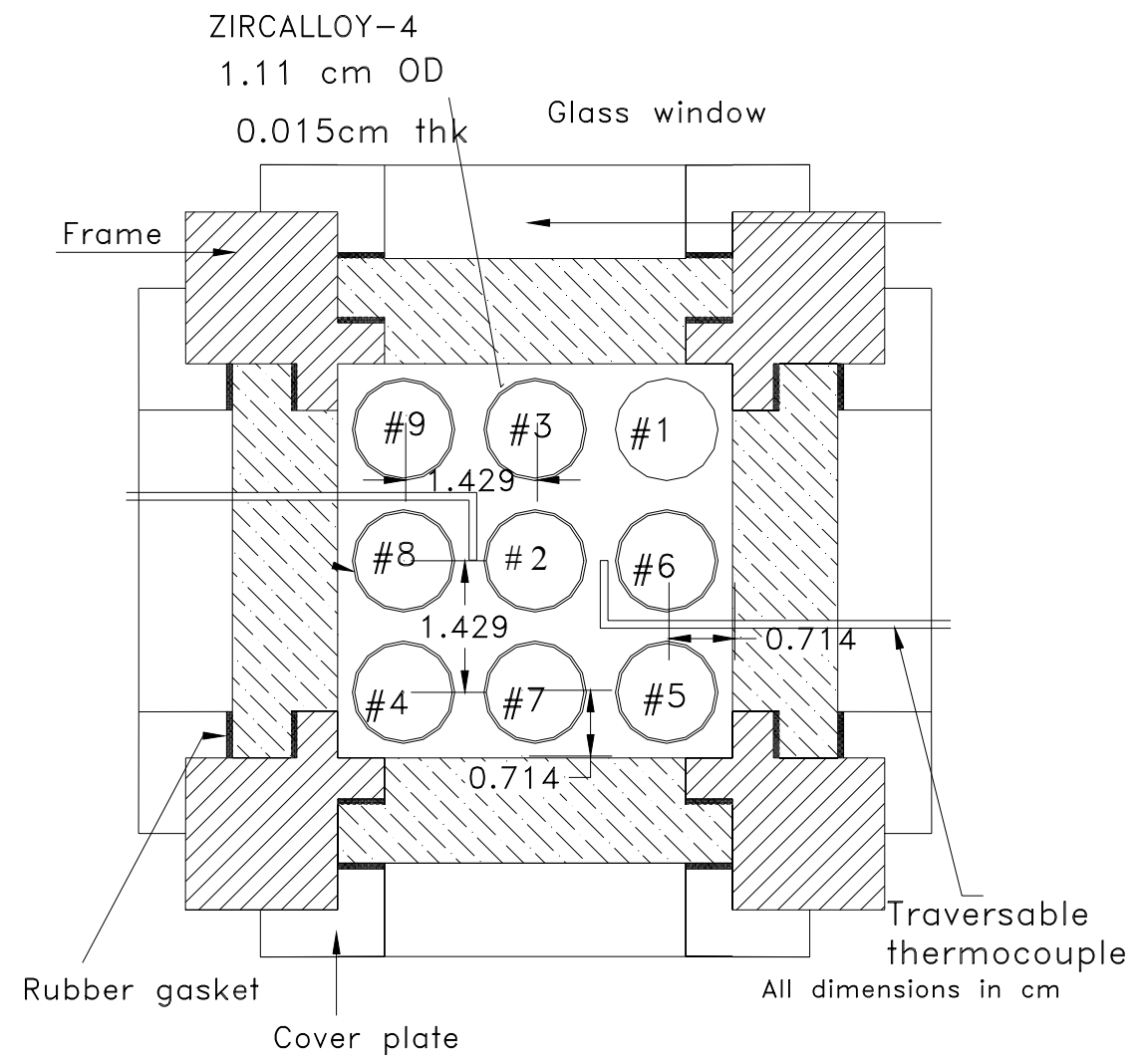

Figure 3-12: Cross section of the flow channel

Microthermocouples are mounted at various axial locations along the flow channel to measure the liquid/fluid temperature profile. The wall temperature of the rods is measured at various axial and radial locations using miniature thermocouples mounted inside the thin-walled tubes. These thermocouples are mounted in slots machined in solid lava rods which are placed inside the Zircalloy rods. The thermocouples are attached and covered with non-conducting cement all through out except at the tips where they are covered with conducting cement. The arrangement of the miniature thermocouples are shown in Figure 3-13. The arrangement of the microthermocouples and the thermocouples within the rod at a given axial plane is shown in Figure 3-14. The average heat generation rate (and hence the heat flux) will be calculated using the voltage and current supplied (power $=I V, I=$ current, $V=$ voltage). 


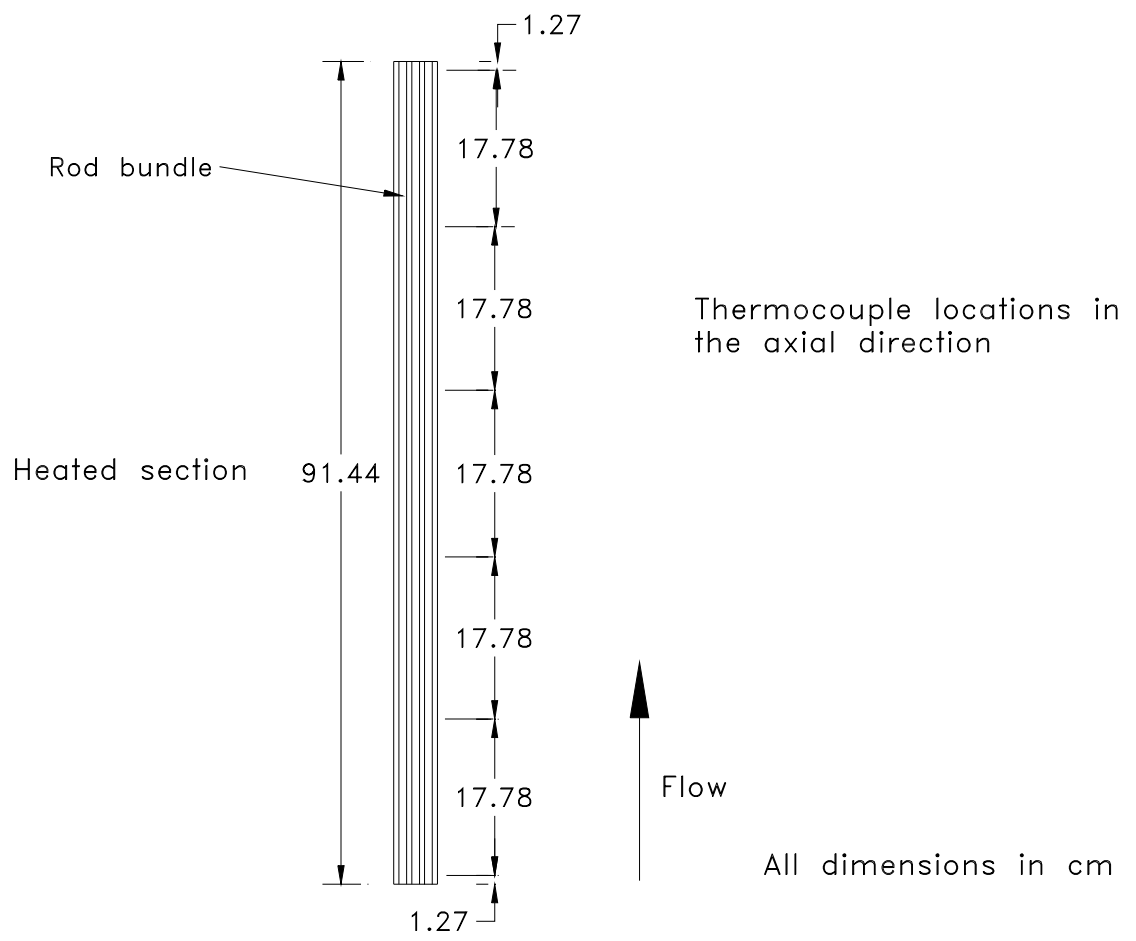

Figure 3-13: Thermocouple location at various axial locations along the rod

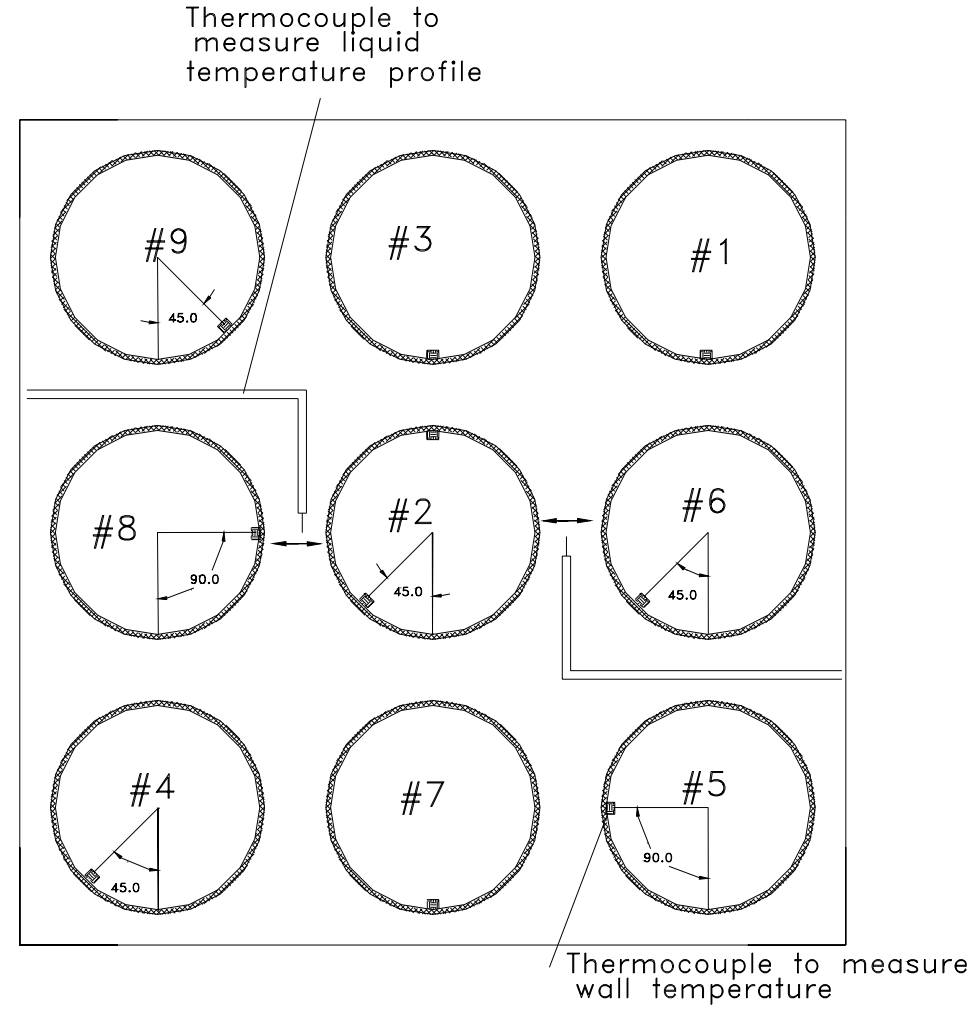

Figure 3-14: Arrangement of thermocouples at a given axial plane 


\subsubsection{Experimental Procedure}

Before each experiment, tank \#1 is filled with distilled water and is heated. The water is degassed by boiling it for approximately 3 hours and then cooling it to the required temperature. During an experiment, water was pumped from tank \#1, passed through the flowmeter, inline preheater, and the test section before being discharged into tank $\# 2$. The liquid flow rate is controlled using the valves at the preheater inlet and the bypass line. The power to the boiling surface is turned on once the required flow rate and liquid subcooling levels at inlet are achieved. Once the test heater reaches steady state, all the required temperature measurements are recorded. A 16-bit data acquisition system (Strawberry Tree, Model DS-16-8-TC) was used to record the temperatures. The boiling phenomena occurring at the heater surface was recorded using a high-speed CCD camera.

\subsection{Uncertainty of Measurements}

The various quantities measured have their own uncertainties associated with them. The liquid velocity is estimated using a turbine flow meter with a manufacturer's calibrated chart with error of measurements of around $0.5 \%$. The volume flow rate is divided by the cross sectional area of the test section to arrive at the bulk liquid velocity. The uncertainty in cross sectional dimensions measurements is $0.1 \mathrm{~mm}$ after using a vernier caliper. The uncertainty in flow velocity measurements comes to around $1 \%$. The uncertainty associated with $\mathrm{K}$ type thermocouples used in this study is about $\pm 0.2^{\circ} \mathrm{C}$ after calibration. The uncertainty in micrometer advance while determining the thermal profile in the liquid and the thickness of boron deposition on the nine-rod bundle is $0.025 \mathrm{~mm}$. While analyzing photographic data the uncertainty in temporal measurements is $0.82 \mathrm{~ms}$, which is given by the frame rate of the camera software. The uncertainty in spatial measurements is taken as 4 pixels, which is the least dimension one can measure from each frame. However the uncertainty of 4 pixels results in different uncertainties in different cases depending on the view of the camera. Thus in horizontal case the uncertainty of 4 pixels amount to an uncertainty in measurement of $0.08 \mathrm{~mm}$ while in vertical case the uncertainty is $0.28 \mathrm{~mm}$. This uncertainty applies to bubble diameter, base diameter and sliding distance. The uncertainty in sliding velocity is calculated from spatial as well as temporal uncertainties and comes to around $0.03 \mathrm{~m} / \mathrm{s}$. 


\section{Chapter 4 Experimental Results}

Bubble dynamics in flow boiling on a single nucleation site without the interference of neighboring bubbles were studied. DI water was used as the test liquid. Two surface orientations were selected, horizontally and vertically placed. Flow velocities, subcooling, and wall superheat were varied parametrically.

Concentration variation near the liquid-vapor interface of single bubble in pool boiling was measured by a miniature concentration sensor. Single bubble was generated at a microfabricated cavity on a polished silicon wafer. An aqueous solution containing 3,000ppm by weight of boric acid were used as test liquids.

Deposition of non-volatile species near the single cavity was found for different test conditions. The shape of the deposition area of pool boiling and flow boiling was recorded and the thickness was measured.

Tests with nine-rod buddle were performed with water and boron added to the water. The concentration of boron in the water was fixed at $7000 \mathrm{ppm}$. These tests with boron were performed to investigate the formation of crud on the heating surface and its effects on the overall heat transfer, active nucleation site density distribution, onset of nucleate boiling, and onset of significant void. Three sets of experiments were performed for the same set of operating conditions. In each set of experiments, keeping the mass flux and inlet subcooling fixed, the heat flux was varied from $1.9 \mathrm{~W} / \mathrm{cm}^{2}$ to $29.3 \mathrm{~W} / \mathrm{cm}^{2}$.

\subsection{Silicon Flat Plate}

\subsubsection{Bubble Dynamics in Saturated Flow Boiling}

Bulk liquid velocities of $0.076 \mathrm{~m} / \mathrm{s}, 0.14 \mathrm{~m} / \mathrm{s}$ and $0.24 \mathrm{~m} / \mathrm{s}$ were studied in horizontal and vertical up surface. Graphs showing bubble equivalent diameter, bubble sliding velocity as well as bubble base diameter as functions of time for various stages during the bubble growth cycle are presented. The equivalent diameter is calculated by assuming a body of revolution about the transverse diameter and equating the volume of the ellipsoid with a sphere. Each data point corresponds to an acquired image.

\section{Horizontal Surface}

In this section results from experiments carried out on a horizontal surface are described. Flow velocity was increased from $0.076 \mathrm{~m} / \mathrm{s}$ to $0.23 \mathrm{~m} / \mathrm{s}$ to study the effect of velocity on different bubble parameters. Two wall superheats were selected for velocity of $0.076 \mathrm{~m} / \mathrm{s}$ to study the effect of wall superheat.

\section{Velocity $0.076 \mathrm{~m} / \mathrm{s}$, wall superheat $5.3^{\circ} \mathrm{C}$, liquid subcooling $0.2^{\circ} \mathrm{C}$}

Shown in Figure 4-1, is a typical bubble ebullition cycle under the conditions of bulk flow velocity of $0.076 \mathrm{~m} / \mathrm{s}$, wall superheat of $5.3^{\circ} \mathrm{C}$ and liquid subcooling of $0.2^{\circ} \mathrm{C}$. The measurement procedure for bubble diameter, base diameter and contact angle has been shown in Figure 4-2. 


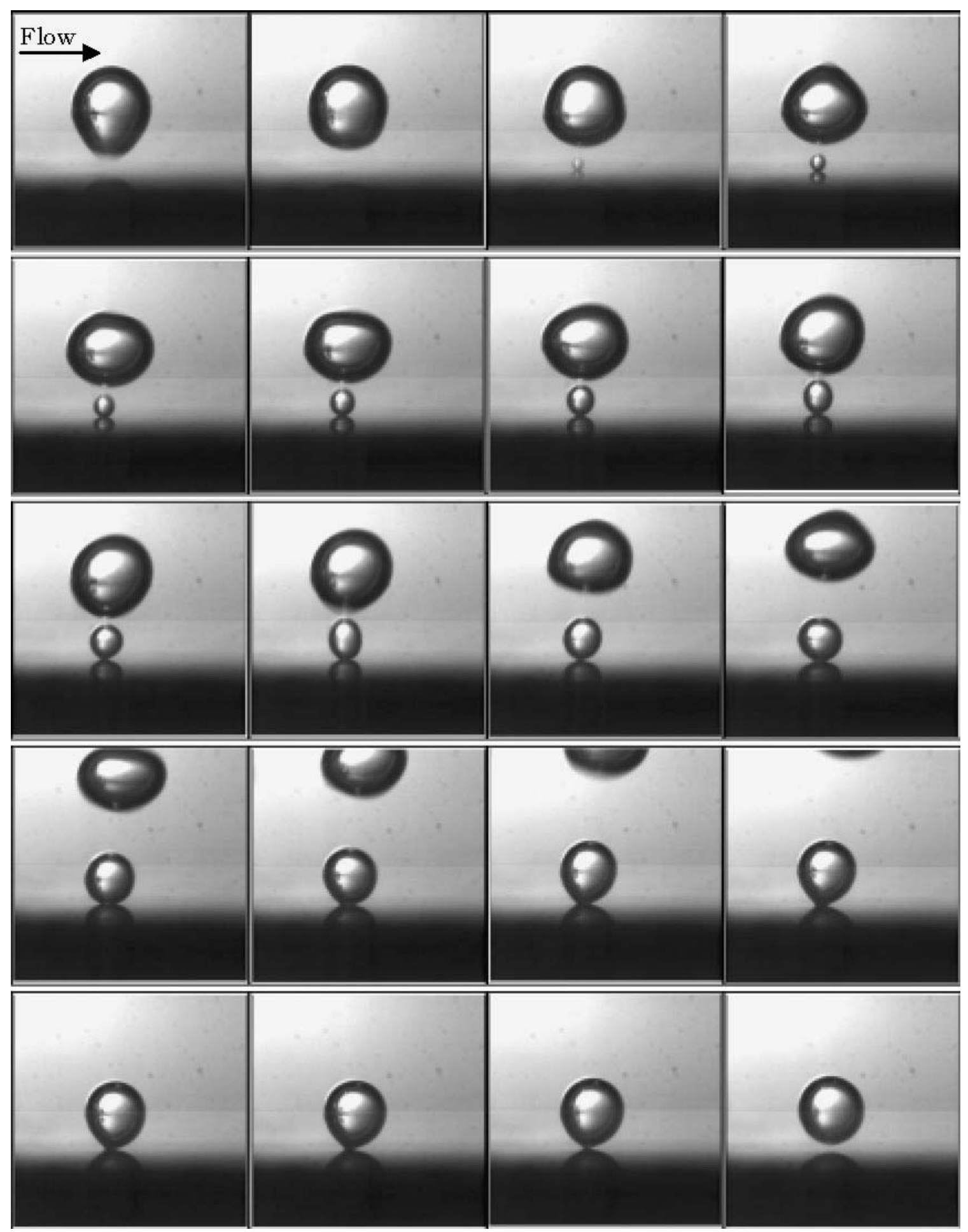

Figure 4-1: Growth Cycle for horizontal surface $\mathrm{V}=0.076 \mathrm{~m} / \mathrm{s}, \Delta \mathrm{T}$ wall $=5.3^{\circ} \mathrm{C}, \Delta \mathrm{Tsub}=0.2^{\circ} \mathrm{C}$

The temperature profile in the liquid has been plotted in Figure 4-3. Comparison has been made with standard laminar and turbulent correlations available in literature. At $\operatorname{Re}_{\mathrm{x}}$ value of $1.9 \times 10^{4}$ the agreement between measured and calculated laminar thermal profile is reasonable. 
At $\operatorname{Re}_{\mathrm{x}}$ of $3.8 \times 10^{4}$, the thermal boundary layer is slightly under-predicted. At $\operatorname{Re}_{\mathrm{x}}$ of $5.6 \times 10^{4}$, there is a reasonable match with the calculated turbulent thermal profile.

As can be seen from Figure 4-1, the bubble nucleates and then grows. Qualitatively it can be seen that as the bubble grows, the base diameter of the growing bubble increases at first. The bubble is nearly spherical and symmetrical in the initial stages. As the bubble grows further it becomes inclined in the direction of flow and the bubble grows asymmetrically henceforth, which is evident from the plot of contact angle in Figure 4-5 (b). The upstream contact angle increases while downstream contact angle decreases. Three different cycles of bubbles have been arbitrarily chosen from the movie file and analyzed and plotted on each graph to get an idea of the variability of the data. After some time, the upstream interface is seen to move towards downstream while the downstream interface continues to move in the same direction. The bubble is considered to have departed at this point. The bubble starts to slide from its nucleation site when its diameter is around $1.2 \mathrm{~mm}$ and when time is around $13 \mathrm{~ms}$. The plot of bubble's sliding velocity and sliding distance have been shown in Figure 4-4 (b) and Figure 4-5 (a) respectively. As can be seen from those plots the bubble slides with increasing velocity. Finally, at around 23 ms when its equivalent diameter is around $1.5 \mathrm{~mm}$, sliding velocity is about $0.05 \mathrm{~m} / \mathrm{s}$ and it has slid nearly $0.2 \mathrm{~mm}$ from its nucleation site, the bubble lifts off into the liquid.

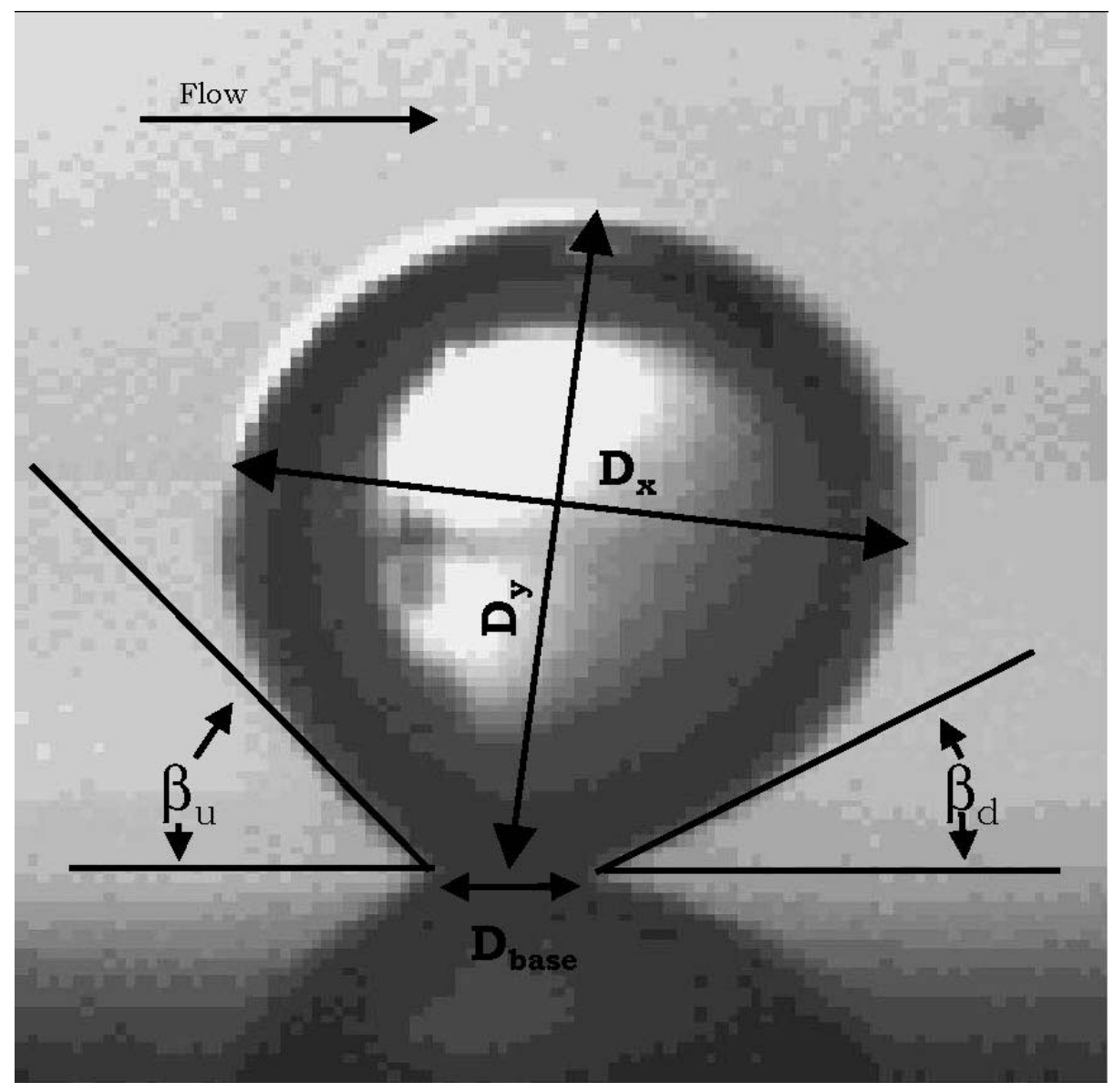

Figure 4-2: Typical bubble under flow conditions 

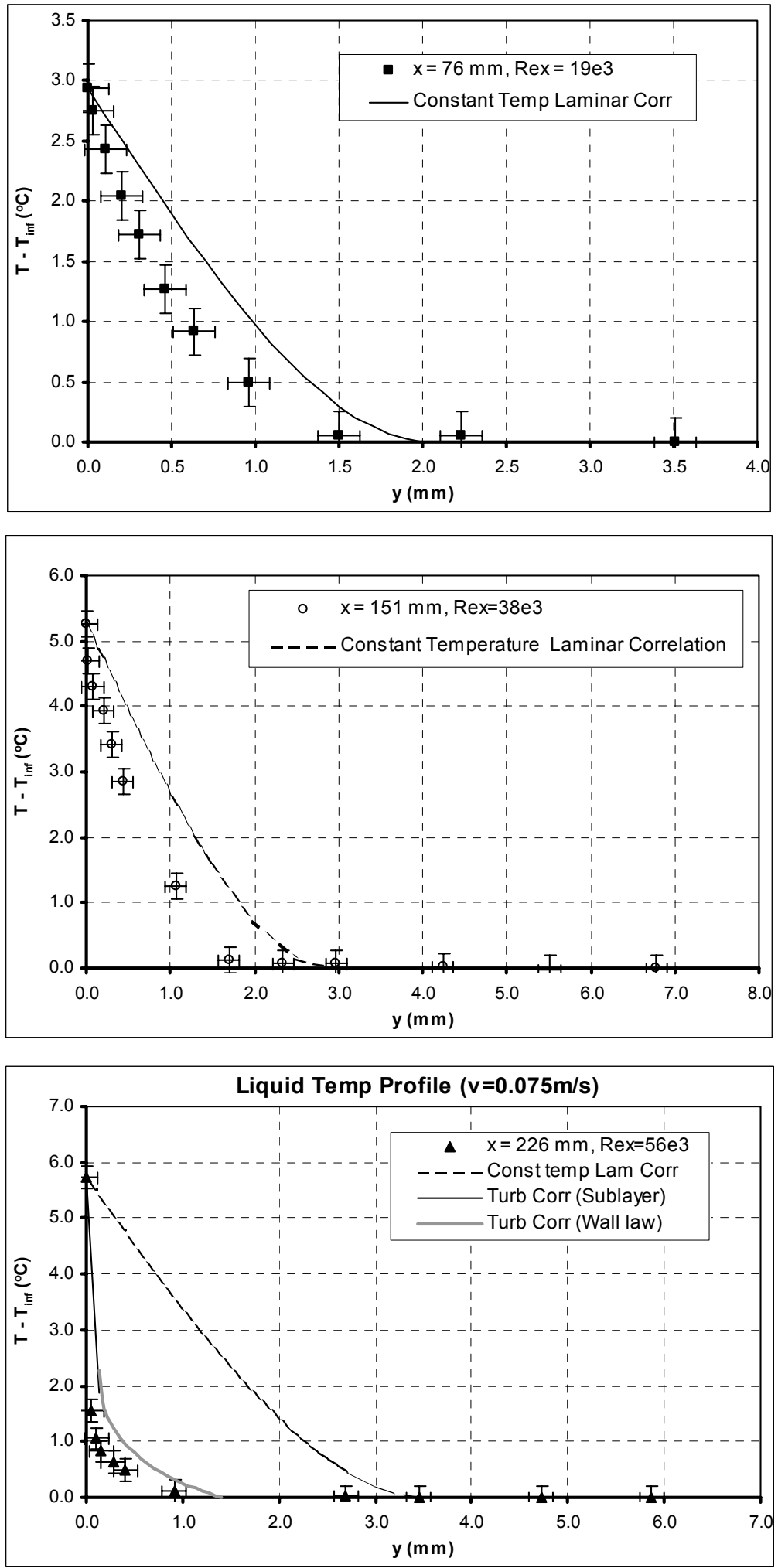

Figure 4-3: Temperature Profile in Liquid, Horizontal, $V=0.076 \mathrm{~m} / \mathrm{s}$ 


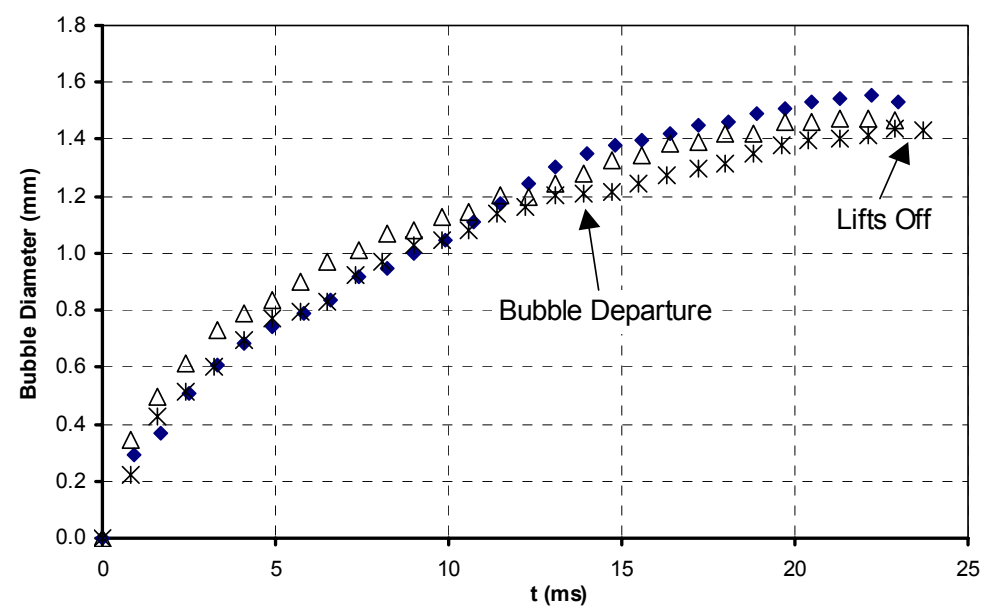

(a)

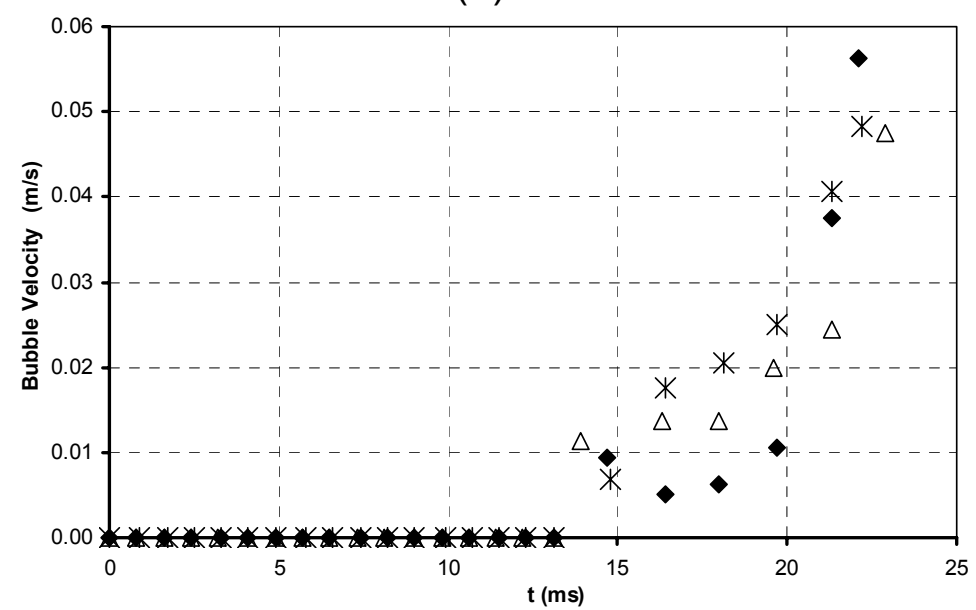

(b)

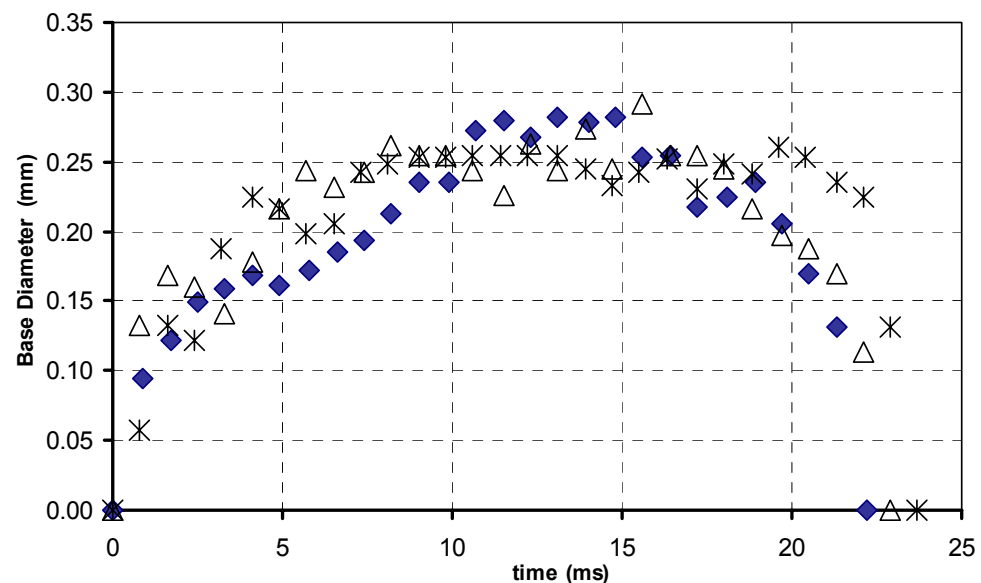

(c)

Figure 4-4: Bubble Growth, Sliding Bubble Velocity \& Base Diameter on Horizontal Surface, $\mathrm{V}=0.076 \mathrm{~m} / \mathrm{s}, \Delta$ Twall $=5.3^{\circ} \mathrm{C}, \Delta \mathrm{Tsub}=0.2^{\circ} \mathrm{C}$ 


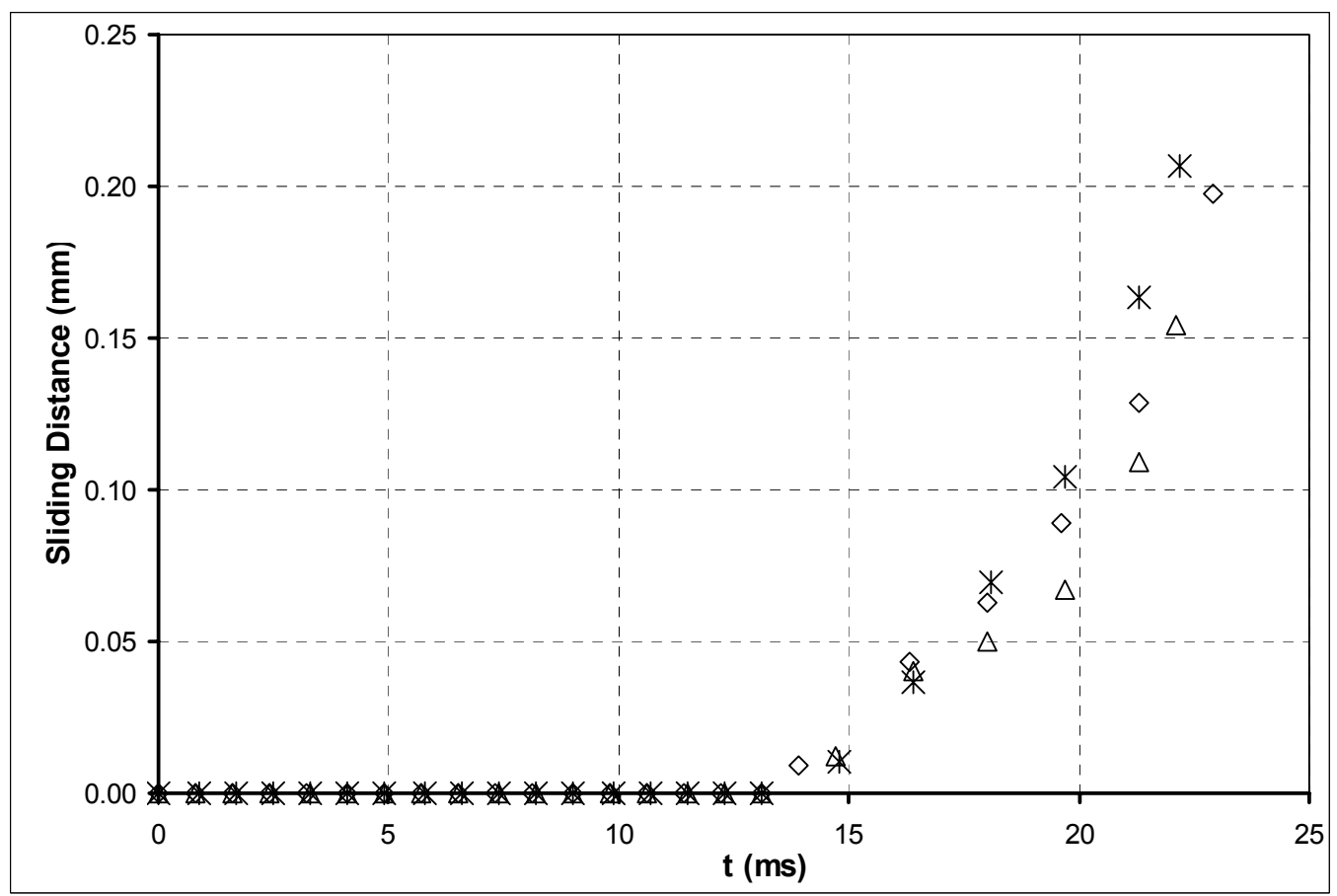

(a)

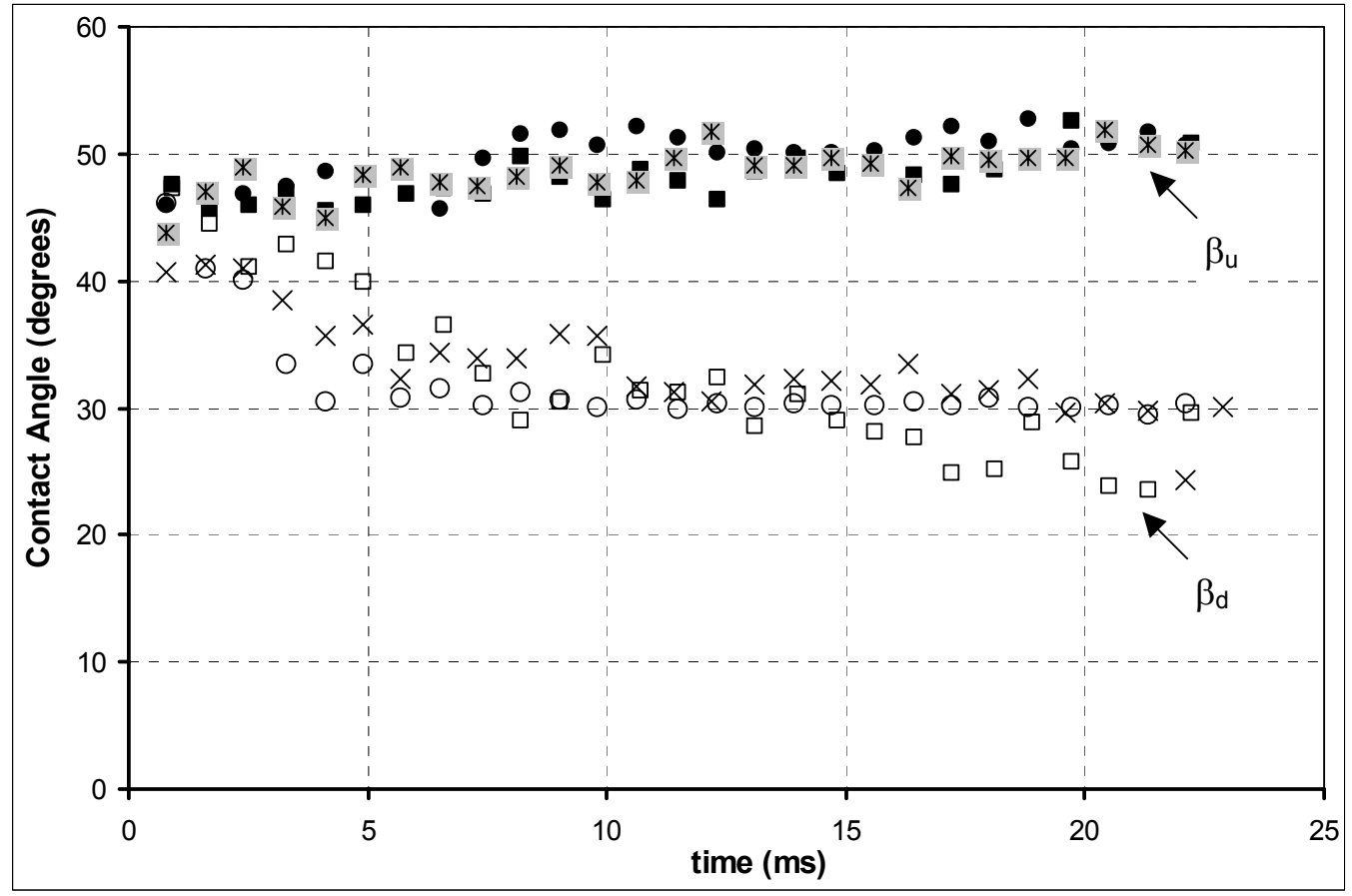

(b)

Figure 4-5: Bubble Sliding Distance and Contact Angle on Horizontal Surface, $V=0.076 \mathrm{~m} / \mathrm{s}, \Delta$ Twall $=5.3^{\circ} \mathrm{C}, \Delta \mathrm{Tsub}=0.2^{\circ} \mathrm{C}$ 
Velocity $0.076 \mathrm{~m} / \mathrm{s}$, wall superheat $3.5^{\circ} \mathrm{C}$, liquid subcooling $0.2^{\circ} \mathrm{C}$

Figure 4-6 shows the bubble growth and departure cycles under the conditions of bulk flow velocity of $0.076 \mathrm{~m} / \mathrm{s}$, wall superheat of $3.5^{\circ} \mathrm{C}$ and liquid subcooling of $0.2^{\circ} \mathrm{C}$. The bubble growth and departure cycles for wall superheat of $5.3^{\circ} \mathrm{C}$ is also shown in this figure. Other conditions were about the same. It can be seen that the growth rate for wall superheat of $3.5^{\circ} \mathrm{C}$ is lower than that for wall superheat of $5.3^{\circ} \mathrm{C}$. The lift-off time for wall superheat of $3.5^{\circ} \mathrm{C}$ is longer and the lift-off diameter is smaller. Other information such as base diameter and contact angle for wall superheat of $3.5^{\circ} \mathrm{C}$ display similar trend as that for wall superheat of $5.3^{\circ} \mathrm{C}$, therefore, they are not shown for the sake of conciseness.

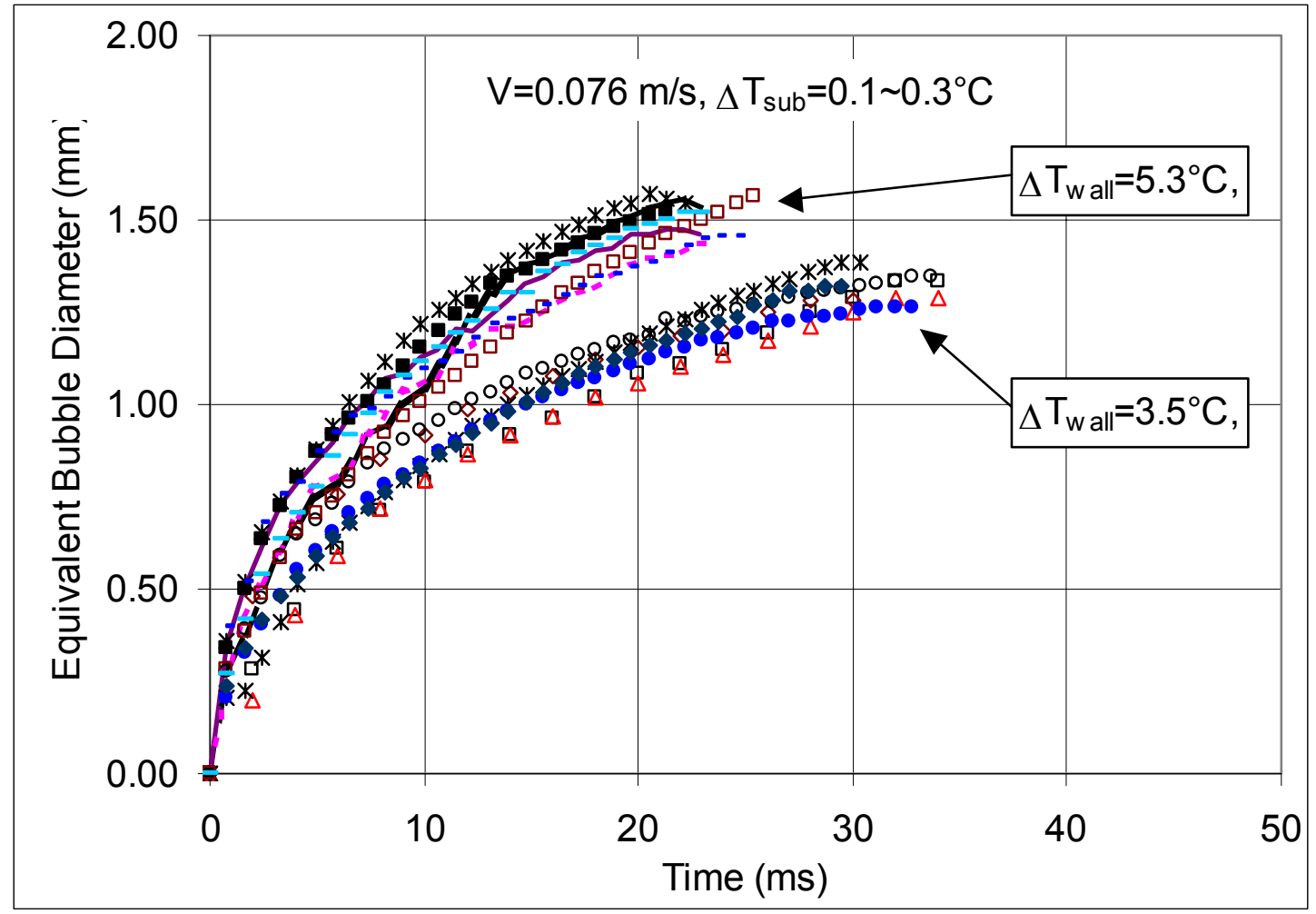

Figure 4-6: Bubble Growth on Horizontal Surface for Different Wall Superheats

\section{Velocity $0.135 \mathrm{~m} / \mathrm{s}$}

In Figure 4-7, an ebullition cycle for the case of bulk velocity $0.135 \mathrm{~m} / \mathrm{s}$, wall superheat of $5.9^{\circ} \mathrm{C}$ and liquid subcooling $0.2^{\circ} \mathrm{C}$ has been shown. The temperature profiles with the standard correlations are shown in Figure 4-8. The thermal boundary layer is noticeably thinner at the higher velocity and transition to turbulence has already taken place. Again the measured thermal profile is observed to agree well with calculated thermal profile. As can be seen in Figure 4-9, the bubble grows till an equivalent diameter of $0.9 \mathrm{~mm}$ in $6 \mathrm{~ms}$ and then starts to slide. Its base diameter is around $0.27 \mathrm{~mm}$ at that time. It grows as it slides and finally lifts off in $14 \mathrm{~ms}$ after sliding for about $0.4 \mathrm{~mm}$. It has reached an equivalent diameter of $1.0 \mathrm{~mm}$ by then, while its sliding velocity has reached $0.09 \mathrm{~m} / \mathrm{s}$. 


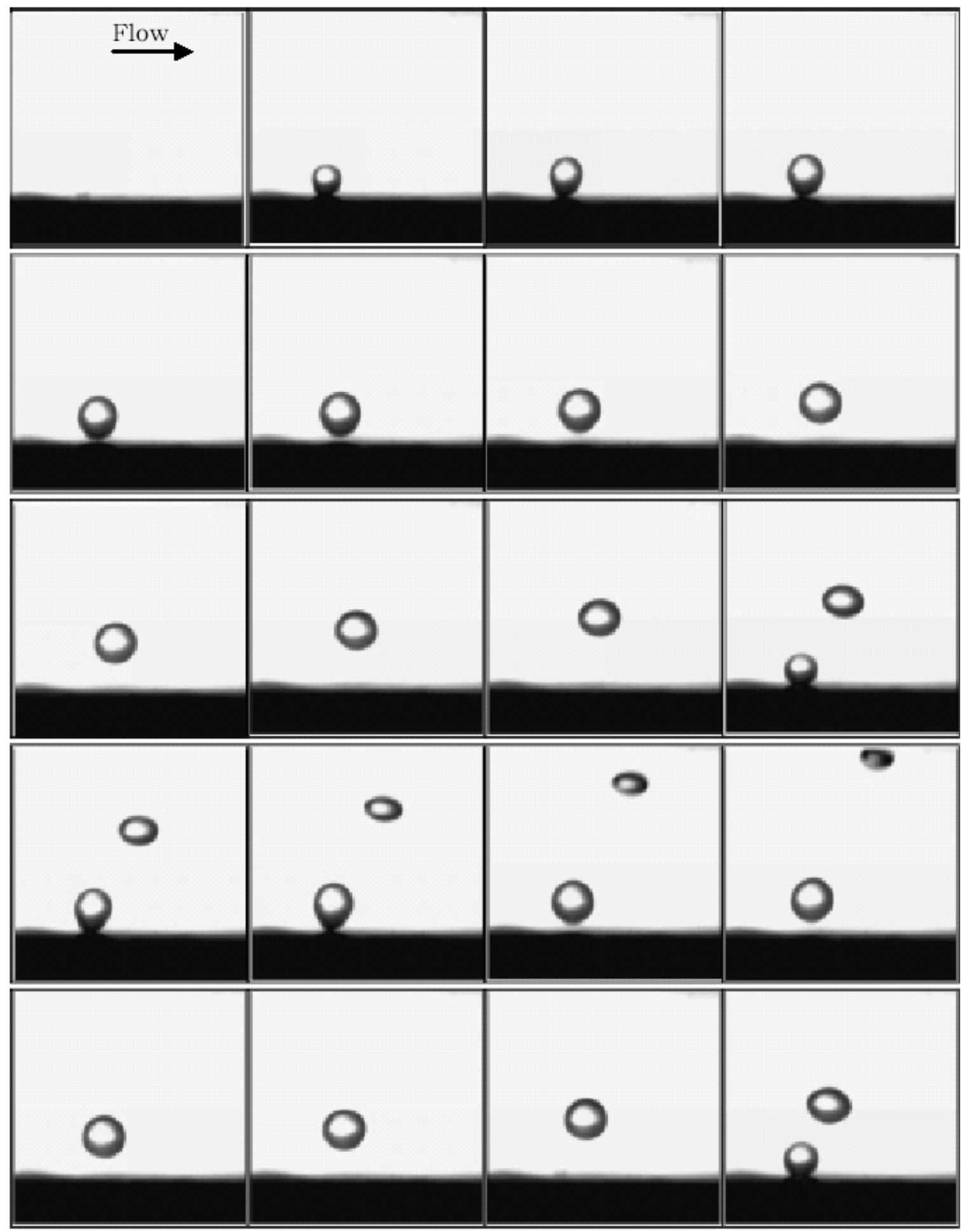

Figure 4-7: Growth Cycle for Horizontal Surface, $\mathrm{V}=0.135 \mathrm{~m} / \mathrm{s}, \Delta \mathrm{T}_{\text {wall }}=5.9^{\circ} \mathrm{C}, \Delta \mathrm{T}_{\text {sub }}=0.2^{\circ} \mathrm{C}$ 

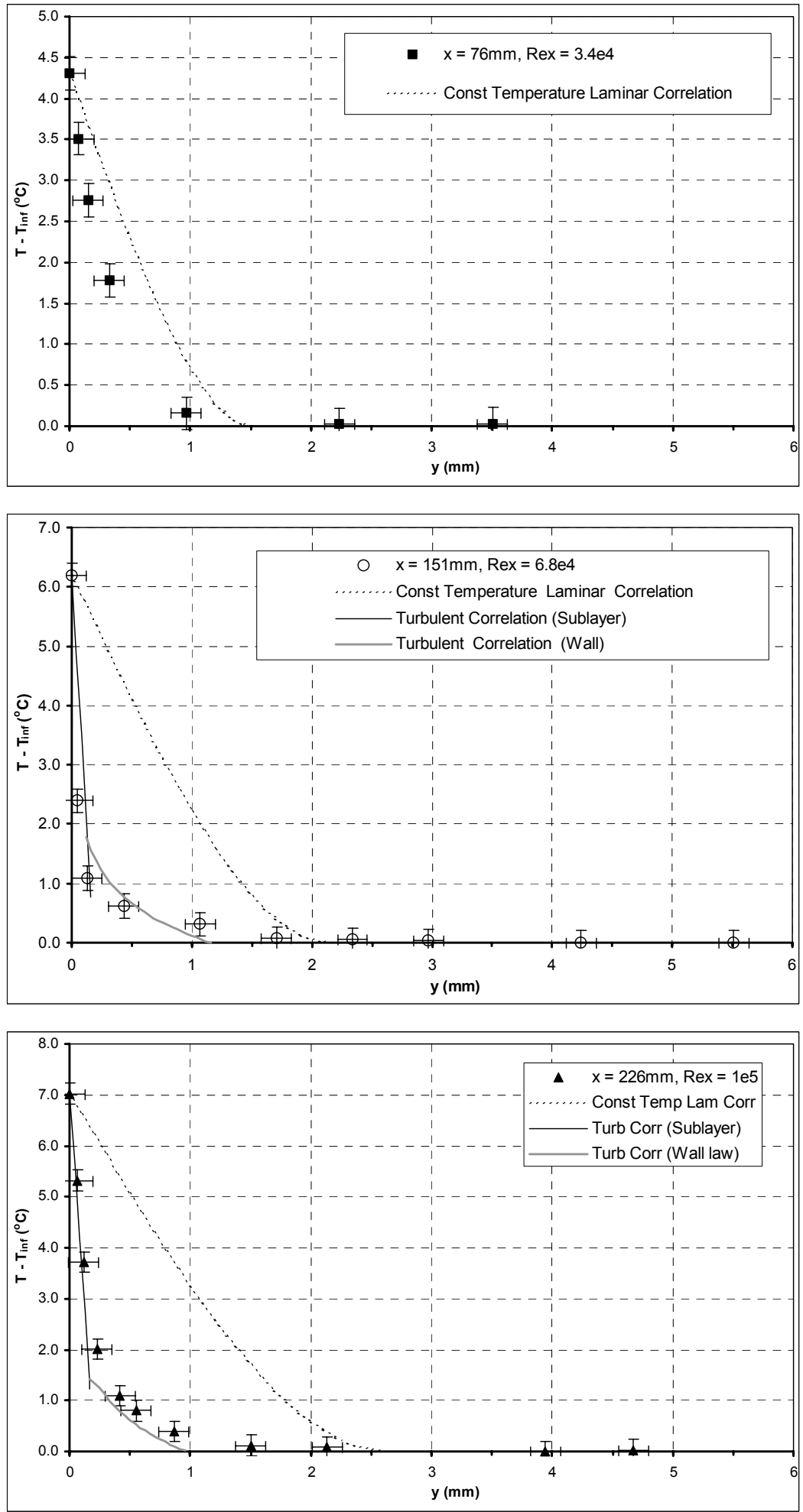

Figure 4-8: Temperature Profile in Liquid, Horizontal, $V=0.135 \mathrm{~m} / \mathrm{s}$ 

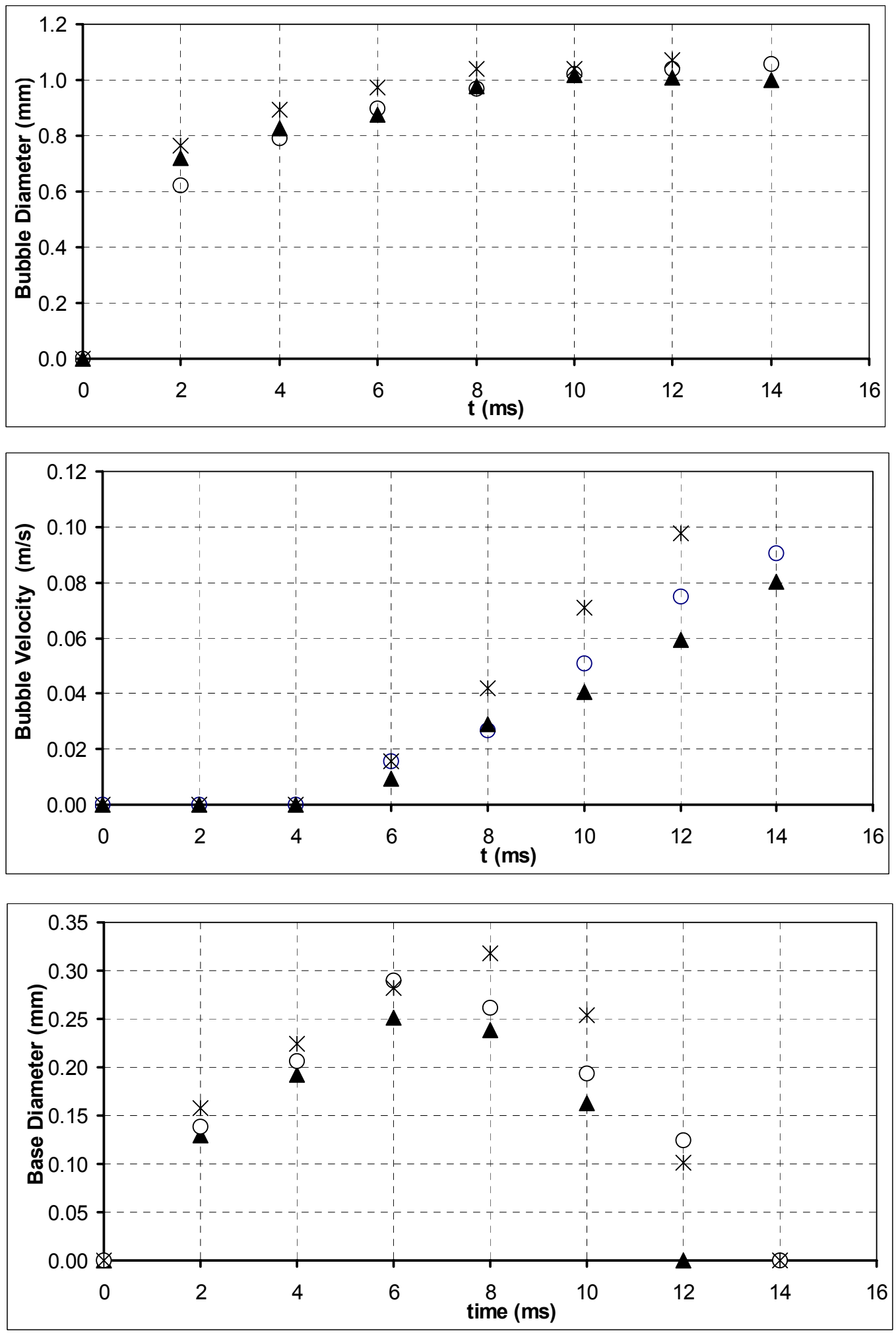

Figure 4-9: Bubble Growth, Sliding Velocity \& Base Diameter on Horizontal Surface, $V=0.135 \mathrm{~m} / \mathrm{s}, \Delta \mathrm{T}_{\text {wall }}=5.9^{\circ} \mathrm{C}, \Delta \mathrm{T}_{\text {sub }}=0.2^{\circ} \mathrm{C}$ 


\section{Velocity $0.23 \mathrm{~m} / \mathrm{s}$}

Figure 4-10 shows the cycle of bubble growth for a case of next higher bulk velocity. The conditions are bulk velocity $0.23 \mathrm{~m} / \mathrm{s}$, wall superheat $5.9^{\circ} \mathrm{C}$ and $0.2^{\circ} \mathrm{C}$ liquid subcooling. The thermal profile has been plotted in Figure 4-11. The measured profiles reasonably agree with calculated turbulent profiles. Thermal boundary layer is thinner than the previous two cases. As seen from Figure 4-12, bubble departs from the cavity and starts to slide at around $1.6 \mathrm{~ms}$ when equivalent diameter is about $0.7 \mathrm{~mm}$. Base diameter of the bubble is around $0.25 \mathrm{~mm}$ at that instant. The bubble is seen to slide for about $0.3 \mathrm{~mm}$ until it lifts off at $4.1 \mathrm{~ms}$ at an equivalent diameter of $0.8 \mathrm{~mm}$ with sliding velocity of about $0.18 \mathrm{~m} / \mathrm{s}$.

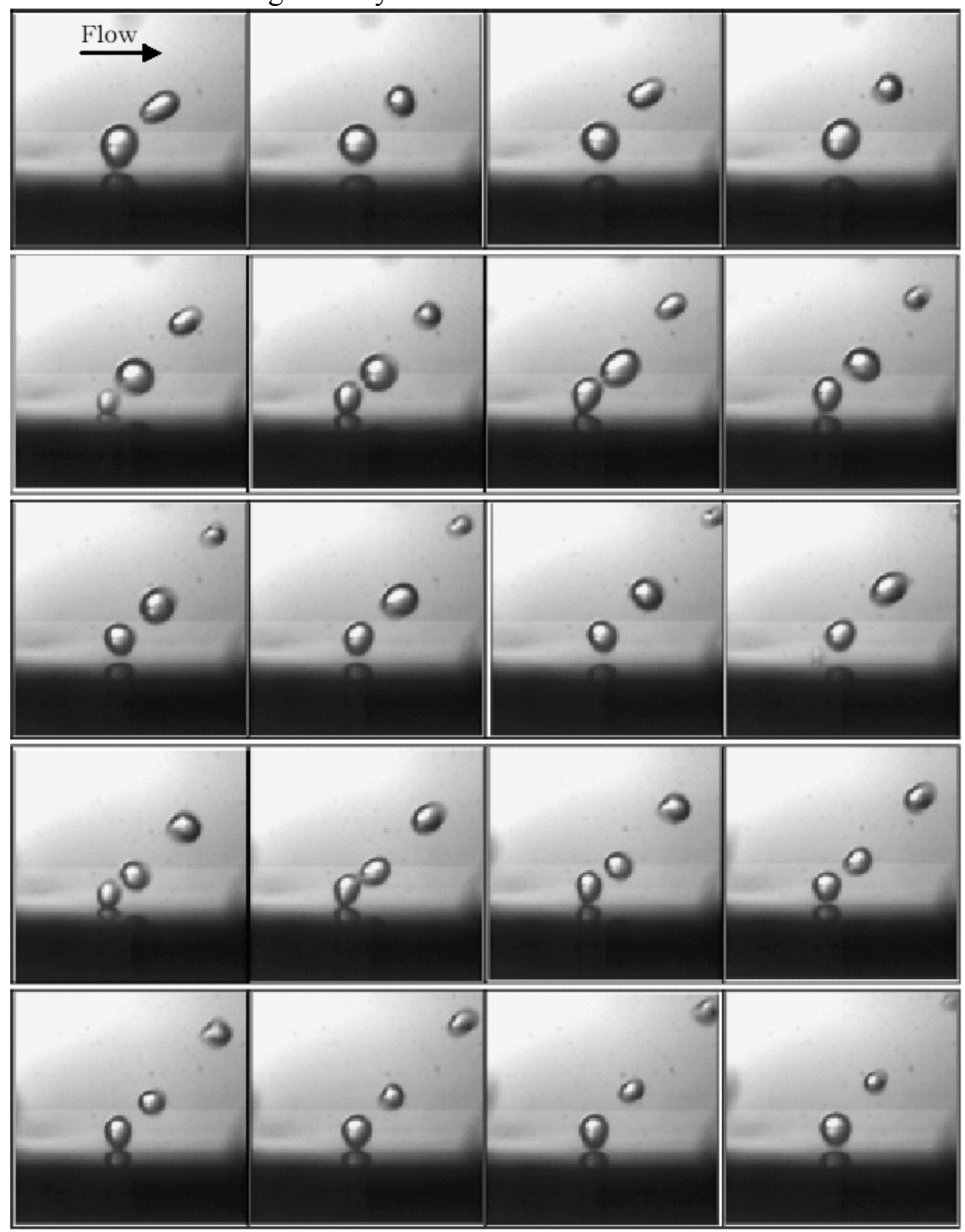

Figure 4-10: Growth Cycle for Horizontal Surface, $\mathrm{V}=0.230 \mathrm{~m} / \mathrm{s}, \Delta \mathrm{T}_{\text {wall }}=5.9^{\circ} \mathrm{C}, \Delta \mathrm{T}_{\mathrm{sub}}=0.2^{\circ} \mathrm{C}$ 

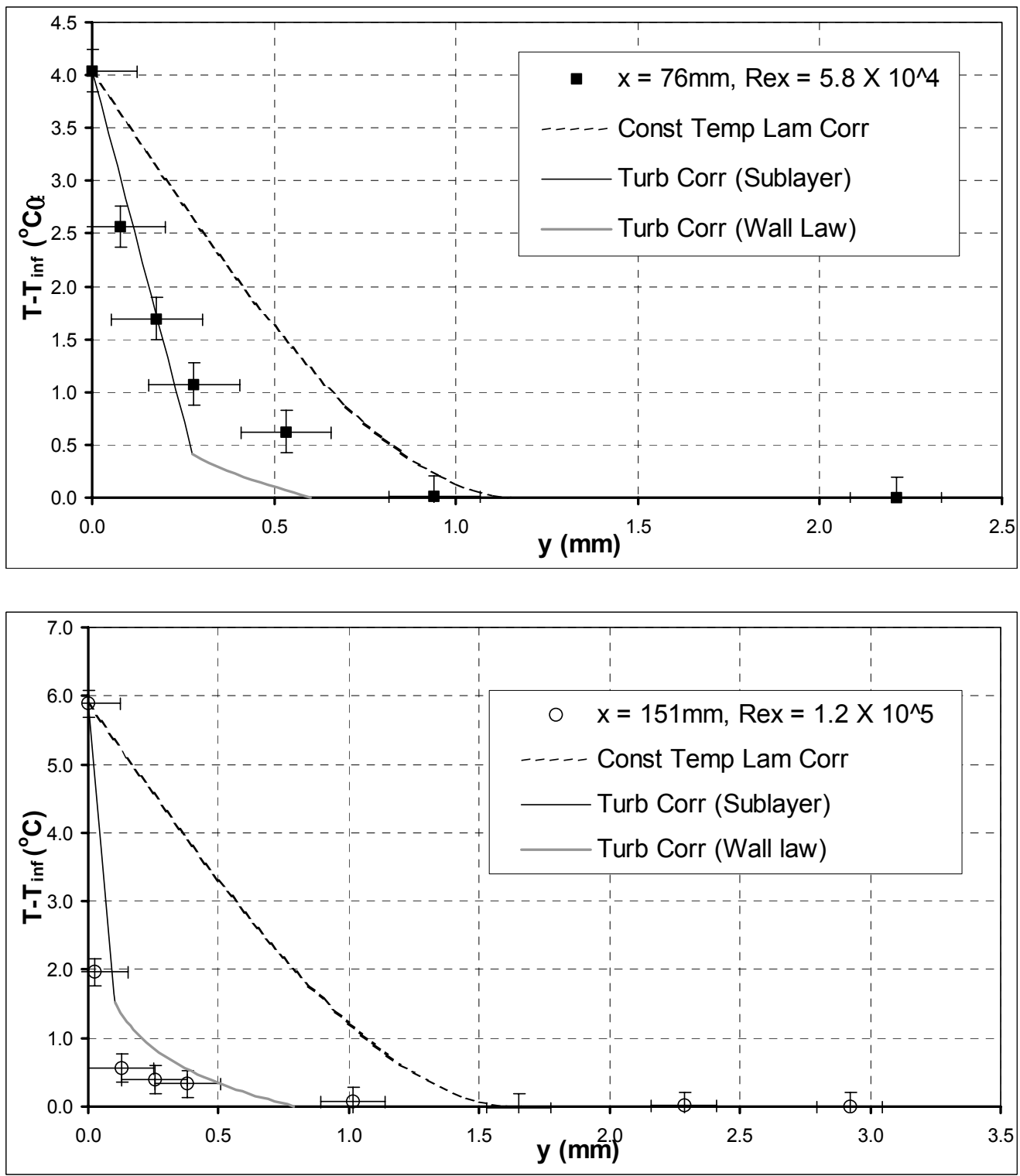

Figure 4-11: Temperature Profile in Liquid, Horizontal, $V=0.23 \mathrm{~m} / \mathrm{s}$ 

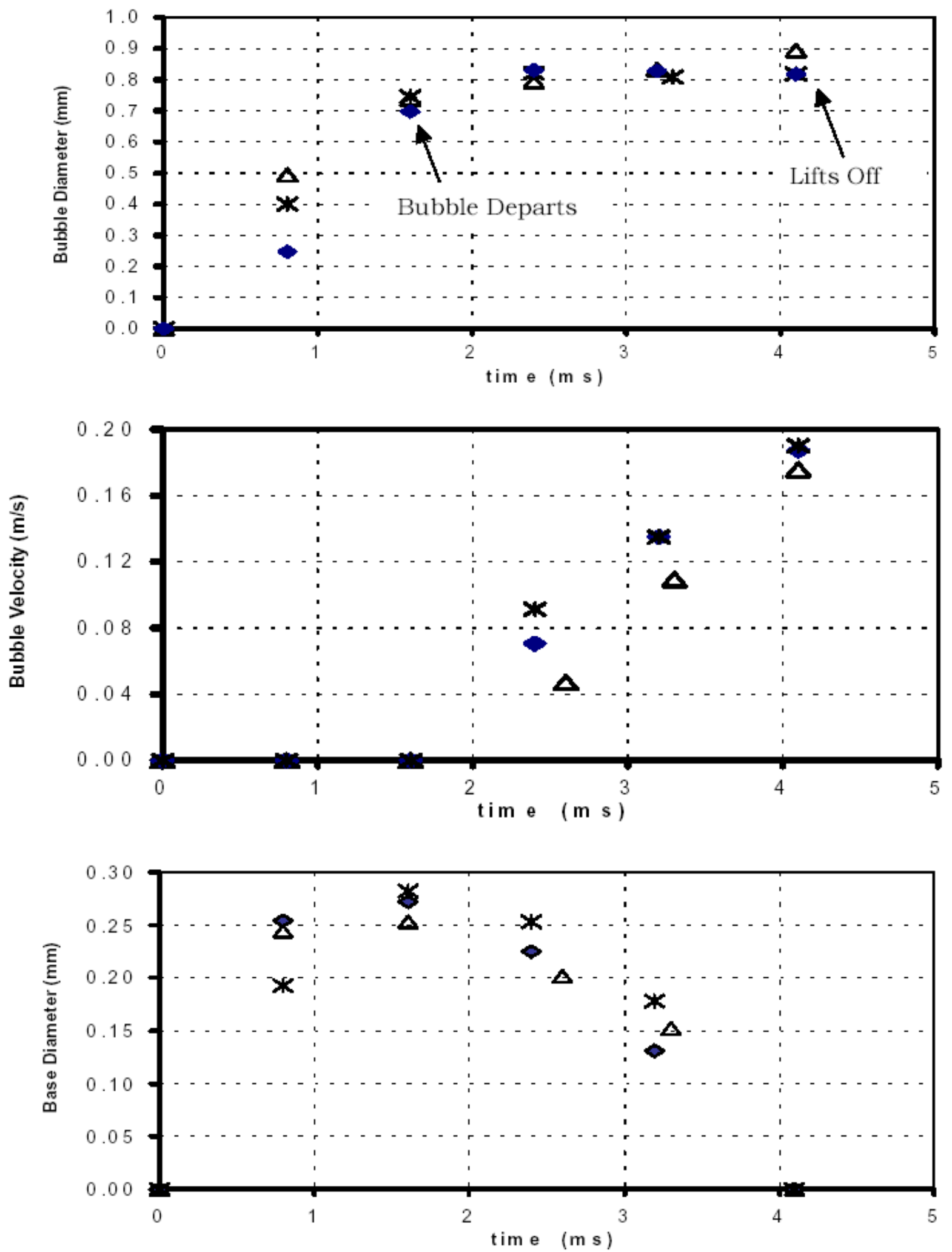

Figure 4-12: Bubble Growth, Sliding Velocity \& Base Diameter on Horizontal Surface, $V=0.23 \mathrm{~m} / \mathrm{s}, \Delta \mathrm{T}_{\text {wall }}=5.9^{\circ} \mathrm{C}, \Delta \mathrm{T}_{\text {sub }}=0.2^{\circ} \mathrm{C}$ 


\section{Comparison among different velocities and with data available in literature}

The effect of bulk liquid velocity on bubble dynamics on horizontal surface is shown in Figure 4-13. It is observed that the departure and lift off diameter decrease with increasing velocity. The drag force due to the bulk liquid velocity flowing past the bubble causes the bubble to assume an asymmetrical shape during the later stages of its growth. While surface tension tries to hold the bubble to the nucleation site, liquid drag tries to drag the bubble away. This causes the bubble to be asymmetrical. As the bubble continues to grow, the drag force increases and ultimately overcomes the restraining force causing the bubble to depart and slide along the surface. As velocity is increased, this drag force increases causing the bubble to depart at a smaller diameter.

As the bubble continues to grow while sliding along the surface, its sliding velocity increases with time and it experiences a lift force magnitude of which depends on the size as well as shape of the bubble and the relative velocity between the bubble and the liquid. Ultimately it reaches a velocity and diameter when the lift force and the buoyancy force are able to overcome the forces attaching the bubble to the surface. The bubble then lifts off from the surface. This lift force increases with velocity too, causing the bubble to lift off at a smaller diameter at higher velocities.

Figure 4-14 shows the effect of bulk liquid velocity on bubble sliding distance, bubble sliding velocity at lift off and the limiting values of upstream and downstream contact angles. It was observed that the sliding velocity at lift off is below the bulk liquid velocity, which is represented by the solid line, for all the cases investigated in horizontal configuration. It is the drag force which causes the bubble to start sliding but the actual distance the bubble slides depends also on how soon the combination of buoyancy and lift force is able to overcome the surface tension forces attaching the bubble to the surface. The effect of velocity on sliding distance is not very clear in the case of horizontal surface. As bulk velocity is increased it is observed that sliding bubble velocity at lift off increases while as already mentioned lift off diameter decreases. This shows that lift force is dependent on both sizes of the bubble as well as its velocity. Upstream contact angle increases and downstream contact angle decreases with time and then reach a limiting value as shown in Figure 4-5. With velocity the values of these limiting values remain unchanged within the uncertainty of measurements as shown in Figure 4-14.

The comparisons with data available in literature have been presented in Figure 4-15 through Figure 4-17. In Figure 4-15, present data have been compared with data of Ramanujapu and Dhir [25] as well as that of Kandlikar and Stumm [26]. Ramanujapu and Dhir conducted experiments on single bubble nucleation and behavior in pool boiling on a polished Silicon wafer very similar to the ones used in present study. In horizontal pool boiling, departure and lift off diameters are the same. Kandlikar and Stumm's data were obtained in flow boiling of water on a horizontal copper surface. They defined departure as when the bubble leaves contact with the surface. However, in this study the convention as defined by Klausner et al. [27] has been followed. According to him departure is when the bubble departs from the nucleating cavity and starts to slide. Lift off is the phenomena associated with the bubble losing contact with the surface. It can be inferred from Figure 4-15 that the results from present study extend the general trend observed by Kandlikar and Stumm. In fact our results seem to show the transition from pool boiling data of Ramanujapu and Dhir to flow boiling data of Kandlikar \& Stumm at high velocities.

Koumoutsos, Moisis \& Spyridonos [28] conducted experiments on flow boiling of water on a horizontal copper surface and presented their lift off diameter data normalized with respect 
to lift off diameter under pool boiling conditions. The comparison with data from present study is shown in Figure 4-16. Though the trend observed in the results from present study seem to agree with that of Koumoutsos' experiments, there is a small difference. Lift off diameter observed in the present study seems to be lower than theirs. The probable reason might have been that they observed a smaller pool boiling lift off diameter, $\mathrm{D}_{0}$, which could have caused a higher ratio of $\mathrm{D} / \mathrm{D}_{0}$.

Klausner, Mei, Bernhard and Zeng [27] studied vapor bubble departure with R113 on a stainless steel heater surface. Comparison with water on Silicon wafer has been made in Figure 4-17 after the diameter data is normalized with a scaling factor to take into account the surface tension and density of the different fluids involved. Velocity is scaled by defining a channel hydraulic Reynolds number. Here again it was observed that the general trend agreed with results of the present set of experiments. The fact that their data is slightly lower than that of present study can be explained by contact angle. Fluorocarbons have lower contact angle than water. And a lower contact angle leads to a lower departure diameter.
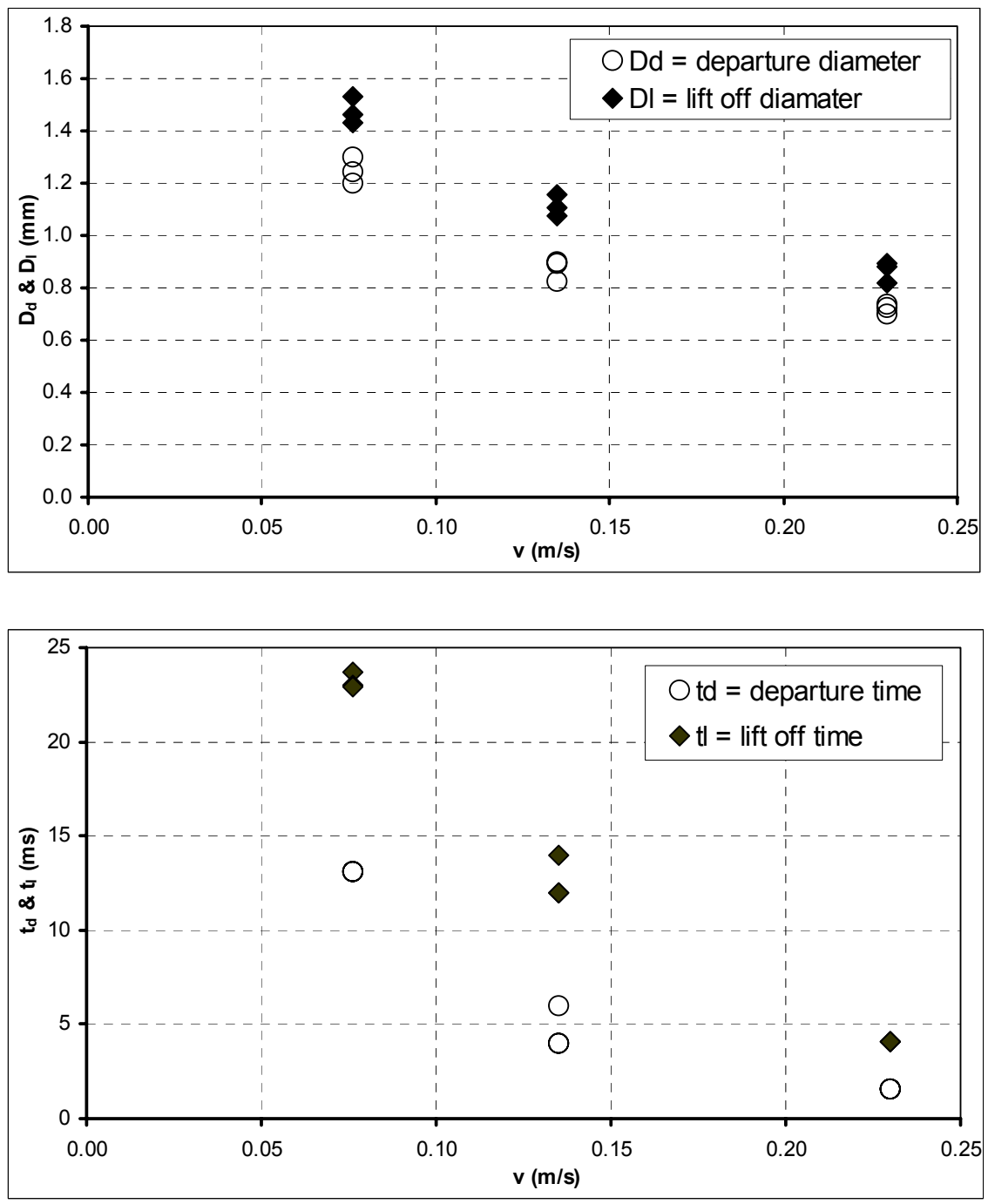

Figure 4-13: Effect of Bulk Liquid Velocity on Departure \& Lift off Diameter and Time (Horizontal) 

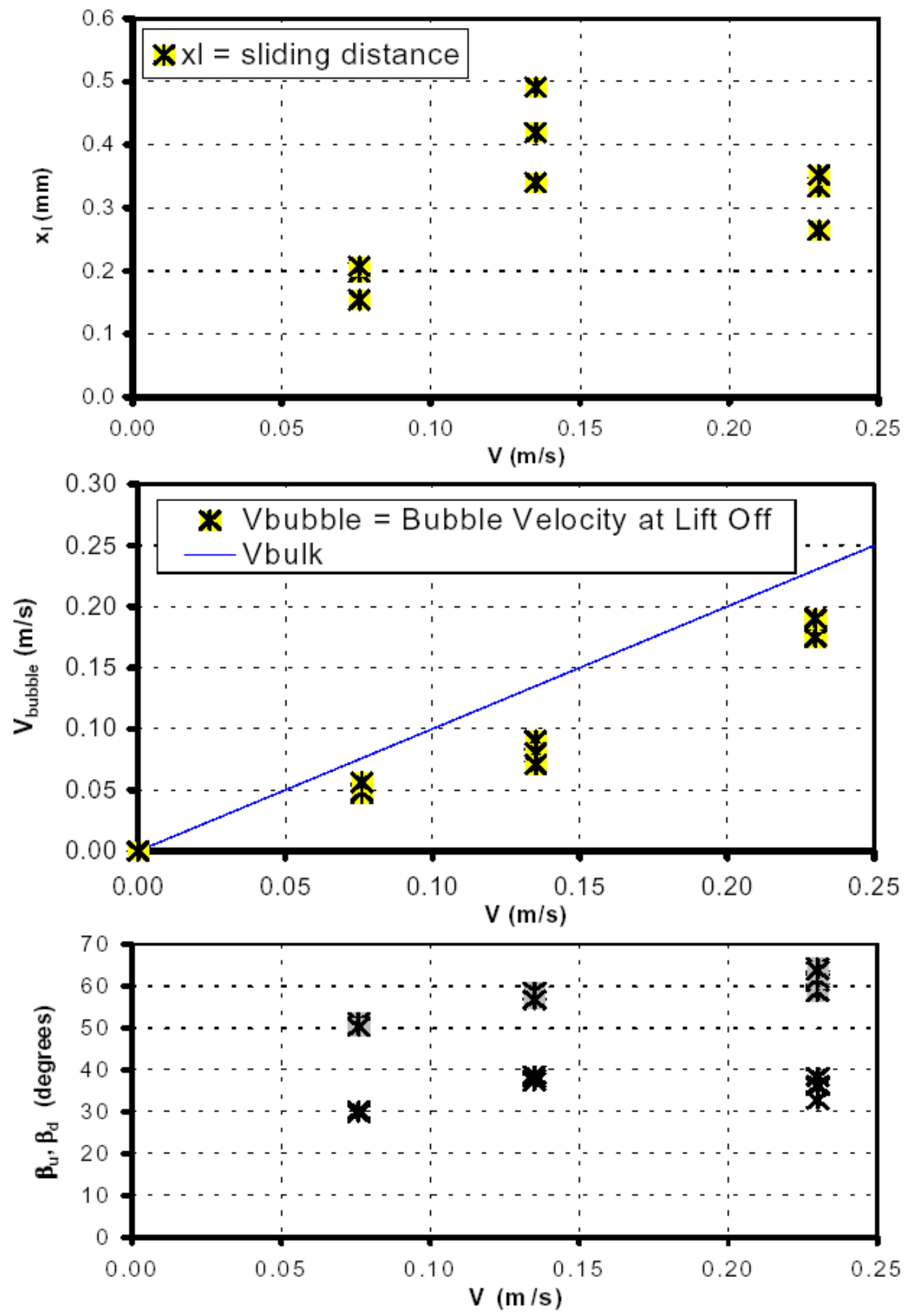

Figure 4-14: Effect of Bulk Liquid Velocity on Sliding Distance, Bubble Velocity at Lift Off and Upstream \& Downstream Contact Angles 


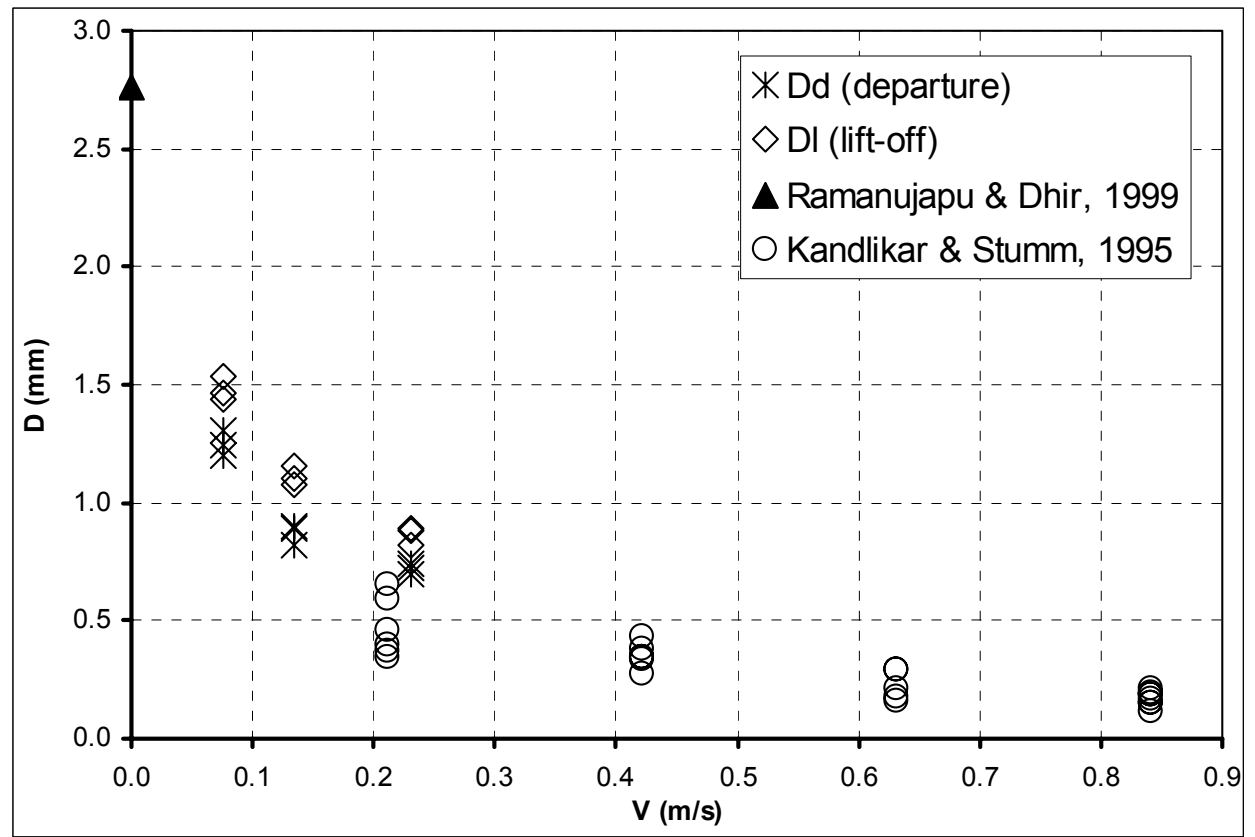

Figure 4-15: Comparison with Ramanujapu \& Dhir's pool boiling Single bubble data on Silicon Wafer and with that of Kandlikar \& Stumm's data on Copper Surface

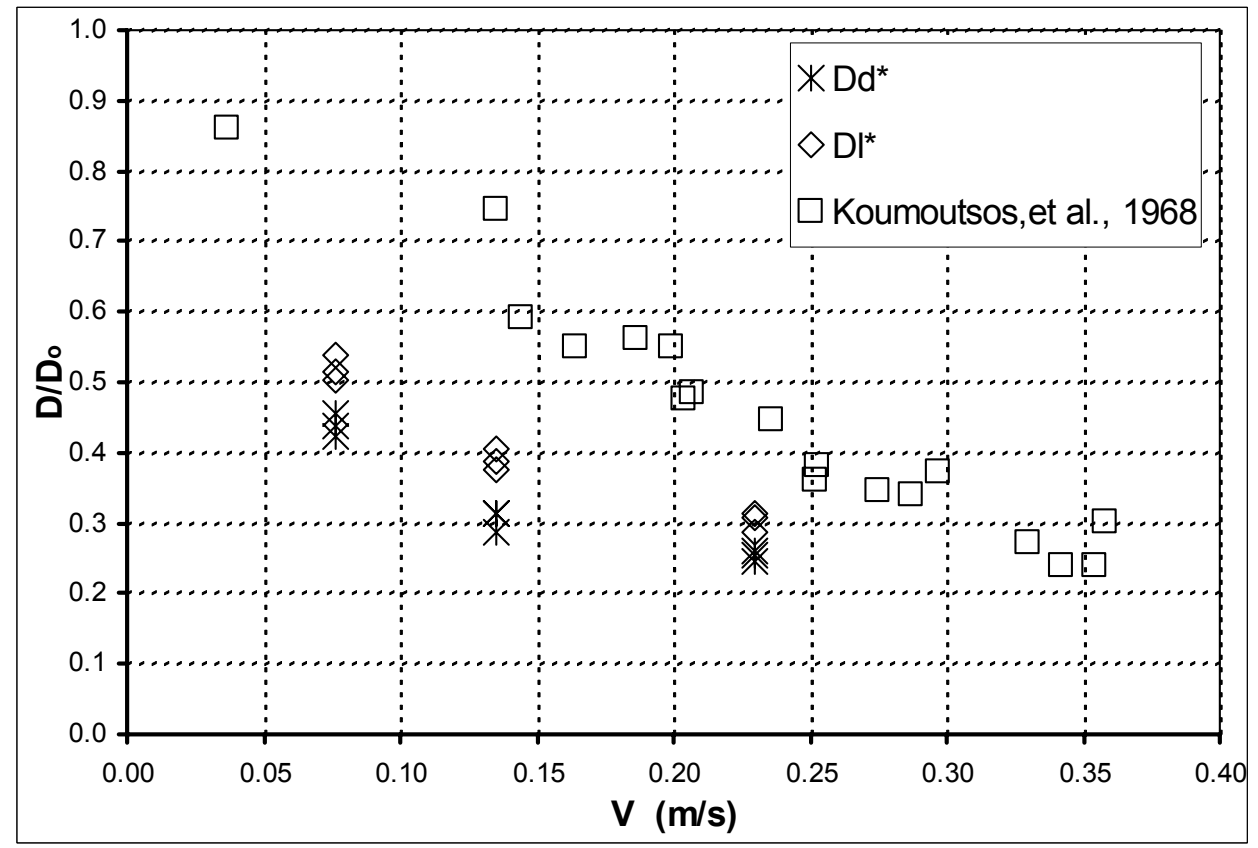

Figure 4-16: Comparison with Koumoutsos, Moisis \& Spyridonos' data on flow boiling on Copper surface $\left(D_{0}=\right.$ Pool boiling departure diameter $)$ 


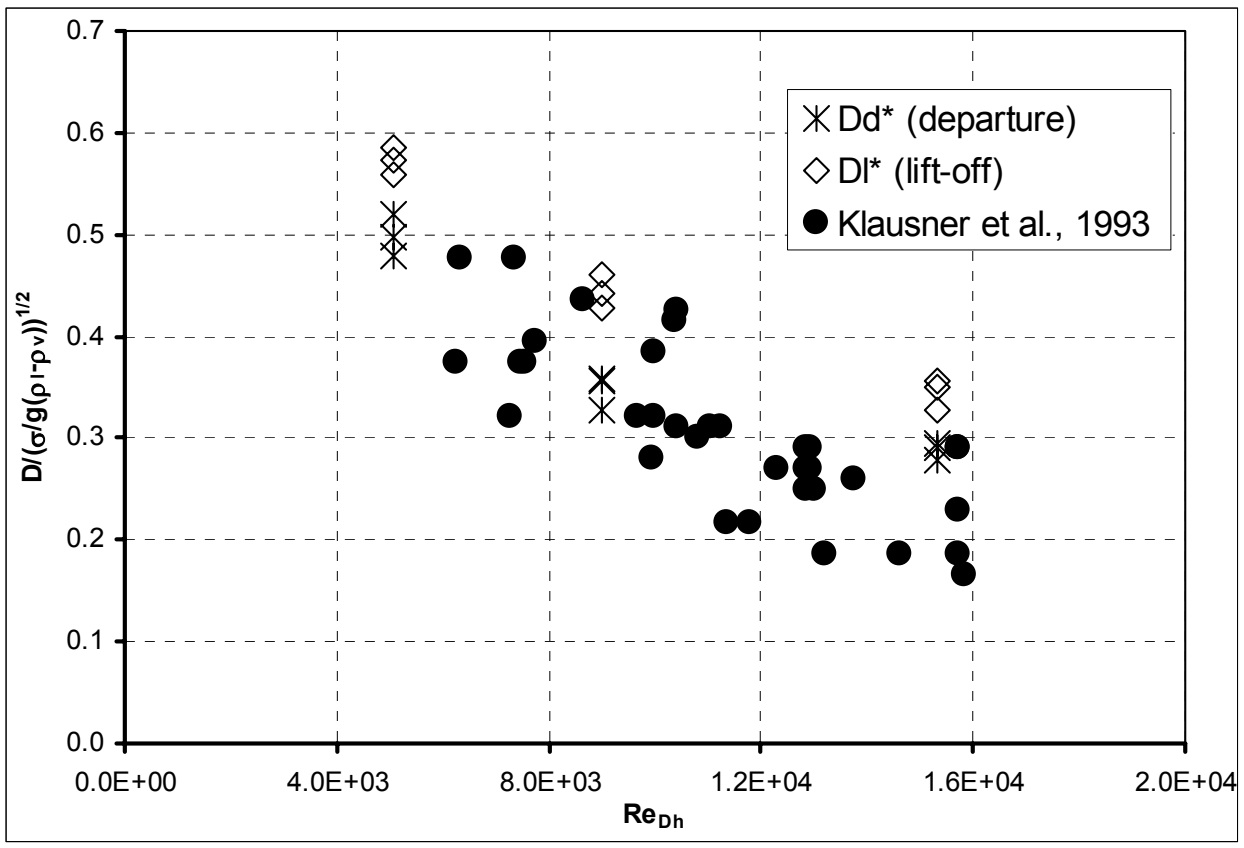

Figure 4-17: Comparison with Klausner, Mei, Bernhard and Zeng's Flow Boiling Data of R113 on Stainless Steel heater surface

\section{Vertical Upflow with Bulk Fluid Nearly Saturated}

The next orientation that was investigated was that of vertical upflow. This section describes the results obtained in this particular orientation.

\section{Pool Boiling Conditions}

Figure 4-18 shows the growth cycle of a vapor bubble on a vertical surface under pool boiling conditions with wall superheat of $5.9^{\circ} \mathrm{C}$ and liquid subcooling of $0.7^{\circ} \mathrm{C}$. As is seen from Figure 4-19, a typical bubble grows to an equivalent diameter of $1.6 \mathrm{~mm}$ in $6 \mathrm{~ms}$ when it departs from the cavity and starts sliding. After it has slid nearly $2 \mathrm{~mm}$, at about $23 \mathrm{~ms}$ it lifts off from the heater surface when its diameter is almost $2.4 \mathrm{~mm}$. Its sliding velocity at point of lift off is about $0.2 \mathrm{~m} / \mathrm{s}$. Its maximum base diameter in its entire growth cycle is around $0.55 \mathrm{~mm}$. It is to be noted here that in vertical upflow case bubbles were observed to slide even under pool boiling conditions. Consequently, as is explained later, bubble velocity in all cases was observed to increase beyond the bulk velocity before lift off. 


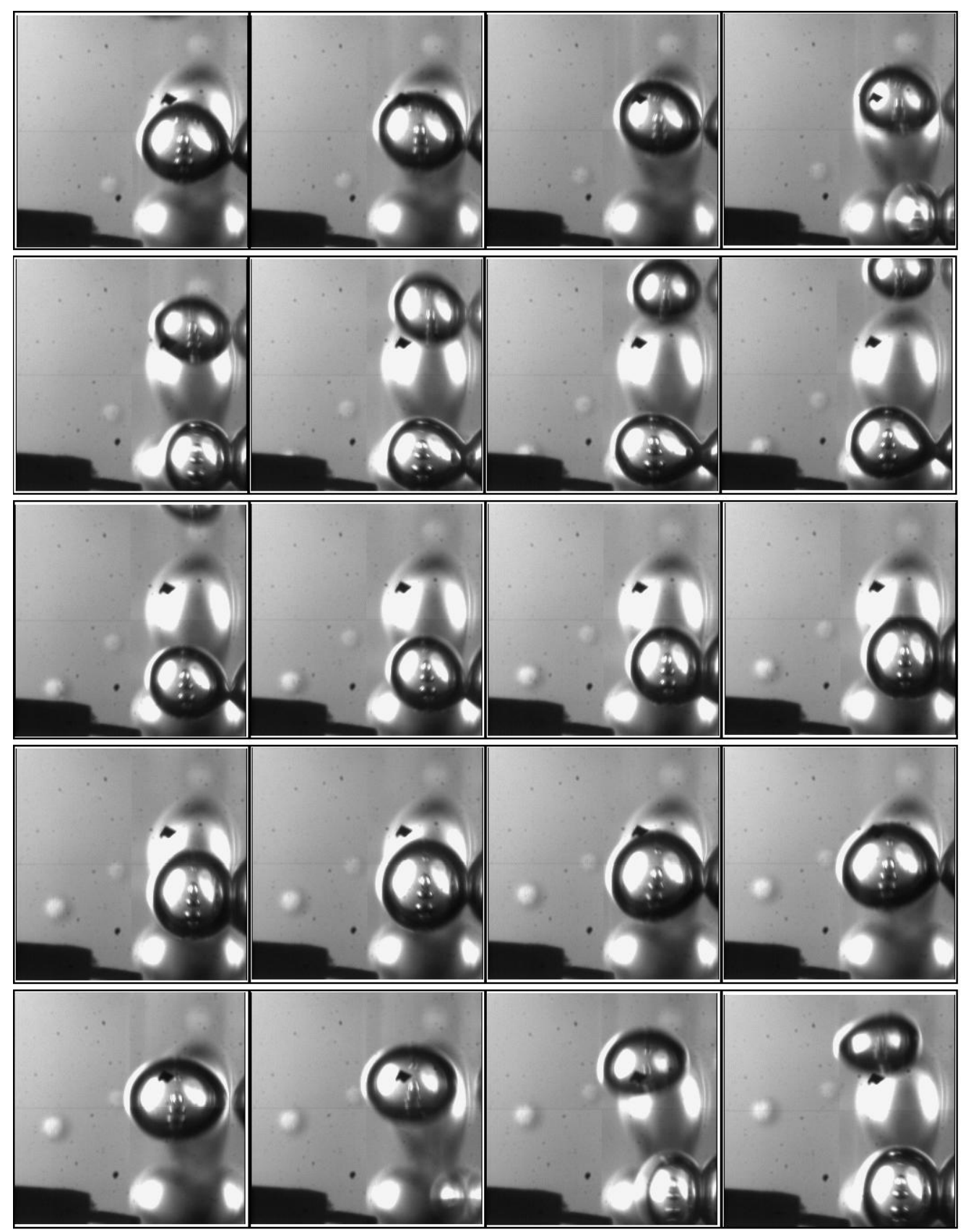

Figure 4-18: Growth Cycle for Vertical surface,Pool, $\Delta$ Twall $=5.9^{\circ} \mathrm{C}, \Delta \mathrm{Tsub}=0.7^{\circ} \mathrm{C}$ 

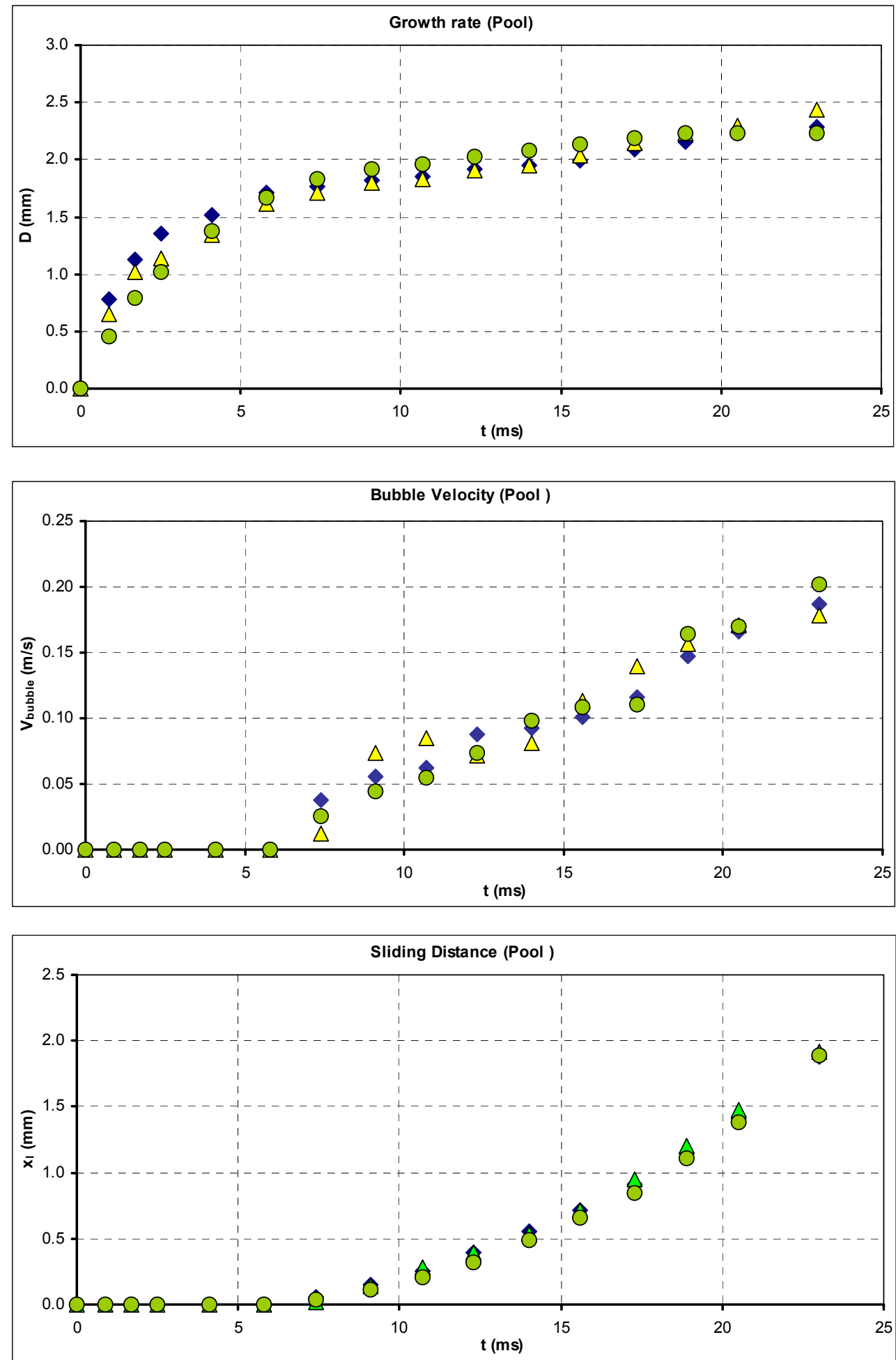

Figure 4-19: Bubble Growth Rate, Bubble Velocity \& Base Diameter on Vertical Surface, Pool, $\Delta$ Twall $=5.9^{\circ} \mathrm{C}, \Delta \mathrm{Tsub}=0.7^{\circ} \mathrm{C}$ 


\section{Velocity $0.077 \mathrm{~m} / \mathrm{s}$}

Figure 4-20 shows the typical growth cycle for the case of bulk velocity $0.077 \mathrm{~m} / \mathrm{s}$, wall superheat of $5^{\circ} \mathrm{C}$ and liquid subcooling of $0.6^{\circ} \mathrm{C}$. Growth curves along with sliding velocity and bubble base diameter have been plotted as functions of time in Figure 4-21. Bubble grows to 1.4 $\mathrm{mm}$ in $15 \mathrm{~ms}$ when it departs and starts to slide. The base diameter at this time is around $0.8 \mathrm{~mm}$. It slides for about $7 \mathrm{~mm}$ with increasing velocity. At around $60 \mathrm{~ms}$, when its diameter is $2.2 \mathrm{~mm}$ and sliding velocity is $0.25 \mathrm{~m} / \mathrm{s}$, it lifts off from the surface into the liquid.
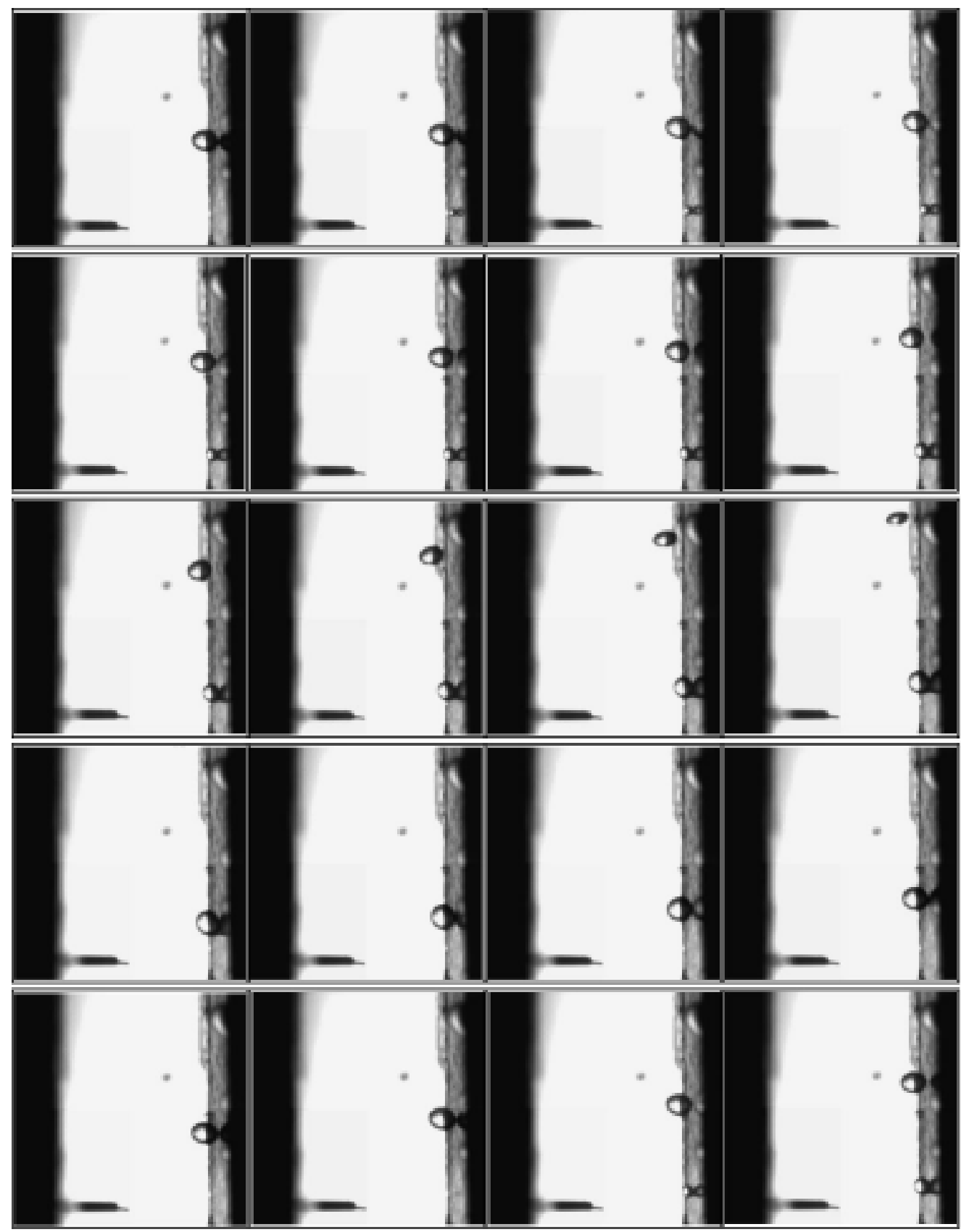

Figure 4-20: Growth Cycle for Vertical surface, Upflow, $\mathrm{V}=0.077 \mathrm{~m} / \mathrm{s}, \Delta \mathrm{Twall}=5.0^{\circ} \mathrm{C}, \Delta \mathrm{Tsub}=0.6^{\circ} \mathrm{C}$ 

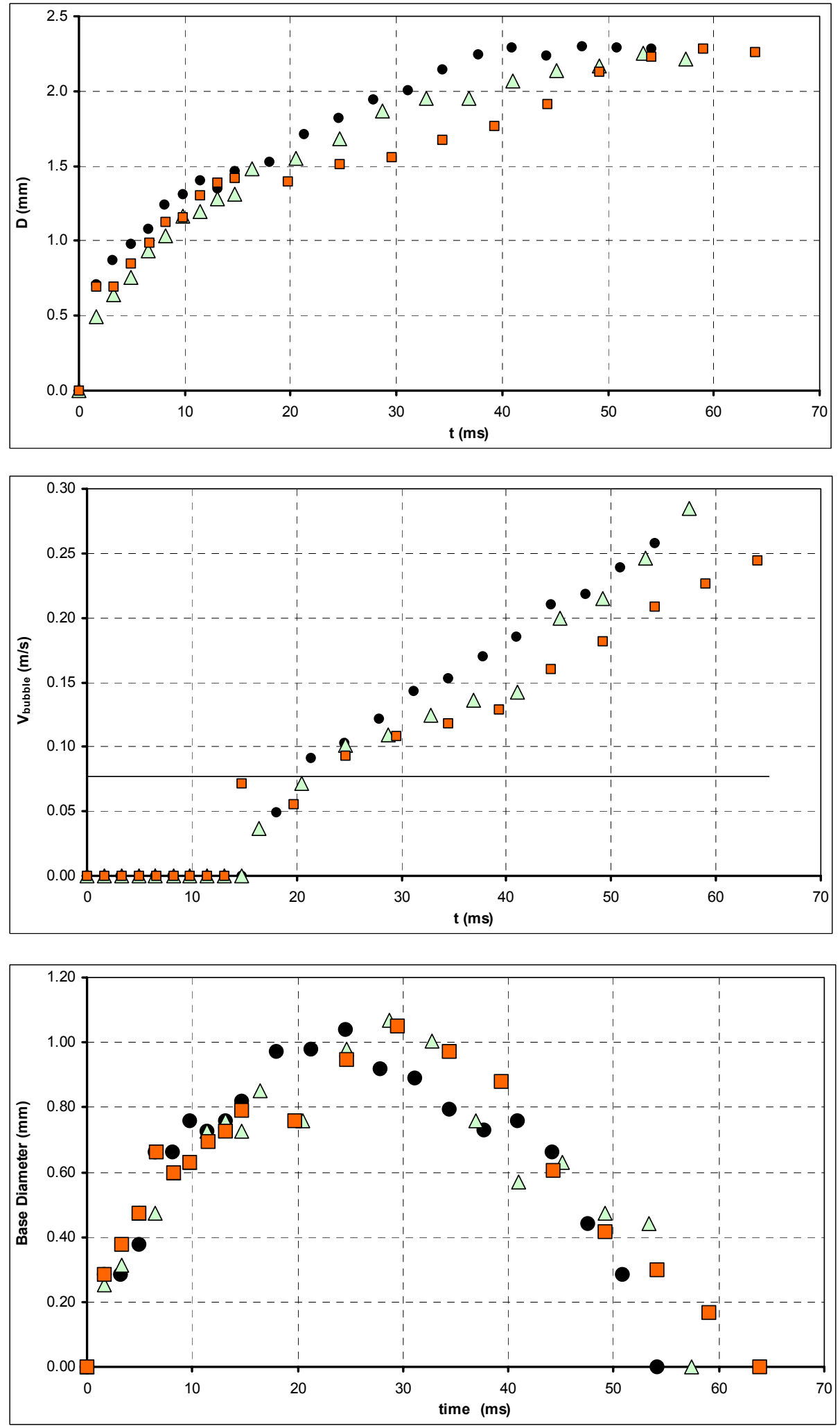

Figure 4-21: Growth Rate, Bubble Velocity \& Base Diameter in Vertical Upflow, $V=0.077 \mathrm{~m} / \mathrm{s}, \Delta$ Twall $=5.0^{\circ} \mathrm{C}, \Delta \mathrm{Tsub}=0.6^{\circ} \mathrm{C}$ 


\section{Velocity $0.15 \mathrm{~m} / \mathrm{s}$}

The next higher velocity investigated was that of $0.15 \mathrm{~m} / \mathrm{s}$. Figure $4-22$ shows the near field view of the bubble ebullition cycle when bulk liquid velocity is $0.15 \mathrm{~m} / \mathrm{s}$, wall superheat is $5.9^{\circ} \mathrm{C}$ and liquid subcooling is $0.3^{\circ} \mathrm{C}$. In this view the bubble is clearly seen to nucleate, grow, depart and slide away from the field of view. Consequently to analyze the data and reduce the whole growth cycle till lift off, the camera had to be moved back and a far field view had to be taken. Growth rate, bubble sliding velocity and base diameter have been shown in Figure 4-23. The bubble is observed to depart at $10 \mathrm{~ms}$ with an equivalent diameter of approximately $1.0 \mathrm{~mm}$ and lifts off from the surface at $90 \mathrm{~ms}$ with a diameter of $2.0 \mathrm{~mm}$ and sliding velocity of $0.3 \mathrm{~m} / \mathrm{s}$.

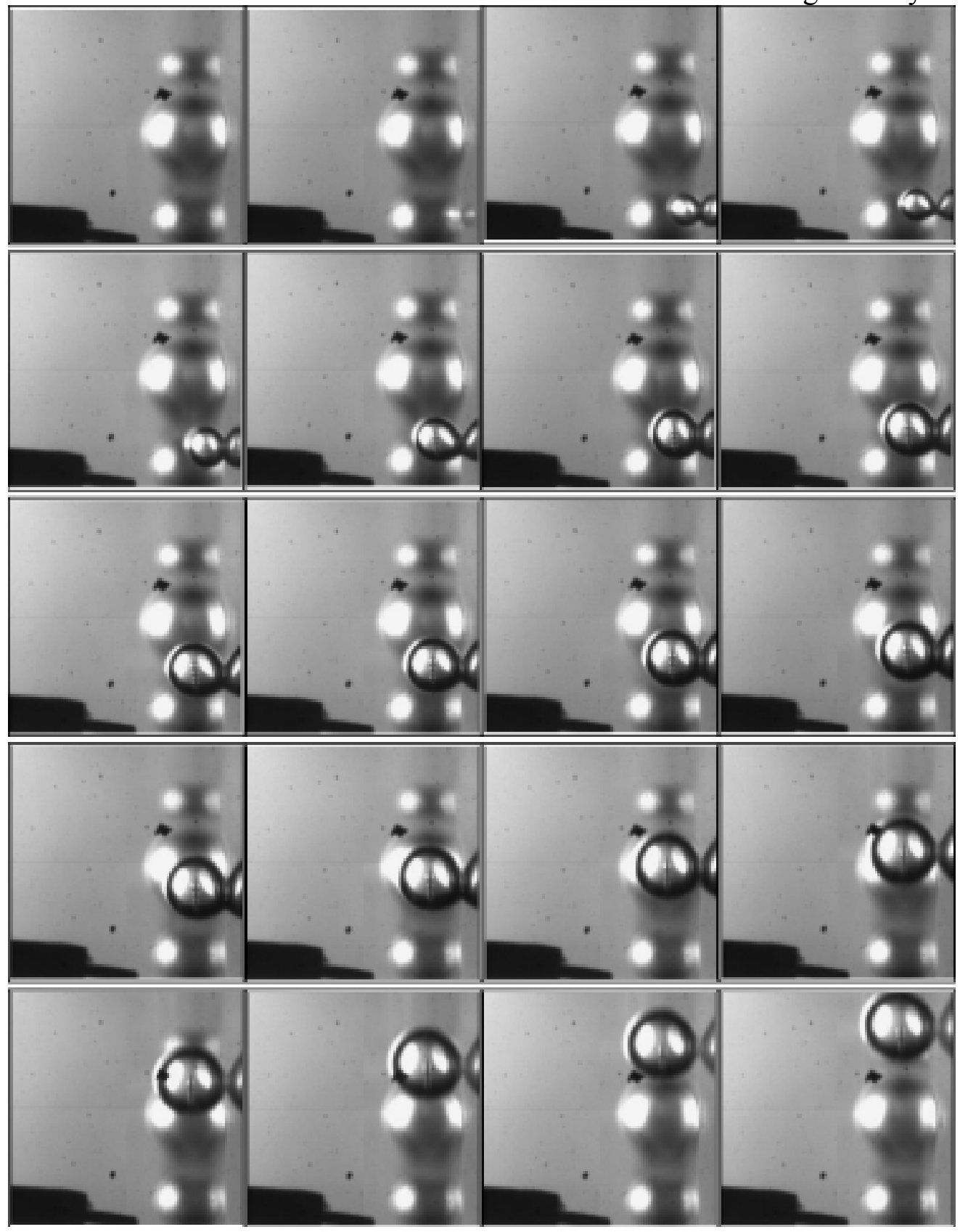

Figure 4-22: Growth Cycle for Vertical surface, Upflow, (near field view) $\mathrm{V}=0.15 \mathrm{~m} / \mathrm{s}, \Delta \mathrm{T}$ wall $=5.9^{\circ} \mathrm{C}, \Delta \mathrm{Tsub}=0.3^{\circ} \mathrm{C}$ 

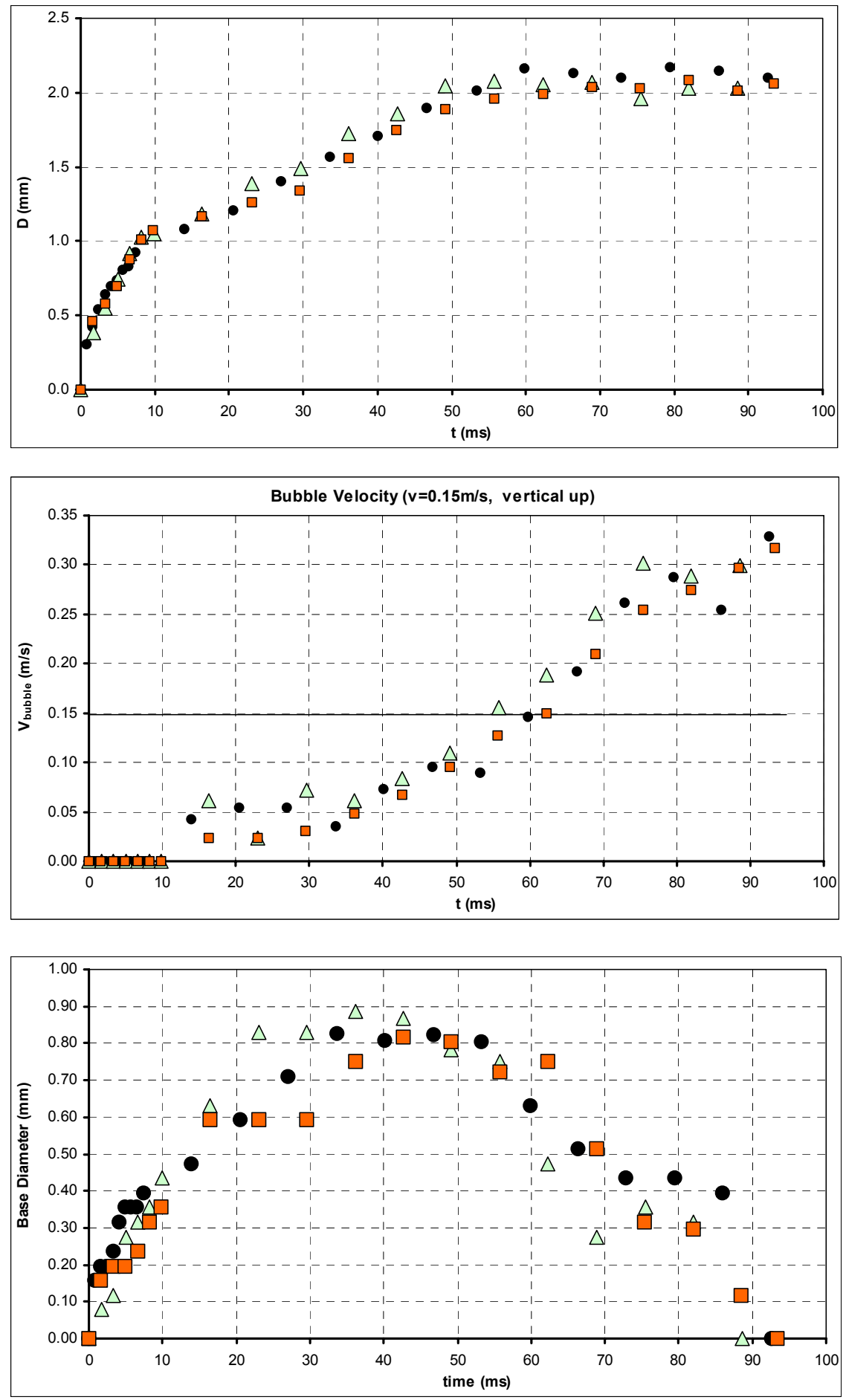

Figure 4-23: Bubble Growth Rate, Bubble Velocity \& Base Diameter in Vertical Upflow, $V=0.15 \mathrm{~m} / \mathrm{s}, \Delta$ Twall $=5.9^{\circ} \mathrm{C}, \Delta \mathrm{Tsub}=0.3^{\circ} \mathrm{C}$

Velocity $0.25 \mathrm{~m} / \mathrm{s}$

The highest velocity investigated was that $0.25 \mathrm{~m} / \mathrm{s}$. Figure $4-24$ shows the near view of the case of liquid velocity $0.25 \mathrm{~m} / \mathrm{s}$, wall superheat $5.9^{\circ} \mathrm{C}$ and liquid subcooling $0.3^{\circ} \mathrm{C}$. As seen 
from Figure 4-24, the bubble is seen to depart and then lift off into the liquid, shrinks in size, returns back to the surface, grows and then finally lifts off into the liquid never to return. Such behavior was reported by Bibeau and Salcudean [29], but was dismissed by them as rare occurrence. In this study, however, such behavior was observed repeatedly for some particular velocities and orientations. Taking example of a typical bubble in Figure 4-25, the growth rate and bubble sliding velocity have been plotted as functions of time. It is observed that the bubble grows at its nucleation site till $4 \mathrm{~ms}$ when its diameter is $0.9 \mathrm{~mm}$. It then starts to slide and continues to grow. Very soon its sliding velocity reaches around $0.28 \mathrm{~m} / \mathrm{s}$ with diameter about $1.1 \mathrm{~mm}$ at $7 \mathrm{~ms}$ when it is observed to have lost contact with the surface. Its diameter is also observed to have decreased leading to the conclusion that some condensation has occurred in the presence of subcooled liquid. At $10 \mathrm{~ms}$ it is observed to have regained contact with the heater surface while its velocity is seen to have decreased to $0.19 \mathrm{~m} / \mathrm{s}$. Thereafter, it continues to grow as it slides and accelerates. Finally at around $55 \mathrm{~ms}$ it lifts off from the surface into the liquid with a diameter of $1.8 \mathrm{~mm}$ and sliding velocity of $0.4 \mathrm{~m} / \mathrm{s}$, never to return to the surface.

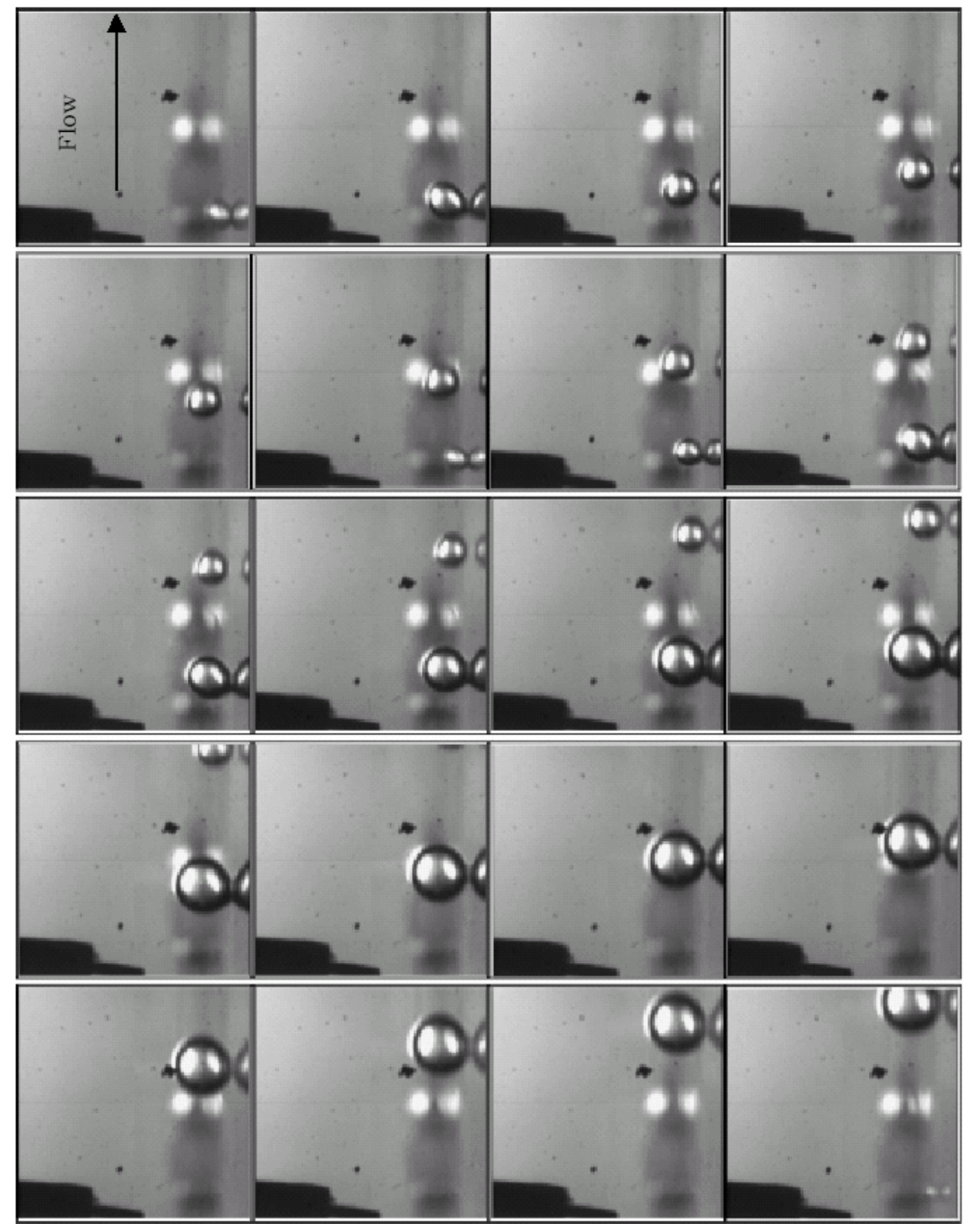

Figure 4-24: Growth Cycle for Vertical surface, Upflow, (near field view) $\mathrm{V}=0.25 \mathrm{~m} / \mathrm{s}, \Delta \mathrm{Twall}=5.9^{\circ} \mathrm{C}, \Delta \mathrm{Tsub}=0.3^{\circ} \mathrm{C}$ 

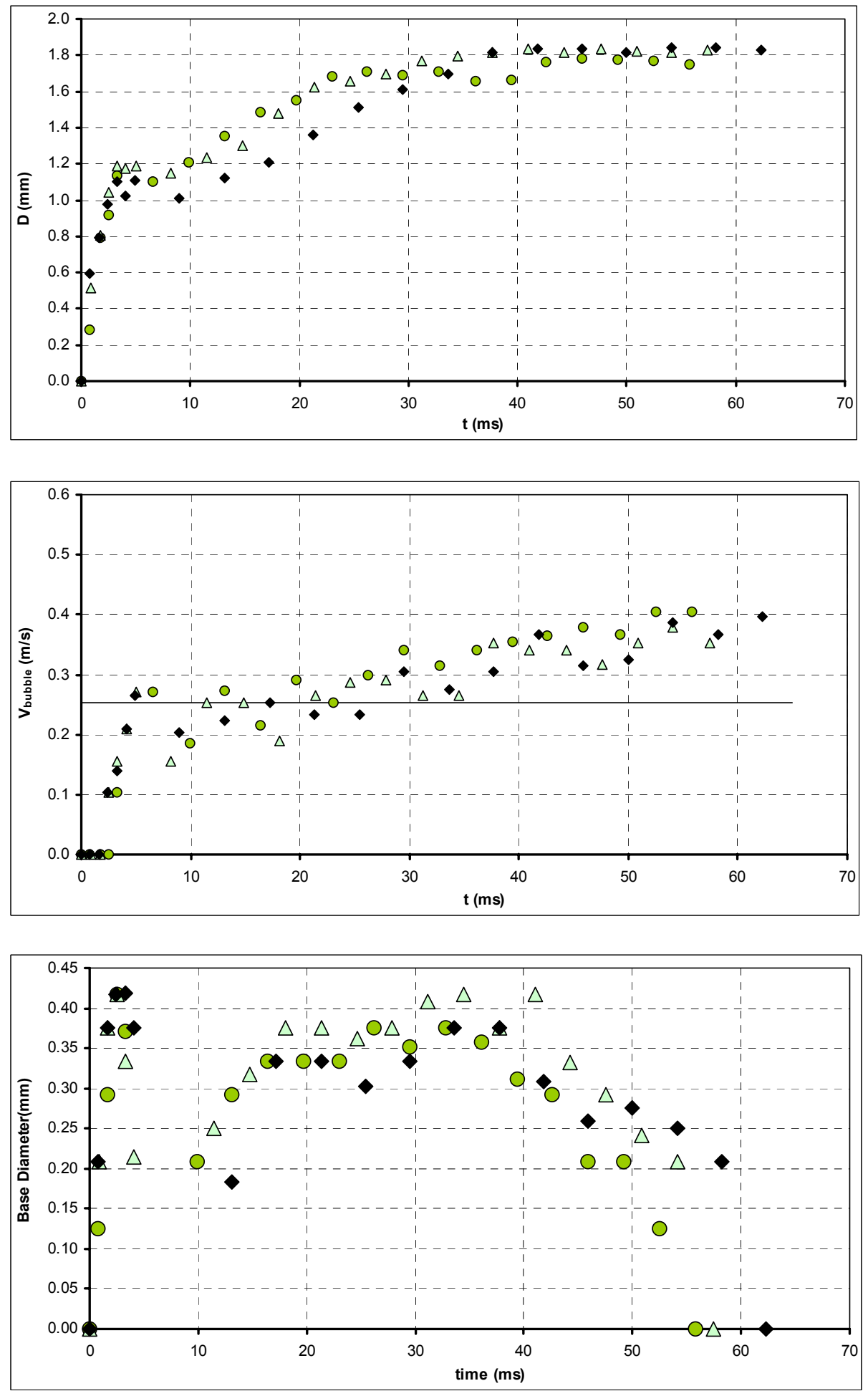

Figure 4-25: Bubble Growth Rate, Velocity \& Base Diameter in Vertical Upflow, $\mathrm{V}=0.25 \mathrm{~m} / \mathrm{s}, \Delta \mathrm{T}$ wall $=5.9^{\circ} \mathrm{C}, \Delta \mathrm{Tsub}=0.3^{\circ} \mathrm{C}$ 
Comparison among different velocities and with data available in literature

The effect of bulk liquid velocity on departure and lift off diameter and time under vertical upflow conditions is shown in Figure 4-26, on sliding distance, bubble sliding velocity at lift off and limiting values of upstream and downstream contact angles is shown in Figure 4-27. As is seen from the graphs, like in horizontal flow, departure and lift off diameter decrease with bulk velocity. Departure time decreases with increasing velocity though lift off time is seen to increase and then decrease with velocity. Sliding distance as well as bubble sliding velocity at lift off increases with velocity. However, it should be noted that while in horizontal case, bubble velocity at lift off though increased with bulk velocity remained less than the bulk velocity. In vertical upflow case however, the bubble velocity at lift off is higher than bulk velocity at lift off in all the cases investigated. Within the uncertainty range, contact angle seems to be fairly constant with velocity.

Comparison with data available in literature on vertical upflow has been presented in Figure 4-28 and Figure 4-29. Bibeau and Salcudean [29] clearly identified departure and lift off while studying vapor bubble dynamics on a vertical stainless steel cylindrical surface. They however reported that the bubble slid with constant velocity after departure while in present study it was observed that the bubble accelerated as it slid along the surface. Akiyama and Tachibana [30] and Abdelmissih, Hooper and Nangia [31] conducted flow boiling experiments with water on vertical stainless steel cylindrical surface and presented their results in the form of maximum vapor bubble diameter. Van Helden, Van der Geld and Boot [32] studied bubble detachment from an artificial cavity locally heated on plane stainless steel wall. They did not observe any sliding and observed that vapor bubbles directly lift off into the liquid from the nucleation site. The general trend of present data seems to agree with the results available in literature. The lift off data observed in the present set of studies seem to agree with those observed by Bibeau and Salcudean. And departure diameter observed here seem to agree with the "lift off" diameters observed by Van Helden, et al. Thus the results of present study give pool boiling data on a vertical surface and show the transition from pool boiling to forced convective flow boiling in Abdelmissih, et al's data at high velocities through Van Helden et al and Bibeau and Salcudean's data.

In Figure 4-29, present data has been compared in a normalized fashion with departure diameter of Thorncroft, Klausner and Mei's [36] experimental data on boiling of FC87 on Nichrome heating surface. They observed bubble departure and lift off in vertical pool boiling. However, they did not observe any lift off in vertical upflow case. As explained in the horizontal case, their lower departure diameter can be explained by the generally lower contact angles of perfluorocarbons. 

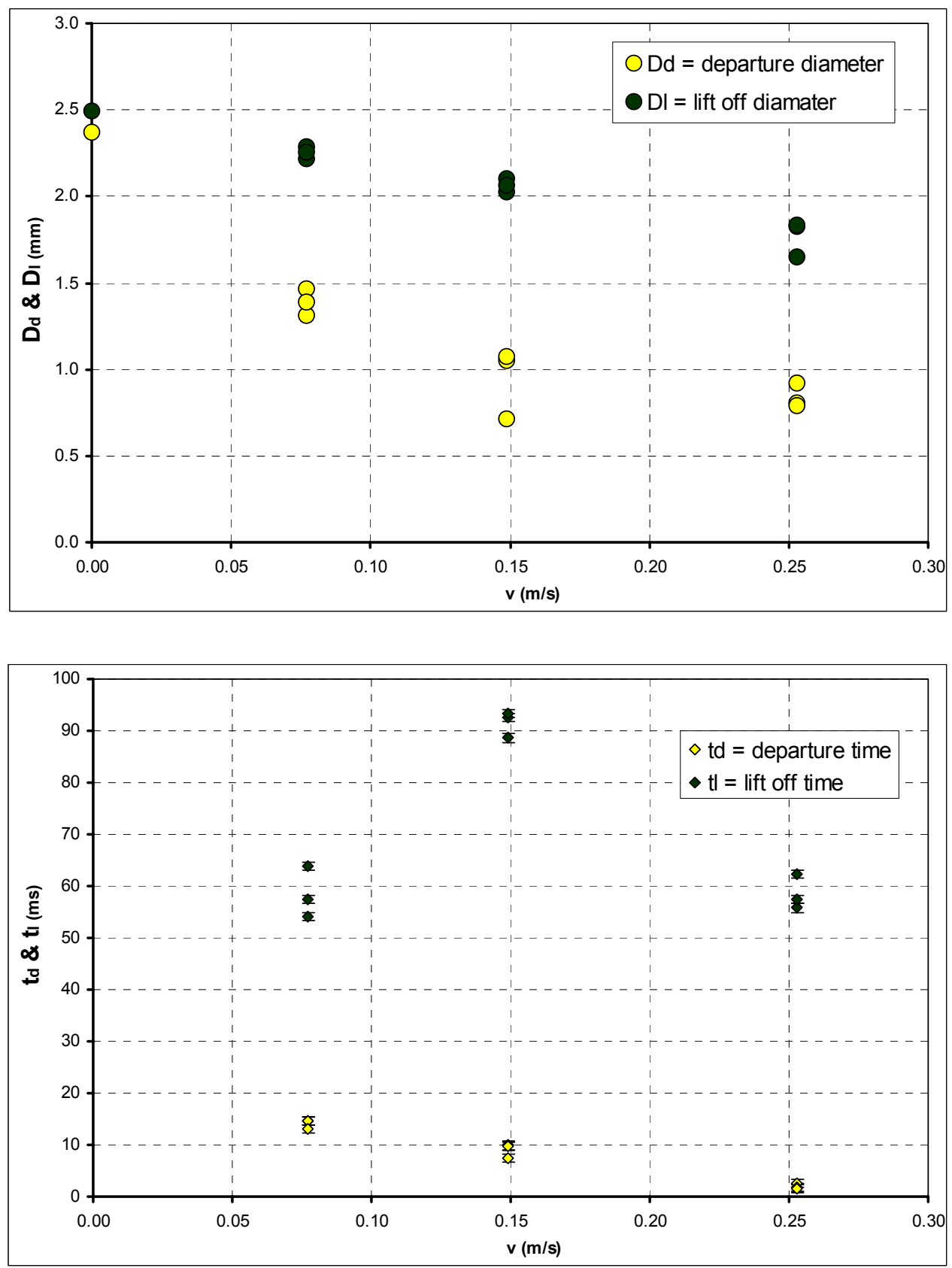

Figure 4-26: Effect of Bulk Liquid Velocity on Departure and Lift off Diameter and Time (Vertical Up) 

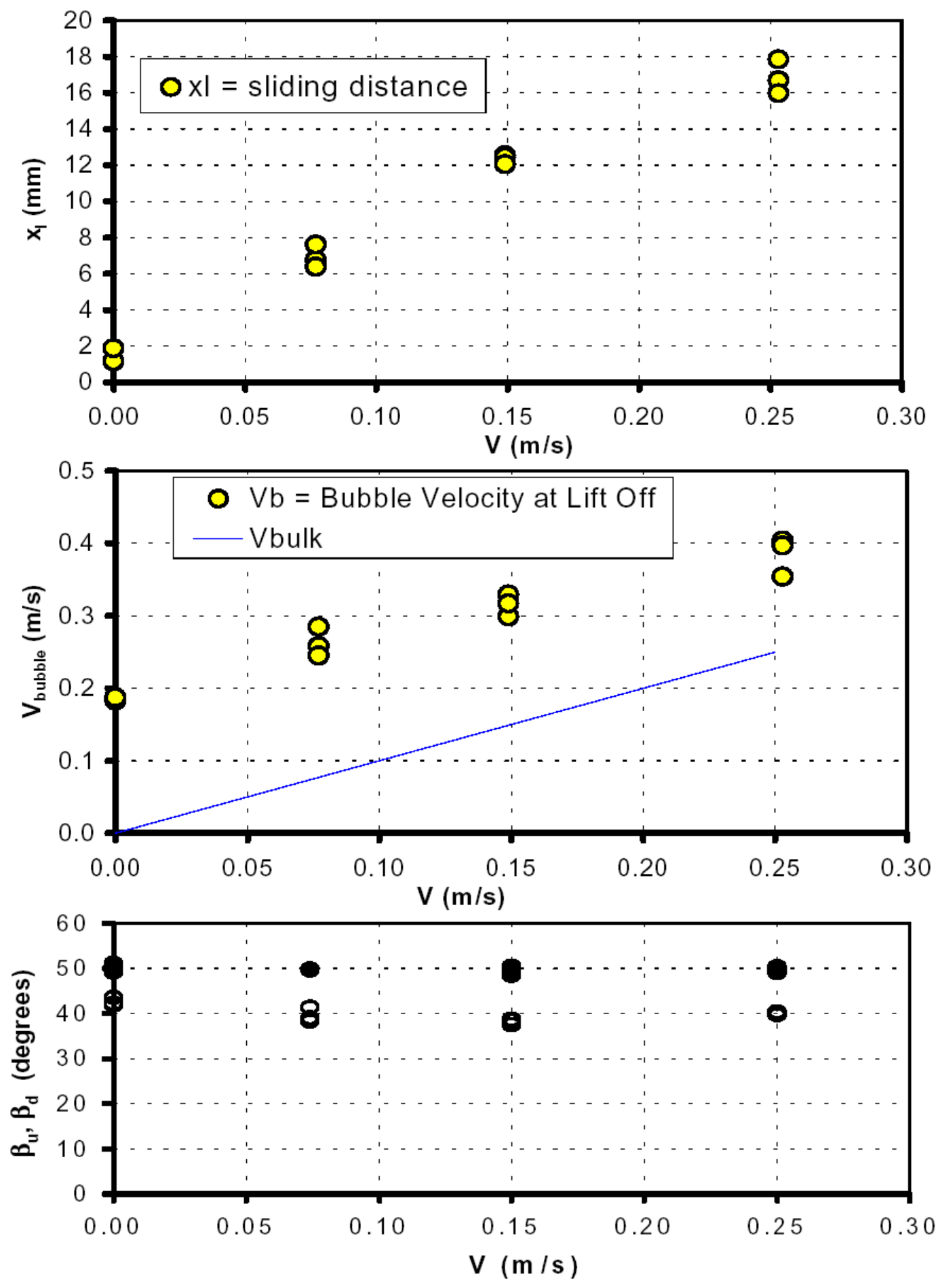

Figure 4-27: Effect of Bulk Liquid Velocity on Sliding Distance, Bubble Velocity at Lift Off and Upstream \& Downstream Contact Angles (Vertical Up) 


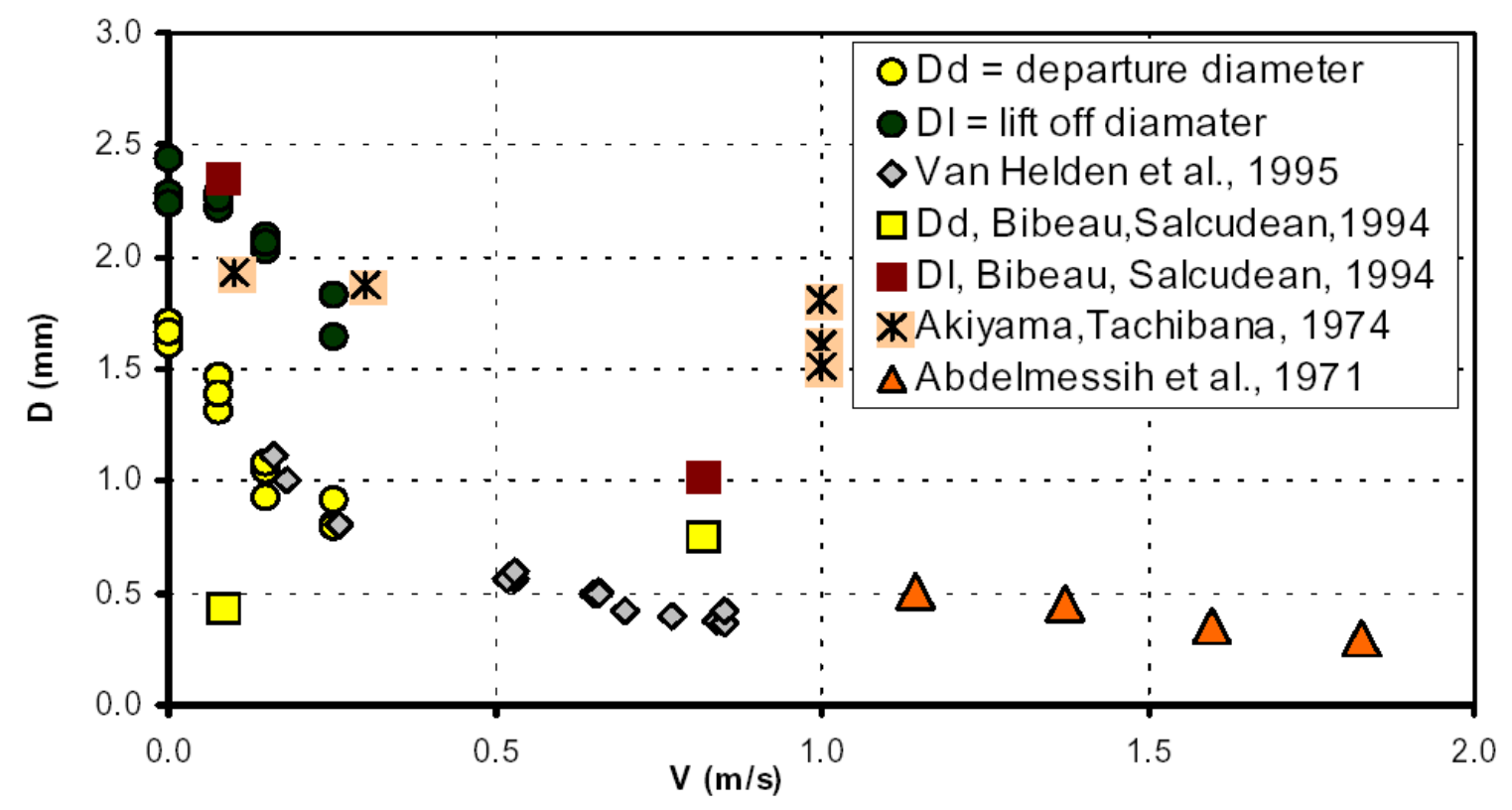

Figure 4-28: Comparison with Bibeau \& Salcudean's data, Abdelmessih, Hooper \& Nangia's data and with that of Akiyama \& Tachibana's data on stainless steel cylindrical surface and with that of Van Helden, Van der Geld \& Boot's single bubble data on stainless steel flat surface.

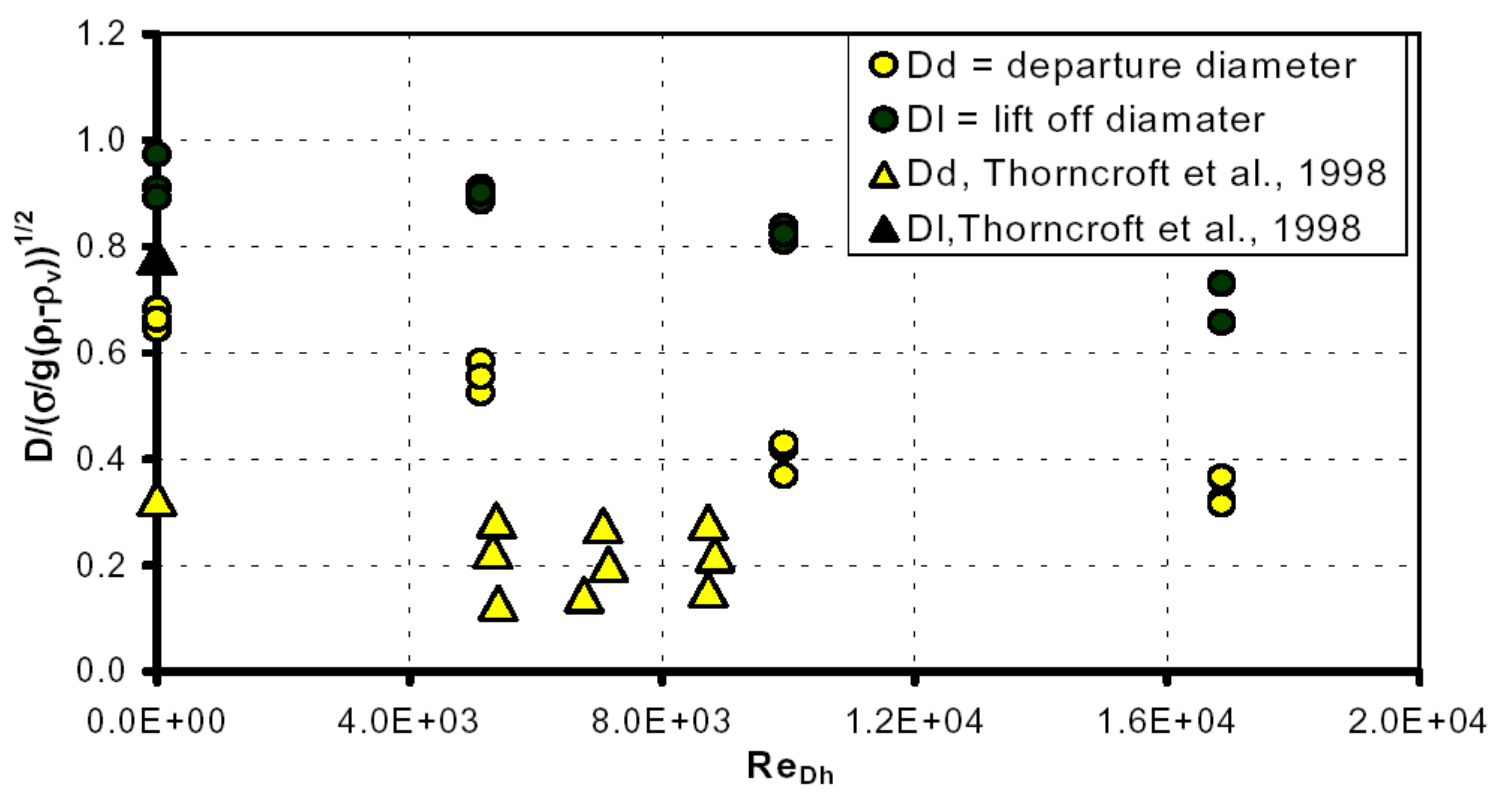

Figure 4-29: Comparison with Thorncroft, Klausner \& Mei's flow boiling data of FC87 on Nichrome heating surface. 


\section{Summary}

The effect of velocity is to decrease the bubble departure diameter and lift off diameter. Bubble sliding velocity at lift off varied with velocity and orientation. Generally it increased with velocity at a given orientation. Sliding distance increased with velocity. However, sliding distance data showed strong dependence on orientation. Sliding distance reaches its maximum in vertical upflow case, going up to $18 \mathrm{~mm}$ at a liquid velocity of $0.25 \mathrm{~m} / \mathrm{s}$. In horizontal flow the sliding distance was very small, of the order of $0.2 \mathrm{~mm}$, which was just above the measurement uncertainty range.

\subsubsection{Bubble Dynamics in Subcooled Flow Boiling}

\section{Horizontal Surface}

The effect of subcooling on horizontal flow boiling was investigated at two different wall superheats, one is $5.3^{\circ} \mathrm{C}$, and another is $3.5^{\circ} \mathrm{C}$. The bulk velocity is $0.076 \mathrm{~m} / \mathrm{s}$. The effect of bulk velocity was also examined with one wall superheat and one subcooling. The results have been plotted in Figure 4-30 to Figure 4-45.

Wall superheats $5.3^{\circ} \mathrm{C}$, bulk velocity $0.076 \mathrm{~m} / \mathrm{s}$

Figure 4-30 depicts four growth-lift-off cycles when the wall superheat is $5.3^{\circ} \mathrm{C}$, liquid subcooling is $1.5^{\circ} \mathrm{C}$, and bulk velocity is $0.076 \mathrm{~m} / \mathrm{s}$. It is observed that the bubble grows quickly in the first 20 milliseconds. The equivalent diameter of the bubble increases to about $1.2 \mathrm{~mm}$ in this period. In the following 20 milliseconds, the equivalent diameter of the bubble increases only about $0.2 \mathrm{~mm}$. The bubble lifts off with a diameter of $1.4 \mathrm{~mm}$ at $40 \mathrm{~ms}$.

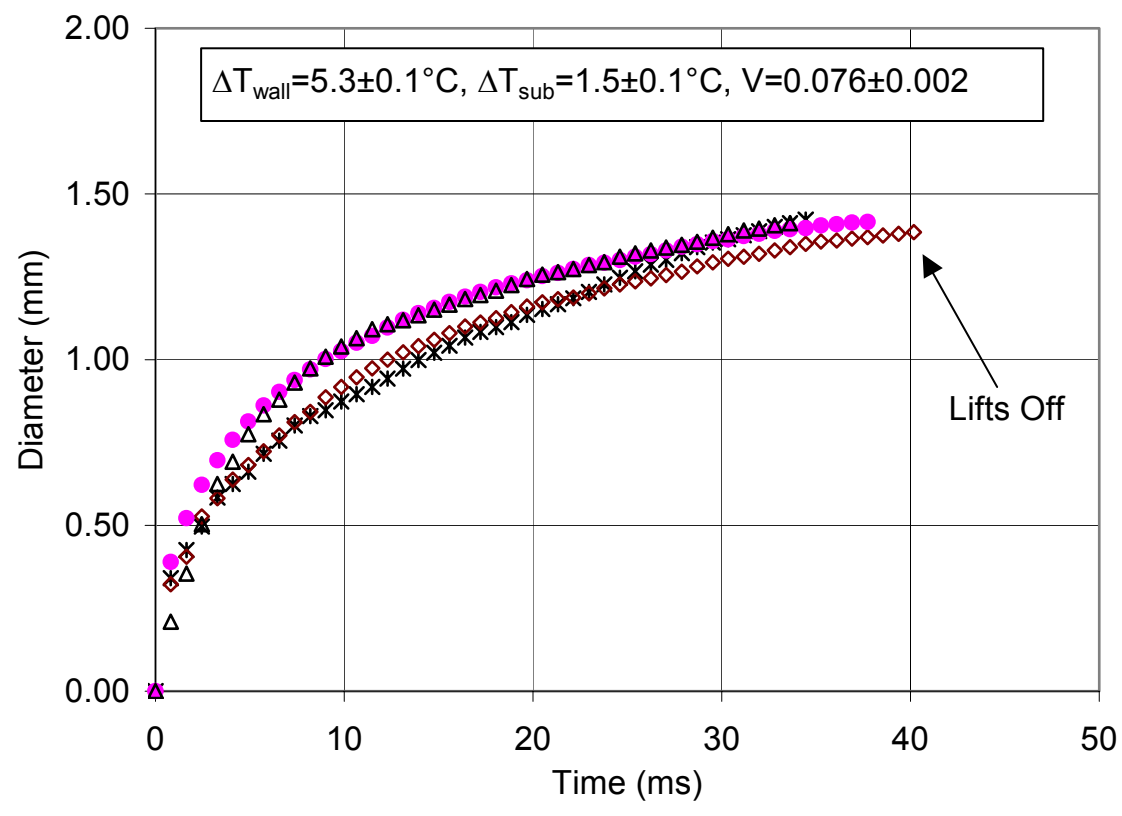

Figure 4-30: Bubble Growth History on Horizontal Surface for $\Delta \mathrm{T}_{\text {wall }}=5.3^{\circ} \mathrm{C}, \Delta \mathrm{T}_{\text {sub }}=1.5^{\circ} \mathrm{C}$ and $v=0.076 \mathrm{~m} / \mathrm{s}$ 
Figure 4-31 shows the growth-lift-off cycles for different liquid subcoolings when wall superheat is $5.3^{\circ} \mathrm{C}$ and bulk velocity is $0.076 \mathrm{~m} / \mathrm{s}$. It can be seen that the common feature for different subcoolings is that bubble grows quickly in the initial period. The bubble monotonically continues to grow and lift off when the liquid is near saturated $\left(\Delta \mathrm{T}_{\text {sub }}=0.2^{\circ} \mathrm{C}\right)$ and liquid subcooling is $1.5^{\circ} \mathrm{C}$. But when the liquid subcooling is $3.0^{\circ} \mathrm{C}$ or higher, the bubble starts to oscillate after its diameter attains a certain value. The oscillating period of the bubble is $7 \mathrm{~ms}$ when the liquid subcooling is $3.0^{\circ} \mathrm{C}$, and it is about $38 \mathrm{~ms}$ when the liquid subcooling is $4.9^{\circ} \mathrm{C}$.

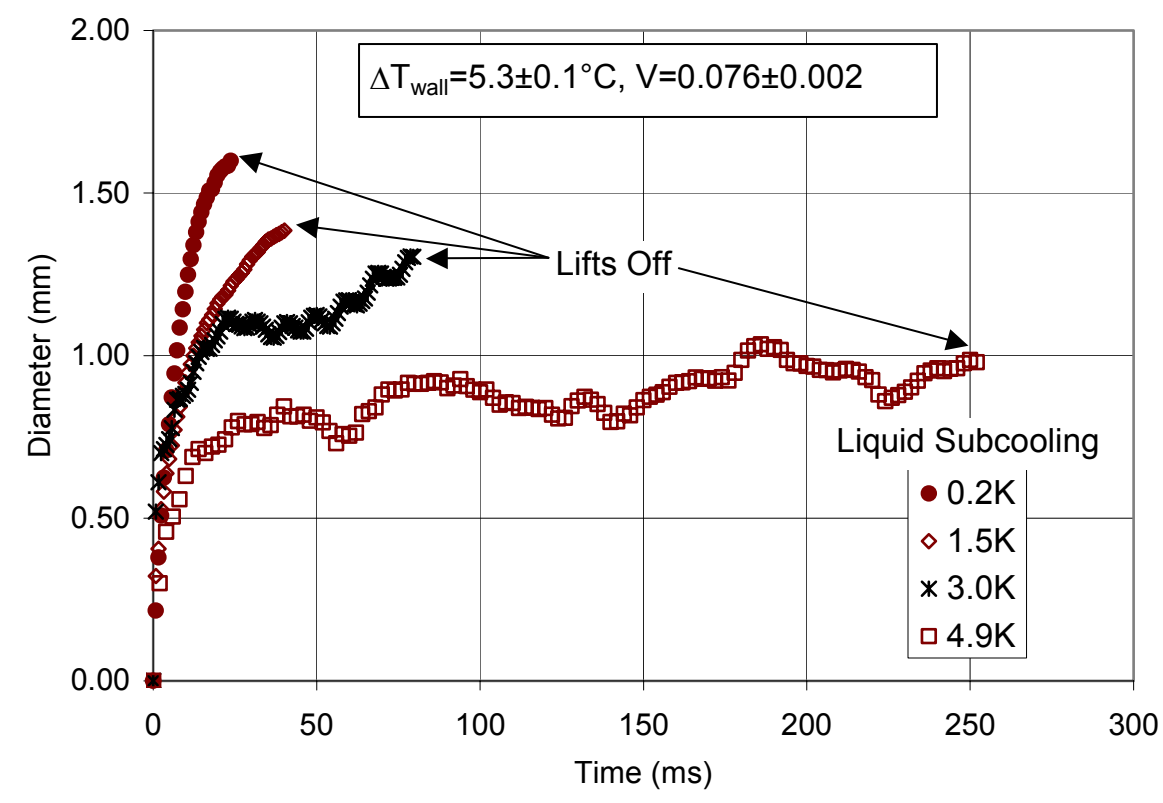

Figure 4-31: Bubble Growth History on Horizontal Surface for $\Delta T_{\text {wall }}=5.3^{\circ} \mathrm{C}, \Delta T_{\text {sub }}=0.2,1.5,3.0,4.9^{\circ} \mathrm{C}$ and $v=0.076 \mathrm{~m} / \mathrm{s}$ 
Figure 4-32 shows the effect of subcooling on lift-off diameter and time. It indicates that lift-off diameter decreases as a parabolic function of subcooling while lift-off time increases as an exponential function of subcooling.
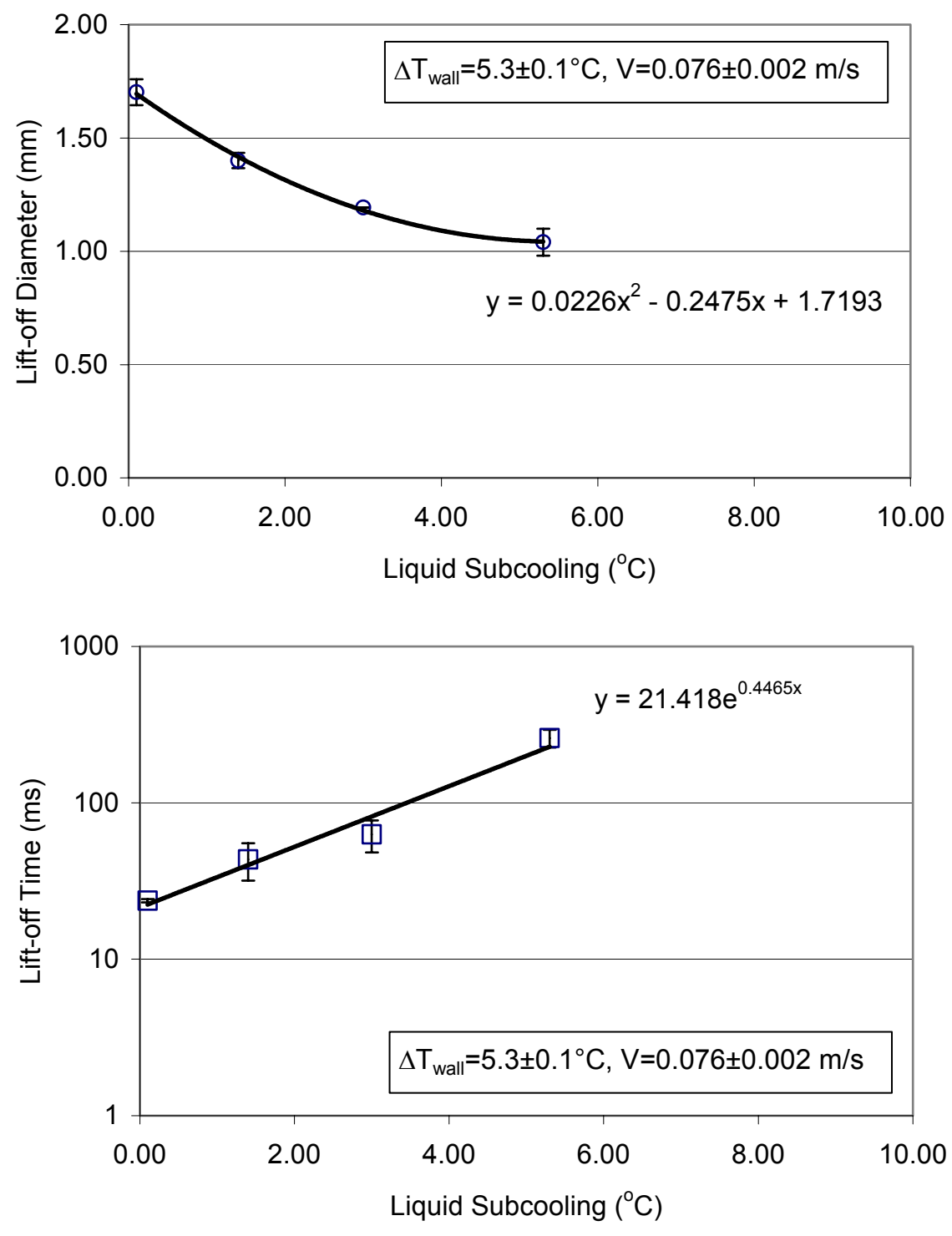

Figure 4-32: Effect of Subcooling on Lift-off Diameter \& Time, Horizontal, $\Delta$ Twall $=5.3^{\circ} \mathrm{C}, \mathrm{V}=0.076 \mathrm{~m} / \mathrm{s}$ 
Wall superheats $3.5^{\circ} \mathrm{C}$, bulk velocity $0.076 \mathrm{~m} / \mathrm{s}$

Figure 4-33 shows three growth-lift-off cycles when the wall superheat is $3.5^{\circ} \mathrm{C}$, liquid subcooling is $1.2^{\circ} \mathrm{C}$, and bulk velocity is $0.076 \mathrm{~m} / \mathrm{s}$. It is observed that the bubble grows quickly in the first 20 milliseconds. The equivalent diameter of the bubble increases to about $1.0 \mathrm{~mm}$ in this period. In the following 30 milliseconds, the equivalent diameter of the bubble increases only about $0.2 \mathrm{~mm}$. The bubble lifts off with a diameter of $1.2 \mathrm{~mm}$ at $50 \mathrm{~ms}$.

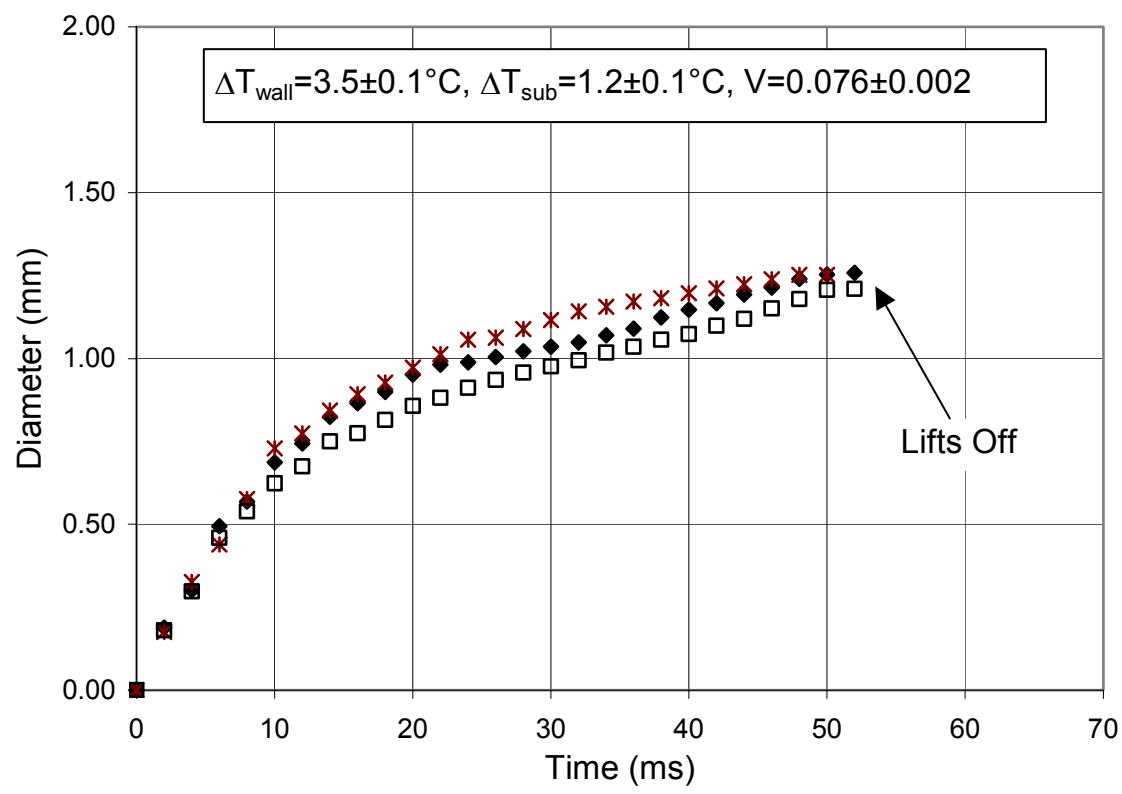

Figure 4-33: Bubble Growth History on Horizontal Surface for $\Delta \mathrm{T}_{\text {wall }}=3.5^{\circ} \mathrm{C}, \Delta \mathrm{T}_{\text {sub }}=1.2^{\circ} \mathrm{C}$ and $v=0.076 \mathrm{~m} / \mathrm{s}$

Figure 4-34 shows three growth-lift-off cycles when wall superheat is $3.5^{\circ} \mathrm{C}$, liquid subcooling is $3.5^{\circ} \mathrm{C}$, and bulk velocity is $0.076 \mathrm{~m} / \mathrm{s}$. It can be seen that bubble grows quickly in the initial period. After that period, the bubble starts to oscillate after its diameter attains a certain value. The amplitude of the oscillation is about $0.1 \mathrm{~mm}$. The bubble lifts off with a diameter of $0.7 \mathrm{~mm}$ at $135 \mathrm{~ms}$. When the liquid subcooling increases to $5.3^{\circ} \mathrm{C}$, the amplitude of oscillation is as high as $0.3 \mathrm{~mm}$ as shown in Figure $4-35$. The bubble lifts off with a diameter of $0.8 \mathrm{~mm}$ at $700 \mathrm{~ms}$. 


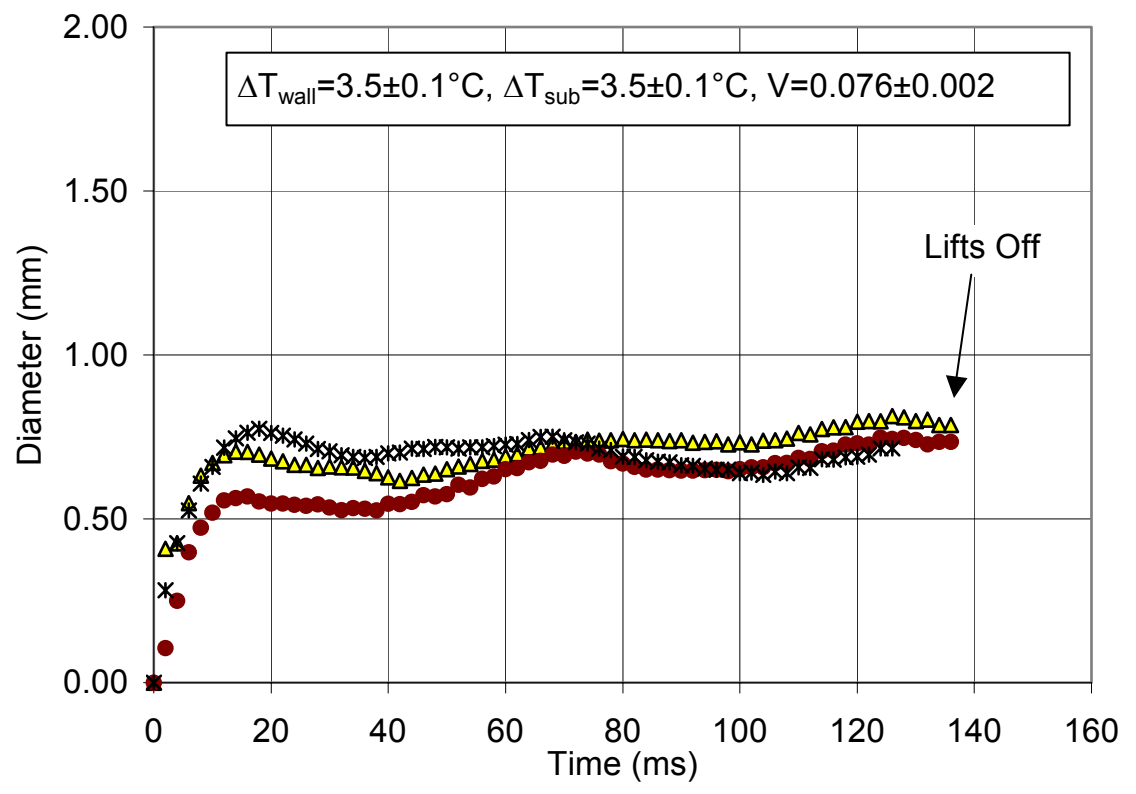

Figure 4-34: Bubble Growth History on Horizontal Surface for $\Delta \mathrm{T}_{\text {wall }}=3.5^{\circ} \mathrm{C}, \Delta \mathrm{T}_{\text {sub }}=1.2^{\circ} \mathrm{C}$ and $v=0.076 \mathrm{~m} / \mathrm{s}$

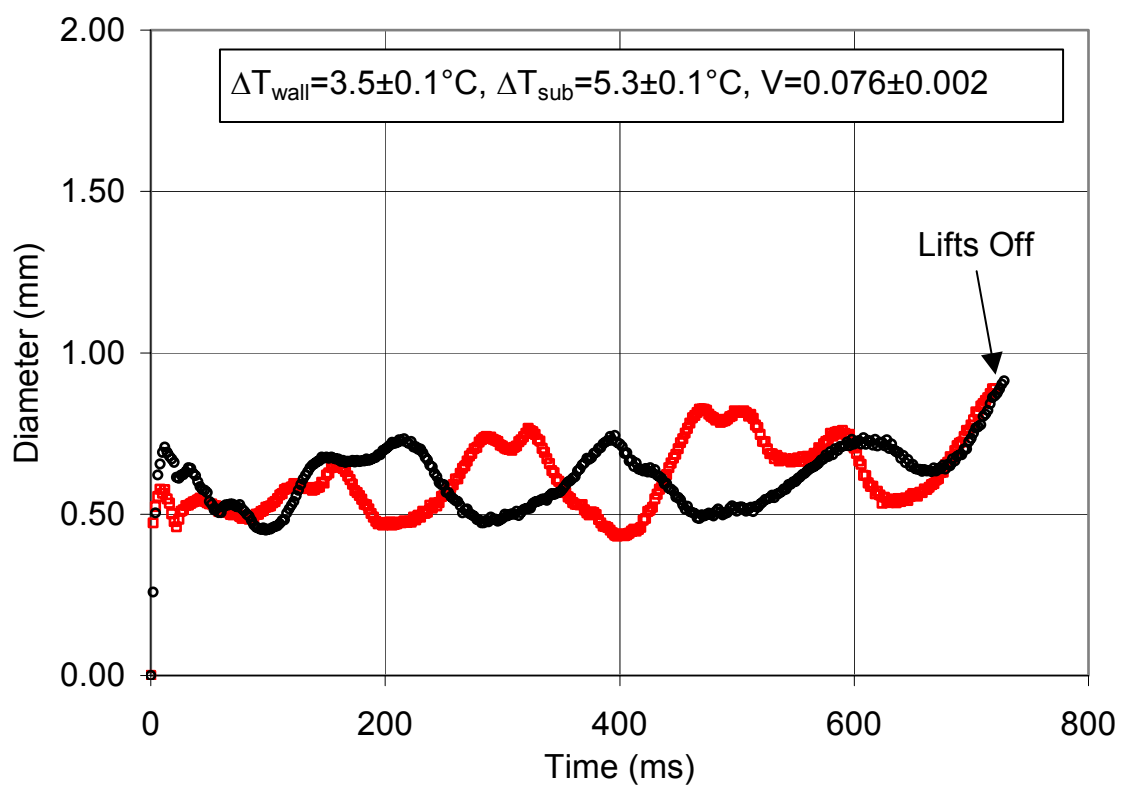

Figure 4-35: Bubble Growth History on Horizontal Surface for $\Delta \mathrm{T}_{\text {wall }}=3.5^{\circ} \mathrm{C}, \Delta \mathrm{T}_{\text {sub }}=5.3^{\circ} \mathrm{C}$ and $v=0.076 \mathrm{~m} / \mathrm{s}$

Figure 4-36 and Figure 4-37 show the growth history and sliding distance of two bubbles when wall superheat is $3.5^{\circ} \mathrm{C}$, liquid subcooling is $10.2^{\circ} \mathrm{C}$, and bulk velocity is $0.076 \mathrm{~m} / \mathrm{s}$. The bubble oscillates a lot and lifts off with a diameter of $0.8 \pm 0.1 \mathrm{~mm}$ at $19.0 \pm 1.0$ seconds. This lift-off time is much longer than that of subcooling of $5.3^{\circ} \mathrm{C}$. Another significant difference is the sliding distance. The bubble slides almost $3.5 \mathrm{~mm}$ away from the nucleation site before it lifts off at this subcooling, but it almost stay on the nucleation site when the subcooling is low. 

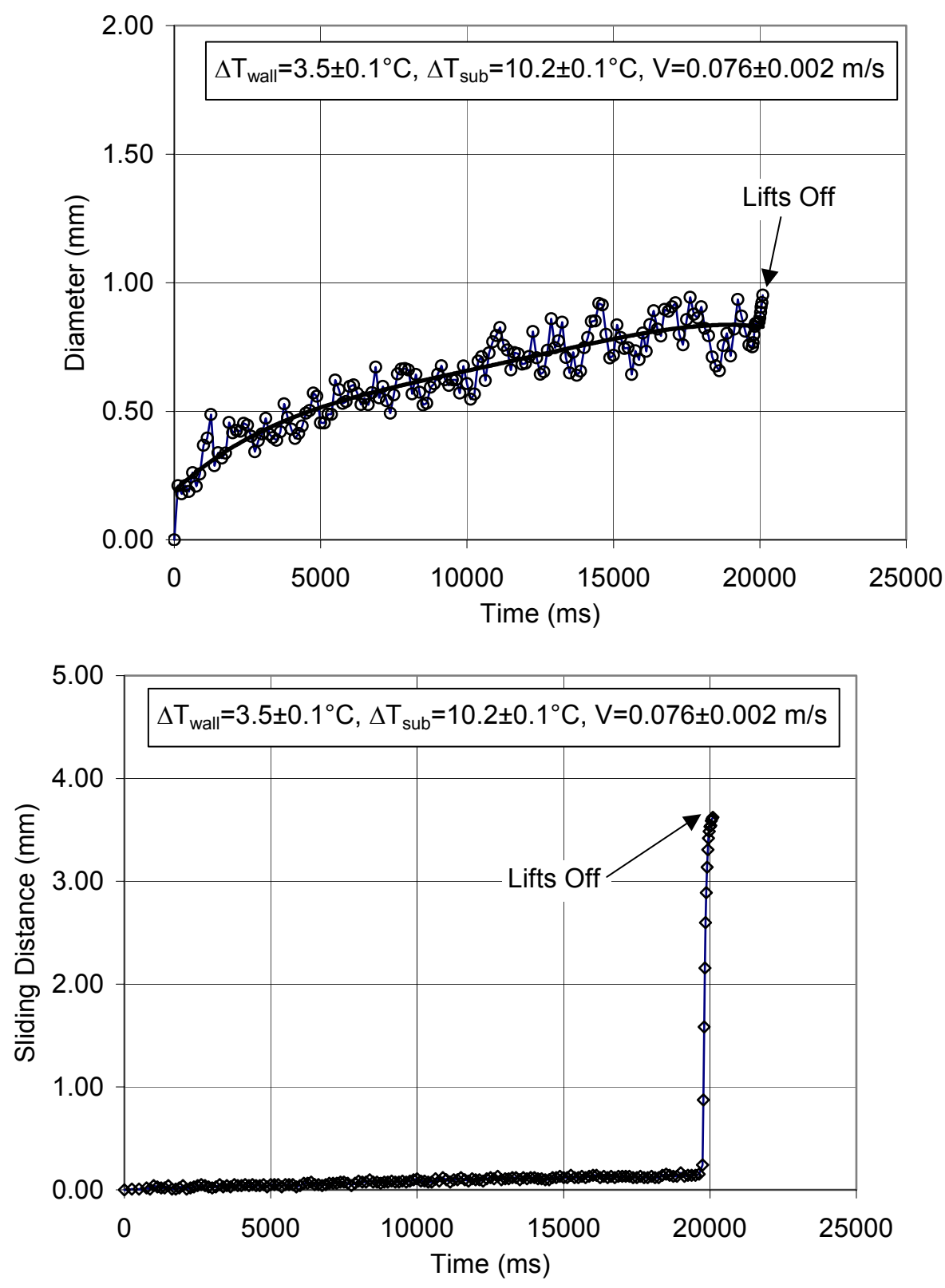

Figure 4-36: Bubble Growth History and Sliding Distance on Horizontal Surface for $\Delta \mathrm{T}_{\text {wall }}=3.5^{\circ} \mathrm{C}, \Delta \mathrm{T}_{\text {sub }}=10.2^{\circ} \mathrm{C}$ and $v=0.076 \mathrm{~m} / \mathrm{s}$ 

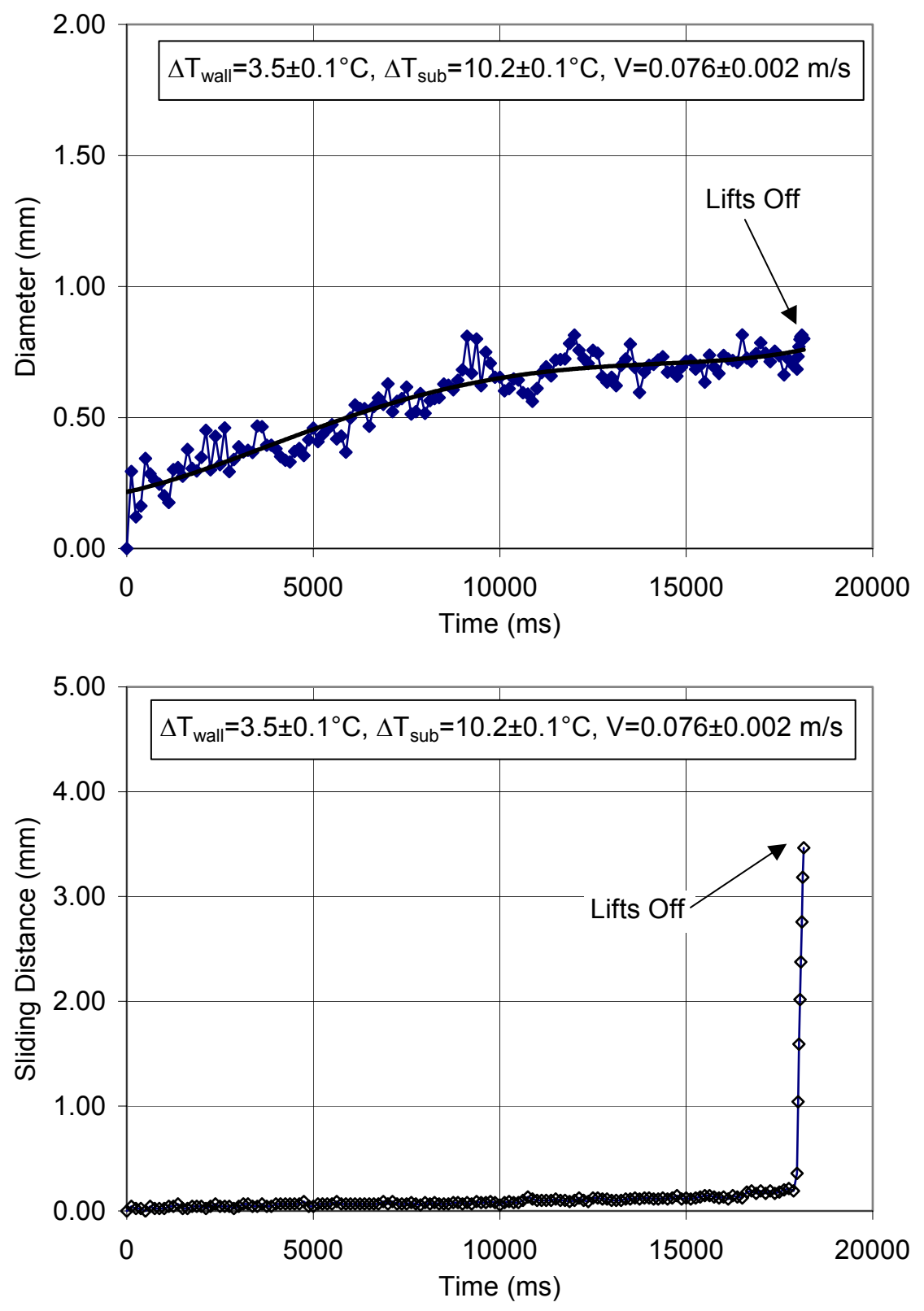

Figure 4-37: Bubble Growth History and Sliding Distance on Horizontal Surface for $\Delta \mathrm{T}_{\text {wall }}=3.5^{\circ} \mathrm{C}, \Delta \mathrm{T}_{\text {sub }}=10.2^{\circ} \mathrm{C}$ and $v=0.076 \mathrm{~m} / \mathrm{s}$

Figure 4-38 shows the effect of subcooling on lift-off diameter and time when wall superheat is $3.5^{\circ} \mathrm{C}$ and bulk velocity is $0.076 \mathrm{~m} / \mathrm{s}$. The lift-off diameter decreases first as a parabolic function of subcooling and then reaches its asymptotic value after the subcooling is higher than $5.3^{\circ} \mathrm{C}$. The lift-off time increases as an exponential function of subcooling. 


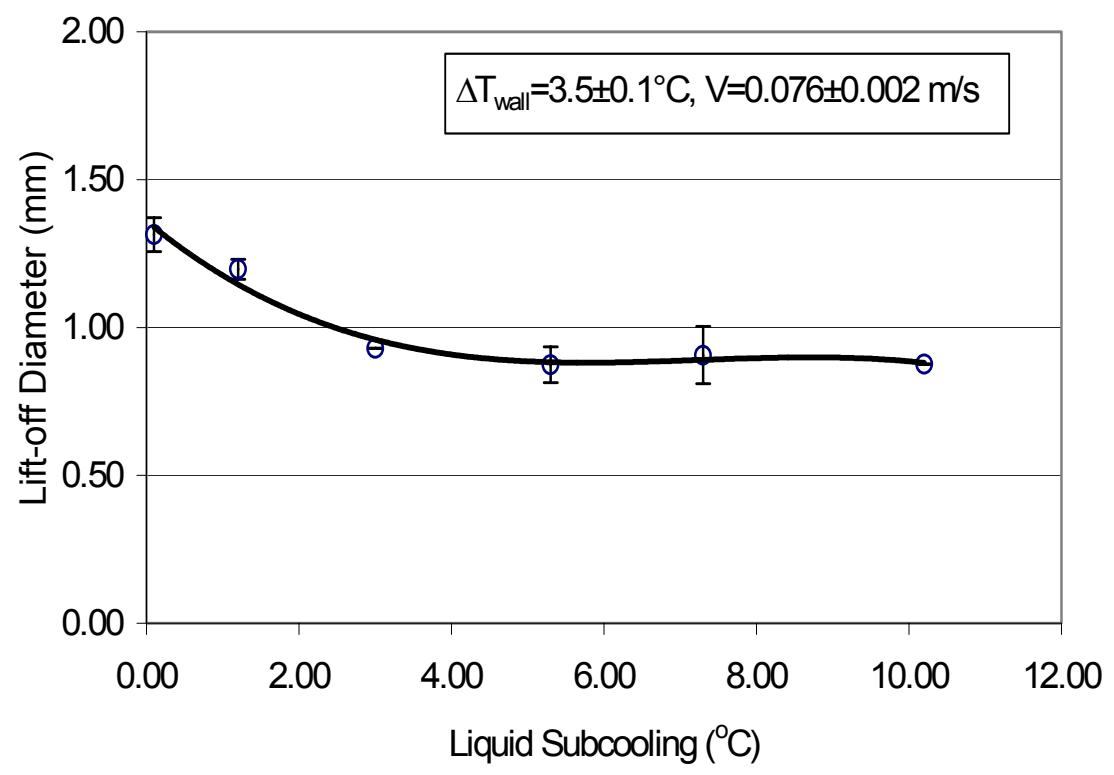

(a)

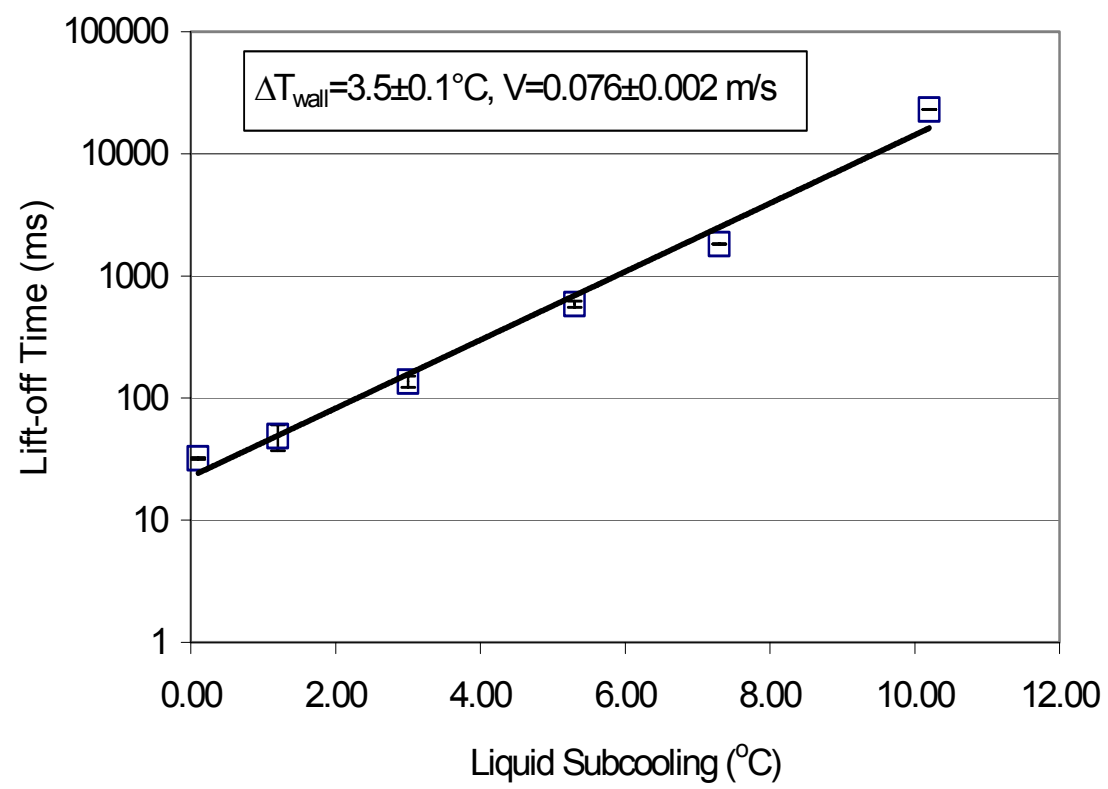

(b)

Figure 4-38: Comparison of Bubble Lift-off Diameter and Time on Horizontal Surface for $\Delta \mathrm{T}_{\text {wall }}=3.5^{\circ} \mathrm{C}$ and Different Subcoolings

Figure 4-39 shows the effect of both wall superheat and liquid subcooling on lift-off diameter and time. The higher the wall superheat, the higher the bubble lift-off diameter and the shorter the bubble lift-off time. Subcooling decreases the bubble's growth rate. As the growing bubble comes in contact with subcooled liquid, condensation takes place at the top of the bubble. Thus there are two competing effects taking place, evaporation at the base and around from the 
superheated liquid and condensation at the top to the subcooled liquid. This decreases the growth rate. Oscillations are caused by imbalance that develops between rates of evaporation and condensation.

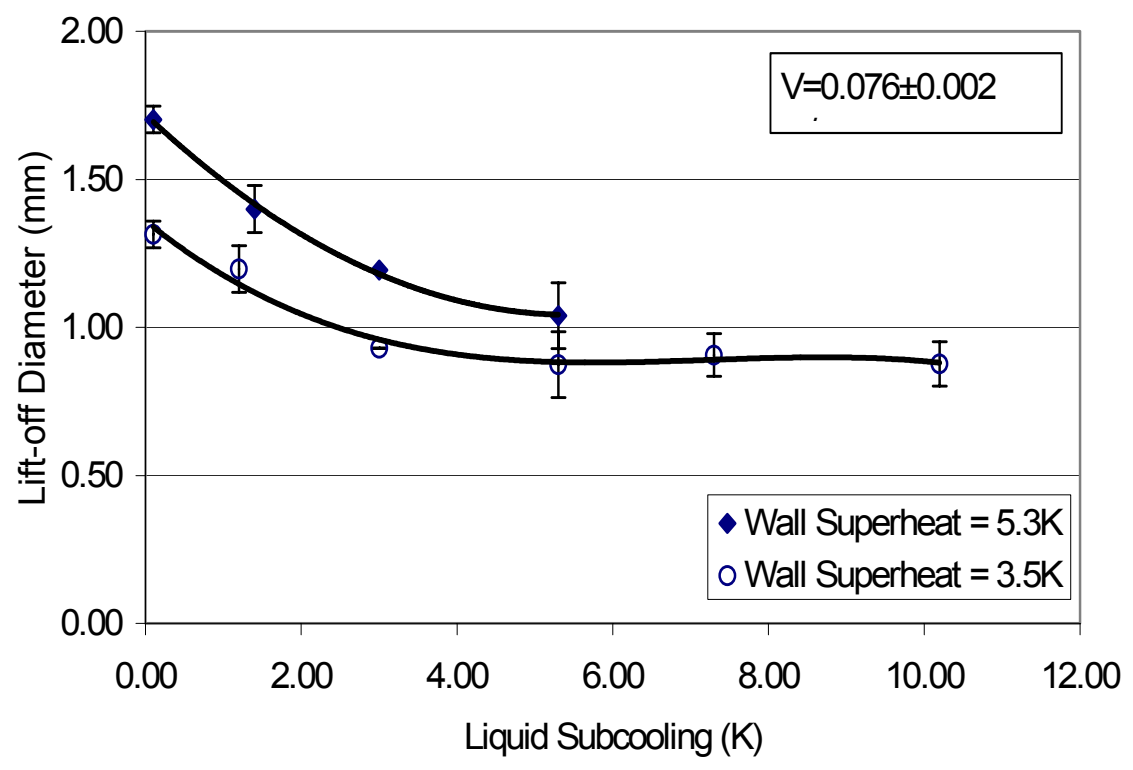

(a)

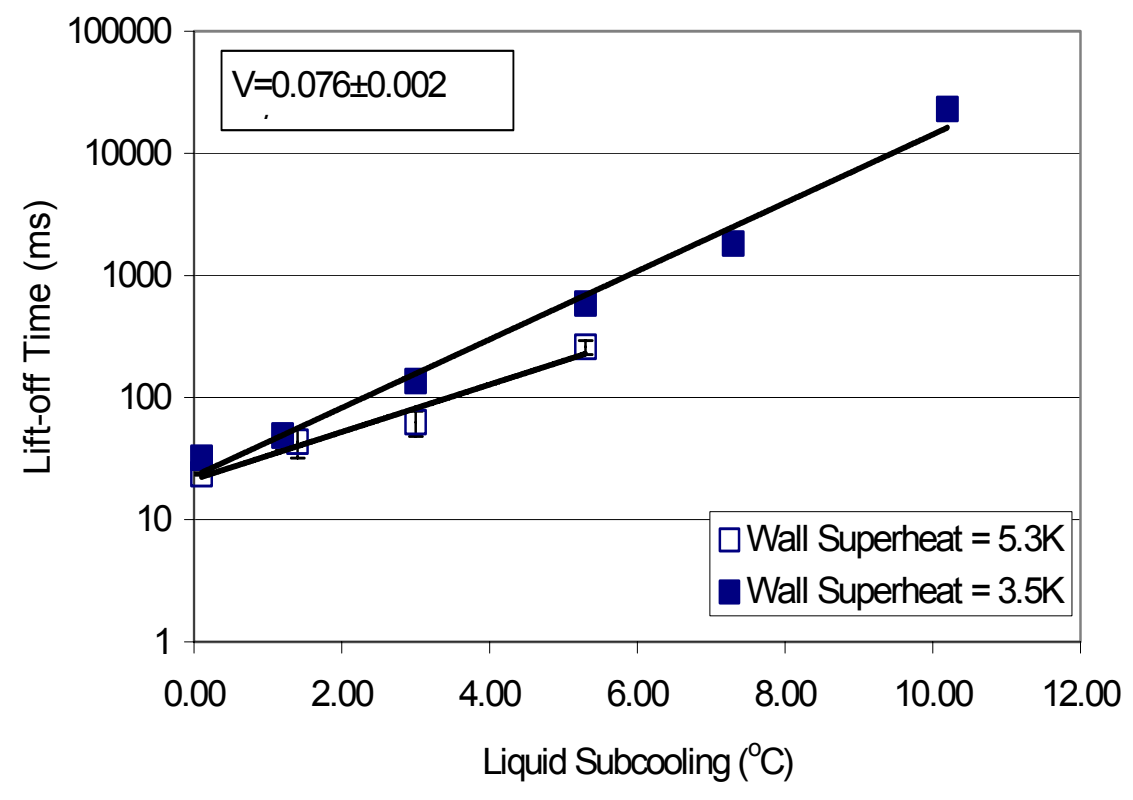

(b)

Figure 4-39: Comparison of Bubble Lift-off Diameter and Time on Horizontal Surface for $\Delta \mathrm{T}_{\text {wall }}=3.5^{\circ} \mathrm{C}, 5.3^{\circ} \mathrm{C}$ and Different Subcoolings 
Wall superheats $3.5^{\circ} \mathrm{C}$, bulk velocity $0.135 \mathrm{~m} / \mathrm{s}$

The growth curve and the sliding distance have been shown in Figure 4-40 when the bulk velocity is $0.135 \mathrm{~m} / \mathrm{s}$, wall superheat is $3.5^{\circ} \mathrm{C}$ and liquid subcooling is $10.2^{\circ} \mathrm{C}$. It is observed that the bubble departs at around $6.2 \mathrm{~s}$ with an equivalent diameter of $0.5 \mathrm{~mm}$. Even the bubble slides as far as $15.6 \mathrm{~mm}$, lift-off has not occurred yet. This sliding distance is already five times as that of bulk velocity of $0.076 \mathrm{~m} / \mathrm{s}$.
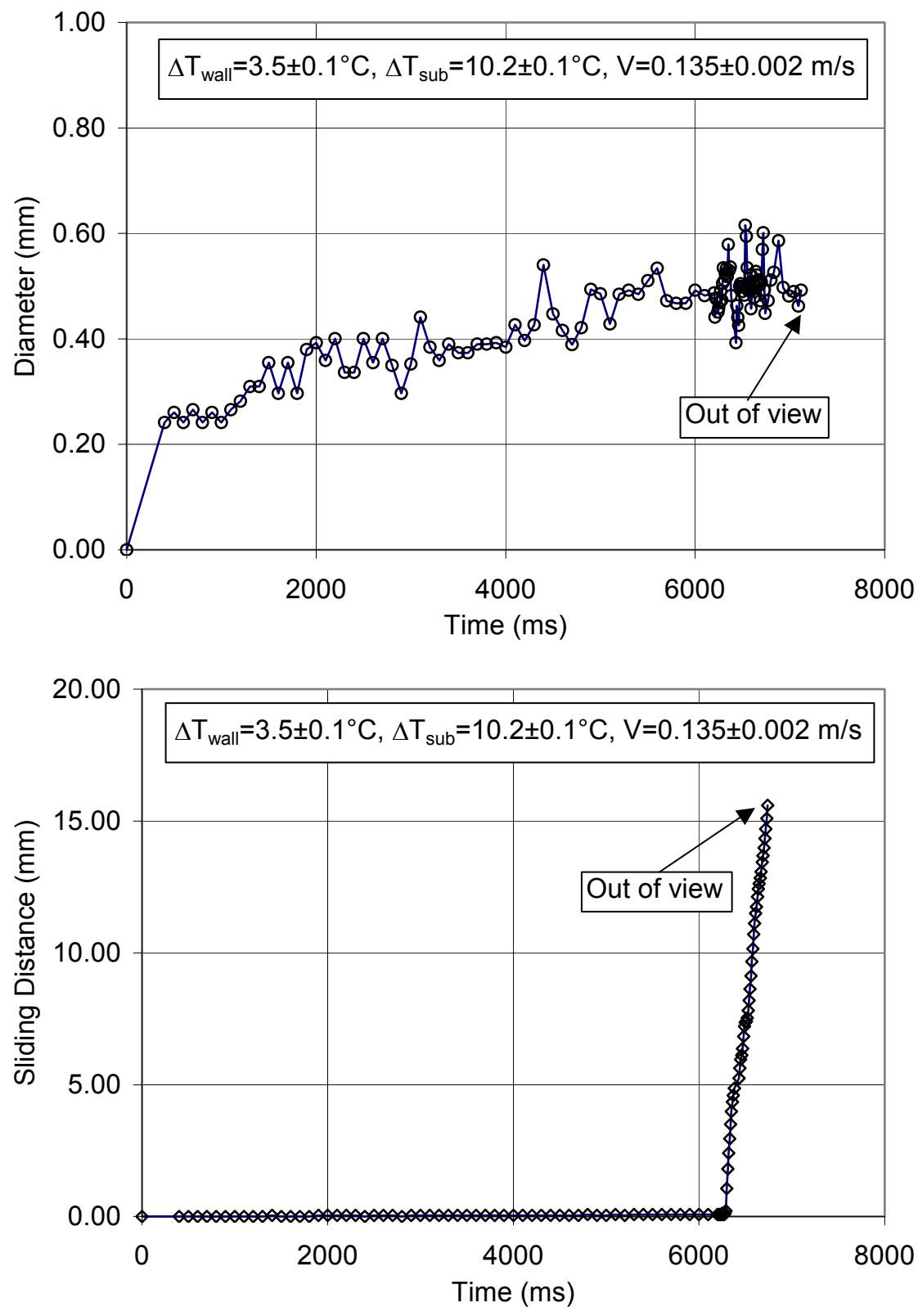

Figure 4-40: Bubble Growth History and Sliding Distance on Horizontal Surface for $\Delta \mathrm{T}_{\text {wall }}=3.5^{\circ} \mathrm{C}, \Delta \mathrm{T}_{\text {sub }}=10.2^{\circ} \mathrm{C}$ and $v=0.135 \mathrm{~m} / \mathrm{s}$ 
Figure 4-41 shows the effect of velocity at this wall superheat and liquid subcooling on departure diameter and time. It is observed that departure time as well as departure diameter decreases with increased velocity.
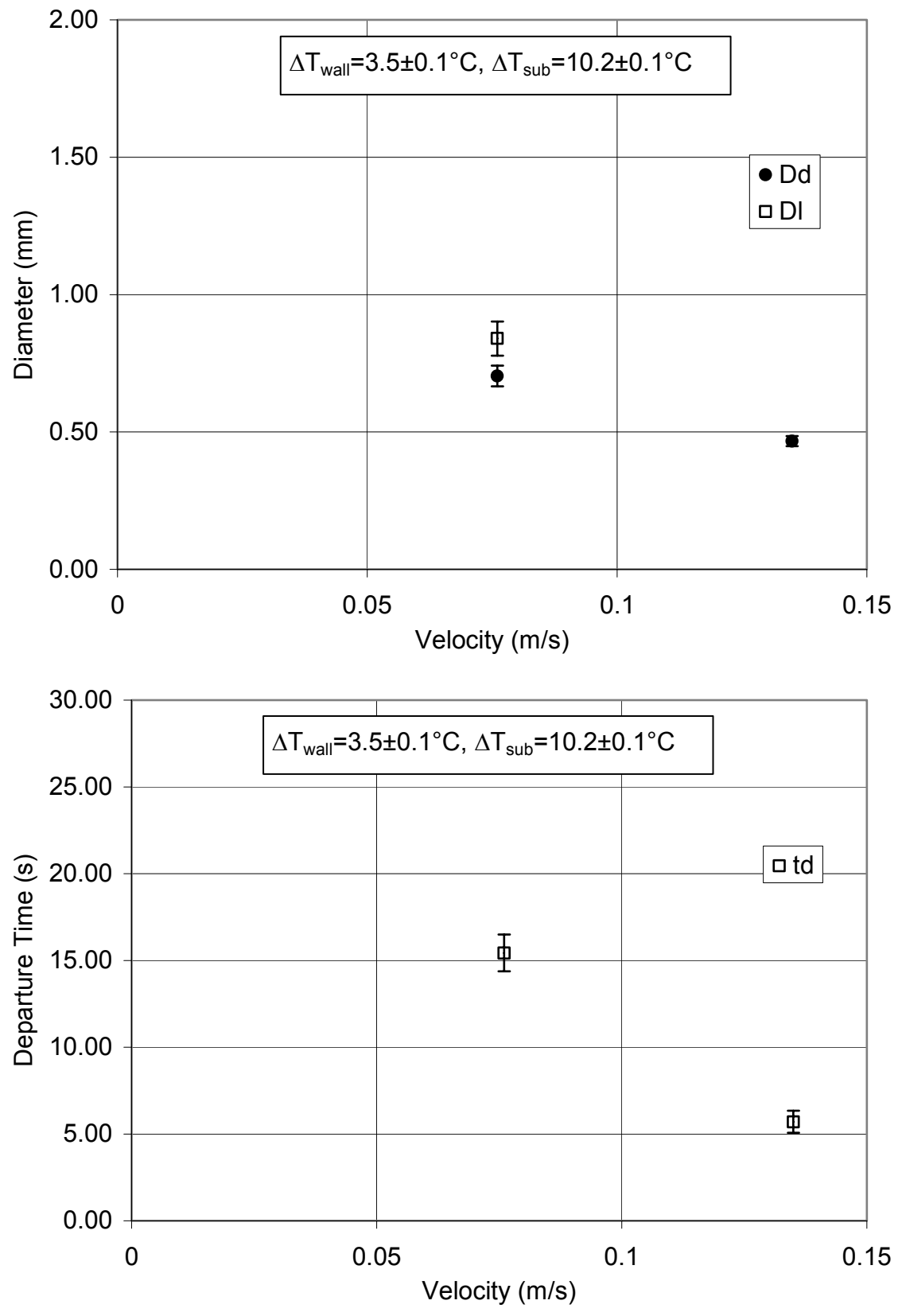

Figure 4-41: Effect of Velocity on Bubble Departure Diameter and Time on Horizontal Surface for $\Delta \mathrm{T}_{\text {wall }}=3.5^{\circ} \mathrm{C}$, and $\Delta \mathrm{T}_{\text {sub }}=5.3^{\circ} \mathrm{C}$

\section{Vertical Upflow}

For the case of vertical surface with up-going flow, one liquid subcooling of $10.3^{\circ} \mathrm{C}$, for a velocity of $0.076 \mathrm{~m} / \mathrm{s}$, and three different wall superheat were tested.

Wall superheats $3.5^{\circ} \mathrm{C}$ 
Figure 4-42 shows the growth and sliding distance data when the wall superheat is $3.5^{\circ} \mathrm{C}$, liquid subcooling is $10.2^{\circ} \mathrm{C}$, and bulk liquid velocity is $0.076 \mathrm{~m} / \mathrm{s}$. The bubble departs at $2.6 \mathrm{~s}$ with a diameter of $0.5 \mathrm{~mm}$. In comparison to that on a horizontal surface, both the departure diameter and time decrease. Furthermore, the bubble slides the whole length of test surface $(50 \mathrm{~mm})$ without lifting off. This is not shown in Figure $4-42$ because the bubble slides out of the view of the camera.
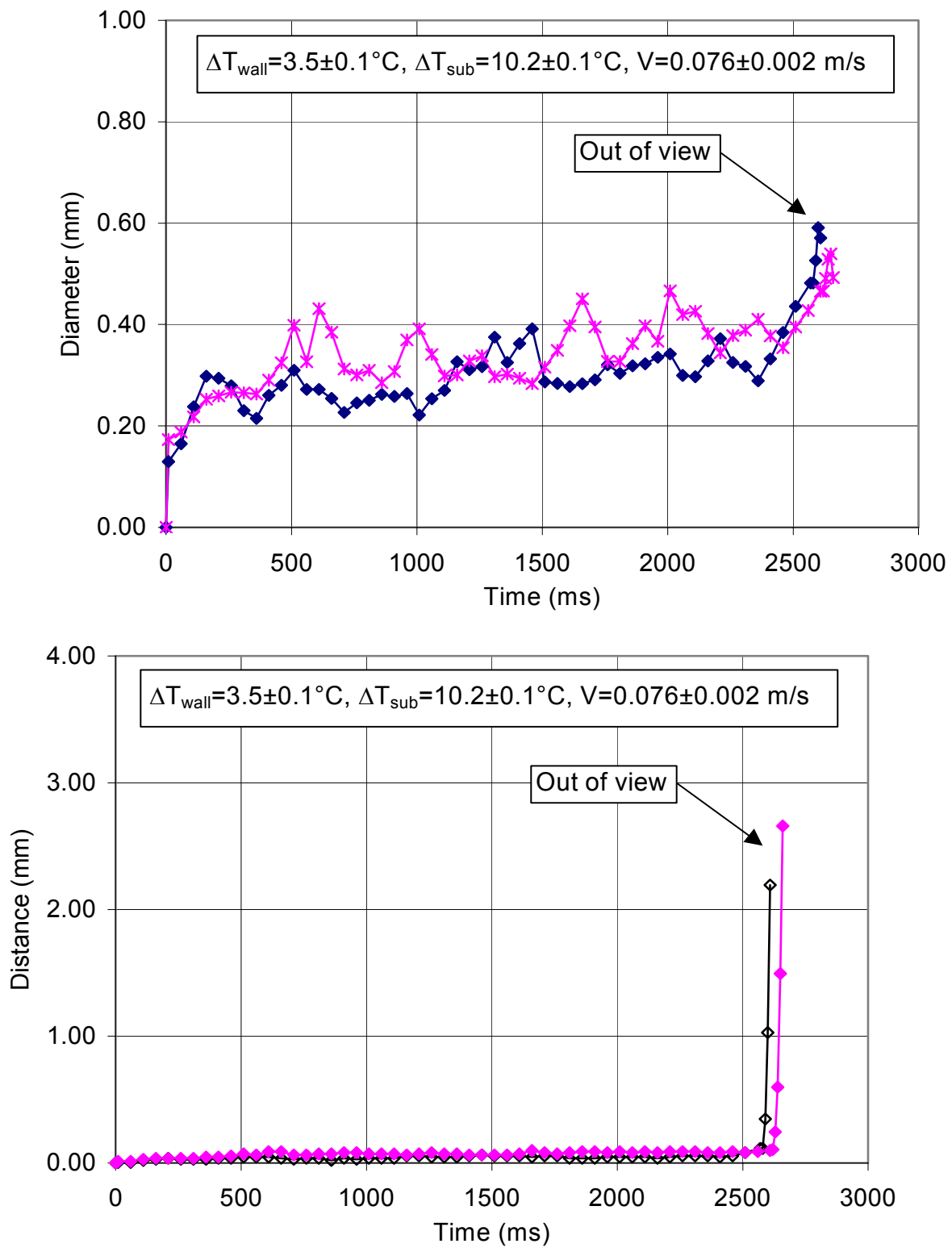

Figure 4-42: Bubble Growth History and Sliding Distance on Vertical Surface for $\Delta \mathrm{T}_{\text {wall }}=3.5^{\circ} \mathrm{C}, \Delta \mathrm{T}_{\text {sub }}=10.2^{\circ} \mathrm{C}$ and $v=0.076 \mathrm{~m} / \mathrm{s}$

Wall superheats $3.0^{\circ} \mathrm{C}$

Figure 4-43 shows the growth and sliding distance curves when the wall superheat is $3.0^{\circ} \mathrm{C}$, liquid subcooling is $10.2^{\circ} \mathrm{C}$, and bulk liquid velocity is $0.076 \mathrm{~m} / \mathrm{s}$. The bubble departs at $6.7 \mathrm{~s}$ with a diameter of $0.5 \mathrm{~mm}$. In comparison to that of wall superheat $3.5^{\circ} \mathrm{C}$, the departure 
time increases. It is also observed that the bubble slides out of the view of the camera before it lifts off.
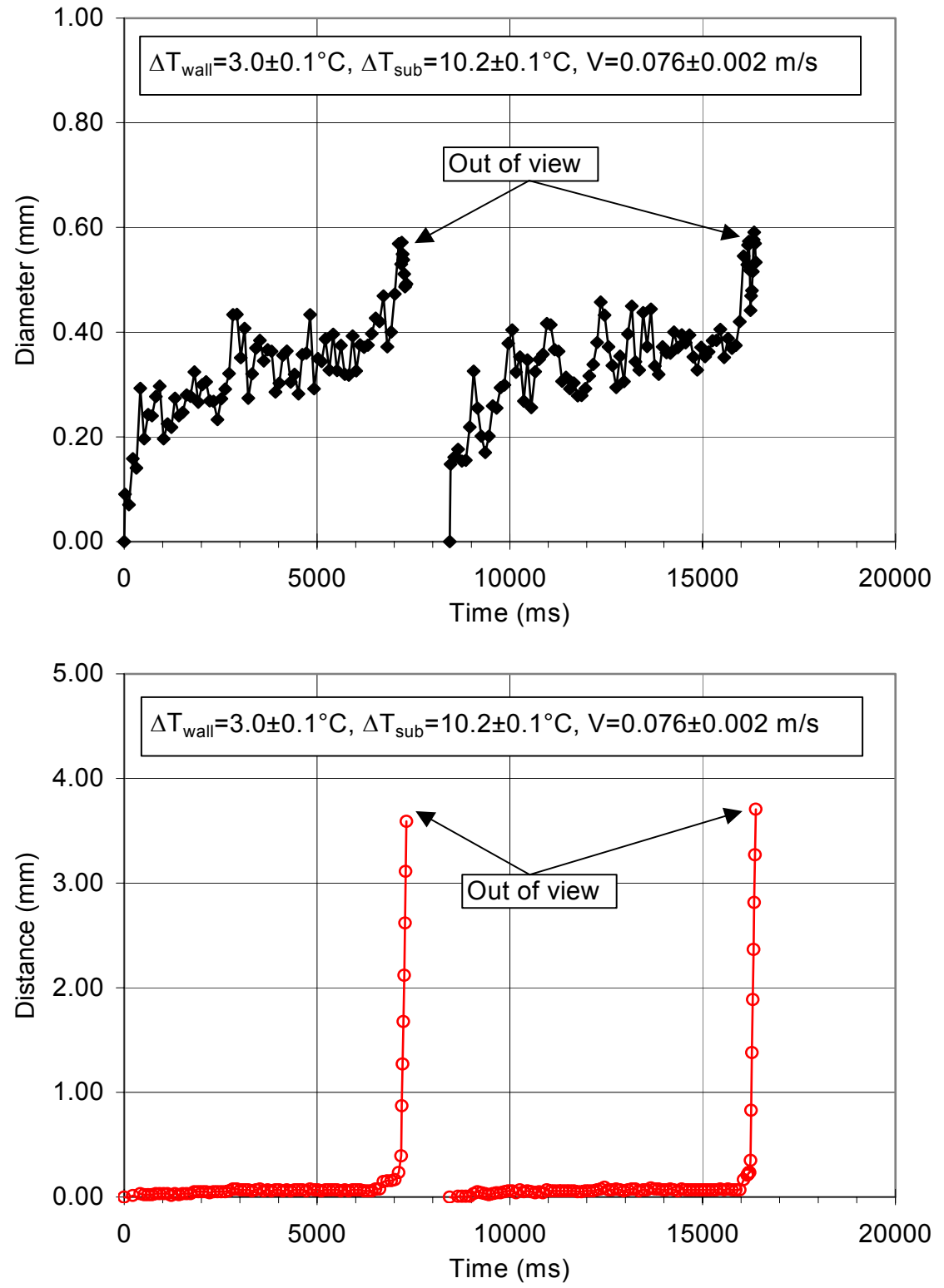

Figure 4-43: Bubble Growth History and Sliding Distance on Vertical Surface for $\Delta \mathrm{T}_{\text {wall }}=3.0^{\circ} \mathrm{C}, \Delta \mathrm{T}_{\text {sub }}=10.2^{\circ} \mathrm{C}$ and $v=0.076 \mathrm{~m} / \mathrm{s}$

Wall superheats $2.0^{\circ} \mathrm{C}$

Figure 4-44 shows the growth and sliding distance curves when the wall superheat is $2.0^{\circ} \mathrm{C}$, liquid subcooling is $10.2^{\circ} \mathrm{C}$, and bulk liquid velocity is $0.076 \mathrm{~m} / \mathrm{s}$. The bubble departs at $15.0 \mathrm{~s}$ with a diameter of $0.4 \mathrm{~mm}$. In comparison to that of wall superheat $3.5^{\circ} \mathrm{C}$, the departure time increases. It is also observed that the bubble slides out of the view of the camera before it lifts off. 

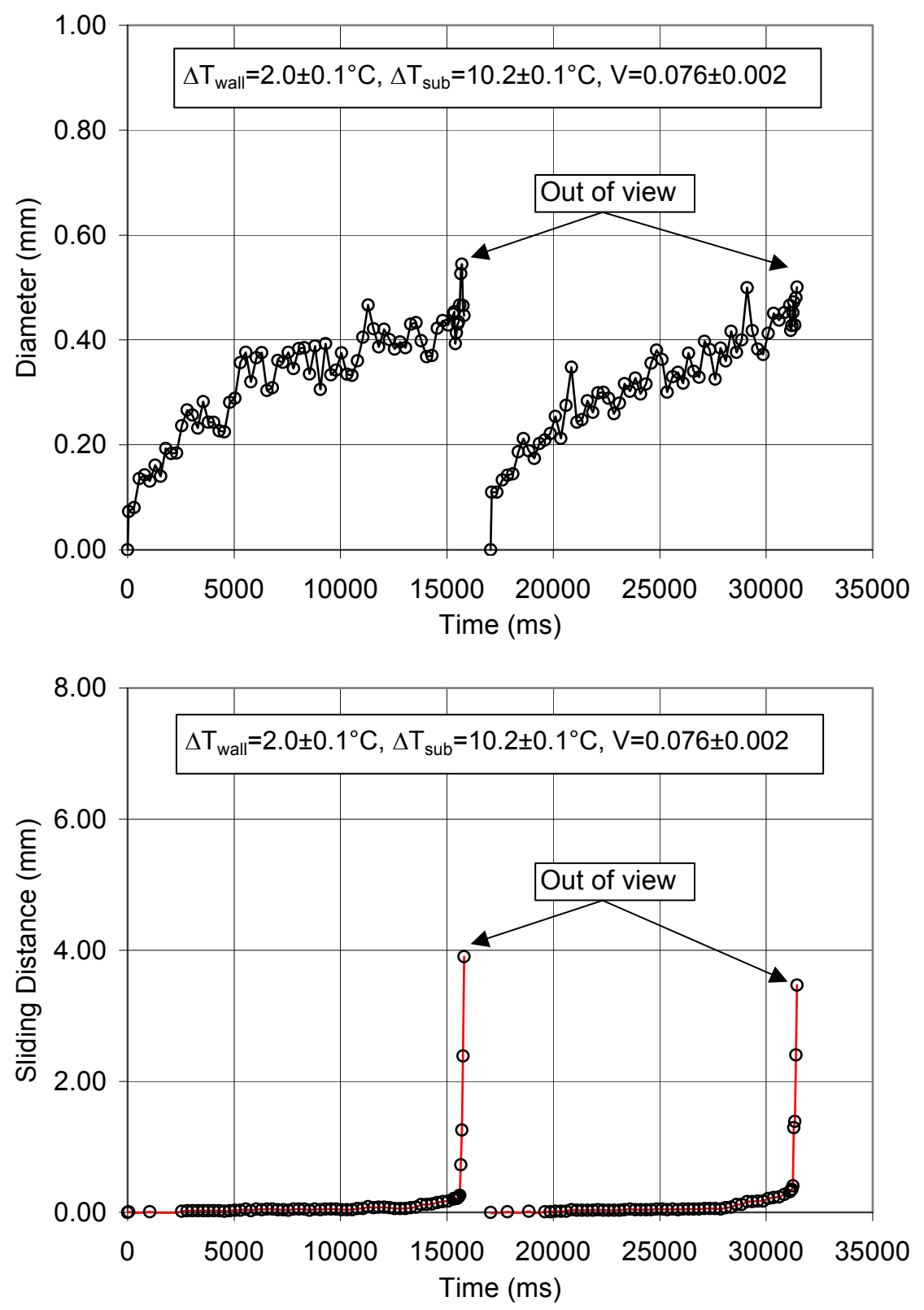

Figure 4-44: Bubble Growth History and Sliding Distance on Vertical Surface for $\Delta \mathrm{T}_{\text {wall }}=2.0^{\circ} \mathrm{C}, \Delta \mathrm{T}_{\text {sub }}=10.2^{\circ} \mathrm{C}$ and $v=0.076 \mathrm{~m} / \mathrm{s}$

\section{Effect of Superheat}

The comparison between the diameter and time at departure has been shown in Figure 4-45. It is observed that there is little effect of wall superheat on departure diameter in the limited range of wall superheats that have been studied while departure time decrease linearly with wall superheat. 

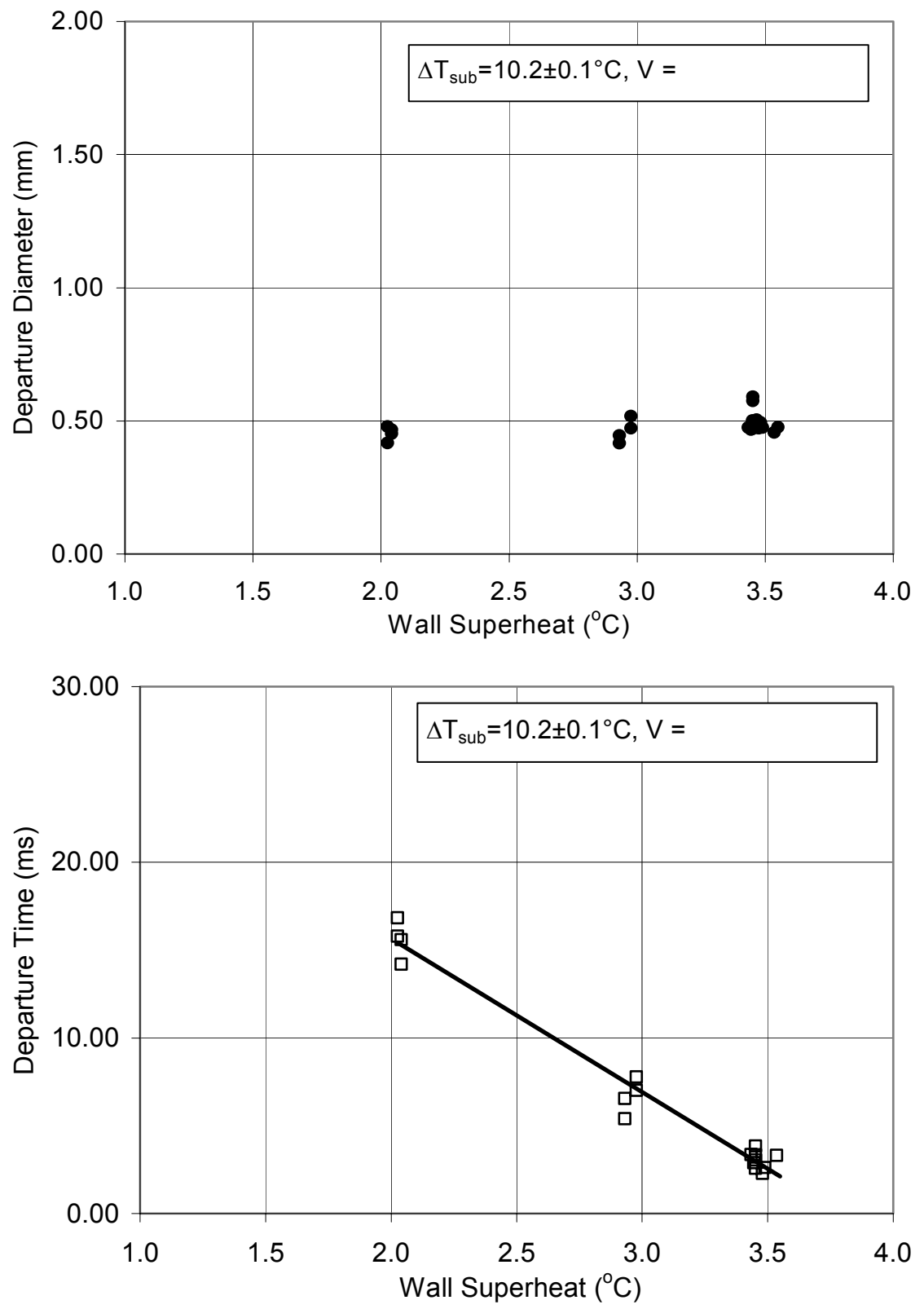

Figure 4-45: Effect of Wall Superheat on Bubble Departure Diameter and Time on Vertical Surface for $\Delta T_{\text {wall }}=3.5^{\circ} \mathrm{C}$, and $V=0.076 \mathrm{~m} / \mathrm{s}$

\subsubsection{Bubble Dynamics in Flow Boiling with Aqueous Solution of Boric Acid}

The effect of the addition of 3,000 ppm by weight of boric acid was examined in vertical flow boiling at two different liquid subcoolings, one is $0.6^{\circ} \mathrm{C}$, and another is $10.2^{\circ} \mathrm{C}$. The wall superheat is $5.3^{\circ} \mathrm{C}$ and bulk velocity is $0.076 \mathrm{~m} / \mathrm{s}$. The results have been plotted in Figure 4-46 and Figure 4-47. 
When the liquid subcooling is $0.6^{\circ} \mathrm{C}$ and the test liquid is DI water, the bubble lifts off from the surface with an average diameter of $2.2 \mathrm{~mm}$ at an average time of $53 \mathrm{~ms}$. The bubble slides along the surface for $8 \mathrm{~mm}$. When the test liquid is 3,000ppm boric acid solution, the bubble lifts off from the surface with an average diameter of $2.1 \mathrm{~mm}$ at an average time of $53 \mathrm{~ms}$. The bubble also slides along the surface for $8 \mathrm{~mm}$. The difference is insignificant as shown in Figure 4-46.
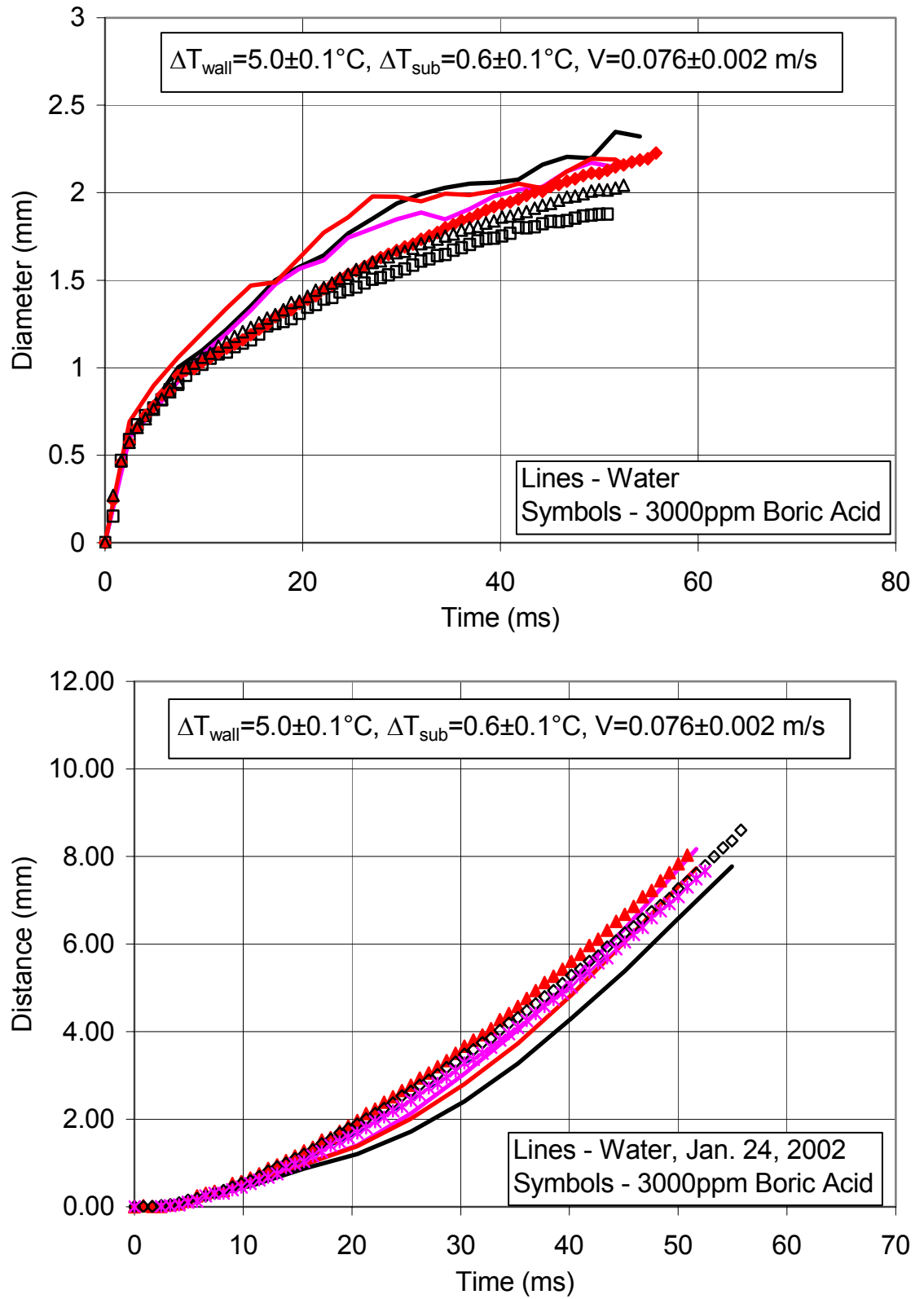

Figure 4-46: Comparison of Bubble Dynamics with DI Water and with Boric Acid Solution - Saturated Condition

When the liquid subcooling is $10.2^{\circ} \mathrm{C}$ and the test liquid is DI water, the bubble departs from the nucleation site with an average diameter of $0.5 \mathrm{~mm}$ at an average time of 3.3 seconds. 
When the test liquid is 3,000ppm boric acid solution, the bubble departs from the nucleation site with an average diameter of $0.5 \mathrm{~mm}$ at an average time of 4.3 seconds. Although there is difference in departure time, the growth curves of two different test liquids almost coincide together as shown in Figure 4-47.

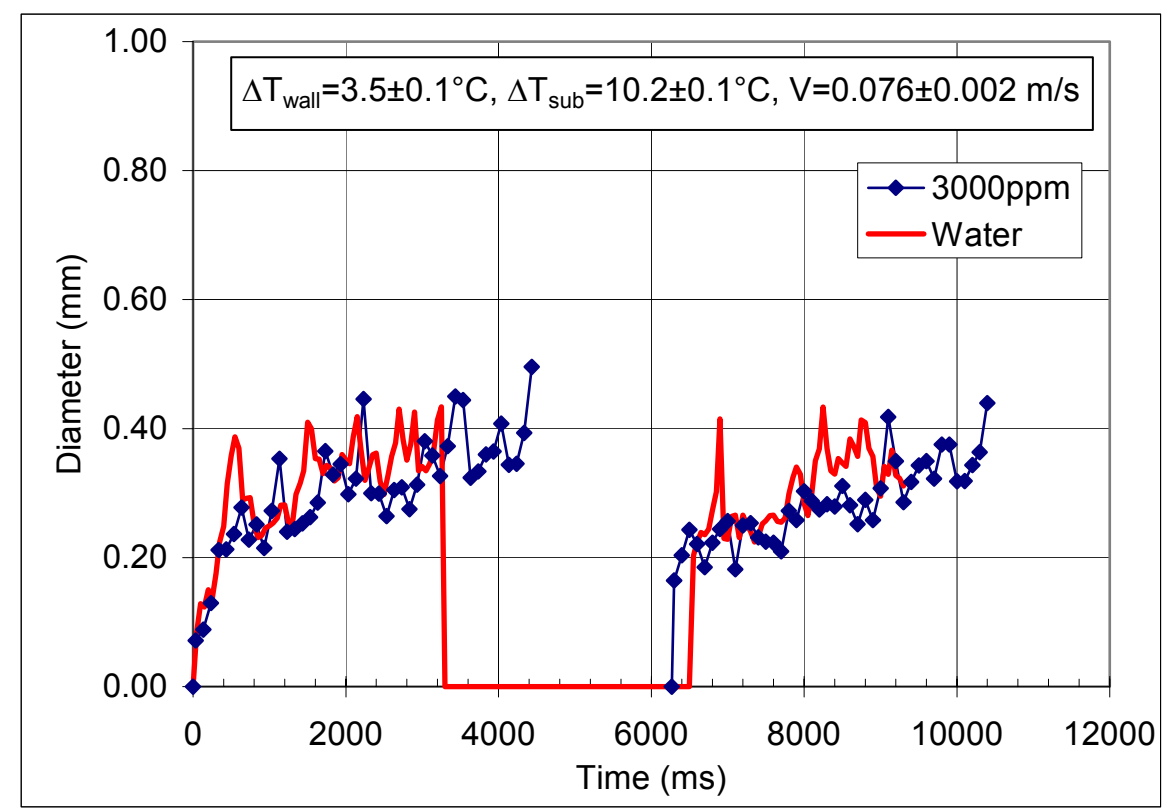

Figure 4-47: Comparison of Bubble Dynamics with DI Water and with Boric Acid Solution - Subcooled Condition

\section{Summary}

The effect of liquid subcooling on the bubble dynamics was first shown. In subcooled flow boiling on horizontal surface, the lift-off diameter decreases first as a parabolic function of subcooling and then reaches its asymptotic value after the subcooling is higher than $5.3^{\circ} \mathrm{C}$. The lift-off time increases as an exponential function of subcooling. Subcooling decreases the bubble's growth rate and causes the oscillation of the bubble. The effects of wall superheat and bulk velocity on the bubble dynamics were also shown with limited data. The higher the wall superheat, the higher the bubble lift-off diameter and the shorter the bubble lift-off time. Departure time as well as departure diameter decreases with increased velocity.

In subcooled flow boiling on vertical surface, lift-off was not observed on the whole length of test surface $(50 \mathrm{~mm})$. In comparison to that on horizontal surface, both the departure diameter and time decrease. As to the effect of wall superheat, departure diameter increases very slightly while departure time decrease linearly with wall superheat.

The effect of the addition of 3,000 ppm by weight of boric acid was examined in vertical flow boiling. Insignificant change in the bubble dynamics was found.

\subsubsection{Concentration Variation}

A miniature sensor for measurement of concentration was developed and calibrated. Concentration variation near the liquid-vapor interface was detected successfully. The measured concentration variations at different radial locations from the center of cavity have the same trend as given by the numerical simulations but the magnitude is much smaller. 


\section{Development of a Miniature Concentration Sensor}

Commercial concentration sensors are normally used to measure the concentration of bulk liquid and are large in size. In current application, concentration variation during a short period $(30-100 \mathrm{~ms})$ around a small bubble (lift-off diameter, 2-3mm) needs to be measured. Therefore, concentration sensor with small measurement volume and short response time must be developed.

\section{Principle}

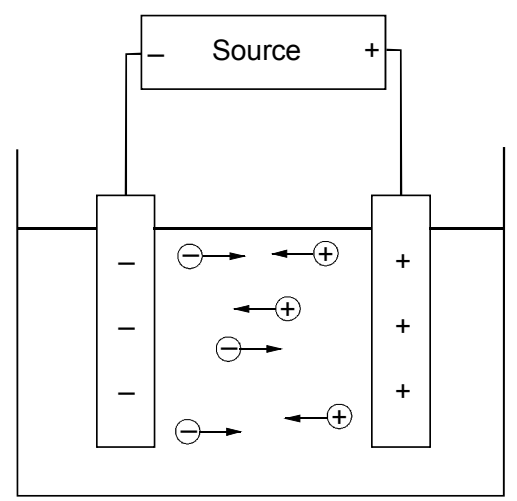

Figure 4-48: Principle of concentration measurement

When two electrodes are inserted into a solution as shown in Figure 4-48, the conductance between these two electrodes is proportional to the number of ions present in the conducting solution. Therefore, a measure of the conductance will give a direct reading of the solution concentration. If DC voltage is applied to the electrodes, the results can be interpreted simply because only the resistance between these two electrodes is included. However, these two electrodes are under continuous oxidizing or deoxidizing condition and the solution composition is changed by electrolysis. If alternating voltage is applied to the electrodes, both resistance between these two electrodes and inductance in the circuit are included, which is quite difficult to be determined. To minimize these problems, low frequency $(0.5 \mathrm{~Hz})$ rectangular wave is utilized. In both positive portion and negative portion of the wave, it can be taken as DC voltage, but the electrodes are under alternating oxidizing or deoxidizing condition.

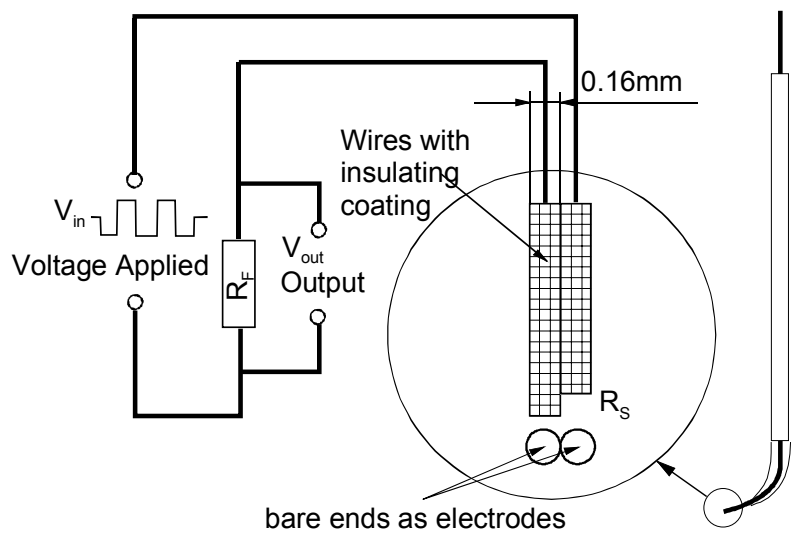

Figure 4-49: Structure of the concentration sensor

The structure of the sensor is shown in Figure 4-49. Two fine copper wires with a diameter of $0.16 \mathrm{~mm}$ serve as the electrodes. The outer surface of the wires was coated with insulating material. The ends are polished and used to conduct current. These two wires were 
bonded together with epoxy glue to fix the distance between the electrodes and then insert into a supporting stainless steel tube.

The circuit to measure the conductance between electrodes is also shown in Figure 4-49. The voltage applied to the electrodes, $V_{i n}$, and the resistance of the reference resistor, $R_{F}$, are known. The output voltage, $V_{\text {out }}$, is measured and recorded by a digital oscilloscope. The conductance $1 / R_{S}$ is related to the output voltage $V_{\text {out }}$ by:

$$
\frac{1}{R_{S}}=\frac{V_{\text {out }}}{\left(V_{\text {in }}-V_{\text {out }}\right) \cdot R_{F}}
$$

The relationship between conductance and the solution concentration needs to be determined by calibration because the exact distance between two electrodes is unknown and is different for different sensors.

\section{Calibration}

The sensor was calibrated dynamically in water at room temperature to study its transient response. It was inserted into aqueous boric acid solution of different concentration and the output was recorded. The results are shown in Figure 4-50. It is seen that it takes $14 \mathrm{~ms}$ for the output to reach its stable value for boric acid solution of $3,000 \mathrm{ppm}$ and $18 \mathrm{~ms}$ for solution of $60,000 \mathrm{ppm}$.
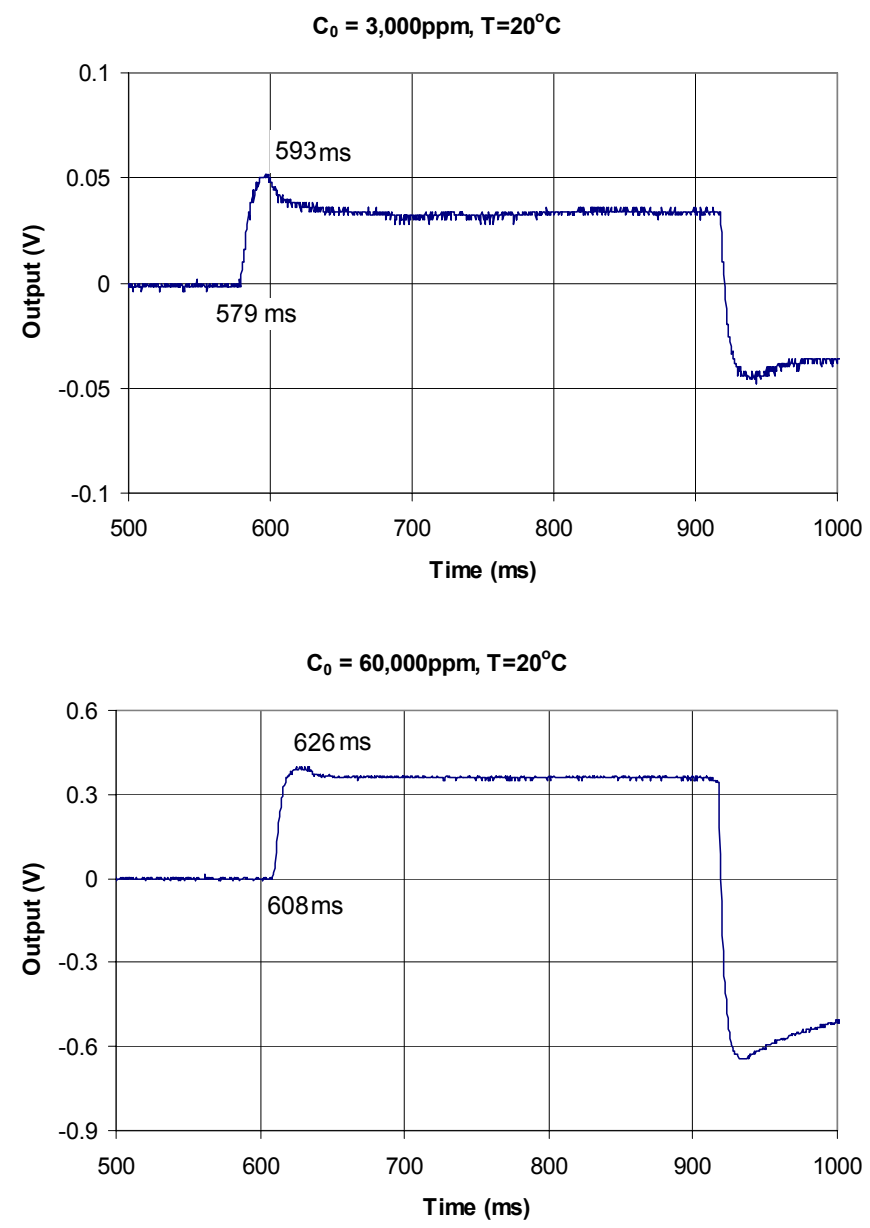

Figure 4-50: Results of dynamic calibration 
Static calibration of the sensor was conducted in boiling aqueous boric acid solution of different concentration because the conductance between two electrodes is also dependent on temperature. At the time of calibration, the output voltage was stable and repeatable as shown in Figure 4-51. When the applied voltage changed from $-6 V$ to $+6 V$, overshoot was observed in the output voltage during the first $1 / 4$ period of the rectangular wave. After the overshoot, stable output voltage is observed and average of the output voltage over a period of 0.5 second is used. The measurement uncertainty of the output voltage is found to be less than $3 \%$.

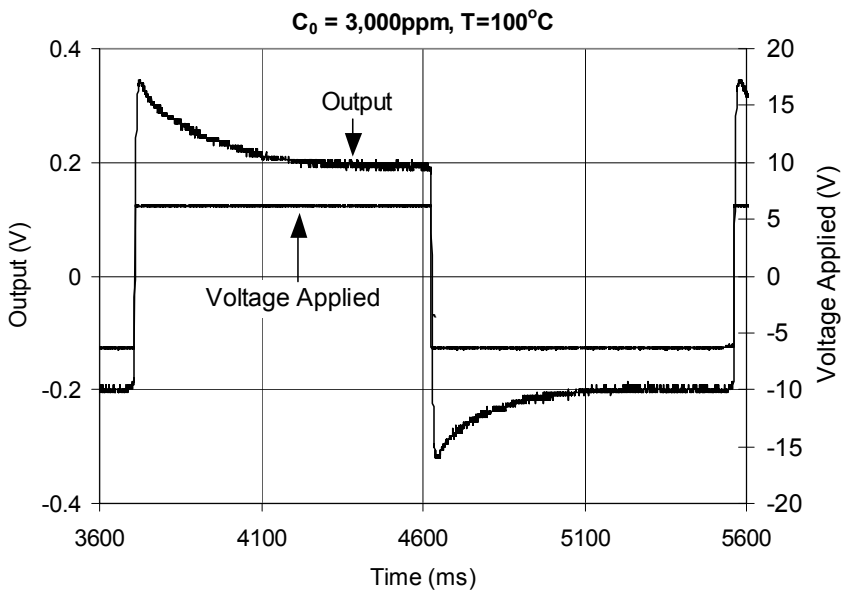

Figure 4-51: Applied voltage and output signal of the concentration sensor during static calibration in boiling solution of boron 
The calibration was carried out for boron concentration varying from $1,000 \mathrm{ppm}$ to $60,000 \mathrm{ppm}$ and results of both output voltage and conductance between the electrodes are shown in Figure 4-52. It can be seen from Figure 4-52 (a) that both output voltage and conductance are linearly related to the concentration when it is less than $10,000 \mathrm{ppm}$. Therefore, output voltage can be used directly to determine the concentration of the solution. At higher concentrations, the conductance is not linearly proportional to the concentration of boron. However, the output voltage continues to be linearly proportional to the concentration when it is less than $60,000 \mathrm{ppm}$ as shown in Figure 4-52 (b). This calibration result is only applicable to a specific sensor being calibrated. New sensor has to be calibrated again because the distance between two electrodes can be different.

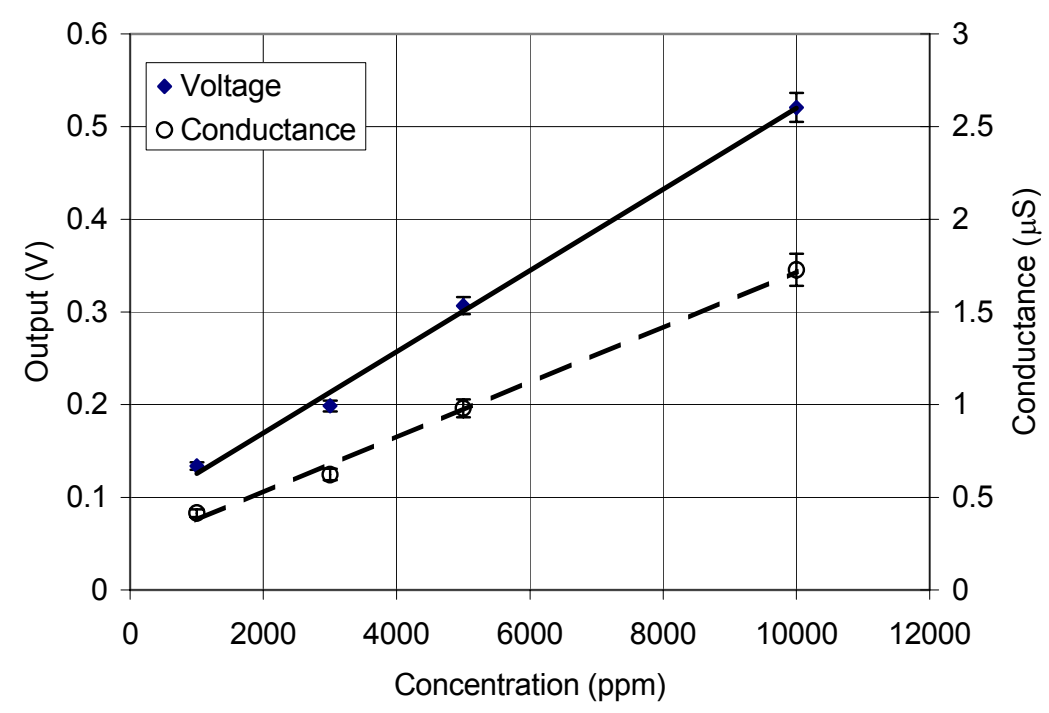

(a)

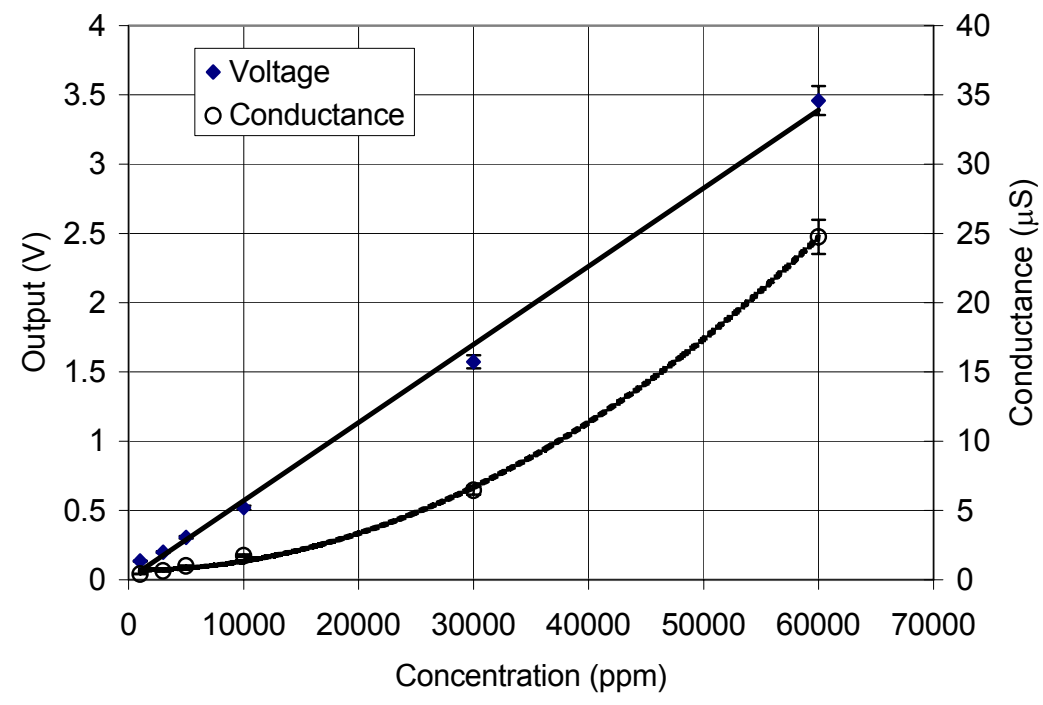

(b)

Figure 4-52: Results of static calibration in boiling solution of boron 


\section{Bubble Dynamics and Concentration Variation}

Single Bubble Dynamics

Partial nucleate boiling experiments with degassed water and boric acid solution were first conducted without the concentration sensor in order to study the effect of boron on the bubble dynamics.

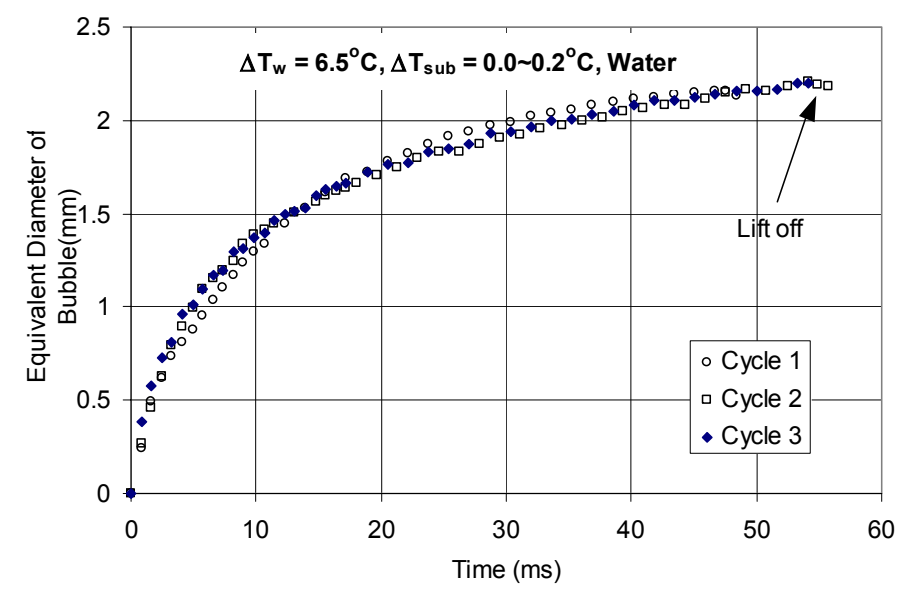

Figure 4-53: Growth rate of single bubbles in water

Figure 4-53 shows the history of equivalent diameter of single bubbles during three growth-departure cycles in nearly saturated water at a wall superheat of $6.5^{\circ} \mathrm{C}$. The equivalent bubble diameter is defined as the diameter of a sphere having the same volume as the bubble. Bubble is seen to lift off when its equivalent diameter is about $2.2 \mathrm{~mm}$. It takes about $55 \mathrm{~ms}$ for the bubble to attain this size. These results agree with those of Qiu and Dhir (2001) obtained on similar surface.

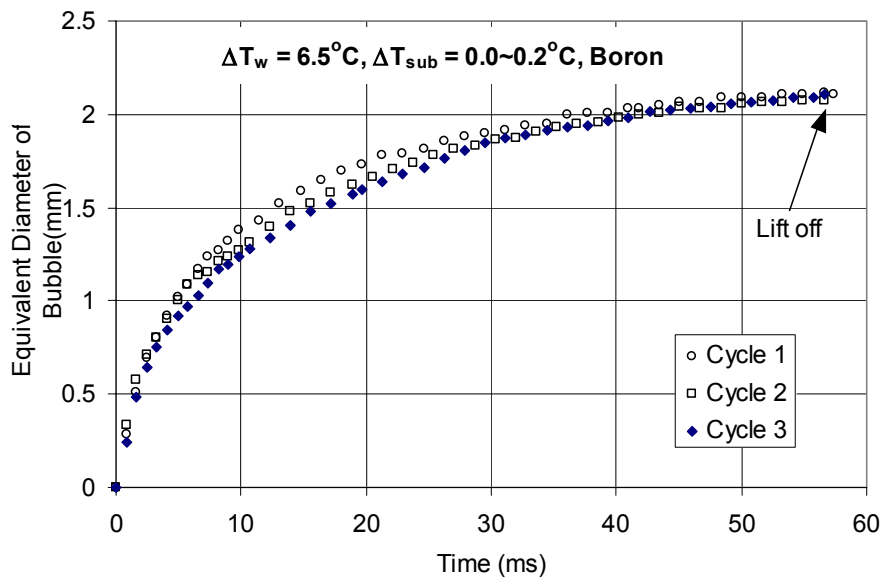

Figure 4-54: Growth rate of single bubbles in 3,000 ppm aqueous boric acid solution

Figure 4-54 shows the history of equivalent diameter of single bubbles during three growth-departure cycles in nearly saturated aqueous solution containing 3,000ppm by weight of boric acid at a wall superheat of $6.5^{\circ} \mathrm{C}$. It was observed that the bubble lifts off when its equivalent diameter is about $2.0 \mathrm{~mm}$. It takes about $57 \mathrm{~ms}$ for the bubble to attain this size. 
Compared to the results for water, there is no significant difference in growth rate, lift off diameter and growth period.

As the contact angle is one of the important parameters that determine the bubble lift-off diameter, the static contact angle was measured by taking photograph of a droplet on the heater surface. It was found to be about $57^{\circ}$ for distilled water and $55^{\circ}$ for $3,000 \mathrm{ppm}$ boric acid solution. The contact angle of water is about the same as that measured by Ramanujapu and Dhir [25] for the same solid-liquid combination.

\section{Variation of Concentration}

After studying single bubble dynamics, the concentration sensor was put into the solution. The electrodes were placed at a location close to the nucleation site $(r=0.26 \mathrm{~mm}, y=0.50 \mathrm{~mm})$. The measurement concentration variation and history of equivalent diameter at a wall superheat of $6.0^{\circ} \mathrm{C}$ and a liquid subcooling of $0.1^{\circ} \mathrm{C}$ are shown in Figure 4-55. Periodical concentration variation can be seen at this location and the period is the same as the bubble growth period. However, compared with the history of equivalent diameter without the sensor in Figure 4-54, the growth of the bubbles is affected by the presence of the sensor. The bubbles have short growth period and small lift off diameter. It was also observed that bubbles were pushed away from the cavity after bubble remained in contact with the sensor for some times.

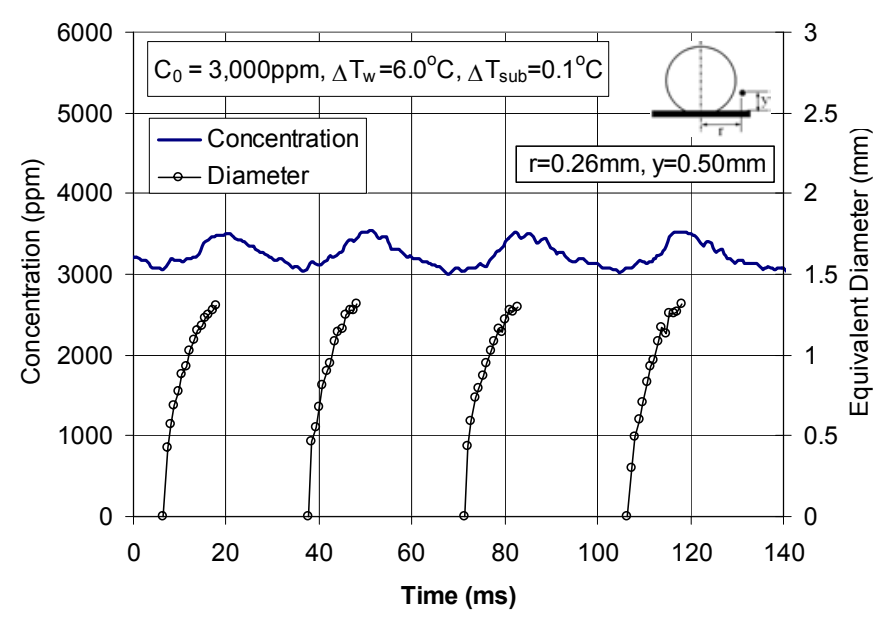

Figure 4-55: Concentration change during the growth-departure cycles of single bubbles

$$
\text { for } \Delta T_{w}=6.0^{\circ} \mathrm{C} \text { and } \Delta t_{s u b}=0.1^{\circ} \mathrm{C}
$$

Higher bubble growth rate can reduce the influence of the sensor on the growth of bubbles; therefore high wall superheat was selected. Figure 4-56 shows the measured concentration change during the growth-departure cycles of single bubbles in an aqueous boric acid with a concentration of $3,000 \mathrm{ppm}$ at a wall superheat of $10.8^{\circ} \mathrm{C}$. The concentration sensor is located near the wall at $2.0 \mathrm{~mm}$ away from the cavity $(r=2.0 \mathrm{~mm}, y=0.2 \mathrm{~mm})$. During the whole lifetime of the bubble, the sensor did not penetrate into the liquid-vapor interface. History of equivalent diameter of bubbles and distance from the interface to the sensor during two growth-departure cycles are also included in Figure 4-56. It shows that the concentration increases as the liquid-vapor interface approaches the sensor and decreases as the interface moves away. A time lag between the maximum concentration and the minimum distance between the interface and the cavity is observed in the data. This is probably because of the response time of the sensor. In a magnified scale, the variation of concentration with distance of 
the interface from the electrodes is shown in Figure 4-57 after eliminating the time lag. It indicates gradient of boron concentration exists near the liquid-vapor interface.

Concentration measured at different locations $(r=2.0,2.5,3.0 \mathrm{~mm} ; y=0.2 \mathrm{~mm})$ is shown in Figure 4-58. The measured concentration variation during a growth-departure cycle decreases with the distance from the cavity. This trend is similar to the numerical results of Bai and Dhir (2001). Bai and Dhir calculated a concentration increase of 300,000ppm at a location of $r=$ $0.21 \mathrm{~mm}, y=0.01 \mathrm{~mm}$, however it reduces to about $140,000 \mathrm{ppm}$ at a location of $r=0.26 \mathrm{~mm}, y=$ $0.14 \mathrm{~mm}$. The measured increase in concentration is much smaller in comparison to that obtained from numerical results. The probable cause is the larger volume which is involved in the probe measurements. The concentration variations during the growth-departure cycle at different locations are similar to each other but the magnitude of the variation decreases with increase in distance from the cavity.

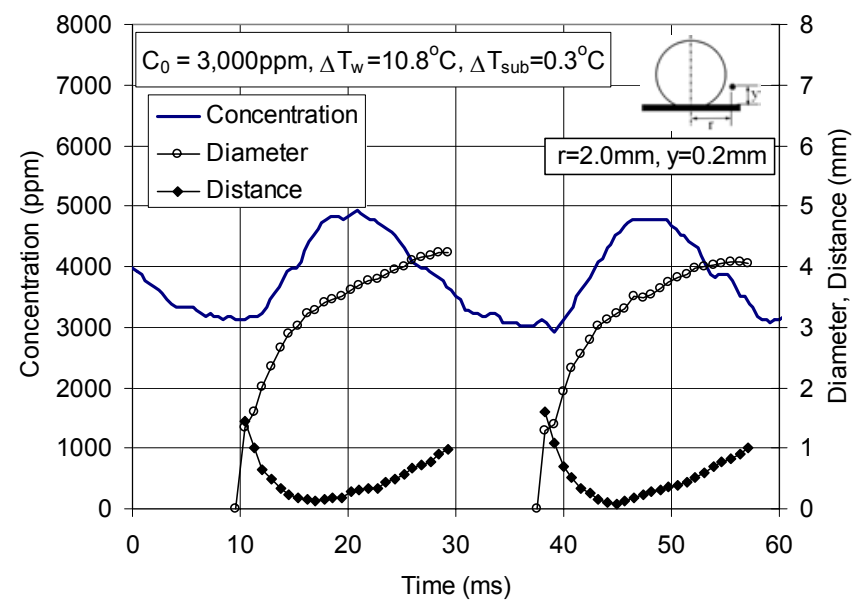

Figure 4-56: Concentration change during the growth-departure cycles of single bubbles for $\Delta T_{w}=10.8^{\circ} \mathrm{C}$ and $\Delta t_{\text {sub }}=0.3^{\circ} \mathrm{C}$

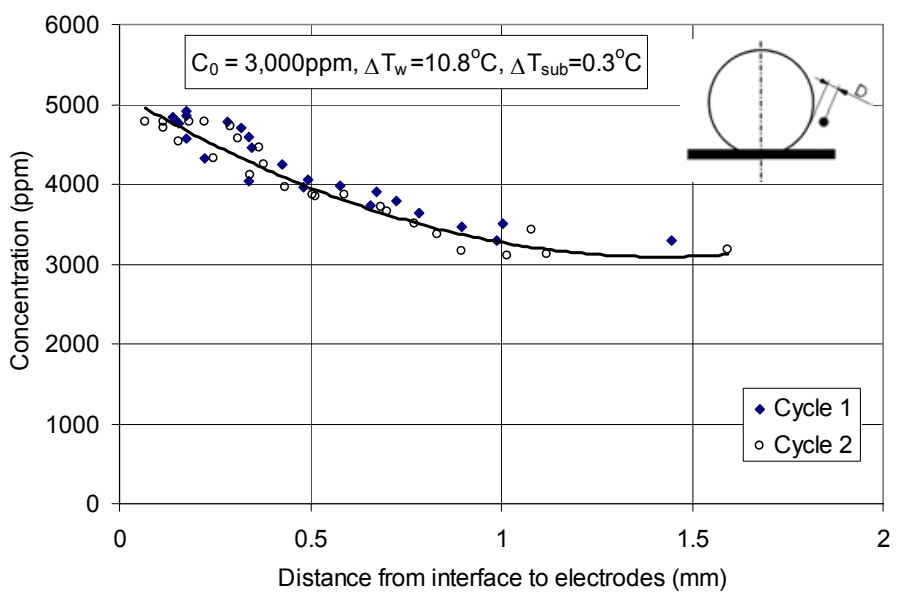

Figure 4-57: Measured concentration vs. Distance from interface to electrodes 


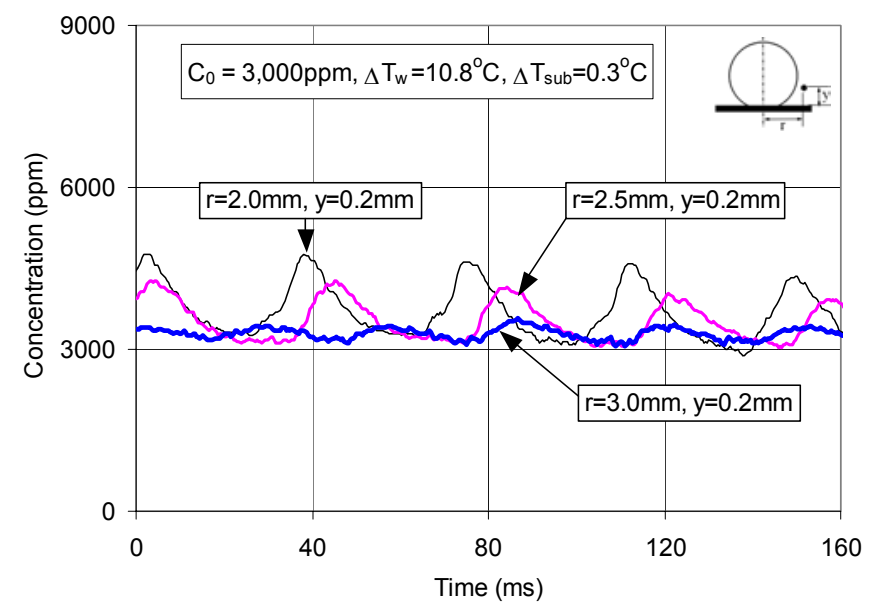

Figure 4-58: Concentration variation during the growth of bubbles at different location

\section{Comparison with Numerical Simulation}

In Figure 4-59, the change in concentration at a location $r=0.26 \mathrm{~mm}, y=0.14 \mathrm{~mm}$ as obtained from numerical simulations is plotted along with the experimental observation for $r=$ $2.00 \mathrm{~mm}, y=0.20 \mathrm{~mm}$. Although the distance from the cavity in the experiments is much larger than that used in the numerical simulations, the observed changes in concentration are much more gradual and the magnitude of the increase in concentration is much smaller. Two reasons are possible for this difference in behavior. First is that values reported from numerical simulations are point values whereas the sensor gives an average value over a small volume of liquid. Secondly, as noted in the sensor development section, the sensor takes on the order of 10 ms to fully respond to the changes in concentration. Further validation of the results for numerical simulation would be possible if the predicted concentrations over a small volume rather than at a point were evaluated. However, the smoothing of the profile because of delayed time response of the sensor would continue to be source of discrepancy between the results of numerical simulations and data.

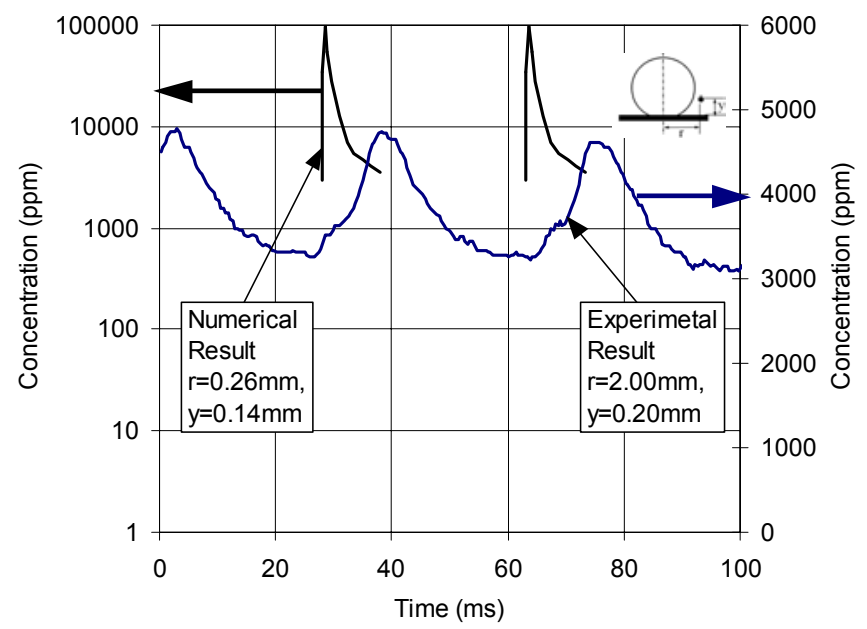

Figure 4-59: Comparison of simulated and measured concentration variation during the growth of bubbles at different location 


\subsubsection{Deposition of Boron near the Cavity}

Subcooled flow boiling experiments with Boron in the liquid to determine the precipitation at a single nucleation site on the heated surface were conducted. Single bubbles were generated at a micro-fabricated cavity on a polished silicon surface. An aqueous solution containing 3,000ppm by weight of boric acid was used as the working liquid. Boron deposition was found to occur at downstream region of the nucleation site as shown in Figure 4-60 (a). It can be seen that boron deposition along the periphery of the deposition area is thick and the size of the deposition area in Figure 4-60 (a) is approximately equal to the diameter of the bubble base in Figure 4-60 (b). This experiment result validates the numerical results, which indicated that precipitation of boron could occur near the advancing and receding liquid-vapor interface.

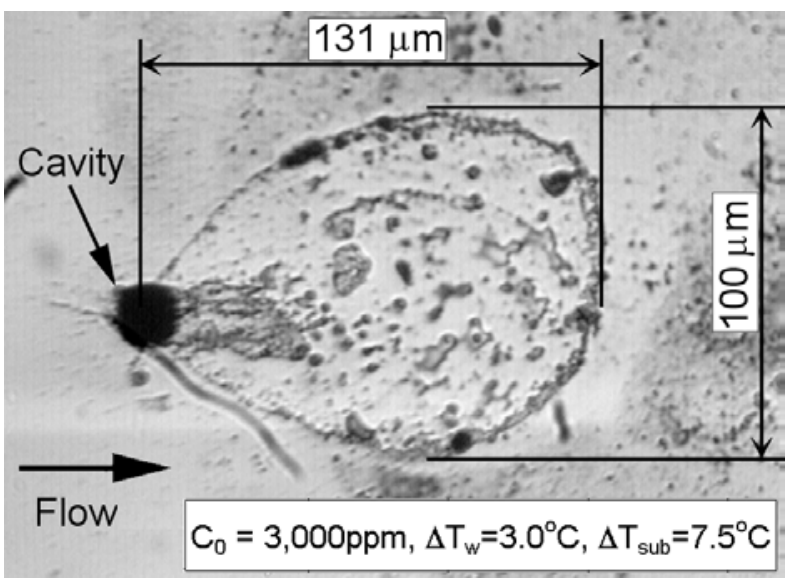

(a)

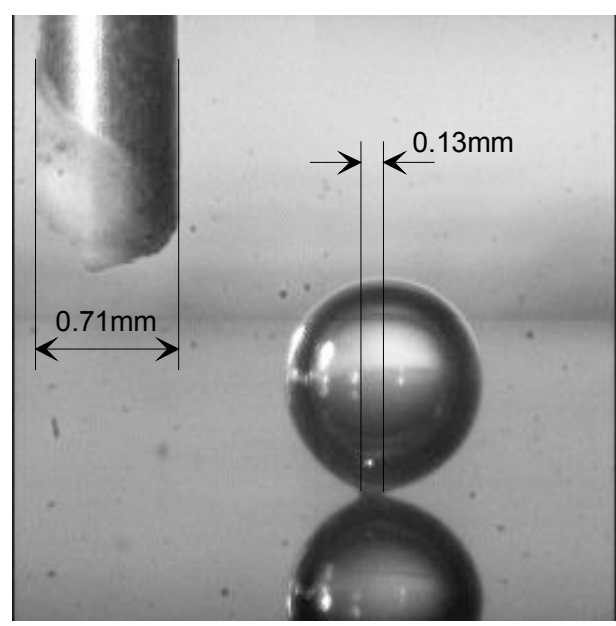

(b)

Figure 4-60: Boron deposition in subcooled flow boiling on horizontal surface for 3 hours

Figure 4-61 shows the boron deposition in subcooled flow boiling on vertical surface. Boron deposition is only found along the periphery of a deposition area downstream of the nucleation site. It is also noted that the boron deposition on vertical surface is less than that on horizontal surface. This may be resulted from the difference in bubble dynamics for these two cases. On horizontal surface, bubble stays on the surface for about 20 seconds before lifting off and new bubble comes out after about 1.5 seconds. On vertical surface, bubble stays on the surface for about 4 seconds before lifting off and new bubble comes out after about 1.5 seconds too. The ratio between deposition period and the period for dissolution back into the liquid on horizontal surface is 13.3 to 1 and it is 2.6 to 1 on vertical surface. 


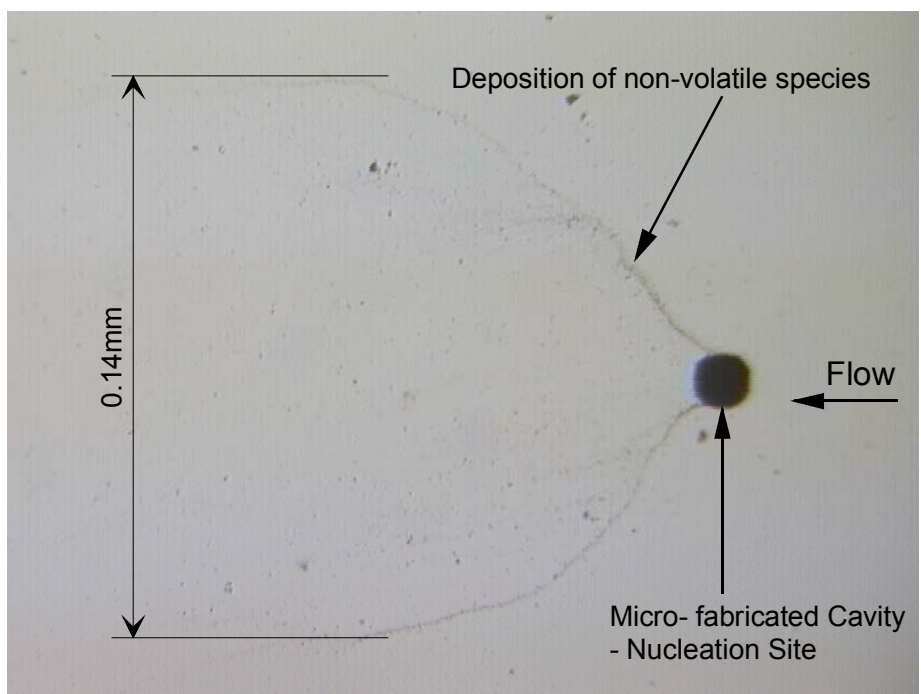

Figure 4-61: Boron deposition in subcooled flow boiling on vertical surface for 3 hours,

$$
\Delta T_{w}=3.5^{\circ} \mathrm{C} \text { and } \Delta T_{\text {sub }}=10.2^{\circ} \mathrm{C}
$$

Deposition was also found near the nucleation site even when the test liquid was DI water as shown in Figure 4-62. The source of the deposition should be the non-volatile species came into the DI water from the tank and the tubing network. Evidence is that the conductivity of the DI water before the experiment was $1.06 \mu \mathrm{S} / \mathrm{cm}$ at $22.5^{\circ} \mathrm{C}$ and it increased to $1.82 \mu \mathrm{S} / \mathrm{cm}$ at $23.2^{\circ} \mathrm{C}$ after the experiment.

The amount of the deposition shown in Figure 4-62 is higher than that of boron for the same experimental conditions shown in Figure 4-61. Furthermore, the deposition of boron is easy to be swept away with wet cotton swab; however, the deposition of non-volatile species in water can only be cleaned with flowing hot water for a long time or with hydrofluoric acid. It tells us that the strength of adhesion between the precipitation of different non-volatile species and the surface is different. This should be considered in the numerical model to simulate the deposition of non-volatile species.

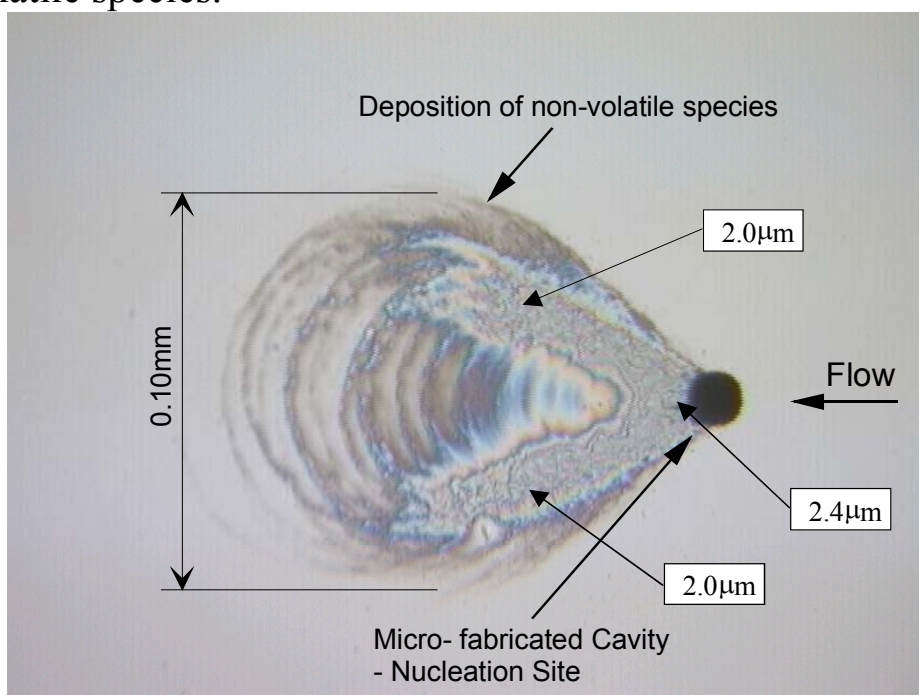

Figure 4-62: Deposition of non-volatile species in subcooled flow boiling with DI water on vertical surface for 3 hours, $\Delta T_{w}=3.5^{\circ} \mathrm{C}$ and $\Delta T_{\text {sub }}=10.2^{\circ} \mathrm{C}$ 


\subsection{Nine Rod Bundle with Zicalloy-4 Cladding}

Subcooled boiling experiments with different flow rates, subcooling, and contact angles were performed as part of this study. The flow conditions are listed in Table A.1 in Appendix A. The contact angles measured at the start of each experiment are also given in Table A.1. Results obtained for variables measured are discussed in detail in the following section.

Additionally tests were also performed with boron added to the water. The concentration of boron in the water was fixed at $7000 \mathrm{ppm}$. The test conditions for these tests are listed in Table A.2 in Appendix A. These tests with boron were performed to investigate the formation of crud on the heating surface and its effects on the overall heat transfer, active nucleation site density distribution, onset of nucleate boiling, and onset of significant void. Three sets of experiments were performed for the same set of operating conditions. In each set of experiments, keeping the mass flux and inlet subcooling fixed, the heat flux was varied from $1.9 \mathrm{~W} / \mathrm{cm}^{2}$ to $29.3 \mathrm{~W} / \mathrm{cm}^{2}$.

\subsubsection{Nine Rod Bundle with Water}

\section{(i) Wall heat flux $\left(q_{w}\right)$}

The wall heat flux for the nine rod bundle was calculated by dividing the input power by the surface area. The input power was obtained from the measured input current $(I)$ and the voltage drop $(V)$ across the rod bundle (i.e., power $=I_{\text {total }} V=I^{2} R$, where $R$ is the resistance of each rod). Each rod has a surface area $\left(A_{S}\right)$ of $327 \mathrm{~cm}^{2}$. The heat flux can then be expressed as

$$
q_{w}=\frac{I^{2} R}{A_{s}}
$$

The uncertainty in the calculated wall heat flux arises mainly due to variation in the thickness of the $\mathrm{Zr}-4$ cladding. The resistance of a rod can be expressed as

$$
R=\rho \frac{l}{A_{c}}
$$

where $R$ is the resistance, $\rho$ the electrical resistivity of the material, $l$ is the length of the rod, and $A_{c}$ the cross sectional area. From eqn. (41) it is evident that any local variation in $A_{c}$ will change the local resistance value which in turn will change the local heat generation rate. From the calibration of the rods (described in the following section) the uncertainty in $q_{w}$ is estimated to be about $8 \%$.

\section{(ii) Wall temperature $\left(T_{w}\right)$}

The wall temperature of the rods are measured from the miniature thermocouples placed inside the cladding at different axial locations. Each of these thermocouples were calibrated before being placed inside the rod. Once they were placed inside the rod, each rod was then individually calibrated. The calibration procedure involved performing natural convection experiments with the rod being placed horizontal and heated electrically. During this calibration process, the voltage drop across the rod, the copper bus bars, and total length of the rod (rod and copper bus bars) were also measured. This was used to account for the end losses. The temperature of the rod was monitored till steady state condition was achieved (approximately two to three hours). Each rod was tested for two different power levels. At steady state, since the heat generation is only in the cladding, the inside temperature (of the lava inserts) will reach a constant value. Since the thermocouples are placed at the inner wall, temperature corrections are 
required to account for the temperature drop occurring in cladding. In order to determine this temperature correction, a one-dimensional heat conduction calculation was performed to determine the temperature distribution within the cladding.

Assuming the inner surface of the cladding to be insulated while the outer surface to be exposed to a prescribed heat transfer coefficient (corresponding to natural convection in air) and assuming volumetric heat generation $\left(Q_{v o l}=I^{2} R\right)$ within the cladding, the temperature distribution in the cladding can be expressed as

$$
T(r)=-\frac{1}{2} \frac{Q_{v o l}}{k_{Z r}} r^{2}+C_{1} \ln (r)+C_{2}
$$

where $r$ is the radius distance, $k_{Z r}$ is the thermal conductivity of the cladding, and $C_{1}$ and $C_{2}$ are constants determined from the imposed boundary conditions. From eqn. (42) the temperature difference between the outer $\left(r_{o}\right)$ and inner $\left(r_{i}\right)$ boundaries can be expressed as

$$
T\left(r_{o}\right)-T\left(r_{i}\right)=-\frac{1}{2} \frac{Q_{v o l}}{k_{Z r}}\left(r_{o}^{2}-r_{i}^{2}\right)+C_{1}\left[\ln \left(r_{o}\right)-\ln \left(r_{i}\right)\right]
$$

where

$$
C_{1}=\frac{1}{2} \frac{Q_{v o l}}{k_{Z r}} r_{i}^{2}
$$

From eqn. (43) it can be seen that the temperature difference between the outer and inner walls varies as the square of the input current. Thus, for each calibration run, the steady state temperature measured at the inner wall of the cladding was corrected using the correction given by eqn. (43). For example, the temperature correction will be $0.3{ }^{\circ} \mathrm{C}$ for $I=100 \mathrm{~A}$ and $1.3{ }^{\circ} \mathrm{C}$ for $I$ $=200 \mathrm{~A}$.

Figure 4-63 shows the typical axial variation of the heater surface temperature for the nine rod bundle. The uncertainty in the measured wall temperatures is $\pm 0.2^{\circ} \mathrm{C}$. The wall temperature data for the rod bundle experiments are included in Appendix B.

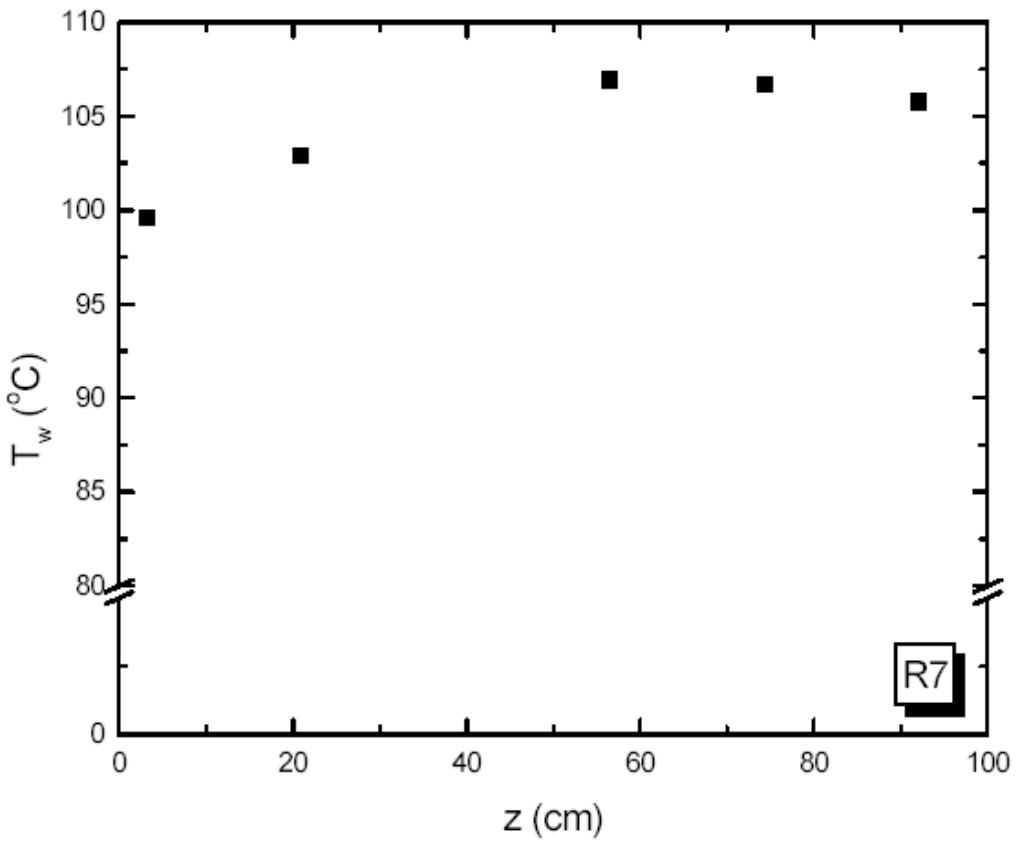

Figure 4-63: Axial variation of heater surface temperature (test case R7) 
Several single phase test cases were also run for rod bundles specially to get some information for the heat transfer coefficient, keeping in mind the scarcity of data available in the literature in this regards in the range of parameters of interest. As such flow rates were varied from $336 \mathrm{~kg} / \mathrm{m}^{2} \mathrm{~s}$ to $2800 \mathrm{~kg} / \mathrm{m}^{2} \mathrm{~s}$ and liquid subcooling at inlet varied from 20 to $70{ }^{\circ} \mathrm{C}$ to take into account the dependency of $h_{\mathrm{sp}}$ on Reynolds number and Prandlt number respectively. Figure 4-64 shows the axial variation of heat transfer coefficient for the central rod (rod 2) one of the corner rods (rod 9) facing the central subchannel and a corner rod facing the wall (rod 4). For the rod arrangement and thermocouple placement in the rods, refer to the cross sectional drawing in Chapter 2. As seen in the cross sectional drawing, rod 2 is the central rod, with thermocouples placed one facing the smallest gap region (referred to as r2_1) and one facing the largest gap between rods. It is found as shown in Figure 4-64 the heat transfer coefficient is enhanced by about $16.0 \%$ for $\mathrm{r} 2-1$ and by $14.0 \%$ for rod 9 over the correlation for a tube with equivalent hydraulic diameter of the central channel. The thermocouples facing the wall as is the case of rod 4 and rod 7 gives lower heat transfer coefficient. This is the same result as obtained by Khattab [33]. who showed that the heat transfer coefficient around a rod in the central subchannel is higher than that of a rod placed at the corner of the channel. In this work, all the other rods with thermocouples facing central subchannels gives heat transfer coefficient higher than that obtained from Dittus-Boelter correlation varying from $12.0 \%$ to $14.0 \%$. Weisman's [34] correlation, however, for square rod bundle arrays with $P / D$ ratio of 1.283 as is the present case, gives an enhancement of $30.0 \%$ over the Dittus Boelter correlation.

From the single phase experiments conducted for rod bundle arrays over a wide range of mass flux it was seen that the $N u$ dependency on $R e$ is same as the tube correlation as has been stated by past studies(e. g Weisman [34]). Figure 4-65 shows the plot for $\mathrm{Nu} / \mathrm{Pr}^{0.4}$ values for Rod 2 _ with $0.023 R e^{0.8}$, for Re varying from 8000 to 95,000 . The experimental values have the same dependency on Reynolds number as that of the standard correlation since a straight line can be drawn with the lead coefficient increased. This graph shows clearly that the experimental values are approximately $16 \%$ higher than that of the standard correlation. All the other rods facing the central channel shows an enhancement of $N u$ by $12-15 \%$ over that given by the standard correlation, whereas the rod 4 and 7 facing the wall indicated a reduction of about 5\% from the standard correlation.

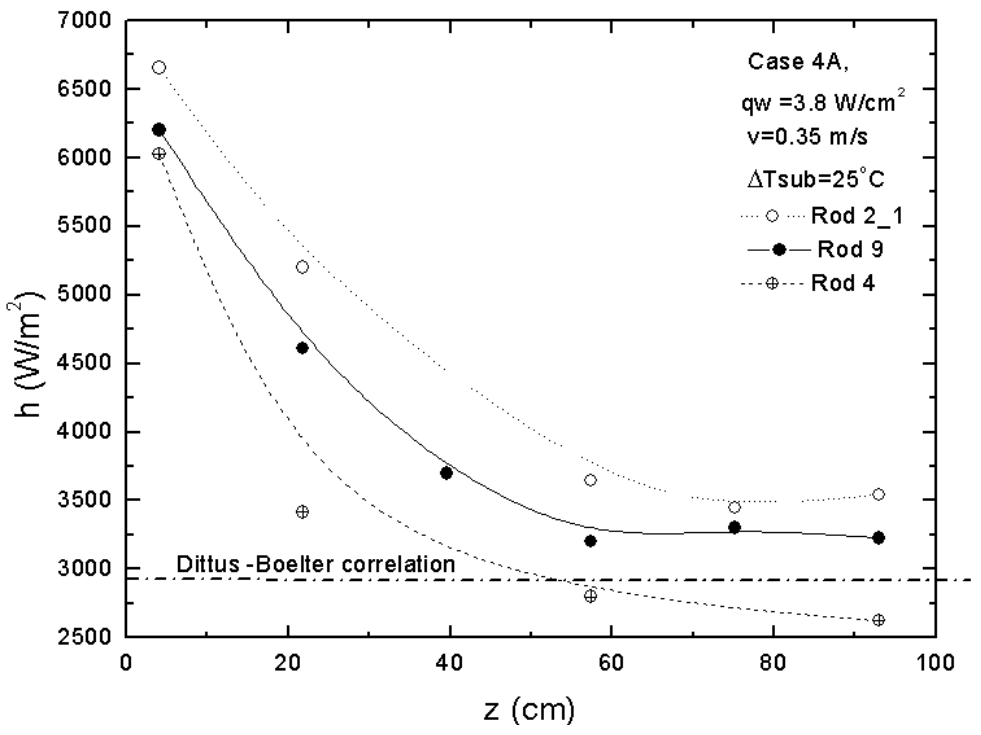

Figure 4-64: Axial variation of single-phase heat transfer coefficient for rod bundle. 


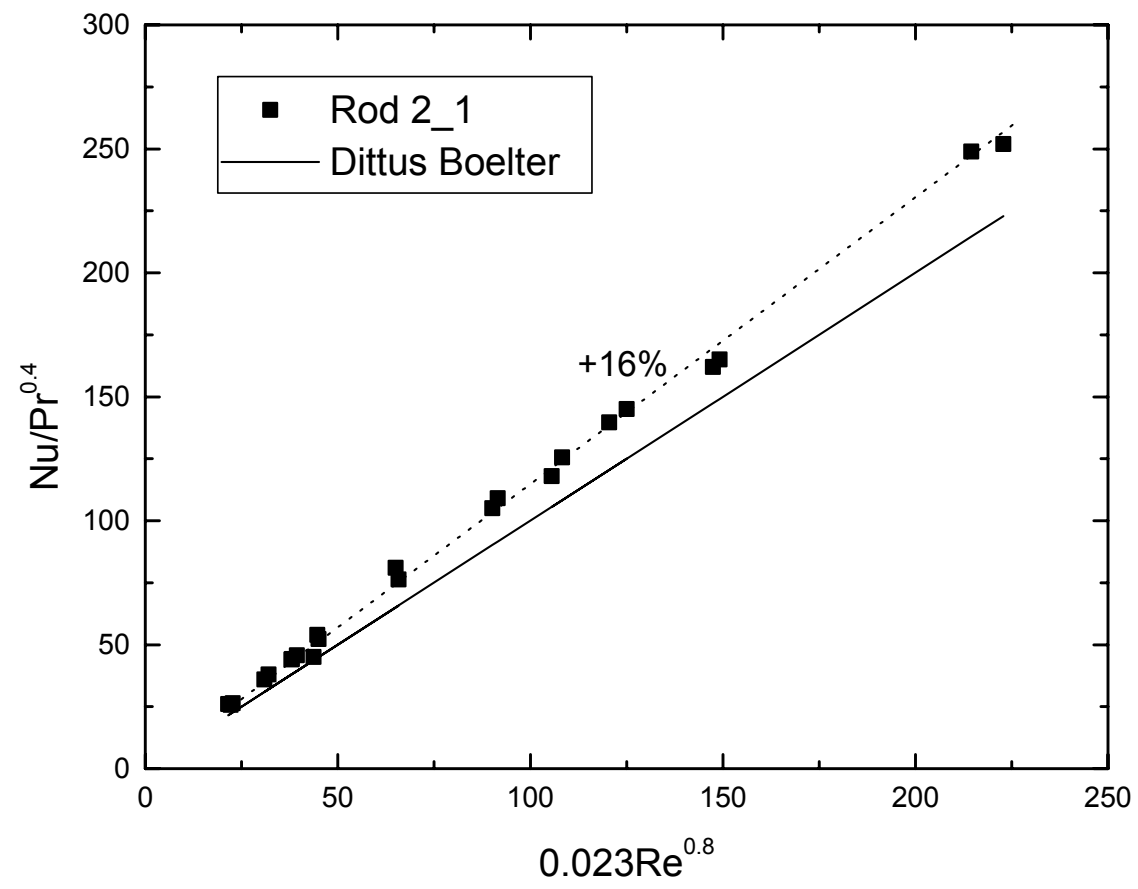

Figure 4-65: Nusselt number variation with Reynolds number for the central rod.

\section{(iii) Onset of nucleate boiling (ONB)}

The onset of nucleate boiling is the location where the first bubbles appear on the heater surface. In the experiments performed, the ONB location was identified by visual observation. Once the axial location $(\mathrm{z})$ at which ONB is observed is identified, the corresponding wall superheat is determined from the measured inner wall temperatures with the appropriate temperature corrections. Table 1 shows the ONB data obtained for the nine rod bundle.

Table 1: Onset of nucleate boiling information for rod bundle.

\begin{tabular}{|c|c|c|c|c|c|c|c|}
\hline Test cases & $\begin{array}{c}\text { Mass flux } \\
G \\
\left(\mathrm{~kg} / \mathrm{m}^{2} s\right)\end{array}$ & $\begin{array}{c}\text { Local } \\
\text { subcooling } \\
\Delta T_{\text {sub }}\left({ }^{\circ} \mathrm{C}\right)\end{array}$ & $\begin{array}{c}\text { Axial location } \\
z \\
(\mathrm{~cm})\end{array}$ & $\begin{array}{c}\text { Heat flux } \\
q_{w} \\
\left(\mathrm{~W} / \mathrm{cm}^{2}\right)\end{array}$ & $\begin{array}{c}\text { Contac } \\
\text { angle } \\
\phi \\
(\mathrm{deg})\end{array}$ & $\begin{array}{c}\text { Wall } \\
\text { superheat at } \\
\text { ONB } \\
\Delta T_{w}\left({ }^{\circ} \mathrm{C}\right)\end{array}$ & $\begin{array}{c}\text { Bergles and } \\
\text { Rohsenow's } \\
\text { prediction } \\
\Delta T_{w}\left({ }^{\circ} \mathrm{C}\right)\end{array}$ \\
\hline R3 & 596 & 4.2 & 52 & 4.4 & 57 & 2.4 & 3.0 \\
\hline R4 & 596 & 1.7 & 25 & 5.4 & 57 & 3.3 & 3.4 \\
\hline R5 & 186 & 2.7 & 45 & 2.5 & 57 & 2.2 & 2.3 \\
\hline R6 & 186 & 2.2 & 35 & 3.2 & 57 & 2.7 & 2.7 \\
\hline R7 & 186 & 2.5 & 25 & 4.4 & 57 & 2.2 & 3.1 \\
\hline R9 & 186 & 9.7 & 40 & 6.3 & 57 & 2.5 & 3.6 \\
\hline Rod1c & 336 & 10.9 & 60 & 2.9 & 57 & 1.8 & 2.5 \\
\hline Rod1d & 336 & 11.6 & 44 & 3.9 & 57 & 2.0 & 2.9 \\
\hline
\end{tabular}




\begin{tabular}{|c|c|c|c|c|c|c|c|}
\hline Test cases & $\begin{array}{c}\text { Mass flux } \\
G \\
\left(\mathrm{~kg} / \mathrm{m}^{2} s\right)\end{array}$ & $\begin{array}{c}\text { Local } \\
\text { subcooling } \\
\Delta T_{\text {sub }}\left({ }^{\circ} \mathrm{C}\right)\end{array}$ & $\begin{array}{c}\text { Axial location } \\
z \\
(\mathrm{~cm})\end{array}$ & $\begin{array}{c}\text { Heat flux } \\
q_{w} \\
\left(\mathrm{~W} / \mathrm{cm}^{2}\right)\end{array}$ & $\begin{array}{c}\text { Contac } \\
\text { tangle } \\
\phi \\
(\mathrm{deg} .)\end{array}$ & $\begin{array}{c}\text { Wall } \\
\text { superheat at } \\
\text { ONB } \\
\Delta T_{w}\left({ }^{\circ} \mathrm{C}\right)\end{array}$ & $\begin{array}{c}\text { Bergles and } \\
\text { Rohsenow's } \\
\text { prediction } \\
\Delta T_{w}\left({ }^{\circ} \mathrm{C}\right)\end{array}$ \\
\hline Rod1e & 336 & 11.1 & 30 & 4.9 & 57 & 2.5 & 3.2 \\
\hline Rod1f & 336 & 11.8 & 20 & 5.9 & 57 & 2.8 & 3.5 \\
\hline Rod1g & 336 & 9.6 & 5 & 8.0 & 57 & 4.0 & 4 \\
\hline Rod2c & 338 & 27.7 & 30 & 9.8 & 57 & 2.8 & 4.5 \\
\hline Rod2d & 334 & 17.2 & 10.5 & 12.2 & 57 & 4 & 4.9 \\
\hline Rod2f & 336 & 31.5 & 44.0 & 10.6 & 57 & 3.0 & 4.6 \\
\hline Rod2g & 336 & 38.6 & 30.0 & 13.3 & 57 & 4.0 & 5.1 \\
\hline Rod3b & 629 & 17.0 & 63.5 & 7.0 & 57 & 2.9 & 3.9 \\
\hline Rod3c & 626 & 13.6 & 35.0 & 8.5 & 57 & 3.0 & 4.2 \\
\hline Rod3d & 629 & 21.8 & 38.0 & 10.0 & 57 & 3.5 & 4.5 \\
\hline Rod3e & 631 & 23.3 & 5.0 & 14.3 & 57 & 4.4 & 5.3 \\
\hline Rod4a & 346 & 18.9 & 45.0 & 5.3 & 57 & 2.3 & 3.4 \\
\hline Rod4b & 346 & 22.5 & 15.0 & 9.3 & 57 & 3.5 & 4.3 \\
\hline RD_1b & 1.03 & 336 & 57 & 30.5 & 21.4 & 10.8 & 2.8 \\
\hline RD_1c & 1.03 & 336 & 57 & 10.2 & 22.6 & 15.2 & 3.5 \\
\hline RD_1d & 1.03 & 336 & 57 & 5.1 & 25.1 & 20.2 & 4.1 \\
\hline RD_2b & 1.03 & 926 & 57 & 30.0 & 19.9 & 15.0 & 4.3 \\
\hline RD_2c & 1.03 & 926 & 57 & 20.0 & 14.2 & 20.0 & 4.5 \\
\hline RD_3e & 2.1 & 346 & 57 & 60.9 & 14.8 & 10.1 & 2.8 \\
\hline RD_3f & 2.1 & 346 & 57 & 30.0 & 22.7 & 13.1 & 3.5 \\
\hline RD_4h & 2.1 & 916 & 57 & 60.0 & 21.6 & 20.1 & 4.2 \\
\hline RD_4i & 2.1 & 916 & 57 & 15.0 & 21.9 & 25.2 & 5 \\
\hline RD_5e & 2.2 & 916 & 57 & 70.0 & 30.1 & 25.6 & 3.2 \\
\hline RD_6d & 2.15 & 346 & 57 & 45.0 & 36.4 & 17.2 & 3.3 \\
\hline RD_6e & 2.15 & 346 & 57 & 25.0 & 37.9 & 20.5 & 3.7 \\
\hline RD_6f & 2.15 & 346 & 57 & 10.0 & 44.7 & 25.8 & 4.2 \\
\hline RD_7d & 3.1 & 346 & 57 & 45.0 & 29.9 & 20.4 & 2.8 \\
\hline RD_7e & 3.1 & 346 & 57 & 30.0 & 34.9 & 25.8 & 3.5 \\
\hline RD_8e & 3.2 & 926 & 57 & 50.0 & 31.8 & 25.4 & 4.1 \\
\hline RD_9e & 3.02 & 926 & 57 & 35.0 & 24.6 & 25.4 & 3.8 \\
\hline RD_10c & 3.02 & 646 & 57 & 85.0 & 29.5 & 15.8 & 3.2 \\
\hline RD_10b & 3.02 & 646 & 57 & 35.0 & 27.5 & 20.0 & 3.5 \\
\hline & & & & & & & \\
\hline & & & & & & \\
\hline
\end{tabular}

(iv) Active nucleation site density $\left(N_{\mathrm{a}}\right)$

The active nucleation site density was measured from the high-speed motion pictures taken of the heater surface during boiling. These pictures were taken from the front of the heater surface using a CCD camera. The CCD camera (HSIS 2002) has a resolution of $256 \times 256$ pixels and a maximum frame rate of 1220 frames/second. Pictures were taken at various axial locations along the heater surface. The recorded movies were then played back and the number of active nucleation sites counted. Since the focusing area was recorded during each experiment, 
the active nucleation site density was calculated by dividing the total number of active nucleation sites by the focusing area. In partial nucleate boiling, where discrete bubbles are present on the surface, the active sites could be easily discerned from the pictures. However, at higher wall superheats, adjacent bubbles begin to merge making it difficult to accurately count the number of individual active sites. To overcome this problem, a technique similar to that used by Wang and Dhir [35] was employed. In this technique, once the required wall superheat was reached, colder water (at about $60{ }^{\circ} \mathrm{C}$ ) stored in tank \#2 was pumped through the test chamber for about two or three minutes. The increased subcooling caused the bubbles to decrease in size and stop merging, thereby facilitating the observation of individual sites. As pointed out by Wang and Dhir, this raises the possibility that if the subcooling is high, the liquid-vapor interface may be pushed back into the cavity, thereby giving the appearance that the site has been deactivated. Pictures taken before and after the cold water was introduced, showed that though the bubbles decreased in size, they did not completely disappear. The error due to deactivation is expected to be small, since the wall superheat and heat flux did not change significantly after the cold water was introduced.

The mean contact angle of the Zircalloy-4 cladding was measured to be approximately $57^{\circ}$ as shown in Figure 4-66. The contact angle measurement was done before the nine rod bundle was placed in the test section. Figure 4-67 shows a photograph of active nucleation sites recorded during nucleate boiling (test case R6). Nucleation site density information was obtained using the high speed CCD camera. While taking pictures of the test surface, care was taken to ensure that the entire width (diameter) of a rod was in focus. These pictures were then scaled knowing the actual diameter of the rod. From the pictures of the heating surface, the individual nucleation sites were manually counted. Now, knowing the actual focusing area and the actual number of nucleation sites in that area the active nucleation site density was calculated. Figure 4-68 shows the variation of $N_{\mathrm{a}}$ with wall superheat for the nine rod bundle. It can be clearly seen from Figure 4-68 that $N_{\mathrm{a}}$ increases with increasing $\Delta T_{\mathrm{w}}$. The nucleation site density data obtained for the rod bundle experiments are shown in Table 2 .

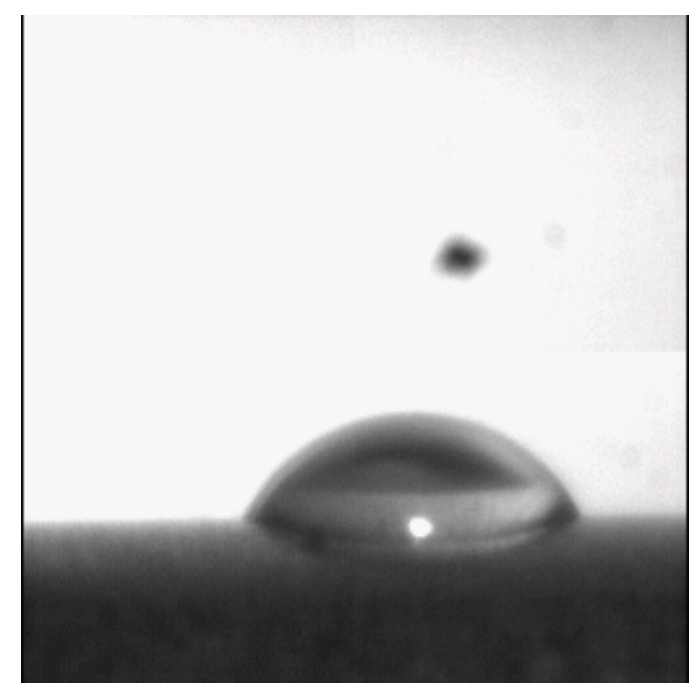

Figure 4-66: Contact angle for Zircalloy-4 cladding. 


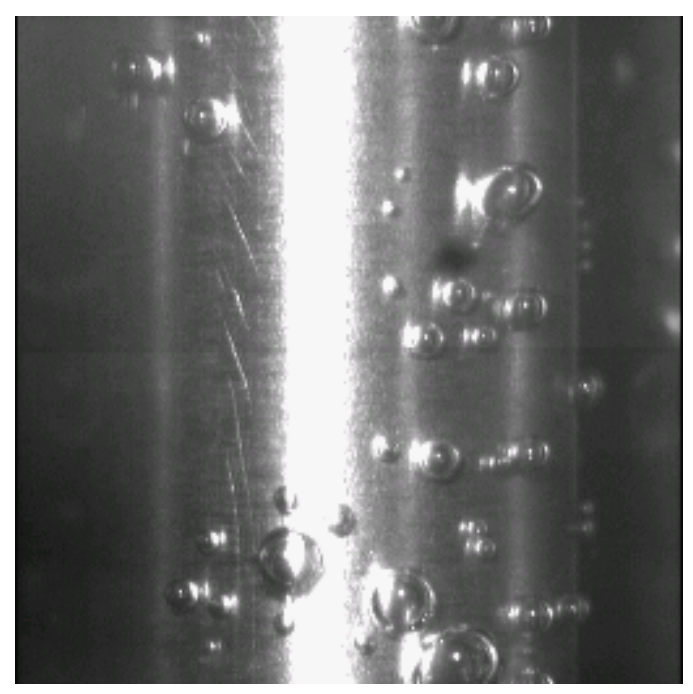

Figure 4-67: Active nucleation site density for nine rod bundle (test case R8).

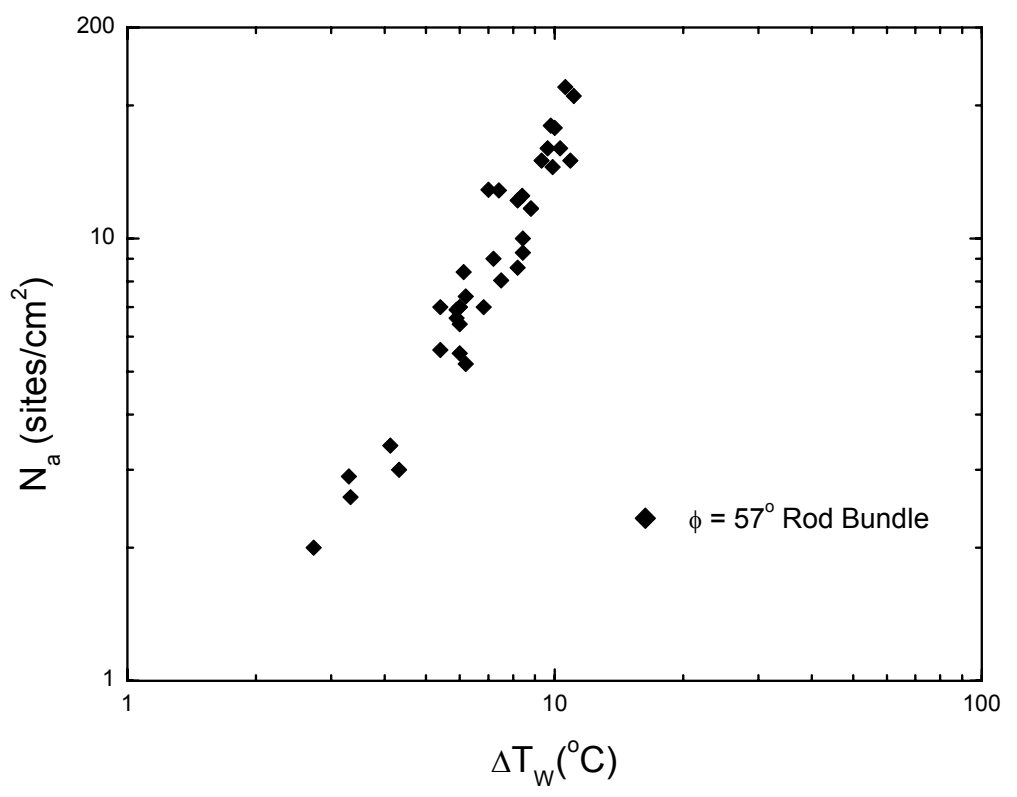

Figure 4-68: Nucleation site density for nine rod bundle. 
Table 2: Active nucleation site density data for nine rod bundle.

\begin{tabular}{|c|c|c|c|c|}
\hline Test case & $\begin{array}{c}\text { Wall Superheat } \\
\left(\Delta T_{w},{ }^{o} C\right)\end{array}$ & $\begin{array}{c}\text { Total active } \\
\text { nucleation sites }\end{array}$ & $\begin{array}{l}\text { Focus area } \\
\qquad\left(\mathrm{cm}^{2}\right)\end{array}$ & $\begin{array}{c}\text { Active nucleation } \\
\text { site density } \\
\left(\text { sites } / \mathrm{cm}^{2}\right)\end{array}$ \\
\hline R4 & 6 & 22 & 3.96 & 5.5 \\
\hline $\mathrm{R} 4$ & 7.2 & 38 & 4.2 & 9 \\
\hline R8 & 6 & 26 & 3.6 & 7 \\
\hline $\mathrm{R} 8$ & 7 & 54 & 4.2 & 12.8 \\
\hline R8 & 7.5 & 35 & 4.4 & 8.8 \\
\hline R9 & 8.2 & 36 & 4.2 & 8.5 \\
\hline R9 & 8.4 & 54 & 4.3 & 12.5 \\
\hline R9 & 7.4 & 50 & 3.9 & 12.8 \\
\hline R10 & 8.8 & 46 & 3.9 & 11.7 \\
\hline R10 & 8.2 & 51 & 4.2 & 12.2 \\
\hline R10 & 9.9 & 56 & 3.9 & 14.5 \\
\hline R10 & 10 & 75 & 4.2 & 17.8 \\
\hline rod1e & 3.3 & 13.05 & 4.5 & 2.9 \\
\hline $\operatorname{rod} 2 \mathrm{c}$ & 5.4 & 20.16 & 3.6 & 5.6 \\
\hline rod2c & 5.9 & 27.72 & 4.2 & 6.6 \\
\hline $\operatorname{rod} 2 d$ & 6.2 & 18.72 & 3.6 & 5.2 \\
\hline $\operatorname{rod} 2 d$ & 6 & 28.8 & 4.5 & 6.4 \\
\hline $\operatorname{rod} 3 c$ & 5.9 & 26.91 & 3.9 & 6.9 \\
\hline rod3c & 5.4 & 29.4 & 4.2 & 7.0 \\
\hline rod3d & 6.2 & 34.78 & 4.7 & 7.4 \\
\hline rod3d & 6 & 29.4 & 4.2 & 7.0 \\
\hline $\operatorname{rod} 2 \mathrm{f}$ & 4.33 & 11.7 & 3.9 & 3.0 \\
\hline $\operatorname{rod} 2 \mathrm{f}$ & 4.13 & 13.26 & 3.9 & 3.4 \\
\hline $\operatorname{rod} 2 g$ & 6.83 & 31.5 & 4.5 & 7.0 \\
\hline $\operatorname{rod} 2 g$ & 6.13 & 37.8 & 4.5 & 8.4 \\
\hline rod3b & 2.73 & 9.4 & 4.7 & 2.0 \\
\hline rod3b & 3.33 & 12.22 & 4.7 & 2.6 \\
\hline rod3e & 8.43 & 42 & 4.2 & 10.0 \\
\hline rod3e & 8.43 & 39.06 & 4.2 & 9.3 \\
\hline rod3e & 9.33 & 63 & 4.2 & 15.0 \\
\hline $\operatorname{rod} 3 \mathrm{f}$ & 9.63 & 67.2 & 4.2 & 16.0 \\
\hline rod3f & 10.3 & 67.2 & 4.2 & 16.0 \\
\hline rod3g & 10.9 & 58.5 & 3.9 & 15.0 \\
\hline rod3g & 11.1 & 81.9 & 3.9 & 21.0 \\
\hline rod3g & 10.6 & 85.8 & 3.9 & 22.0 \\
\hline rod3g & 9.8 & 70.2 & 3.9 & 18.0 \\
\hline
\end{tabular}




\section{(v) Onset of significant voids (OSV)}

The onset of significant void is the axial location at which the bubbles move from the bubble layer close to the wall and enter the bulk liquid. The onset of significant void is accompanied by an increase in the void fraction. In the present study, the OSV location for each test run was identified by visual observation. Table 3 lists the OSV locations and the corresponding wall superheats obtained for the nine rod bundle.

Table 3: Onset of significant void information for rod bundle test cases.

\begin{tabular}{|c|c|c|c|c|c|}
\hline Test cases & $\begin{array}{c}\text { Mass flux } G \\
\left(\mathrm{~kg} / \mathrm{m}^{2} \mathrm{~s}\right)\end{array}$ & $\begin{array}{c}\text { Local subcooling } \\
\Delta T_{\text {sub }}\left({ }^{\circ} \mathrm{C}\right)\end{array}$ & $\begin{array}{c}\text { Axial location } z \\
(\mathrm{~cm})\end{array}$ & $\begin{array}{c}\text { Heat flux } q_{w} \\
\left(\mathrm{~W} / \mathrm{cm}^{2}\right)\end{array}$ & $\begin{array}{c}\text { Contact angle } \phi \\
(\text { deg. })\end{array}$ \\
\hline \hline Rod1d & 336 & 6.6 & 85 & 3.9 & 57 \\
\hline Rod1e & 336 & 7.2 & 70 & 4.9 & 57 \\
\hline Rod1f & 336 & 7.6 & 55 & 5.9 & 57 \\
\hline Rod1g & 336 & 8.9 & 15 & 8.0 & 57 \\
\hline Rod2c & 338 & 17.5 & 75 & 9.8 & 57 \\
\hline Rod2d & 334 & 12.1 & 35 & 12.2 & 57 \\
\hline Rod2g & 336 & 23.7 & 70 & 13.3 & 57 \\
\hline Rod3e & 628 & 14.6 & 65 & 14.3 & 57 \\
\hline Rod3g & 626 & 15.7 & 50 & 20 & 57 \\
\hline Rod4c & 335 & 14.4 & 55 & 9.3 & 57 \\
\hline Rod4e & 336 & 23.6 & 12 & 20 & 57 \\
\hline RD_1b & 336 & 13.1 & 63.5 & 10.8 & 57 \\
\hline RD_1c & 336 & 15.5 & 30.5 & 15.2 & 57 \\
\hline RD_1d & 336 & 18 & 20.3 & 20.2 & 57 \\
\hline RD_2c & 926 & 14.3 & 38.1 & 20 & 57 \\
\hline RD_2c & 926 & 18.2 & 15 & 25 & 57 \\
\hline RD_3f & 346 & 15.9 & 50 & 13.3 & 57 \\
\hline RD_3g & 346 & 23.1 & 40 & 15.2 & 57 \\
\hline RD_3h & 346 & 26.9 & 20 & 20.1 & 57 \\
\hline RD_4i & 916 & 14.2 & 50 & 25.2 & 57 \\
\hline RD_6d & 346 & 25.8 & 70 & 17.2 & 57 \\
\hline RD_6e & 346 & 23.3 & 55 & 20.4 & 57 \\
\hline RD_6f & 346 & 24 & 45 & 25.2 & 57 \\
\hline RD_9e & 926 & 19.2 & 60 & 25.4 & 57 \\
\hline RD_10d & 646 & 17.3 & 80 & 20.2 & 57 \\
\hline & & & & & \\
\hline
\end{tabular}

\subsubsection{Nine Rod Bundle with Boron}

\section{(i) Wall heat flux $\left(q_{\mathrm{w}}\right)$}

The procedure to calculate the wall heat flux for the nine rod bundle experiments with boron identical to that described in the previous section.

(ii) Wall temperature $\left(T_{\mathrm{w}}\right)$

The procedure to calculate the wall temperature for the nine rod bundle experiments with boron identical to that described in the previous section.

(iii) Boiling curves 
Figure 4-69 shows a comparison of the boiling curves with and without boron. In Figure 4-69, comparing the boiling curves for the first set (test cases RB1a - RB10a) of experiments with that obtained without boron, it can be seen that the data for these two runs are almost identical. This may be due to the fact that the thickness of the crud deposit is still negligible.

Now comparing the boiling curves for test cases two (RB1b - RB10b) and three (RB1c $\mathrm{RB} 10 \mathrm{c})$ with the one obtained without boron, it can be clearly seen that in the single phase forced convection region, the wall superheats obtained (for the same heat flux level) for the test cases with boron are higher than those without boron. This can be explained by the fact that once the thickness of the crud deposit increases, it results in an increase in the thermal resistance of the heating surface. Hence, for the same heat flux level, the wall temperature will be higher in cases with crud deposit. However, once nucleate boiling begins, the boiling curves for the tests with boron shift to the left as compared to the case without boron (i.e., for the same heat flux level, the wall temperature is lower in the presence of crud deposit). We believe that this is due the fact that the porous nature of the crud deposit results in an increase in the number of nucleation sites that can trap gas or vapor and become active. Thus, the presence of the crud results in an increase in the active nucleation sites, which in turn results in more evaporative energy being removed from the heating surface. As a result, the wall temperature will be lower that compared to test cases without boron.

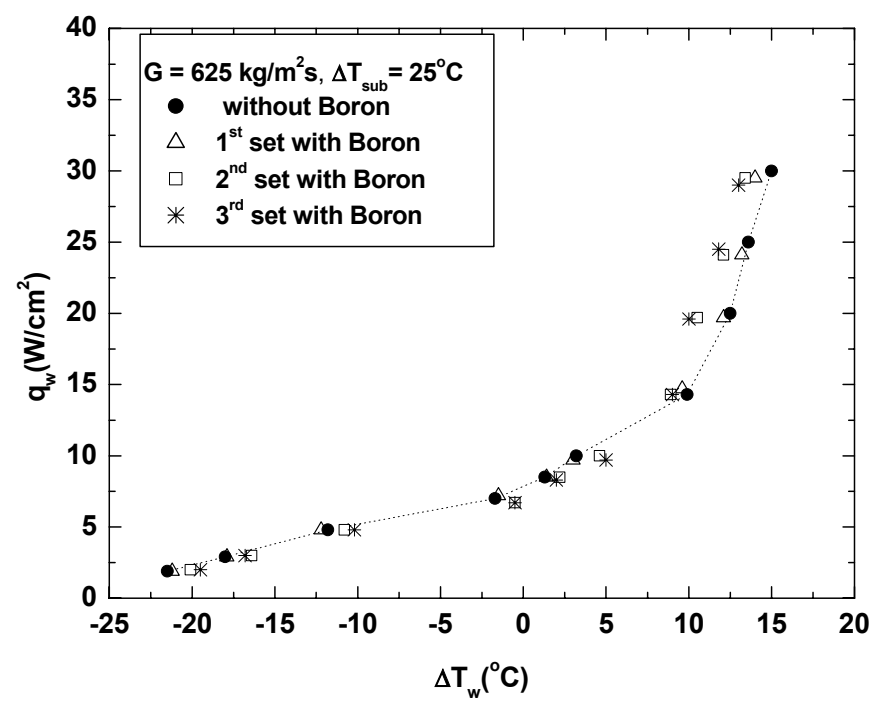

Figure 4-69: Comparison of boiling curves for test cases with and without boron.

\section{(iv) Crud thickness}

During these experiments, the time taken for each individual experiment was recorded. The thickness of the crud was measured using traversable microthermocouples (used to measure the liquid temperature profile). Before the experiments were started, the microthermocouple was moved such that it made contact with the heating surface (the CCD camera was used to check if contact was actually made) and this reading on the micrometer was used as the base value. After each set of experiments, the above procedure was repeated. The crud thickness was determined by subtracting the base values from the measured micrometer readings. Figure 4-70 shows the crud thickness as a function of time. From Figure 4-70 it can be seen that the crud thickness 
increases as a function of time. Figure 4-71 shows photographs taken of the heating surface before and after the experiments. In Figure 4-71 (b), the presence of crud on the surface can be clearly seen.

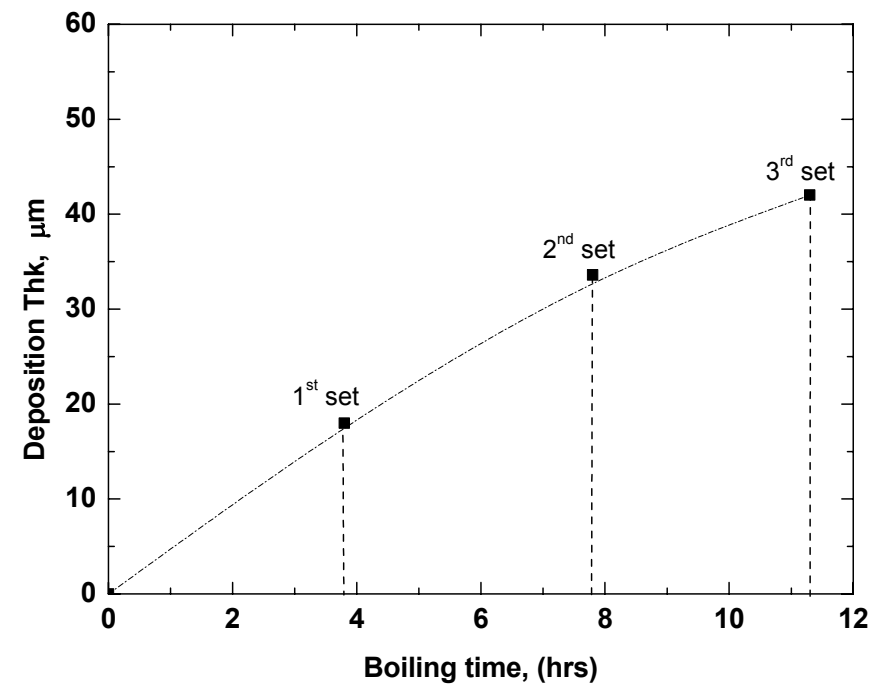

Figure 4-70: Thickness of boron deposit as a function of time.

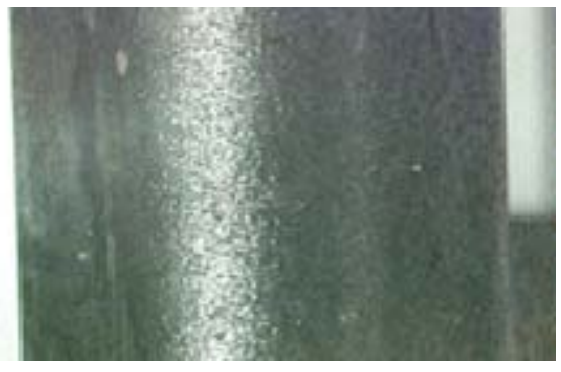

(a)

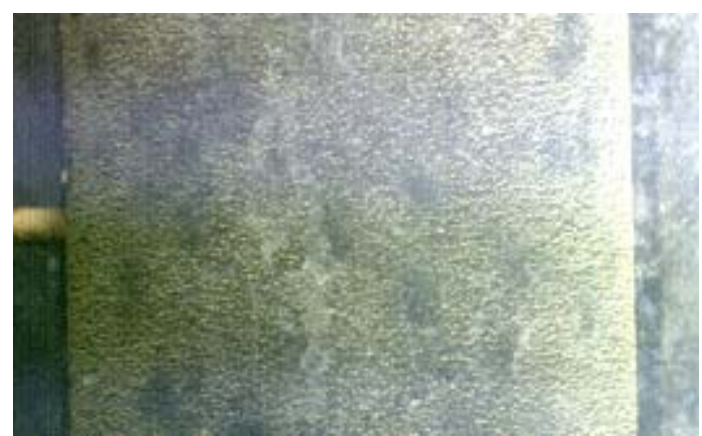

Figure 4-71: Photographs showing the rod bundle heater surface

(a) clean surface and (b) surface after boron deposition

\section{(v) Onset of nucleate boiling $(\mathrm{ONB})$}

As mentioned in the previous sections, the ONB location was determined from visual observation as well as the temperature data. Table 4 lists the ONB data for the nine rod bundle 
experiments with boron. Also included in Table 4 is the ONB wall superheat predicted by Bergles and Rohsenow's correlation.

Table 4: Onset of nucleate boiling information for rod bundle with boron.

\begin{tabular}{|c|c|c|c|c|c|c|c|}
\hline Test cases & $\begin{array}{c}\text { Mass flux } \\
G \\
\left(\mathrm{~kg} / \mathrm{m}^{2} \mathrm{~s}\right)\end{array}$ & $\begin{array}{c}\text { Local } \\
\text { subcooling } \\
\Delta T_{\text {sub }}\left({ }^{\circ} \mathrm{C}\right)\end{array}$ & $\begin{array}{c}\text { Axial } \\
\text { location } \\
z \\
(\mathrm{~cm})\end{array}$ & $\begin{array}{c}\text { Heat flux } \\
q_{w} \\
\left(\mathrm{~W} / \mathrm{cm}^{2}\right)\end{array}$ & $\begin{array}{c}\text { Contact } \\
\text { angle } \\
\phi \\
(\mathrm{deg} .)\end{array}$ & $\begin{array}{c}\text { Wall } \\
\text { superheat at } \\
\text { ONB } \\
\Delta T_{w}\left({ }^{\circ} \mathrm{C}\right)\end{array}$ & $\begin{array}{c}\text { Bergles and } \\
\text { Rohsenow's } \\
\text { prediction } \\
\Delta T_{w}\left({ }^{\circ} \mathrm{C}\right)\end{array}$ \\
\hline $\mathrm{Rb} 5 \mathrm{a}$ & 625 & 17.3 & 63.5 & 7.2 & 57 & 2.7 & 4.2 \\
\hline $\mathrm{Rb} 6 \mathrm{a}$ & 625 & 13.7 & 35.6 & 8.5 & 57 & 3.0 & 4.4 \\
\hline $\mathrm{Rb7a}$ & 625 & 22.3 & 38.1 & 10.0 & 57 & 3.8 & 5.4 \\
\hline $\mathrm{Rb} \mathrm{a}$ & 625 & 23.8 & 5.1 & 14.3 & 57 & 5.0 & 6.2 \\
\hline $\mathrm{Rb} 5 \mathrm{~b}$ & 635 & 24.4 & 38.1 & 8.3 & 57 & 3.0 & 4.1 \\
\hline $\mathrm{Rb} 6 \mathrm{~b}$ & 635 & 20.0 & 40.64 & 9.7 & 57 & 3.5 & 4.4 \\
\hline $\mathrm{Rb} 7 \mathrm{~b}$ & 635 & 20.1 & 25.4 & 14.4 & 57 & 4.5 & 5.3 \\
\hline $\mathrm{Rb} 8 \mathrm{~b}$ & 635 & 26.9 & 5.08 & 19.7 & 57 & 5.7 & 6.2 \\
\hline $\mathrm{Rb} 5 \mathrm{c}$ & 625 & 23.4 & 40.6 & 8.3 & 57 & 2.8 & 4.1 \\
\hline $\mathrm{Rb} 6 \mathrm{c}$ & 625 & 22.2 & 20.3 & 9.7 & 57 & 3.5 & 4.4 \\
\hline $\mathrm{Rb} 7 \mathrm{c}$ & 625 & 24.9 & 12.7 & 14.7 & 57 & 4.8 & 5.3 \\
\hline $\mathrm{Active}$
\end{tabular}

(vi) Active nucleation site density $\left(N_{\mathrm{a}}\right)$

Figure 4-72 shows the $N_{\mathrm{a}}$ data obtained the test runs with boron. Also included in Figure 4-72 is the $N_{\mathrm{a}}$ data obtained for test cases without boron. Comparing the data shown in Figure 4-72, it is clear that the presence of crud on the heating surface increases the active nucleation site density. As reported earlier, this increase in $N_{\mathrm{a}}$ is the reason that the boiling curves for the tests with boron shift to the left (compared to the boiling curve for tests without boron).

Figure 4-73 shows photographs of the test surface when bubbles are nucleating. Figure 4-73 (a) was taken for a clean surface while Figure 4-73 (b) was taken for a surface with boron deposits. From Figure 4-73 it can be seen that there is an increase in the active nucleation site density once the boron deposit is present on the surface.

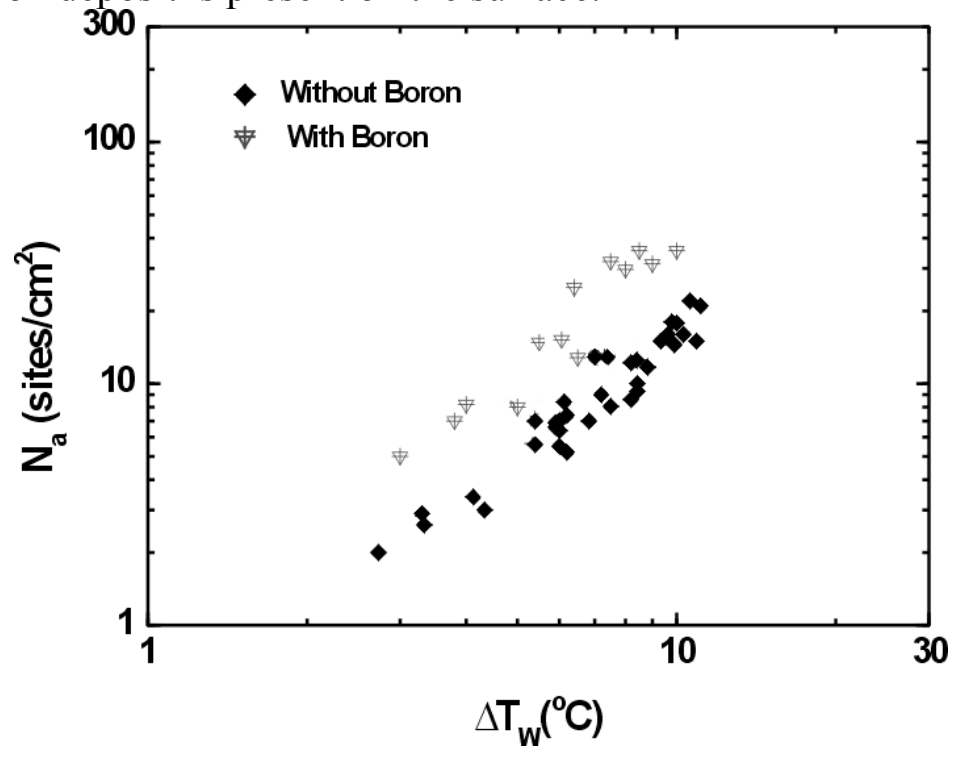

Figure 4-72: Comparison of $\mathrm{N}_{\mathrm{a}}$ data for test cases with and without boron. 


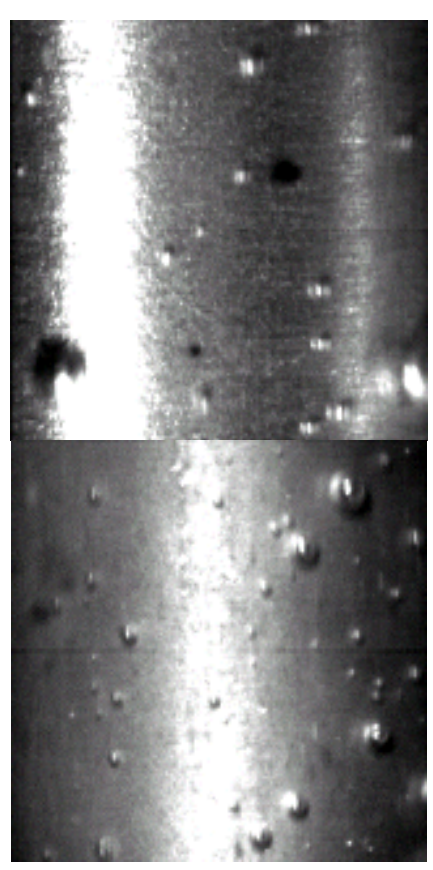

Figure 4-73: Comparison of heater surface during nucleate boiling, (a) clean surface, and (b) surface with boron deposit.

\section{(vii) Onset of significant void (OSV)}

As in case of flat plate surface, the OSV location for the nine rod bundle experiments with boron were also determined from visual observation. Table 5 lists the OSV locations and the corresponding wall superheats obtained for the nine rod bundle.

Table 5: Onset of significant void for rod bundle with boron.

\begin{tabular}{|c|c|c|c|c|c|}
\hline Test cases & $\begin{array}{c}\text { Mass flux } \\
G \\
\left(\mathrm{~kg} / \mathrm{m}^{2} s\right)\end{array}$ & $\begin{array}{c}\text { Local subcooling } \\
\Delta T_{\text {sub }}\left({ }^{\circ} \mathrm{C}\right)\end{array}$ & $\begin{array}{c}\text { Axial location } \\
z \\
(\mathrm{~cm})\end{array}$ & $\begin{array}{c}\text { Heat flux } \\
q_{w} \\
\left(\mathrm{~W}_{\mathrm{cm}}{ }^{2}\right)\end{array}$ & $\begin{array}{c}\text { Contact angle } \\
\phi \\
(\text { deg. })\end{array}$ \\
\hline \hline Rb7a & 625 & 14.1 & 61.0 & 14.3 & 57 \\
\hline Rb8a & 625 & 14.4 & 50.8 & 19.5 & 57 \\
\hline Rb9a & 625 & 15.9 & 58.4 & 25.0 & 57 \\
\hline Rb10a & 625 & 14.4 & 45.7 & 29.5 & 57 \\
\hline Rb6b & 635 & 15.3 & 83.4 & 9.7 & 57 \\
\hline Rb7b & 635 & 15.5 & 53.3 & 14.7 & 57 \\
\hline Rb8b & 635 & 18.9 & 40.6 & 19.7 & 57 \\
\hline Rb9b & 635 & 19.5 & 25.4 & 24.3 & 57 \\
\hline Rb10b & 635 & 21.4 & 12.7 & 29.1 & 57 \\
\hline Rb7c & 625 & 15.9 & 66.0 & 14.7 & 57 \\
\hline rb8c & 624 & 15.1 & 53.3 & 19.7 & 57 \\
\hline rb9c & 624 & 14.6 & 38.1 & 24.1 & 57 \\
\hline rb10c & 624 & 13.1 & 30.5 & 29.2 & 57 \\
\hline
\end{tabular}




\section{Chapter 5 Conclusions}

Both numerical simulation and experimental investigation were carried out to study the inception, growth, and departure of vapor bubbles on a single nucleation site on a flat plate with and without boron. Subcooled flow boiling experiments were also conducted on a nine rod bundle with flow rates varying from $186 \mathrm{~kg} / \mathrm{m}^{2} \mathrm{~s}$ to $2800 \mathrm{~kg} / \mathrm{m}^{2} \mathrm{~s}$, inlet liquid subcooling varying from $2.7{ }^{\circ} \mathrm{C}$ to $69.6{ }^{\circ} \mathrm{C}$, and wall heat fluxes varying from $1.0 \mathrm{~W} / \mathrm{cm}^{2}$ to $30.0 \mathrm{~W} / \mathrm{cm}^{2}$.

The major conclusions of this study are:

i) Numerical simulation shows that the boron concentration in the solution has a little effect on the heat transfer through the micro-layer and on mass flow rate in the micro region. Experimental results confirm that the growth and departure processes of single bubbles are similar for both DI water and an aqueous solution of 3,000 ppm boric acid.

ii) Numerical simulation indicates that the precipitation of boron can occur in meniscus area (including micro region) of bubble and the advancing and receding interface near the heated surface during bubble growth and departure processes. In the experiments, gradient of boron concentration near the liquid-vapor interface was detected successfully. Boron deposition as a circular shape with thick edge was found at downstream region leading by the nucleation site.

iii) As to the bubble dynamics on a single nucleation site, the bubble departure and lift off diameters decrease with velocity. The lift-off diameter decreases with subcooling but the liftoff time increases with subcooling. Subcooling causes the oscillation of the bubble. The distance the bubble slides before it lifts off into the liquid increases with velocity and also with the magnitude of the parallel component of gravity along the heater in the flow direction.

iv) The crud thickness on the nine-rod bundle increases as a function of time in subcooled flow boiling with the addition of 7,000 ppm boric acid. Boron deposition on the rods leads to increased nucleation site density and increased nucleate boiling heat flux at a given wall superheat. However, the single phase heat transfer coefficient is suppressed by the presence of crud on the surface. 


\section{Assessment:}

The goal of present project it to cast the validated model in a form that it can be readily combined with a neutronic package to analyze and avoid conditions leading to AOA without economic penalty. As such, the specific objectives of the proposed work are:

(i) Develop a three dimensional complete numerical simulation model for thermal and hydrodynamics associated with a single bubble formed on a heated surface subjected to forced flow of liquid parallel to the surface. The bulk liquid will contain specified concentrations of boron and lithium. Chemical concentration, liquid subcooling, flow velocity, and system pressure are to be considered as variables of the problem.

Assessment: The model has been developed, but chemical concentration was considered without the presence of flow.

(ii) Extend the three dimensional complete numerical simulation model for a single bubble to multiple bubbles present on the heater surface. Specifically, address the issues of bubble merger on the heated wall and merger of a sliding bubble with bubbles attached to the heated surface. Delineate the differences between boiling on a plane surface and that on a rod.

Assessment: The issue of bubble merger on the heated wall has not been addressed.

(iii) Conduct single and multiple bubble boiling experiments on a plane heated surface forming one wall of a square channel. Carryout detailed measurements of bubble dynamics, and temperature and chemical species concentration profiles including formation of crud on the heated surface. Compare predictions from the numerical simulations with the data. In the experiments, vary systematically, the heat flux, liquid subcooling, flow velocity, and bulk concentrations of boron and lithium and system pressure. Vary system pressure from 1 to 20 atmospheres. Although in a reactor system, the system pressure of interest is about 150 atmospheres, the numerical simulation results validated up to 20 atmosphere pressure will be used to scale the effect of pressure.

Assessment: Detailed experiments of single bubble boiling experiments on a plane-heated surface forming one wall of a square channel were conducted. Bubble dynamics, temperature and chemical species concentration profiles including formation of crud on the heated surface were measured in detail. System pressure was fixed at $1 \mathrm{~atm}$. Bubble merger on the heated wall has not been investigated.

(iv) Conduct experiments on a nine-rod bundle enclosed in a square channel to delineate differences between subcooled boiling on a flat surface to that on a simulated fuel rod surface. These experiments will be limited to system pressures up to five atmospheres.

Assessment: The experiments were conducted but the system pressure was limited to $3 \mathrm{~atm}$. 
(v) Use results of numerical simulations to develop a model for vapor production and chemical concentration including deposition of boron on the fuel rod surface during subcooled boiling at high pressures. The model should include a submodel for nucleation site density. The model should be in a form that it can be easily coupled with a neutronic package to provide a mechanistic basis for determination of conditions that can lead to AOA.

Assessment: The proposed work was too ambitious. This aspect of the work will require a much further expanded study.

The schedule of completed activities and milestones is given below:

\begin{tabular}{|c|c|}
\hline Time & Completed Activities and Milestones \\
\hline $\begin{array}{l}\text { JULY 1, } 1999 \text { - } \\
\text { JUNE 30, } 2000\end{array}$ & $\begin{array}{l}\text { An axi-symmetric numerical simulation model of a single bubble } \\
\text { formed on a horizontal surface containing a chemical species has } \\
\text { been developed. } \\
\text { An experimental apparatus for flow boiling studies has been } \\
\text { developed. }\end{array}$ \\
\hline $\begin{array}{l}\text { JULY 1, } 2000 \text { - } \\
\text { JUNE 30, } 2001\end{array}$ & $\begin{array}{l}\text { Three dimensional model for flow boiling situation was developed. } \\
\text { Bubble dynamics from inception to bubble growth at a nucleation site } \\
\text { and sliding motion prior to lift off from the wall and lift off was } \\
\text { captured by the numerical simulation. } \\
\text { Saturated single bubble flow boiling experiments were conducted. } \\
\text { Subcooled boiling experiments were also conducted on a 9-rod } \\
\text { bundle with water and with boron in the liquid. } \\
\text { One paper was published at the } 35^{\text {th }} \text { National Heat Transfer } \\
\text { Conference, } 2001\end{array}$ \\
\hline $\begin{array}{l}\text { JULY 1, } 2001 \text { - } \\
\text { JUNE 30, } 2002\end{array}$ & $\begin{array}{l}\text { A miniature sensor to measure local concentration was developed. } \\
\text { Experiments for the determination of boron concentration during } \\
\text { bubble growth and departure cycle in pool boiling were conducted } \\
\text { successfully. } \\
\text { One paper was published in the proceeding of the } 2001 \text { ASME } \\
\text { International Mechanical Engineering Congress and Exposition }\end{array}$ \\
\hline $\begin{array}{l}\text { JULY 1, } 2002- \\
\text { March 31, } 2003\end{array}$ & $\begin{array}{l}\text { The effect of dynamic contact angle in the simulation of single bubble } \\
\text { in flow boiling was considered. } \\
\text { Subcooled single bubble flow boiling experiments were conducted. } \\
\text { Deposition of boron near the nucleation site was studied. } \\
\text { One paper was presented at the } 2002 \text { ASME International Mechanical } \\
\text { Engineering Congress and Exposition }\end{array}$ \\
\hline
\end{tabular}




\section{Reference:}

[1] Thermal-Hydraulic Bases for Fuel Cycle Designs to Prevent Axial Offset Anomalies, EPRI TR-108781, Dec. 1997.

[2] Tong, L.S. and Weisman, J., "Thermal Analysis of Pressurized Water Reactors," American Nuclear Society, La Grange, IL, 1970.

[3] Marek J., Maubach, K., and Rehmen, K., "Heat Transfer and Pressure Drop Performance of Rod Bundles Arranged in Square Arrays," Int'l. J. Heat Mass Transfer, Vol. 16, pp. 215-228, 1973.

[4] Chen, J.C., "A Correlation for Boiling Heat Transfer to Saturated Fluids in Convective Flow," ASME Paper 63-HT-34, 1963.

[5] Lahey, R.T. and Moody, F.J., "The Thermal Hydraulics of Boiling Water Nuclear Reactor," American Nuclear Society, La Grange, IL, 1977.

[6] Chexal, B., et al., "Void Fraction Technology for Design and Analysis," EPRI TR106326, March 1997.

[7] Kelly, J.M., "Constitutive Model Development Needs for Reactor Safety Thermal Hydraulic Code," paper presented at OECD, CSMS Specialists Meeting on Advanced Instrumentation and Measurement Techniques, Santa Barbara, CA, March 17-20, 1997.

[8] Rogers, J.T., Salcudean, M., Abdullah, Z., Meleon, D., and Poirier, D., "The Onset of Significant Void in Upflow Boiling of Water at Low Pressures and Velocities," Int'l J. Heat Mass Transfer, Vol. 30, No. 1, pp. 2247-2260, 1987.

[9] Sussman, M., Smerka, P., and Osher, S., "A Level Set Approach for Computing Solutions to Incompressible Two Phase Flow," J. Comput. Phys., Vol. 114, pp. 146-159, 1994.

[10] Wayner, P.C., "Evaporation and Stress in the Contact line Region," Engineering Fdn. Conf. on Pool and External Flow Boiling, V.K. Dhir and A.E. Bergles, eds., Santa Barbara, CA 1992.

[11] Son, G., Dhir, V.K., and Ramanajapu, N., "Numerical Simulation of Growth and Departure of a Single Bubble During Partial Nucleate Boiling on a Horizontal Surface," to appear in J. Heat Transfer.

[12] Celata, G. P., Cumo, M., and Setaro, T., 1994, "A Review of Pool and Forced Convective boiling of binary mixtures", Experimental Thermal and Fluid Science, Vol. 9, pp367-381.

[13] Fujita, Y. and Tsutsui, M., 1994, "Heat transfer in Nucleate Boiling of Binary Mixtures", Int. J. Heat Mass Transfer, Vol. 37, pp. 291-302.

[14] Kern, J., and Stephan, P., 2000, "Influence of Microscale Concentration Gradients in Nucleate Boiling Heat Transfer of Binary Mixtures", Porc. of Boiling 2000: Phenomena Emerging Applications, Alaska, pp.698-716.

[15] Lee, C. C., Chuah, Y. K., Lu, D. C. and Chao, H. Y., 1991, "Experimental Investigation of Pool Boiling of Lithium Bromide Solution on a Vertical Tube Under Subatmospheric Pressure", Int. Comm. Heat Mass Transfer, Vol. 18, pp. 309-320.

[16] Varma, H. K., Mehrotra, R. K., Agrawal, K. N. and Singh, S., 1994, "Heat Transfer during Pool Boiling of LiBr-water Solutions at Subatmospheric Pressures", Int. Communications in Heat and Mass Transfer, Vol. 21, No. 4, pp.539-548.

[17] Miyatake, O., Tanaka, I., and Lior, N., 1997, “A Simple Universal Equation for Bubble Growth in Pure Liquids and Binary Solutions with a Non-volatile Solute", Int. J. Heat Mass Transfer, Vol. 40, No. 7, pp.1577-1584. 
[18] Manity, S., "Effect of Velocity and Gravity on Bubble Dynamics", MSc Thesis, University of California, Los Angeles, 2000

[19] Son, G., Dhir, V. K. and Ramanujapu N., 1999, "Dynamics and Heat Transfer Associated With a Single Bubble During Nucleate Boiling on a Horizontal Surface", Journal of Heat Transfer, Vol. 121, pp.623-631.

[20] Stephan, P., and Hammer, J., 1994, "A New Model for Nucleate Boiling Heat Transfer", Heat and Mass Transfer, Vol.30, pp. 119-125.

[21] Lay, J. H., and Dhir, V. K., 1995, "Numerical Calculation of Bubble Growth in Nucleate Boiling of Saturated Liquids", ASME J. of Heat Transfer, Vol. 117, pp.394-401.

[22] Wayner, P. C., Jr., 1999, "Intermolecular Forces in Phase-change Heat Transfer: 1998 Kern Award Review”, AIChE Journal, Vol 45, No. 10, pp.2055-2068.

[23] Sussman, M., Smereka, P., and Osher, S., 1994, "A Level Set Approach for Computing Solutions to Incompressible Two-phase Flow”, J. of Comput. Phys., Vol. 114, pp. 146159.

[24] Son, G., and Dhir, V. K., 1998, "Numerical Simulation of Film Boiling Near Critical Pressures with a Level Set Method”, J. of Heat Transfer, Vol. 120, pp. 183-192.

[25] Ramanujapu, N., and Dhir, V. K., 1999, "Dynamics of Contact Angle During Growth and Departure of a Vapor Bubble at a Single Nucleation Site," Proceedings of $5^{\text {th }}$ ASME/JSME Joint Thermal Engineering Conference, San Diego.

[26] Kandlikar, S. G., and Stumm, B. J., Nov 1995, "A Control Volume Approach for Investigating Forces on a Departing Bubble Under Subcooled Flow Boiling," Journal of Heat Transfer, Vol. 117, pp. 990-997.

[27] Klausner, J. F., Mei, R., Bernhard, D. M., and Zeng, L. Z., 1993, "Vapor Bubble Departure in Forced Convection Boiling," International Journal of Heat and Mass Transfer, Vol. 36, No. 3, pp. 651-662

[28] Koumoutsos, N., Moissis, R., and Spyridonos, A., May 1968, "A Study of Bubble Departure in Forced-Convection Boiling," Journal of Heat Transfer, Vol. 90, pp. 223-230.

[29] Bibeau, E. L., and Salcudean, M., 1994, "A Study of Bubble Ebullition in ForcedConvective Subcooled Nucleate Boiling at Low Pressure," International Journal of Heat and Mass Transfer, Vol. 37, No. 15, pp. 2245-2259.

[30] Akiyama, M., and Tachibana, F., Feb 1974, "Motion of Vapor Bubbles in Subcooled Heated Channel," Bulletin of the JSME, Vol. 17, No. 104, pp. 241-247.

[31] Abdelmessih, A. H., Hooper, F. C., and Nangia, S., 1972, "Flow Effects on Bubble Growth and Collapse in Surface Boiling," International Journal of Heat and Mass Transfer, Vol. 15, pp. 115-125.

[32] Van Helden, W. G. J., Van der Geld, C. W. M., and Boot, P. G. M., 1995, "Forces on Bubble Growing and Detaching in Flow Along a Vertical Wall," International Journal of Heat and Mass Transfer, Vol. 38, No. 11, pp. 2075-2088.

[33] Khattab, M., Mariy, A., and Habib, M., 1984, “ Experimental Heat Transfer in Tube Bundle (Part II)," Atomkernenergie-Kerntechnik, Vol. 45, No. 2, pp. 93-97.

[34] Weisman, J., 1959, Letters to the Editors, Nuclear Science and Engineering, Vol. 6, No.1., July 1959.

[35] Wang, C. H. and Dhir., V. K., 1993, "Effect of Surface Wettability on Active Nucleation Site Density During Pool Boiling of Water on a Vertical Surface," Journal of Heat Transfer, Vol. 115, pp. 659-669. 
[36] Thorncroft, G. E., Klausner, J. F., and Mei, R., 1998, “An Experimental Investigation of Bubble Growth and Detachment in Vertical Upflow and Downflow Boiling," International Journal of Heat and Mass Transfer, Vol. 41, pp. 3857-3871. 


\section{Appendix A: List of test cases}

List of all the test cases for nine-rod bundle test section with and without boron are given in Tables A.1 and A.2 respectively.

Table A.1. Test conditions for nine rod bundle with water

\begin{tabular}{|l|l|l|l|l|l|}
\hline No. & Mass flux & $\begin{array}{l}\text { Pressure } \\
\left(G, \mathrm{~kg} / \mathrm{m}^{2} s\right)\end{array}$ & $\begin{array}{l}\text { Inlet liquid } \\
\text { subcooling } \\
(\Delta, \text { bar })\end{array}$ & $\begin{array}{l}\text { Heat flux } \\
\left(q_{w}, W / \mathrm{cm}^{2}\right)\end{array}$ & $\begin{array}{l}\text { Contact angle } \\
(\phi, \text { deg. })\end{array}$ \\
\hline \hline R1 & 186 & 1.03 & 18.8 & 1.63 & 57 \\
\hline R2 & 596 & 1.03 & 10.7 & 2.2 & 57 \\
\hline R3 & 596 & 1.03 & 5.6 & 4.4 & 57 \\
\hline R4 & 596 & 1.03 & 3.5 & 5.4 & 57 \\
\hline R5 & 186 & 1.03 & 4.8 & 2.5 & 57 \\
\hline R6 & 186 & 1.03 & 3.3 & 3.2 & 57 \\
\hline R7 & 186 & 1.03 & 3.3 & 4.4 & 57 \\
\hline R8 & 186 & 1.03 & 2.7 & 5.4 & 57 \\
\hline R9 & 186 & 1.03 & 16.2 & 6.3 & 57 \\
\hline R10 & 186 & 1.03 & 14.7 & 8.3 & 57 \\
\hline Rod1a & 336 & 1.03 & 15.0 & 1.0 & 57 \\
\hline Rod1b & 336 & 1.03 & 14.4 & 1.9 & 57 \\
\hline Rod1c & 336 & 1.03 & 13.8 & 2.9 & 57 \\
\hline Rod1d & 336 & 1.03 & 14.7 & 3.9 & 57 \\
\hline Rod1e & 336 & 1.03 & 14.4 & 4.8 & 57 \\
\hline Rod1f & 336 & 1.03 & 14.2 & 5.9 & 57 \\
\hline Rod1g & 336 & 1.03 & 10.3 & 8.0 & 57 \\
\hline Rod2a & 338 & 1.03 & 45.4 & 3.8 & 57 \\
\hline Rod2b & 334 & 1.03 & 42.9 & 8.2 & 57 \\
\hline Rod2c & 336 & 1.03 & 34.1 & 9.8 & 57 \\
\hline Rod2d & 336 & 1.03 & 22.1 & 12.2 & 57 \\
\hline Rod2e & 336 & 1.03 & 49.1 & 4.8 & 57 \\
\hline Rod2f & 326 & 1.03 & 42.1 & 10.6 & 57 \\
\hline Rod2g & 326 & 1.03 & 46.6 & 13.3 & 57 \\
\hline Rod3a & 631 & 1.03 & 25.4 & 4.8 & 57 \\
\hline Rod3b & 629 & 1.03 & 22.0 & 7.2 & 57 \\
\hline Rod3c & 626 & 1.03 & 17.1 & 8.5 & 57 \\
\hline Rod3d & 629 & 1.03 & 25.8 & 10.0 & 57 \\
\hline Rod3e & 628 & 1.03 & 24.1 & 14.3 & 57 \\
\hline Rod3f & 626 & 1.03 & 26.5 & 6.5 & 57 \\
\hline Rod3g & 626 & 1.03 & 24.5 & 20 & 57 \\
\hline Rod3h & 626 & 1.03 & 25.5 & 25 & 57 \\
\hline Rod3i & 626 & 1.03 & 26.1 & 30 & 57 \\
\hline Rod4a & 336 & 1.03 & 26.1 & 3.8 & 57 \\
\hline & & & & & \\
\hline
\end{tabular}


Table A.1. Test conditions for nine rod bundle with water (cond.)

\begin{tabular}{|l|c|c|c|c|c|}
\hline No. & $\begin{array}{l}\text { Mass flux } \\
\left(G, \mathrm{~kg} / \mathrm{m}^{2} s\right)\end{array}$ & $\begin{array}{l}\text { Pressure } \\
(P, \text { bar })\end{array}$ & $\begin{array}{l}\text { Inlet liquid } \\
\text { subcooling } \\
\left(\Delta T_{\text {sub }}{ }^{\circ} \mathrm{C}\right)\end{array}$ & $\left(\begin{array}{l}\text { Heat flux } \\
\left(q_{w}, W / \mathrm{cm}^{2}\right)\end{array}\right.$ & $\begin{array}{l}\text { Contact angle } \\
(\phi, \text { deg. })\end{array}$ \\
\hline \hline Rod4b & 335 & 1.03 & 24.1 & 5.3 & 57 \\
\hline Rod4c & 335 & 1.03 & 25.5 & 9.3 & 57 \\
\hline Rod4d & 335 & 1.03 & 29 & 4.4 & 57 \\
\hline Rod4e & 336 & 1.03 & 27.2 & 20 & 57 \\
\hline Rod4f & 336 & 1.03 & 26.2 & 25.1 & 57 \\
\hline Rod4g & 336 & 1.03 & 26.5 & 30.0 & 57 \\
\hline Rod5a & 336 & 1.03 & 69.2 & 1.8 & 57 \\
\hline Rod5b & 336 & 1.03 & 68.2 & 4.5 & 57 \\
\hline Rod6a & 626 & 1.03 & 69.6 & 4.5 & 57 \\
\hline Rod6b & 636 & 1.03 & 67.6 & 9.5 & 57 \\
\hline Rod7a & 1800 & 1.03 & 68.8 & 8.7 & 57 \\
\hline Rod7b & 1800 & 1.03 & 67.7 & 13.3 & 57 \\
\hline Rod8a & 2700 & 1.03 & 67.8 & 8.6 & 57 \\
\hline Rod8b & 2800 & 1.03 & 67.7 & 13.2 & 57 \\
\hline Rod9a & 1224 & 1.03 & 27.4 & 7.0 & 57 \\
\hline Rod9b & 1244 & 1.03 & 20.4 & 11.2 & 57 \\
\hline Rod10a & 1850 & 1.03 & 23.2 & 10.3 & 57 \\
\hline Rod10b & 1800 & 1.03 & 22.2 & 14.5 & 57 \\
\hline Rod11a & 2800 & 1.03 & 24.2 & 9.4 & 57 \\
\hline Rod11b & 2775 & 1.03 & 21.2 & 14.5 & 57 \\
\hline RD_1a & 336 & 1.03 & 28.9 & 3.2 & 57 \\
\hline RD_1b & 336 & 1.03 & 29 & 10.8 & 57 \\
\hline RD_1c & 336 & 1.03 & 26.2 & 15.2 & 57 \\
\hline RD_1d & 336 & 1.03 & 27.5 & 20.2 & 57 \\
\hline RD_aa & 926 & 1.03 & 26.5 & 5 & 57 \\
\hline RD_2b & 926 & 1.03 & 24 & 15 & 57 \\
\hline RD_2c & 926 & 1.03 & 20.7 & 20 & 57 \\
\hline RD_dd & 926 & 1.03 & 21.4 & 25 & 57 \\
\hline RD_3a & 346 & 2.1 & 29.2 & 1 & 57 \\
\hline RD_3b & 346 & 2.1 & 29.8 & 3.2 & 57 \\
\hline RD_3c & 346 & 2.1 & 28.8 & 5.1 & 57 \\
\hline RD_3d & 346 & 2.1 & 27.8 & 7.2 & 57 \\
\hline RD_3e & 346 & 2.1 & 24.4 & 10.1 & 57 \\
\hline RD_3f & 346 & 2.1 & 31.6 & 13.3 & 57 \\
\hline RD_3g & 346 & 2.1 & 37.5 & 15.2 & 57 \\
\hline RD_3h & 346 & 2.1 & 36.5 & 20.1 & 57 \\
\hline RD_4a & 916 & 2.1 & 30.2 & 1 & 57 \\
\hline RD_4b & 916 & 2.1 & 29.8 & 3.2 & 57 \\
\hline RD_4c & 916 & 2.1 & 29.2 & 5.6 & 57 \\
\hline & & & & \\
\hline
\end{tabular}


Table A.1. Test conditions for nine rod bundle with water (cond.)

\begin{tabular}{|l|c|c|c|c|c|}
\hline No. & $\begin{array}{l}\text { Mass flux } \\
\left(G, \mathrm{~kg} / \mathrm{m}^{2} s\right)\end{array}$ & $\begin{array}{l}\text { Pressure } \\
(P, \text { bar })\end{array}$ & $\begin{array}{l}\text { Inlet liquid } \\
\text { subcooling } \\
\left(\Delta T_{\text {sub }},{ }^{\circ} \mathrm{C}\right)\end{array}$ & $\begin{array}{l}\text { Heat flux } \\
\left(q_{w}, W / \mathrm{cm}^{2}\right)\end{array}$ & $\begin{array}{l}\text { Contact angle } \\
(\phi, \text { deg. })\end{array}$ \\
\hline \hline RD_4d & 916 & 2.1 & 30.4 & 7.3 & 57 \\
\hline RD_4e & 916 & 2.1 & 27.7 & 10.5 & 57 \\
\hline RD_4f & 916 & 2.1 & 27.8 & 13.1 & 57 \\
\hline RD_4g & 916 & 2.1 & 28.1 & 15.2 & 57 \\
\hline RD_4h & 916 & 2.1 & 31.8 & 20.1 & 57 \\
\hline RD_4i & 916 & 2.1 & 25.1 & 25.2 & 57 \\
\hline RD_5a & 916 & 2.2 & 50.3 & 5.4 & 57 \\
\hline RD_5b & 916 & 2.2 & 48.4 & 10.6 & 57 \\
\hline RD_5c & 916 & 2.2 & 49.3 & 16.6 & 57 \\
\hline RD_5d & 916 & 2.2 & 46.3 & 20.6 & 57 \\
\hline RD_5e & 916 & 2.2 & 45.3 & 25.6 & 57 \\
\hline RD_6a & 346 & 2.15 & 50.9 & 5.2 & 57 \\
\hline RD_6b & 346 & 2.15 & 49 & 10.4 & 57 \\
\hline RD_6c & 346 & 2.15 & 50.6 & 15.1 & 57 \\
\hline RD_6d & 346 & 2.15 & 53.7 & 17.2 & 57 \\
\hline RD_6e & 346 & 2.15 & 49.3 & 20.4 & 57 \\
\hline RD_6f & 346 & 2.15 & 50.3 & 25.2 & 57 \\
\hline RD_7a & 346 & 3.1 & 55.4 & 5 & 57 \\
\hline RD_7b & 346 & 3.1 & 53.3 & 10.2 & 57 \\
\hline RD_7c & 346 & 3.1 & 53 & 15.3 & 57 \\
\hline RD_7d & 346 & 3.1 & 50.3 & 20.2 & 57 \\
\hline RD_7e & 346 & 3.1 & 52.2 & 25.8 & 57 \\
\hline RD 8a & 926 & 3.2 & 46 & 5.2 & 57 \\
\hline RD_8b & 926 & 3.2 & 45.4 & 10.4 & 57 \\
\hline RD_8c & 926 & 3.2 & 42.2 & 15.3 & 57 \\
\hline RD_8d & 926 & 3.2 & 43.3 & 20.2 & 57 \\
\hline RD 8e & 926 & 3.2 & 42.3 & 25.4 & 57 \\
\hline RD_9a & 926 & 3.02 & 31.8 & 5.6 & 57 \\
\hline RD_9b & 926 & 3.02 & 31.4 & 10.8 & 57 \\
\hline RD_9c & 926 & 3.02 & 31.7 & 16.5 & 57 \\
\hline RD_9d & 926 & 3.02 & 31.1 & 20.2 & 57 \\
\hline RD_9e & 926 & 3.02 & 32.0 & 25.4 & 57 \\
\hline RD_10a & 646 & 3.02 & 33.4 & 5.4 & 57 \\
\hline RD_10b & 646 & 3.02 & 33.4 & 10.8 & 57 \\
\hline RD_10c & 646 & 3.02 & 38.0 & 15.8 & 57 \\
\hline RD_10d & 646 & 3.02 & 37.0 & 20.0 & 57 \\
\hline & & & & & \\
\hline
\end{tabular}


Table A.2. Test conditions for rod bundle in the presence of boron.

\begin{tabular}{|l|l|l|l|l|}
\hline No. & $\begin{array}{l}\text { Mass flux } \\
\left(G, \mathrm{~kg} / \mathrm{m}^{2} \mathrm{~s}\right)\end{array}$ & $\begin{array}{l}\text { Pressure } \\
(P, \text { bar })\end{array}$ & $\begin{array}{l}\text { Inlet } \\
\text { subcooling } \\
\left(\Delta \mathrm{T}_{\text {sub }}{ }^{\circ} \mathrm{C}\right)\end{array}$ & $\left(\begin{array}{l}\text { liquideat flux } \\
\left(q_{w}, \mathrm{~W}^{\prime} \mathrm{cm}^{2}\right)\end{array}\right.$ \\
\hline \hline RB1a & 625 & 1.03 & 24.7 & 1.9 \\
\hline RB2a & 625 & 1.03 & 25.8 & 2.9 \\
\hline RB3a & 625 & 1.03 & 24.4 & 4.9 \\
\hline RB4a & 625 & 1.03 & 23.2 & 6.7 \\
\hline RB5a & 625 & 1.03 & 27.3 & 8.5 \\
\hline RB6a & 625 & 1.03 & 26.6 & 9.7 \\
\hline RB7a & 625 & 1.03 & 23.6 & 14.7 \\
\hline RB8a & 625 & 1.03 & 26.9 & 19.7 \\
\hline RB9a & 625 & 1.03 & 25.5 & 24.1 \\
\hline RB10a & 625 & 1.03 & 27.2 & 29.2 \\
\hline RB1b & 635 & 1.03 & 26.5 & 1.9 \\
\hline RB2b & 635 & 1.03 & 25.6 & 2.9 \\
\hline RB3b & 635 & 1.03 & 24.8 & 4.9 \\
\hline RB4b & 635 & 1.03 & 24.6 & 6.8 \\
\hline RB5b & 635 & 1.03 & 27.3 & 8.3 \\
\hline RB6b & 635 & 1.03 & 23.9 & 9.7 \\
\hline RB7b & 635 & 1.03 & 23.6 & 14.4 \\
\hline RB8b & 635 & 1.03 & 27.4 & 19.7 \\
\hline RB9b & 635 & 1.03 & 25.9 & 24.3 \\
\hline RB10b & 635 & 1.03 & 25.0 & 29.3 \\
\hline RB1c & 625 & 1.03 & 26.6 & 1.9 \\
\hline RB2c & 625 & 1.03 & 25.9 & 2.9 \\
\hline RB3c & 625 & 1.03 & 25.3 & 4.8 \\
\hline RB4c & 625 & 1.03 & 27.4 & 6.7 \\
\hline RB5c & 625 & 1.03 & 26.8 & 8.3 \\
\hline RB6c & 625 & 1.03 & 23.9 & 9.7 \\
\hline RB7c & 625 & 1.03 & 26.5 & 14.3 \\
\hline RB8c & 625 & 1.03 & 26.9 & 19.6 \\
\hline RB9c & 625 & 1.03 & 25.1 & 24.5 \\
\hline RB10c & 625 & 1.03 & 23.0 & 29.0 \\
\hline & & & & \\
\hline
\end{tabular}




\section{Appendix B: Wall temperatures}

The wall temperature measured along the axial direction for rod bundle test cases is listed in Table B.1

Table B.1 Wall temperature for rod bundle test case

\begin{tabular}{|c|c|c|c|c|c|c|c|c|c|c|}
\hline & $\mathbf{R 1}$ & $\mathbf{R 2}^{\mathbf{R}}$ & $\mathbf{R 3}$ & $\mathbf{R 4}$ & $\mathbf{R 5}$ & $\mathbf{R 6}$ & $\mathbf{R} 7$ & $\mathbf{R 8}$ & $\mathbf{R 9}$ & $\mathbf{R 1 0}$ \\
\hline $\mathbf{z}(\mathbf{c m})$ & ${ }^{\mathbf{0}} \mathbf{C}$ & ${ }^{\mathbf{0}} \mathbf{C}$ & ${ }^{\mathbf{0}} \mathbf{C}$ & ${ }^{\mathbf{0}} \mathbf{C}$ & ${ }^{\mathbf{0}} \mathbf{C}$ & ${ }^{\mathbf{0}} \mathbf{C}$ & ${ }^{\mathbf{0}} \mathbf{C}$ & ${ }^{\mathbf{0}} \mathbf{C}$ & ${ }^{\mathbf{0}} \mathbf{C}$ & ${ }^{\mathbf{0}} \mathbf{C}$ \\
\hline 4.1 & 84.3 & 91.2 & 98.6 & 101.7 & 98.8 & 101.2 & 99.6 & 101.4 & 89 & 102.4 \\
\hline 21.8 & 87.6 & 91.9 & - & - & - & - & 102.9 & 105.7 & 93.2 & 103.8 \\
\hline 39.6 & 89.6 & 93.1 & - & - & - & - & - & - & - & - \\
\hline 57.4 & 91.1 & 95.5 & 102.5 & 106.0 & 103.9 & 105.0 & 106.9 & 107.9 & 108.4 & 109.5 \\
\hline 75.2 & 90.9 & 95.3 & 103.6 & 106.7 & 104.5 & 105.7 & 106.7 & 107.4 & 108.1 & 110.2 \\
\hline 92.5 & 91.9 & 96.0 & 104.3 & 107.2 & 104.4 & 106.0 & 105.8 & 106.4 & 107 & 109.8 \\
\hline
\end{tabular}

Table B.1 Wall temperature for rod bundle test cases (contd.)

\begin{tabular}{|c|c|c|c|c|c|c|c|}
\hline Rod 1 & $\mathbf{a}$ & $\mathbf{b}$ & c & d & $\mathbf{e}$ & f & $\mathbf{g}$ \\
\hline $\mathbf{z}(\mathbf{c m})$ & ${ }^{\circ} \mathrm{C}$ & ${ }^{0} \mathrm{C}$ & ${ }^{0} \mathrm{C}$ & ${ }^{0} \mathrm{C}$ & ${ }^{\circ} \mathrm{C}$ & ${ }^{\circ} \mathrm{C}$ & ${ }^{\circ} \mathrm{C}$ \\
\hline 4.064 & 87 & 89.2 & 90.2 & 90.5 & 91.9 & 93.2 & 105.8 \\
\hline 21.844 & 88 & 90.4 & 91.6 & & 96.5 & 103.5 & 106.8 \\
\hline 57.404 & 89.8 & 93.6 & 99.5 & 102.5 & 103.2 & 104.5 & 107.4 \\
\hline 75.184 & 90.2 & 95.1 & 102.5 & 102.8 & 103.9 & 104.8 & 107.8 \\
\hline 92.964 & 90.5 & 95.4 & 103.1 & 103.2 & 104.5 & 104.6 & 108.2 \\
\hline $\operatorname{Rod} 2$ & $\mathbf{a}$ & b & c & d & e & f & g \\
\hline $\mathbf{Z}(\mathbf{c m})$ & ${ }^{\circ} \mathrm{C}$ & ${ }^{\circ} \mathrm{C}$ & ${ }^{\circ} \mathrm{C}$ & ${ }^{\circ} \mathrm{C}$ & ${ }^{\circ} \mathrm{C}$ & ${ }^{\circ} \mathrm{C}$ & ${ }^{\circ} \mathrm{C}$ \\
\hline 4.06 & 60.1 & 69.2 & 76.2 & 95.8 & 58 & 72.3 & 72 \\
\hline 21.84 & 63.2 & & 85.8 & 106.5 & & & 103.1 \\
\hline 57.40 & 71.8 & 90.9 & 103.3 & 107.8 & 73.1 & 103.2 & 106.6 \\
\hline 75.18 & 73.3 & 95.1 & 104.5 & 108.5 & 74.5 & 104.2 & 107.8 \\
\hline 92.96 & 74.7 & 96.9 & 106.5 & 108.9 & 76.2 & 105.2 & 107.5 \\
\hline Rod 3 & a & b & c & d & e & f & g \\
\hline $\mathrm{z}(\mathrm{cm})$ & ${ }^{\circ} \mathrm{C}$ & ${ }^{\circ} \mathrm{C}$ & ${ }^{\circ} \mathrm{C}$ & ${ }^{\circ} \mathrm{C}$ & ${ }^{\circ} \mathrm{C}$ & ${ }^{\circ} \mathrm{C}$ & ${ }^{\circ} \mathrm{C}$ \\
\hline 4.06 & 79.5 & 84.5 & 91.5 & 83.3 & 104.8 & 68 & 104.5 \\
\hline 21.84 & & 86.5 & 100.5 & 93.1 & 105.6 & 75.5 & 105.5 \\
\hline 39.62 & 84.6 & 88.4 & 103.5 & 103.5 & 107.5 & 82 & 109.2 \\
\hline 57.40 & 87.2 & 102.5 & 104.6 & 104.4 & 110.7 & 88 & 111.5 \\
\hline 75.18 & 88.2 & 103.5 & 105.6 & 105.5 & 111 & 93.2 & \\
\hline 92.96 & 89.3 & 103.9 & 106.5 & 105.9 & 111.8 & 96.5 & 112.8 \\
\hline $\operatorname{Rod} 4$ & $\mathbf{a}$ & b & c & d & e & f & g \\
\hline $\mathrm{z}(\mathrm{cm})$ & ${ }^{\circ} \mathrm{C}$ & ${ }^{\circ} \mathrm{C}$ & ${ }^{\circ} \mathrm{C}$ & ${ }^{\circ} \mathrm{C}$ & ${ }^{\mathbf{0}} \mathrm{C}$ & ${ }^{\circ} \mathrm{C}$ & ${ }^{\circ} \mathrm{C}$ \\
\hline 4.06 & 80.5 & 84.5 & 88.5 & 83.5 & 102.3 & 103.4 & 105.4 \\
\hline 21.84 & 82.7 & 81.5 & 103.8 & 86.5 & 103.4 & 106.5 & 109.4 \\
\hline 39.62 & 86 & 102.8 & 104.5 & 88.5 & 105.6 & 108.5 & 110.5 \\
\hline 57.40 & 90.5 & 103.7 & 105.2 & 91.8 & 112.8 & 113.2 & 114.5 \\
\hline 75.18 & 91.3 & 104.1 & 106.5 & 93.2 & & & \\
\hline 92.96 & 92.5 & 104.7 & 106.8 & 94.5 & 115.6 & 115.8 & 116.4 \\
\hline
\end{tabular}


Table B.1 Wall temperature for rod bundle test cases (contd.)

\begin{tabular}{|c|c|c|c|c|c|c|c|c|c|c|c|c|c|c|}
\hline & Rod5a & Rod5! & Rod6a & Rod6b & Rod7a & Rod7k & Rod8a & Rod8k & Rod9a & Rod9b & Rod10 & od10 & Rod11 & Rod11b \\
\hline $\mathrm{z}(\mathrm{cm})$ & ${ }^{\circ} \mathrm{C}$ & ${ }^{\circ} \mathrm{C}$ & ${ }^{\circ} \mathrm{C}$ & ${ }^{\circ} \mathrm{C}$ & ${ }^{\circ} \mathrm{C}$ & ${ }^{\circ} \mathrm{C}$ & ${ }^{\circ} \mathrm{C}$ & ${ }^{\circ} \mathrm{C}$ & ${ }^{\circ} \mathrm{C}$ & ${ }^{\circ} \mathrm{C}$ & ${ }^{\circ} \mathrm{C}$ & ${ }^{\circ} \mathrm{C}$ & ${ }^{\circ} \mathrm{C}$ & ${ }^{\circ} \mathrm{C}$ \\
\hline 4.06 & 33.4 & 40.0 & 34.0 & 42.0 & 35.1 & 38.0 & 35.0 & 37.0 & 76.7 & 86.4 & 80.0 & 84.7 & 77.5 & 81.7 \\
\hline 21.84 & - & - & - & - & - & - & 35.3 & 39.0 & - & - & - & - & - & - \\
\hline 39.62 & - & - & - & - & - & - & 35.7 & 42.4 & - & - & - & - & - & - \\
\hline 57.40 & 38.4 & 51.0 & 43.0 & 61.9 & 41.2 & 49.0 & 37.4 & 44.9 & 82.7 & 95.1 & 85.0 & 90.6 & 81.9 & 88.7 \\
\hline 75.18 & 39.0 & 52.0 & 45.4 & 63.9 & 42.1 & 50.0 & - & - & 84.1 & - & - & - & - & - \\
\hline 92.96 & 39.7 & 53.0 & 46.3 & 64.7 & 43.4 & 51.4 & 39.0 & 47.0 & 84.7 & 98.0 & 87.0 & 93.6 & 82.7 & 90.0 \\
\hline
\end{tabular}

Table B.1 Wall temperature for rod bundle test cases (contd.)

\begin{tabular}{|c|c|c|c|c|c|c|c|c|}
\hline & RD_1a & RD_1b & RD_1c & RD_1d & & & & \\
\hline $\mathrm{z}(\mathrm{cm})$ & ${ }^{\circ} \mathrm{C}$ & ${ }^{\circ} \mathrm{C}$ & ${ }^{\circ} \mathrm{C}$ & ${ }^{\circ} \mathrm{C}$ & & & & \\
\hline 4.1 & 75.5 & 89.5 & 98 & 104.5 & & & & \\
\hline 21.84 & 82.7 & 102.8 & 104.5 & 108.5 & & & & \\
\hline 39.62 & 86 & 103.5 & 105.2 & 110.5 & & & & \\
\hline 57.40 & 90.5 & 104.2 & 106.5 & 112.5 & & & & \\
\hline 75.18 & 91.3 & 104.5 & 106.8 & 113.8 & & & & \\
\hline \multirow{2}{*}{92.96} & 92.5 & 106.2 & 107.5 & 115.2 & & & & \\
\hline & RD_2a & RD_2b & RD_2c & RD_2d & & & & \\
\hline $\mathrm{z}(\mathrm{cm})$ & ${ }^{\circ} \mathrm{C}$ & ${ }^{\circ} \mathrm{C}$ & ${ }^{\circ} \mathrm{C}$ & ${ }^{\circ} \mathrm{C}$ & & & & \\
\hline 4.1 & 77.5 & 83.1 & 85.2 & 102.2 & & & & \\
\hline 21.84 & 78.5 & 101.2 & 105 & 107.5 & & & & \\
\hline 39.62 & 81.8 & 105.2 & 106.2 & 109.2 & & & & \\
\hline 57.40 & 82.1 & 106.5 & 107.6 & 110.1 & & & & \\
\hline 75.18 & 82.8 & 106.8 & 108.5 & 110.2 & & & & \\
\hline \multirow[t]{2}{*}{92.96} & 83.8 & 107.2 & 110.2 & 110.6 & & & & \\
\hline & RD_3a & RD_3b & RD_3c & RD_3d & RD_3e & RD_3f & RD_3g & RD_3h \\
\hline $\mathrm{z}(\mathrm{cm})$ & ${ }^{\mathbf{0}} \mathrm{C}$ & ${ }^{\circ} \mathrm{C}$ & ${ }^{\mathbf{0}} \mathbf{C}$ & ${ }^{\mathbf{0}} \mathrm{C}$ & ${ }^{\mathbf{0}} \mathrm{C}$ & ${ }^{\mathbf{0}} \mathrm{C}$ & ${ }^{\mathbf{0}} \mathrm{C}$ & ${ }^{\mathbf{0}} \mathrm{C}$ \\
\hline 4.1 & 92.3 & 95.1 & 103.5 & 108.5 & 110.5 & 115.5 & 120.5 & 124.6 \\
\hline 21.84 & 92.6 & 101.2 & 105.6 & 116.2 & 118.5 & 120.5 & 124.5 & 126.5 \\
\hline 39.62 & 93.5 & 103.2 & 108.9 & 118.4 & 120.2 & 124.8 & 126.5 & 128.9 \\
\hline 57.40 & 93.4 & 104.5 & 111.2 & 121.3 & 124.8 & 127.5 & 128.5 & 131.8 \\
\hline 75.18 & 94.5 & 105.2 & 114.2 & 123.7 & 126.5 & 128.5 & 130.5 & 132.5 \\
\hline 92.96 & 95.2 & 105.1 & 115.2 & 124.2 & 127.5 & 129.5 & 130.2 & 132.8 \\
\hline
\end{tabular}


Table B.1 Wall temperature for rod bundle test cases (contd.)

\begin{tabular}{|c|c|c|c|c|c|c|c|c|c|}
\hline & RD_4a & RD_4b & RD_4c & RD_4d & RD_4e & RD_4f & RD_4g & RD_4h & RD_4i \\
\hline $\mathrm{z}(\mathrm{cm})$ & ${ }^{\circ} \mathrm{C}$ & ${ }^{\mathbf{0}} \mathbf{C}$ & ${ }^{\mathbf{0}} \mathrm{C}$ & ${ }^{\circ} \mathrm{C}$ & ${ }^{\mathbf{0}} \mathrm{C}$ & ${ }^{\mathbf{0}} \mathrm{C}$ & ${ }^{\mathbf{0}} \mathrm{C}$ & ${ }^{\mathbf{0}} \mathrm{C}$ & ${ }^{\mathbf{0}} \mathrm{C}$ \\
\hline 4.10 & 88.5 & 91.2 & 95.2 & 98.2 & 102.1 & 103.1 & 103.4 & 115.2 & 126.8 \\
\hline 21.84 & 91.1 & 101.5 & 101.2 & 104.5 & 107 & 108.2 & 107.5 & 121.2 & 128.6 \\
\hline 39.62 & 92.6 & 102.1 & 104.6 & 106.2 & 107.5 & 110.2 & 110.5 & 124.8 & 129.6 \\
\hline 57.40 & 92.6 & 102.4 & 106.7 & 109.2 & 110.1 & 112.7 & 115.2 & 126.8 & 130.2 \\
\hline 75.18 & 93.2 & 103.1 & 107.2 & 109.7 & 112.2 & 117.7 & 120.2 & 127.5 & 131.2 \\
\hline \multirow[t]{2}{*}{92.96} & 93.1 & 102.5 & 108.2 & 110.7 & 113.2 & 120.7 & 123.2 & 128.2 & 132.2 \\
\hline & RD_5a & RD_5b & RD_5c & RD_5d & RD_5e & & & & \\
\hline $\mathrm{z}(\mathrm{cm})$ & ${ }^{\mathbf{0}} \mathbf{C}$ & ${ }^{\circ} \mathbf{C}$ & ${ }^{\mathbf{0}} \mathrm{C}$ & ${ }^{\circ} \mathbf{C}$ & ${ }^{\circ} \mathrm{C}$ & & & & \\
\hline 4.10 & 73.5 & 77.5 & 84.5 & 90.5 & 110.2 & & & & \\
\hline 39.62 & 74.5 & 82.5 & 90.5 & 105.2 & 115.2 & & & & \\
\hline 57.40 & 76.5 & 83.1 & 100.2 & 110.5 & & & & & \\
\hline 75.18 & 78.5 & 90.5 & 105.2 & & 125.2 & & & & \\
\hline \multirow[t]{2}{*}{92.96} & 79.5 & 94.5 & 108.5 & 115.2 & 126.5 & & & & \\
\hline & RD_6a & RD_6b & RD_6c & RD_6d & RD_6e & RD_6f & & & \\
\hline $\mathrm{z}(\mathrm{cm})$ & ${ }^{\mathbf{0}} \mathrm{C}$ & ${ }^{\mathbf{0}} \mathrm{C}$ & ${ }^{\mathbf{0}} \mathbf{C}$ & ${ }^{\mathbf{0}} \mathrm{C}$ & ${ }^{\mathbf{0}} \mathrm{C}$ & ${ }^{\mathbf{0}} \mathrm{C}$ & ${ }^{\circ} \mathrm{C}$ & ${ }^{\circ} \mathrm{C}$ & ${ }^{\circ} \mathrm{C}$ \\
\hline 4.1 & 78.5 & 94.5 & 98.5 & 115.2 & 122.7 & 124.8 & & & \\
\hline 21.84 & 82.5 & 98.5 & & 120.5 & 125.7 & 128.5 & & & \\
\hline 39.62 & 84.5 & 102.5 & 120.5 & 124.4 & & & & & \\
\hline 57.40 & 88.5 & 110.5 & & 126.1 & 128.5 & 134.5 & & & \\
\hline 75.18 & 90.5 & 115.5 & & 0 & & & & & \\
\hline 92.96 & 95.6 & 120.5 & 122.5 & 128.5 & 131.2 & 136.8 & & & \\
\hline
\end{tabular}


Table B.1 Wall temperature for rod bundle test cases (contd.)

\begin{tabular}{|c|c|c|c|c|c|}
\hline & RD_7a & RD_7b & RD_7c & RD_7d & RD_7e \\
\hline 4.00 & 84.5 & 101.2 & 110.2 & 134.5 & 138.1 \\
\hline 21.84 & 85.2 & 105.2 & & 137.1 & 138.6 \\
\hline 75.18 & 94.5 & & & 138.5 & 142.5 \\
\hline \multirow[t]{2}{*}{92.96} & 96.5 & 116 & 128.5 & 140.2 & 144.6 \\
\hline & RD_8a & RD_8b & RD_8c & RD_8d & RD_8e \\
\hline 4.00 & 95.5 & 100.2 & 108 & 112.5 & 132.5 \\
\hline 21.84 & 96.5 & 105.2 & 112.2 & 121.2 & 139.5 \\
\hline 75.18 & 99.5 & 110.5 & 115.5 & 128.5 & 142.2 \\
\hline \multirow[t]{2}{*}{92.96} & 102.4 & 116.5 & & 132.5 & 143.2 \\
\hline & RD_9a & RD_9b & RD_9c & RD_9d & RD_9e \\
\hline 4.00 & 106.5 & 112.5 & 116.5 & 120.5 & 135.5 \\
\hline 21.84 & 106.5 & & 122.5 & 128.5 & 138.7 \\
\hline 75.18 & & & & 132.5 & 144.2 \\
\hline \multirow[t]{2}{*}{92.96} & 110.5 & 128.5 & 132.5 & 136.5 & 146.2 \\
\hline & RD_10a & RD_10b & RD_10c & RD_10d & \\
\hline 4.00 & 109.5 & 117.5 & 123.5 & 138.2 & \\
\hline 21.84 & 112.5 & & 132.2 & 138.7 & \\
\hline 75.18 & & & 138.2 & 146.2 & \\
\hline 92.96 & 124.5 & 132.5 & 138.7 & 147.8 & \\
\hline
\end{tabular}

